\title{
FIRST SURVEY OF THE NEOTROPICAL SPECIES OF MICROCHELONUS SZÉPLIGETI WITH DESCRIPTIONS OF TWENTY-FIVE NEW SPECIES (HYMENOPTERA: BRACONIDAE: CHELONINAE)
}

\author{
Jenó PAPP \\ Department of Zoology, Hungarian Natural History Museum \\ H-1088 Budapest, Baross utca 13, Hungary; E-mail: j.papp1933@gmail.com
}

\begin{abstract}
A short review is supplied of the history and search of the Microchelonus species in the Neotropics, taxonomic status of the genus Microchelonus and the features employed for the species differentiation. Descriptions of 25 new species of Microchelonus are presented from the Neotropical Region, completed with their taxonomic position. The enumeration of the new species is presented in the Introduction. Fifty-six Microchelonus species are registered in the region, their checklist are compiled. Identification key was constructed to the species occurring in Central and South America, females and males separately. A new synonymy; Microchelonus parkeri Papp, 2010 sen. syn. / Chelonus (Microchelonus) murici Nascimento et Penteado-Dias, 2011, jun. syn. and a new combination; Microchelonus kellieae (Marsh, 1979) originally Chelonus (Microchelonus) kellieae are presented. With 519 line-drawn figures.
\end{abstract}

Key words: Neotropics, Hymenoptera: Braconidae: Cheloninae, Microchelonus, survey.

\section{INTRODUCTION}

Historical review - The genus Microchelonus was described by SzÉPLigeti in 1908. The first Microchelonus species was described from the Neotropical Region (from Peru) by Szépligeti in 1904 under the name Chelonus sobrinus. The Microchelonus species by Ashmead (1895), Cameron (1881, 1886), Cresson (1873), Cushman (1931) and Provancher (1881) (albobasilaris, blackburni, cautus, pectiniphorae and carinatus, respectively) were discovered in other regions (East Palaearctic, Pacific, Nearctic) and described in the genus Chelonus, however, (many years) later they were also recorded from the Neotropic, too and assigned to Microchelonus (SHenefelt 1973).

From the beginning of the twentieth century the following authors have considerably increased the number of the Microchelonus species in the Neotropical Region: Brues (1912), Viereck (1912, 1913), Marsh (1979), Papp (1999, 2010) and Nascimento \& Penteado-Dias (2011). As a result of their contributions 30 Microchelonus species have been recorded in the region so far. In the present paper further 26 are added. Yu et al. (2012) listed only 25 Microchelonus species in the Neotropical Region including (1) the name M. murici (Nascimento et Penteado-Dias) which proved to be a new synonym of M. parkeri Papp (details see there) as well as (2) the valid species M. phthorimaeae (Ga- 
han). Consequently, the checklist presented here comprises 56 Microchelonus species known and distributed in the Neotropics. In the northern half of the American continent, i.e. in the Nearctic Region 111 Microchelonus species are treated in a monograph of which 90 proved to be new to science (МсСомв 1965, 1968). It also seems reasonable to indicate that 601 Microchelonus species are listed in the Holarctic Region of which 113 are Nearctic and 488 are Palaearctic (Tobias 2010, Papp 2014, Yu et al. 2012). The Microchelonus species living in the Neotropical Region may be estimated at least 500-600, although it may be as high as $900-1100$.

Taxonomy of Microchelonus - The taxon Microchelonus is here regarded as a valid genus. The generic / subgeneric status of the taxon Microchelonus depends mainly on the debate of which feature-composition is considered more conclusive for splitting Microchelonus as subgenus of Chelonus or as valid genus near to Chelonus. In this respect I am on the standpoint of Tobias's interpretation of the generic validity of Microchelonus (TовіAs 1995, 2010, 2011). Undoubtedly there are transitional species between Chelonus and Microchelonus, nevertheless, the overwhelming majority of the Microchelonus species unambiguously show the generic differing features.

The Neotropical species, hitherto known, belong to the genus Microchelonus s. str. (Tobias 1995, 2011). The 25 species herewith described are as follows: M. acutulus (Costa Rica), M. amelot (Costa Rica), M. aperon (Costa Rica), M. avron (Costa Rica), M. bermus (Honduras), M. candidus (Costa Rica, Honduras), M. curticarinulus (Costa Rica, Honduras), M. curtulus (Costa Rica), M. danzas (Costa Rica), M. exceptus (Costa Rica), M. flavicoxa (Costa Rica), M. fodicus (Costa Rica), M. fulgens (Costa Rica), M. hebes (Costa Rica), M. jamaicus (Jamaica), M. latistigma (Costa Rica), M. levigena (Peru), M. mccombi (Honduras), M. ormos (Costa Rica), M. polites (Costa Rica), M. projectus (Honduras), M. sulcifera ((Costa Rica), M. tuberulus (Costa Rica), M. vissas (Costa Rica) and M. zobocus (Costa Rica).

Type depositories - The type material of the new and known species are deposited in the following four institutions: DEUU = Department of Entomology, Utah State University, Logan (USA); HNHM = Hungarian Natural History Museum, Budapest (Hungary); USNM = United States National Museum of Natural History, Washington (USA); ZMLU = Zoological Institute and Museum, The University, Lund (Sweden).

Specific differentation - The Microchelonus species, similarly to other braconid genera with a long series of species, are frequently morphologically very similar to each other and thus their identification is considerably difficult. The following features consistently serve for the separation of the Neotropical Microchelonus species:

(1) Length to breadth of the penultimate flagellomere(s). (2) Breadth to length of head in dorsal view, temple rounded to receded, proportional length 
of eye to temple. (3) Height to width of eye in lateral view, proportional width of eye to gena in lateral view. (4) Substriolation size of vertex and occiput. (5) Sculpture size of scutellum (smooth, punctate to scabrous). (6) Propodeal carina with its four denticules in dorsal view: strength, size. (7) Length to breadth of hind femur (+ tibia). (8) Fore wing: length to width of pterostigma, proportional length of pterostigma to 1-R1, proportional length of $r$ to 3-SR, run of SR1 (straight to bent). (9) Length to breadth of carapace in dorsal and lateral view. (10) Microsculpture of carapace: polished to scabrous in a high variability of size and extense. (11) Size of apical ventral incurvation of carapace. (12) Male: size and form of apical foramen on carapace. (13) Female: rarely with (small) apical foramen.

Besides these 13 "consistent feature-kinds" the following five ones are additionally and possibly significant in species separation: (1) Length to height of clypeus, its sculpture. (2) punctation to rugosity of face. (3) sculpture of mesosoma: (subrugulose to) rugose to scabrous. (4) Apico-dorsally acute or pointed carapace. (5) Extreme colour-pattern of corporal parts as well as legs.

Several features are highly variable (within species too): (1) Every size and form is present from the widely rounded to strongly receded temple in dorsal view. (2) Width of gena beyond eye varies from as wide as to clearly (1.3-1.6 times) wider than eye. (3) Striation of vertex and occiput varies from very weak to fairly strong sizes. (4) Microsculpture of carapace in dorsal view: strength and extent of polished to subrugulose to scabrous sculpture as well as the longitudinal striation. (5) Fore wing: proportional length of $1-R 1$ to pterostigma varies considerably. (6) Light colouration of proximal part of antenna as well as (hind) tibial dark suffusion.

States of the features - Plesiomorphic states are: (1) Long penultimate flagellomere(s), at least twice longer than broad. (2) Head in dorsal view about twice (1.9-2.2 times) broader than long, temple (weakly) rounded. (3) Thin hind femur: three or more times longer than broad. (4) Fore wing: pterostigma less wide, about three times as long as wide, 1-R1 about (0.7-0.9-1 times) as long as pterostigma. (5) Carapace in dorsal view belly: about 1.61.7(-1.8 times) as long as broad, carapace in lateral view high posteriorly: 2.5-3.2 times as long as high. - Apomorphic states are: (1) Short penultimate flagellomere(s): subcubic to cubic. (2) Head in dorsal view less broad to subcubic, 1.6-1.7 times as broad as long. (3) Thick hind femur: (2.3-)2.5 times longer than broad. (4) Fore wing: pterostigma wide, about twice as long as wide, 1-R1 half (0.5-0.6 times) as long as pterostigma. (5) Carapace in dorsal view long to elongate, twice to more than twice as long as broad; carapace in lateral view less high posteriorly (even flattened), about four times as long as high behind. (6) Acute, pointed or other emergencies apically on carapace.

The above plesio- and apomorphic features (or character states) were expounded and published by Papp (1974), Tobias (1967), van ACHTERberg 
(1988), Wharton et al. (1992), Belshaw et al. (2001) and Belokobylskij et al. (2004). There are, certainly, much more plesio- and apomorphous states in Microchelonus species. The examined little Neotropical material, however, allowes only these few states to recognize. The future significant extension of the species composition of the region will promote their better knowledge in this respect too.

Behaviour - An unusual aggregation manner of M. hadrogaster (McComb) was observed by S. R. Shaw in a mountain meadow of the Medicine Bow National Forest (Albany County, Wyoming, USA) on June 1990. A black species of chelonine braconid (later identified its above name) was found to be quite abundant on the grass stems in close association with the ant mounds Formica podzolica Francoeur. Interpreting his observation he came to the conclusion that "Chelonus hadrogaster may be utilizing ant mounds as landmarks for mate location, although the possibility of a chemical basis for the aggregations cannot be ruled out. Additionally there is the possibility that Chelonus hadrogaster locates the mounds via chemical cues released from the ant themselves, perhaps some chemical that resembles the usual sex pheromone of the wasp." (SHAw 1991).

\section{CHECKLIST OF THE MICROCHELONUS SZÉPLIGETI, 1908 SPECIES OF THE NEOTROPICAL REGION}

Valid and synonymous names are enumerated in alphabetic order. Valid names are in italics, synonymous names are in roman. Synonymous names either in bracket (....) or below the valid names with indentation and equality sign $(=)$. New distributional country is assigned with asterisk $\left(^{*}\right)$. - In the checklist 56 Microchelonus species are recorded.

M. acutulus sp. n. - Costa Rica

(M. albobasilaris (Ashmead, 1895) (Chelonus)

= M. cautus (Cresson, 1872) (Chelonus)

M. amelot sp. n. - Costa Rica

M. angustus Papp, 1999 - Argentina

M. aperon sp. n. - Costa Rica

M. avron sp. n. - Costa Rica

M. bermus sp. n. - Honduras

M. blackburni (Cameron, 1886) (Chelonus) -

USA: Hawaii (type locality), intro-

duced: Mexico, Puerto Rico

$=$ Chelonus carinatus (Cameron, 1881)

nec (Provancher, 1881)

M. bolsoni Papp, 1999 - Argentina

M. brasiliensis (Brues, 1912) (Chelonus)

- Brazil, *Costa Rica, *Honduras,

*Paraguay
= M. szepligetii $($ Viereck, 1913: 360)

(Chelonus [Chelonella])

M. buscki (Viereck, 1912) (Chelonus [Microchelonus]) - ${ }^{*}$ Costa Rica, ${ }^{*}$ Honduras, *Panama, *Peru, Trinidad and Tobago

M. cacumenus Papp, 2010 - Honduras

M. candidus sp. n. - Costa Rica, Honduras

(M. carinatus [Cameron, 1881] [Chelonus])

$=$ M. blackburni (Cameron, 1886)

(Chelonus)

M. carinatus (Provancher, 1881) (Chelonus) Canada: ?Quebec (type locality), USA

M. cautus (Cresson, 1873) (Chelonus) - USA:

Texas (type locality), Mexico, *Hon-

duras, ${ }^{*}$ Nicaragua

= Chelonus albobasilarus Ashmead, 1895

= Chelonus nucleolus Viereck, 1905 
M. cavei Papp, 2010 - Costa Rica, Honduras

M. constrictus Papp, 1999 - Argentina

M. curticarinulus sp. n. - Costa Rica, Honduras

M. curtulus sp. n. - Costa Rica

M. danzas sp. n. - Costa Rica

M. effusus PAPP, 2010 - Costa Rica

M. exceptus sp. n. - Costa Rica

M. fascis PAPP, 2010 - Honduras

M. flavicoxa sp. n. - Costa Rica

M. flavopax Papp, 2010 - Costa Rica, Ecuador

M. fodicus sp. n. - Costa Rica

M. fulgens sp. n. - Costa Rica

M. hebes sp. n. - Costa Rica

M. jamaicus sp. n. - Jamaica

M. johni (Marsh, 1979) (Chelonus [Microchelonus]) - Colombia, *Costa Rica,

*Honduras, ${ }^{*}$ Mexico

M. kellieae (Marsh, 1979) (Chelonus [Microchelonus]) - Costa Rica, ${ }^{*}$ Honduras, USA (California, introduced)

M. latistigma sp. n. - Costa Rica

M. lavernae (Ashmead, 1889) (Chelonus) Canada, USA

M. levigena sp. n. - Peru

M. masoni (McComb, 1968) (Chelonus [Microchelonus]) - USA, *Costa Rica, *Honduras

M. mccombi sp. n. - Honduras

(M. murici [Nascimento et Penteado-Dias, 2011] (Chelonus [Microchelonus])) syn. $\mathbf{n}$.

= M. parkeri Papp, 2010

(M. nucleolus [Viereck, 1905] [Chelonus]) $=M$. cautus (Cresson, 1872) (Chelonus))

M. ormos sp. n. - Costa Rica

M. parkeri Papp, $2010-{ }^{*}$ Brazil, Costa Rica

= Chelonus (Microchelonus) murici

Nascimento et Penteado-Dias, 2011, syn. $n$.

M. paululus (McComb, 1968) (Chelonus

[Microchelonus]) - USA, ${ }^{*}$ Costa Rica

M. pectiniphorae (Cushman, 1931) (Che-

lonus [Microchelonus]) - USA, Mexico (introduced), Costa Rica, Korea (locus typicus), Asiatic Russia, Japan, Taiwan, China

M. peruensis (Shenefelt, 1973) (Chelonus) -

Peru

= Chelonus sobrinus Szépligeti, 1904 nec Haldeman 1849

= Chelonus szepligetii Viereck, 1912

M. phthorimaeae (Gahan, 1917) (Chelonus) -

USA, Mexico (introduced), Bermuda

Islands (introduced)

M. polites sp. n. - Costa Rica

M. projectus sp. n. - Honduras

M. pyriformis Papp, 2010 - Costa Rica, Honduras

M. refluus Papp, 2010 - Honduras

M. rubescus Papp, 2010 - Costa Rica

M. ruficollis (Viereck, 1912) (Chelonus) Brazil, *Costa Rica

M. shenefelti (McComb, 1968) (Chelonus

[Microchelonus]) - USA, ?Mexico

(M. sobrinus [Szépligeti, 1904] [Chelonus]) $=$ M. peruensis (Shenefelt, 1973) (Chelonus)

M. subplanus Papp, 1999 - Costa Rica, Honduras

M. sulcifera sp. n. - Costa Rica

(M. szepligetii [Viereck, 1912: 620] [Chelonus])

$=$ M. peruensis (Shenefelt, 1973)

(Chelonus)

(M. szepligetii [Viereck, 1913: 360] [Chelonus (Chelonella)])

$=$ M. brasiliensis $($ Brues, 1912) (Chelonus)

M. topali Papp, 1999 - Argentina

M. townsendi (Viereck, 1912) (Chelonus

[Chelonella]) - Peru

M. tuberulus sp. n. - Costa Rica

M. turgoclarus Papp, 2010 - Ecuador

M. vissas sp. n. - Costa Rica

M. zobocus sp. n. - Costa Rica 


\section{DESCRIPTIONS OF THE NEW MICROCHELONUS SPECIES and emendational features of the known Microchelonus species}

In the descriptions, emendations and additions as well as in the identification keys the following abbreviations are applied after van ACHTERbERG (1993: 5 Figs H-K) :

Ocelli - OOL = ocellar-ocular line, i.e. shortest distance between hind ocellus and compound eye; POL = postocellar line, i.e. shortest distance between hind two ocelli.

Fore wing venation $-r=$ first section of the radial vein; $1-R 1=$ first section of the metacarpal vein; $3-S R=$ second section of the radial vein; $S R 1=$ third section of the radial vein.

The denomination of the very variable surface microsculpture is adopted after EADY (1968) and HARRIS (1979). - Structure terminology is used after GAUld and Bolton (1988: 58-74).

In the description of the new species (and frequently in the emendational features and additions to the known species) the sculptural phrase "substriolation" is regularly applied. I mean under this phrase a continuously interrupted striation / striolation, the striae / striolae themselves are very short and dense, more or less parallel with each other, see Figs 12, 27, 35, 55, 94, 102 etc.

\section{Microchelonus acutulus sp. $\mathrm{n}$.}

$$
\text { (Figs 1-9) }
$$

Material examined - Female holotype: Costa Rica, Guanacaste, $3 \mathrm{~km}$ SE from river Navanjo, May 1992, leg. F. D. Parker. - Holotype is in fairly good condition: (1) glued direct to the pin by its right pro- and mesopleuron; (2) missing: middle pair of legs, right flagellomeres 4-14, tarsomeres 4-5 of right hind leg. Type depository: HNHM, Hym. Typ. No. 12226.

Etymology - The species name "acutulus" refers to the acute posterior end of the carapace (Fig. 7).

Description of the female holotype - Body $3.3 \mathrm{~mm}$ long. Antenna (left one) short: as long as head and mesosoma combined and with 16 antennomeres. Scape 2.5 times as long as wide, first flagellomere three times as long as broad apically, further flagellomeres shortening so that flagellomeres 10-13 cubic; flagellomeres proximo-distally attenuating. - Head in dorsal view transverse (Fig. 1), clearly twice as broad as long, eye 2.2 times longer than temple, temple receded. OOL somewhat longer $(12: 10)$ than POL. Eye in lateral view 1.8 times as high as wide, gena beyond eye weakly broadening ventrally: 0.6 times as wide as eye (Fig. 2 see arrows). Gena substriolated. Clypeus 1.7 times as wide below as high medially, its lower margin faintly convex (cf. Fig. 36). Face 1.7 times as wide as high. Clypeus with confluent punctation, shiny. Face rugulo-rugose (Fig. 3). Vertex and occiput densely substriolated (Fig. 1).

Mesosoma in lateral view 1.6 times as long as high. Mesosoma scabrous, scutellum rugose. Transverse carina of propodeum with four denticules (Fig. 5). Hind femur thicken- 

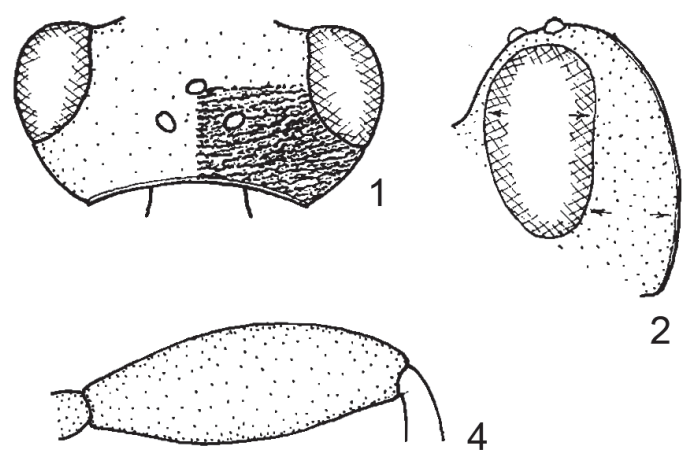

2
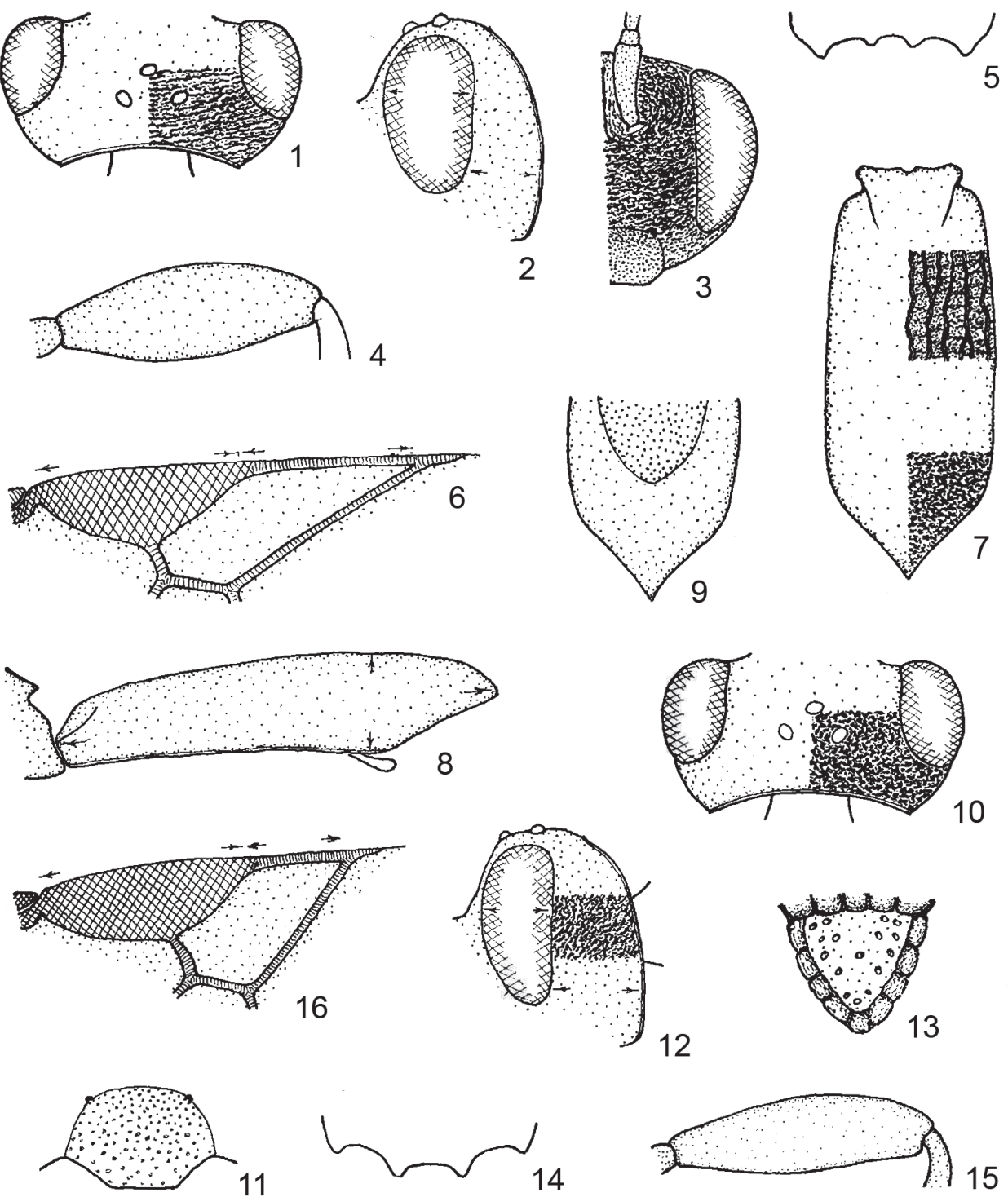

Figs 1-16. 1-9. Microchelonus acutulus sp. n. (female holotype): 1 = head in dorsal view with indication of its sculpture, 2 = head in lateral view, 3 = right half of head in frontal view with indication of its sculpture, $4=$ hind femur, 5 = propodeal carina in dorsal view, $6=$ distal part of right fore wing, $7=$ carapace in dorsal view with indication of its sculpture, $8=$ carapace in lateral view, $9=$ posterior half of carapace in ventral view. 10-16. Microchelonus amelot sp. n. (female holotype): $10=$ head in dorsal view with indication of its sculpture, 11 = clypeus, 12 = head in lateral view with indication of its sculpture, $13=$ scutellum, $14=$ propodeal carina in dorsal view, 15 = hind femur, 16 = distal part of right fore wing. 
ing, 2.6 times as long as broad medially (Fig. 4). Hind basitarsus as long as tarsomeres $2-4$ combined.

Fore wing shorter than body ( $2.5 \mathrm{~mm}$ long). Pterostigma 2.5 times as long as wide and issuing $r$ from its middle; 3-SR 1.6 times longer than $r$, SR1 almost straight, 1-R1 almost, 0.87 times, as long as pterostigma (Fig. 6 see arrows).

Carapace in dorsal view feebly broadening posteriorly, 2.8 times as long as broad, carapace apically acute, its anterior two-thirds striate, interstriations subcrenulate (Fig. 7). Carapace in lateral view 4.3 times as long as high posteriorly, apically pointed dorsally (Fig. 8). Carapace apico-ventrally deeply incurved: incurved part as long as hind tarsomeres 1-3 combined (Fig. 9). Ovipositor sheath short, concealed (Fig. 8).

Ground colour of body black. Scape and pedicel ochre yellow, flagellum blackish. Tegula brownish black. Legs testaceous, hind tibia proximally and hind basitarsus straw yellow, distal end of hind tibia brownish. Wings hyaline, pterostigma brown, veins yellow to light brown.

Male and host unknown.

Distribution - Costa Rica.

Taxonomic position - The new species, M. acutulus, is close to M. cacumenus Papp and $M$. parkeri Papp, the three species are distinguished in the key to the females couplets 18(19) - 21(20).

\section{Microchelonus amelot sp. $\mathrm{n}$.}

(Figs 10-19)

Material examined - Female holotype: Costa Rica, Limon, 7 miles N from Guacimo, 22 February - 1 March 1988, leg. F. D. Parker. - Holotype is in good condition: (1) glued direct to the pin by the right side of mesosoma; (2) right fore leg and proximal half of flagellum less visible owing to the mounting. Holotype is deposited in the HNHM, Hym. Typ. No. 12227.

Etymology - The new species received the latinized phantasy name "amelot".

Description of the female holotype - Body $3.3 \mathrm{~mm}$ long. Antenna short, as long as head and mesosoma combined (2.2 mm long). First flagellomere 3.3 times and penultimate flagellomere 1.5 times as long as broad. - Head in dorsal view transverse (Fig. 10), twice as broad as long, eye twice longer than temple, temple receded. OOL one-third longer than POL, ocelli middle sized. Eye in lateral view 2.3 times as high as wide, gena beyond eye broadening ventrally and wider (18:14) than eye, gena rugulose (Fig. 12 see arrows). Clypeus 1.5 times as wide below as high medially, densely punctate and dull, its lower margin medially truncate (Fig. 11). Malar space 1.5 times as long as basal width of mandible. Face 1.5 times as wide as high, rugose. Vertex, occiput and frons rugose (like face).

Mesosoma in lateral view 1.5 times as long as high, scabrous. Notaulix distinct. Scutellum punctate-subfoveolate, interspaces shiny (Fig. 13). Four denticules of propodeal transverse carina rather small (Fig. 14). Hind femur 3.3 times as long as broad medially (Fig. 15). Hind basitarsus as long as tarsomeres $2-3$ combined.

Fore wing shorter than body. $2.7 \mathrm{~mm}$ long. Pterostigma almost 2.7 times as long as wide, issuing $r$ distally from its middle and almost 0.8 times as long as $3-S R$ (or 3-SR almost 1.3 times longer than $r$ ), $S R 1$ straight, 1-R1 half as long as pterostigma (Fig. 16). 


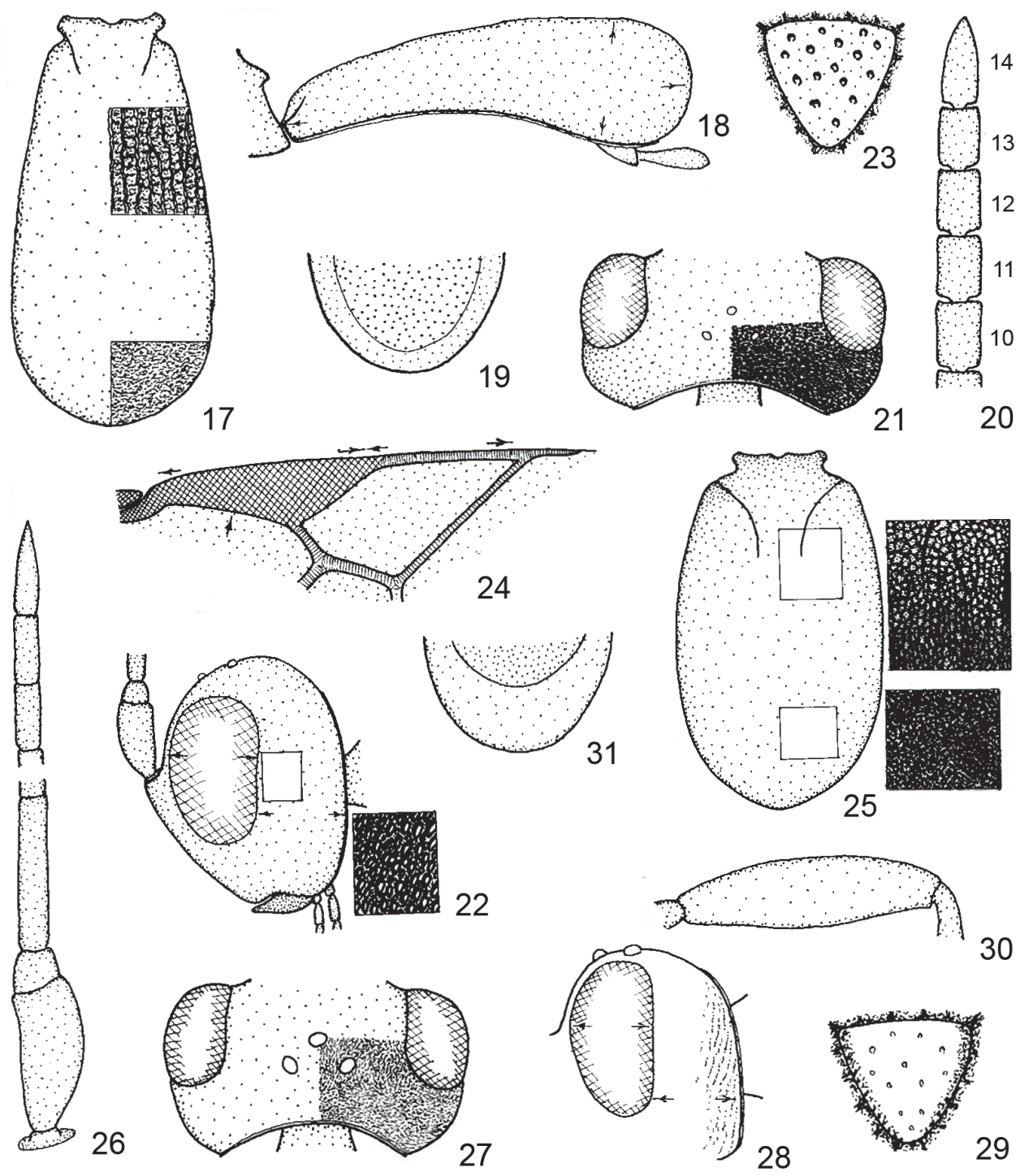

Figs 17-31. 17-19. Microchelonus amelot sp. n. ( 9 , holotype): 17 = carapace in dorsal view with indication of its sculpture, 18 = carapace in lateral view, $19=$ posterior third of carapace in ventral view. 20-25. M. angustus Papp, 1999 ( 9 , holotype): $20=$ flagellomeres 10-14, 21 = head in dorsal view with indication of its sculpture, $22=$ head in lateral view with indication of its sculpture, 23 = scutellum, 24 = distal part of right fore wing, 25 = carapace in dorsal view with indication of its sculpture. 26-31. M. aperon sp. n. (ㅇ, holotype): $26=$ scape, pedicel and proximal / distal parts of flagellomeres, 27 = head in dorsal view with indication of its sculpture, 28 = head in lateral view with indication of its sculpture, $29=$ scutellum, 30 = hind femur, 31 = posterior third of carapace in ventral view. 
Carapace in dorsal view (Fig. 17) twice as long as broad and evenly broadening posteriorly, longitudinally and fairly strongly striated, interstriations crenulated, hind fourth of carapace rugulose. Carapace in lateral view 3.2 times as long as high posteriorly, apically rounded (Fig. 18). Carapace apico-ventrally weakly incurved (Fig. 19). Ovipositor sheath as long as hind basitarsus.

Ground colour of body black. Scape and pedicel testaceous, flagellomeres 1-4 darkening testaceous, rest of flagellum blackish brown. Palpi light brownish. Tegula and parategula blackish to brown. Fore leg yellowish to yellow, femur brown, tarsus yellow. Middle leg: coxa + trochanters yellow, femur + tibia brownish black, tarsus yellow with brownish suffusion. Hind leg blackish to black, trochanters yellow, tarsus blackish. Wings hyaline to subhyaline, marginal cell brownish fumous. Pterostigma brown, veins yellow to light brown.

Male and host unknown.

Distribution - Costa Rica.

Taxonomic position - With the help of McComb's key to the Nearctic species of Microchelonus the new species runs to M. periplocae (McComb), their distinction is keyed (couplet-text quoted from the description):

1 (2) "Mesoscutum...finely rugulose, shiny and almost punctate medially"; scutellum rugulose. Gena in lateral view almost as wide as eye. "Carapace [in dorsal view] 0.65 times as wide as long", i.e. carapace less than twice as long as broad. Fore wing: pterostigma 2.5 times as long as wide (Fig. 130 in МсСомв 1968: 146). "Anterior and middle femora narrowly testaceous." o: 2.4-3.1 mm. - USA: California

M. periplocae (McComb, 1968)

2 (1) Mesoscutum scabrous, scutellum smooth. Gena in lateral view wider than eye (18:14) (Fig. 12 see arrows). Carapace 0.5 times as broad as long, i.e. carapace twice as long as broad (Fig. 17). Fore wing: pterostigma almost 2.7 times as long as wide (Fig. 16). Fore and middle femora brown. q: $3.3 \mathrm{~mm}$. - Costa Rica

M. amelot sp. n.

In the key to the female Microchelonus species it runs to M. kellieae (Marsh), see couplets $72(75)-74(73)$.

\section{Microchelonus angustus Papp, 1999}

(Figs 20-25)

Microchelonus angustus Papp, 1999: 179 q, type locality: Argentina, Tucuman, female holotype and male paratype in HNHM; examined.

Emendated features to the original description (Papp l.c.) - Temple in dorsal view strongly rounded to feebly receded (Fig. 21). Gena densely subfoveolate (Fig. 22). Scutellum strongly punctate, interspaces shiny to subshiny (Fig. 23). Fore wing: pterostigma unusually narrow, three times as long as wide and its antero-inner margin faintly concave, 1-R1 0.7 times as long as pterostigma (Fig. 24 see arrows). 
Taxonomic position - In the key to the female Microchelonus species it runs to $M$. blackburni (Cameron), see couplets 76 (79) - 78 (77). In the original description (Papp l.c.) M. angustus is related to M. bucculentus (McComb) and $M$. constrictus Papp.

\section{Microchelonus aperon sp. $\mathrm{n}$.}

(Figs 26-34)

Material examined - Female holotype: Costa Rica, San José, Escazu, 8 February 1987, leg. G. E. Bohart. - Holotype is in good condition: glued direct to the pin by its right mesosomal side. Holotype is deposited in HNHM, Hym. Typ. No. 12228.

Etymology - The new species received the latinized phantasy name "aperon".

Description of the female holotype - Body $3 \mathrm{~mm}$ long. Antenna as long as body and with 16 antennomeres. Scape in lateral view somewhat globose, 2.5 times as long as broad medially (Fig. 26). Flagellum long, first flagellomere six times and penultimate flagellomere 2.6 times as long as broad (Fig. 26). - Head in dorsal view transverse (Fig. 27), 1.8 times as broad as long, eye 1.5 times longer than temple, temple rounded. OOL 1.2 times longer than POL (11:9). Eye in lateral view 1.8 times as high as wide, gena beyond eye broadening ventrally and just wider than eye (17:16), gena posteriorly with weak substriolation, otherwise shiny to polished (Fig. 28 see arrows). Clypeus 1.4 times as wide below as high medially, its lower margin convex (cf. Fig. 48), finely and densely punctate, subshiny. Face transversely rugulo-striolate; frons smooth and shiny to polished. Vertex and occiput densely subrugulose (Fig. 27).

Mesosoma in lateral view stout, 1.2 times as long as high, scabrous, lateral lobe of mesoscutum uneven to subrugulose. Notaulix distinct anteriorly. Scutellum smooth with a few subpunctures, shiny (Fig. 29). Hind femur 3.5 times as long as broad medially (Fig. 30). Hind basitarsus just longer than tarsomeres $2-4$ combined.

Fore wing shorter than body, $2.5 \mathrm{~mm}$ long. Pterostigma 2.3 times as long as wide, issuing $r$ from its middle, $r$ almost as long as 3-SR (8:9), SR1 straight, 1-R1 0.8 times as long as pterostigma (Fig. 32).

Carapace in dorsal view 2.1 times as long as broad posteriorly, anteriorly longitudinally striated with little anastomoses, interstriations finely crenulated, posteriorly rugorugulose (Fig. 33). Carapace in lateral view 2.6 times as long as high posteriorly, apically deeply rounded (Fig. 34 see arrows). Carapace apico-ventrally deeply incurved (Fig. 31). Ovipositor sheath short, concealed.

Body black. Scape and pedicel yellowish, flagellum black. Palpi pale yellow. Tegula dark brown, parategula brown. Fore leg yellow, coxa brownish. Middle leg yellow, coxa blackish, femur proximally brownish. Hind leg blackish to dark brown, trochanters and base and apex of femur yellow(ish). Wings hyaline, pterostigma brown, veins yellow to light brown.

Male and host unknown.

Distribution - Costa Rica.

Taxonomic position - The new species is near to the Nearctic species Microchelonus minimus (Cresson) viewing their common features: short corporal length (at most $3 \mathrm{~mm}$ long), smooth scutellum, head in dorsal view somewhat less transverse, 1.8-1.9 times as broad as long (Figs 27, 317); cylindric form of 
carapace in dorsal view and black colour of body. The distinction between them is keyed:

1 (2) Fore wing: Pterostigma slightly wider, 2.3 times as long as wide and issuing $r$ from its middle, 1-R1 long, 0.75 ttimes as long as pterostigma (Fig. 32 see arrows). Eye in dorsal view 1.5 times longer than temple, temple slightly more rounded (Fig. 27). Hind femur thin, 3.5 times as long as broad (Fig. 30). Carapace in lateral view moderately rising posteriorly, apically deeply incurved (Fig. 34 see arrows). Fore leg yellow. $+: 3 \mathrm{~mm}$. - Costa Rica

M. aperon sp. $\mathrm{n}$.

2 (1) Fore wing: Pterostigma less wide, 2.5 times as long as wide and issuing $r$ distally from its middle, 1-R1 0.6 times as long as pterostigma (Fig. 319). Eye in dorsal view slightly longer than temple (17:15), temple slightly less rounded (Fig. 317). Hind femur thick, 2.5 times as long as broad (cf. Fig. 300). Carapace in lateral view hardly rising posteriorly, apically perpendicularly truncate (Fig. 320 see arrows). Fore leg dark brown to brownish. + : 2.6-2.7 mm. - USA: New York, Texas

M. mimimus (Cresson, 1873)

In the key to the female Microchelonus species M. aperon runs to M. danzas sp. n. and M. subplanus Papp, see couplets 44 (49) - 48 (47).

\section{Microchelonus avron sp. n.}

(Figs 35-44)

Material exmined - Male holotype: Costa Rica, San José, Escazu, 2-13 May 1988, leg. F. D. Porter. - Holotype is in good order: (1) glued direct to the pin by its right mesosomal side; (2) left antenna apically deficient: flagellum with 13 flagellomeres (i.e. ultimate five flagellomeres missing); (3) right hind femur less visible owing to the mounting. Holotype is deposited in HNHM, Hym. Typ. No. 12229.

Etymology - The new species received the latinized phantasy name "avron".

Description of the male holotype - Body $2.3 \mathrm{~mm}$ long. Antenna shorter than body, $2 \mathrm{~mm}$ long, with 18 antennomeres. First flagellomere three times and penultimate flagellomere 1.4 times as long as broad. - Head in dorsal view transverse (Fig. 35), 1.9 times as broad as long, eye almost twice longer than temple (20:11), temple rather receded. OOL twice longer than POL, ocelli small and almost round. Eye in lateral view 1.7 times as high as wide, gena beyond eye almost evenly broad and slightly less broad than eye (15:17), gena weakly substriolate, shiny (Fig. 37 see arrows). Clypeus 1.75 times as wide below as high medially, its lower margin truncate, punctate to dispersely punctate, interspaces polished (Fig. 36). Malar space 1.3 times longer than basal width of mandible. Face 1.9 times as wide as high, rugose, inner margin of eyes faintly diverging ventrally. Vertex weakly and transversely substriolate, shiny to subshiny, occiput substriolate (Fig. 35).

Mesosoma in lateral view scabrous. Notauli distinct. Scutellum scabrous (cf. Fig. 82). Four denticules of propodeal carina strong (Fig. 38). Hind femur 3.1 times as long as broad 

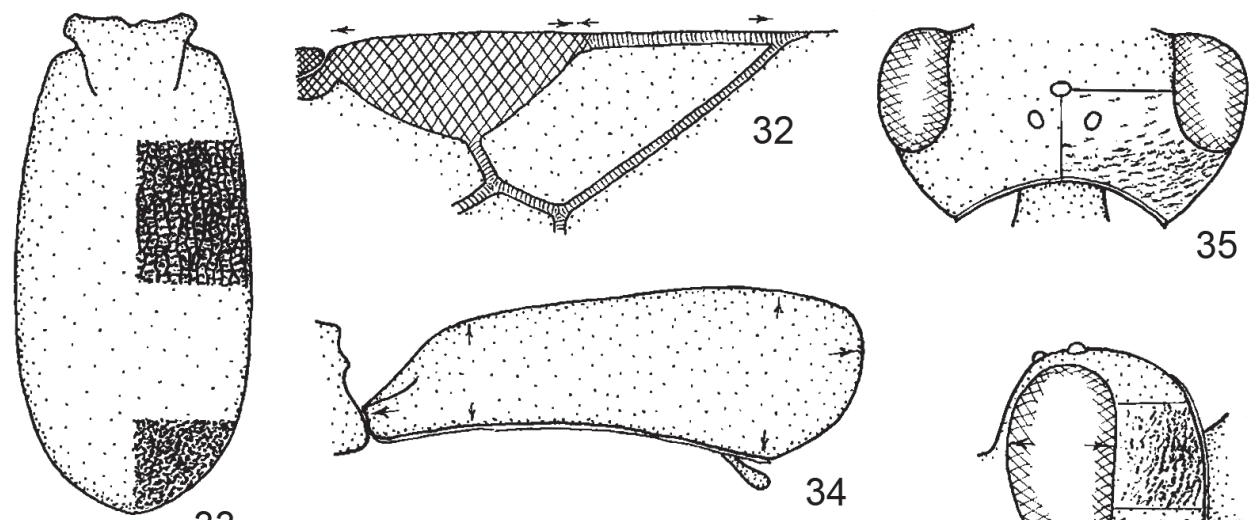

33

35
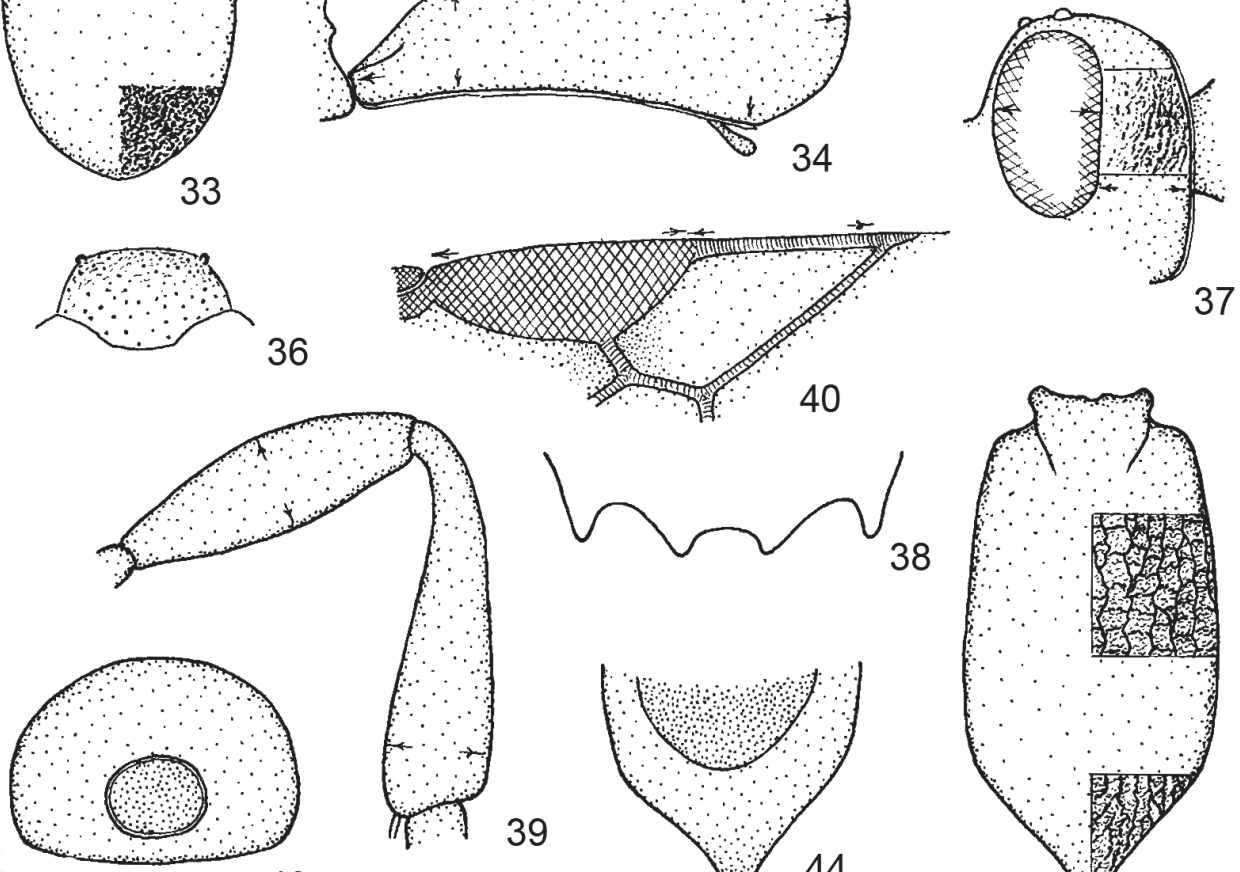

43
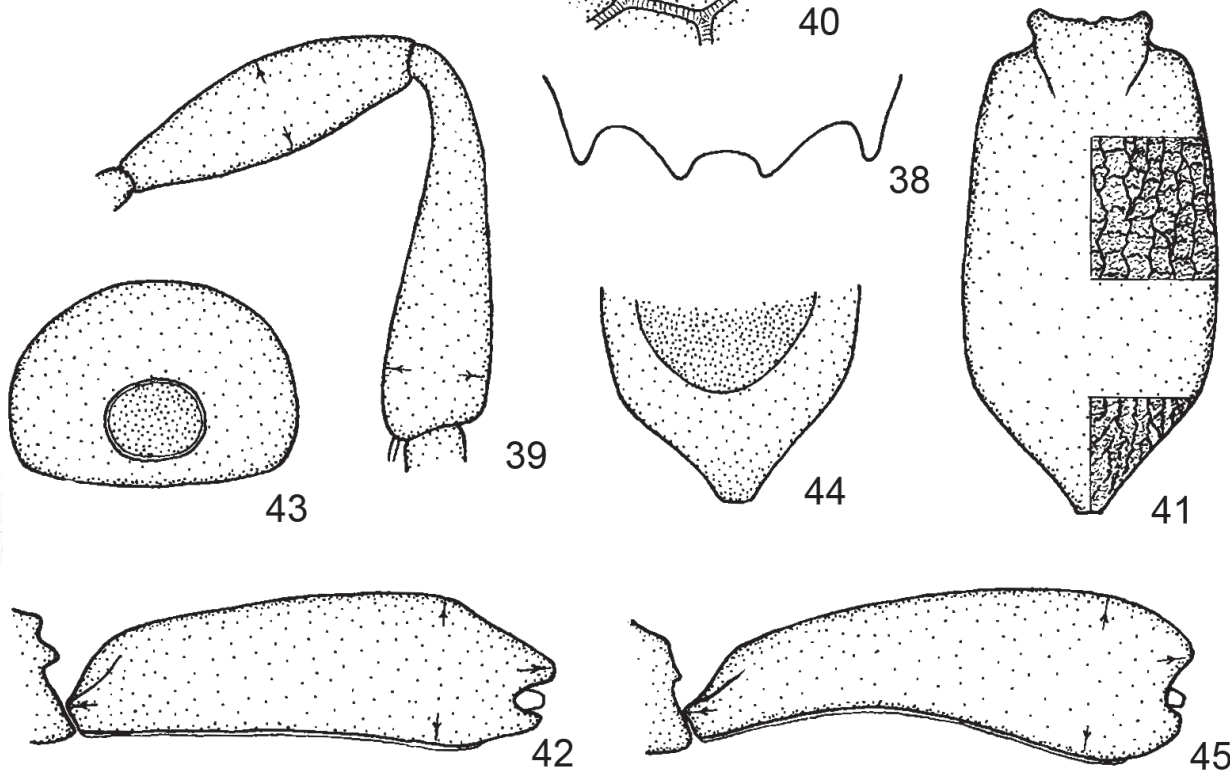

Figs 32-45. 32-34. Microchelonus aperon sp. n. (, holotype): $32=$ distal part of right fore wing, 33 = carapace in dorsal view with indication of its sculpture, $34=$ carapace in lateral view. 35-44. Microchelonus avron sp. n. ( 3 , holotype): $35=$ head in dorsal view with indication of its sculpture, 36 = clypeus, 37 = head in lateral view with indication of its sculpture, 38 = propodeal carina in dorsal view, $39=$ hind femur + tibia, $40=$ distal part of right fore wing, 41 = carapace in dorsal view with indication of its sculpture, 42 = carapace in lateral view, 43 = apical foramen of carapace, 44 = posterior third of carapace in ventral view. 45 . Microchelonus bermus sp. n. ( $\sigma^{\lambda}$, holotype): 45 = capace in lateral view. 
medially, hind tibia distally as broad as femur (Fig. 39 see arrows). Hind basitarsus as long as tarsomeres 2-3 combined.

Fore wing shorter than body, $2 \mathrm{~mm}$ long. Pterostigma 2.5 times as long as wide and issuing $r$ clearly distally from its middle, $r 0.7$ times as long as 3-SR (or 3-SR 1.4 times longer than $r$ ), SR1 straight, 1-R1 0.7 times as long as pterostigma (Fig. 40).

Carapace in dorsal view cylindrical, almost twice (80:41) as long as broad posteriorly, longitudinally striate with few anastomoses, interstriations uneven-subshiny; carapace apically conicule-shaped and here strio-rugose, shiny (Fig. 41). Carapace in lateral view 3.3 times as long as high posteriorly, its hind fourth declivous (Fig. 42). Apical foramen of carapace small and nearly round: slightly wider than high (15:12, Fig. 43). Apico-ventral incurved part of carapace as long as hind basitarsus (cf. Fig. 54).

Body black. Scape and pedicel yellow, flagellum darkening brownish to blackish. Palpi light brownish. Tegula + parategula dark brown, Legs black (coxae) to dark brown, brown, fore and middle tibiae with light brownish tint, tarsi pale yellow. Wings subhyaline, area around pterostigma brownish infumate, pterostigma brown, veins light brown.

Female and host unknown.

Distribution - Costa Rica.

Taxonomic position - The new species, Microchelonus avron, is closest to M. hebes sp. n. considering their posteriorly conicule-shaped carpace (Figs 41, 243), antenna 18-19 antennomeres, hind femur 2.9-3.1 times as long as broad (Figs 39, 241) and black body. The two species differ from each other by the following features keyed:

1 (2) Head in dorsal view transverse, 1.9 times as broad as long, eye almost twice longer (20:11) than temple, temple rather receded (Fig. 35). Four denticules of propodeal carina strong (Fig. 38). Fore wing: pterostigma less wide, 2.5 times as long as wide, issuing $r$ distally from its middle, $1-$ R1 0.7 times as long as pterostigma (Fig. 40). Fore tibia + tarsus brownish. ग̃: $2.3 \mathrm{~mm}$. - Costa Rica

M. avron sp. n.

2 (1) Head in dorsal view slightly less transverse, 1.8 times as broad as long, eye as long as temple, temple rounded (Fig. 235). Four denticules of propodeal carina less strong (Fig. 240). Fore wing: pterostigma wide, 2.2 times as long as wide issuing $r$ from its middle, $1-R 10.6$ times as long as pterostigma (cf. Fig. 146). Fore tibia + tarsus yellow. $\delta^{\lambda}: 2.7 \mathrm{~mm}$. - Costa Rica

M. hebes sp. n.

In the key to the male Microchelonus species $M$. avron runs to M. curticarinulus sp. n. and M. topali Papp, see couplets 4 (9) -8 (7).

\section{Microchelonus bermus sp. $\mathrm{n}$.}

(Figs 45-54)

Material examined - Male holotype: Honduras, Olancho, Parque Nacional la Muralla, $15 \mathrm{~km} \mathrm{~N}$ from La Unión, $15^{\circ} 07^{\prime} \mathrm{N} / 86^{\circ} 45^{\prime} \mathrm{W}$, taken with Malaise trap set up in high elevation 
rain forest, April 1995, leg. R. Cave. - Holotype is in good condition: glued on card point by its right meso- and metapleuron. Holotype is deposited in ZMLU.

Etymology - The new species received the latinized phantasy name "bermus".

Description of the male holotype - Body $4 \mathrm{~mm}$ long. Antenna somewhat longer than body ( $4.5 \mathrm{~mm}$ long) and with 24 antennomeres. Flagellomeres long, first flagellomerer four times and penultimate flagellomeres 2.3 times as long as broad (Fig. 46). Flagellum proximo-distally attenuating. - Head in dorsal view transverse (Fig. 47), 1.7 times as broad as long, temple somewhat swollen, eye slightly longer than temple (19:17), temple rounded. OOL about half as long as POL, ocelli faintly ellptic. Eye in lateral view twice as high as wide, gena beyond eye broadening ventrally so that one-third wider than eye (21:14), gena strilate with anastomoses (cf. Fig. 248). Clypeus subquadrate, somewhat wider below than higgh medially (30:25), its lower margin convex, densely (not confluently) punctate, interpunctations (sub)shiny (Fig. 48). Malar space almost 1.7 times as long as basal width of mandible. Frontal greatest width of face twice as long as middle height, rugose, inner margin of eyes slightly diverging ventrally. Vertex, occiput and frons densely rugose.

Mesosoma in lateral view 1.6 times as long as high, scabrous. Notaulix less distinct. Scutellum rugose (Fig. 49). Propodeal carina with prominent four denticules (Fig. 50). Hind femur 3.5 times as long as broad somewhat distally (cf. Fig. 30). Hind basitarsus as long as tarsomeres $2-4$ combined.

Fore wing shorter than body ( $3.3 \mathrm{~mm}$ long). Pterostigma 2.3 times as long as wide and issuing $r$ from its middle, $r$ long: twice longer than 3-SR, SR1 straight, 1-R1 0.7 times as long as pterostigma (Fig. 51).

Carapace in dorsal view cylindrical, 2.3 times as long as broad posteriorly, longitudinally and somewhat undulate striated with much anastomoses, interstriations rugulose. Apical foramen of carapace elliptic: 1.6 times wider than high (Fig. 53). Carapace in lateral view three times as long as high posteriorly (Fig. 45 see arrows). Apico-ventral incurved part of carapace almost as long as hind basitarsus (Fig. 54).

Antenna and body black. Palpi dark brown. Legs black to blackish, fore and middle femora and fore tibia feebly rusty. Wings subhyaline, area around pterostigma brownish infumate. Pterostigma blackish brown, veins light brown to brown.

Female and host unknown.

Distribution - Honduras.

Taxonomic position - The new species, Microchelonus bermus, is close to $M$. egregicolor (Viereck) viewing their common features: temple in dorsal view somewhat swollen and striate sculpture of carapace; their distinction is keyed:

1 (2) Fore wing: $r$ long, twice as long as 3-SR, 1-R1 short, 0.7 times as long as pterostigma (Fig. 51). Striation of carapace undulate and with anastomoses (Fig. 52). Propodeum: lateral pair of denticules less prominent and middle pair more prominent (Fig. 50). Apical foramen of carapace elliptic: 1.6 times wider than high (Fig. 53). Carapace entirely black. $\widehat{\jmath}: 4$ mm. - Honduras

M. bermus sp. n.

2 (1) Fore wing: $r$ short, either as long as 3-SR or 3-SR somewhat longer , 1-R1 almost as long as pterostigma (Fig. 179). Striation of carapace straight and without anastomoses (Fig. 181). Propodeum: lateral pair of denticules more and middle pair less prominent (Fig. 180). Apical foramen of 
carapace "very broad and slit-like". Basal third to half of carapace lemon yellow, otherwise black. of: 4.7-5.2 mm. - Widely distributed in the USA M. egregicolor (Viereck, 1905)

The new species is also near to M. ashmeadi (Dalla Torre) by their swollen temple and dark coloured legs; the two species differ from each other by the following traits (M. ashmeadi known only be the female):

1 (2) Fore wing: pterostigma 2.3 times as long as wide, isuing $r$ from its middle, $r$ twice longer than 3-SR (Fig. 51). Carapace with rather straight striations (Fig. 52). Scutellum rugose (Fig. 49). Wings hyaline, area around pterostigma infumate (Fig. 51). $0: 4 \mathrm{~mm}$. - Honduras M. bermus sp. $\mathrm{n}$.

2 (1) Fore wing: pterostigma 3 times as long as wide, issuing $r$ distally from its middle, $r$ about as long as 3-SR. "Carapace with rather irregular longitudinal rugulose sculpturing." Scutellum "confluently punctate." Wings "strongly, uniformly infumated." o: $2.6 \mathrm{~mm}$. - USA: Colorado (=Chelonus atripes Ashmead, 1893 nec Thomson, 1874) M. ashmeadi (Dalla Torre, 1898)

In the key to the male Microchelonus species M. bermus runs to M. carinatus (Provancher), see couplets $22(25)-24$ (23).

\section{Microchelonus blackburni (Cameron, 1886)} (Figs 55-63)

Chelonus carinatus Cameron, 1881 (nec Provancher, 1881 sen. syn.) + , type locality: “Oahu” (USA: Hawaii), type series in The Natural History Museum, London; not examined.

Chelonus blackburni Cameron, 1886: 181 and 242 (replacement or new name for Ch. carinatus Cameron).

Chelonus (Microchelonus) blackburni Cameron: МсСомв, 1968: 10 (in key) and 28 (redescription).

Microchelonus blackburni (Cameron, 1886): SHenefelt 1973: 877 (comb. n., literature up to 1968). PAPp 2010: 189 (faunistics, distribution).

Material examined - Localities of 16 females and 10 males in PApp 2010: 189-190). New locality: 1 o (in HNHM): Marqueses Islands, Eiao, 1500 feet, 22 April 1931, leg. Bromec et Tanraa.

Additional features to the redescription (McComb l.c.):

Female - Body (2.3-)3-3.4 mm long. Penultimate flagellomere 1.1 times (subcubic) to 1.25 times as long as broad. Head in dorsal view distinctly transverse (60:29, Fig. 55) to transverse (60:30), temple receded. Frons, vertex, occiput and gena densely substriolate (Figs 55, 56). Gena beyond eye evenly and slightly wider (13:11) than eye (Fig. 56). Scutellum smooth with very fine and few punctures, apically rugulose (Fig. 57). Fore wing: pterostigma 2.3-2.6(-2.8) times, usually 2.5 times, as long as wide, issuing $r$ distally from its middle, 
1-R1 (0.55-) 0.75 times as long as pterostigma (Fig. 58). Propodeal carina distinct, its middle pair of denticules small, lateral pair prominent (Fig. 63). Carapace in dorsal view belly, 1.6 times as long as broad posteriorly, its basal third yellow, apically rounded (Fig. 59 see arrows). Carapace in lateral view 3.4-3.6 times as long as high posteriorly (Fig. 61 see arrows).
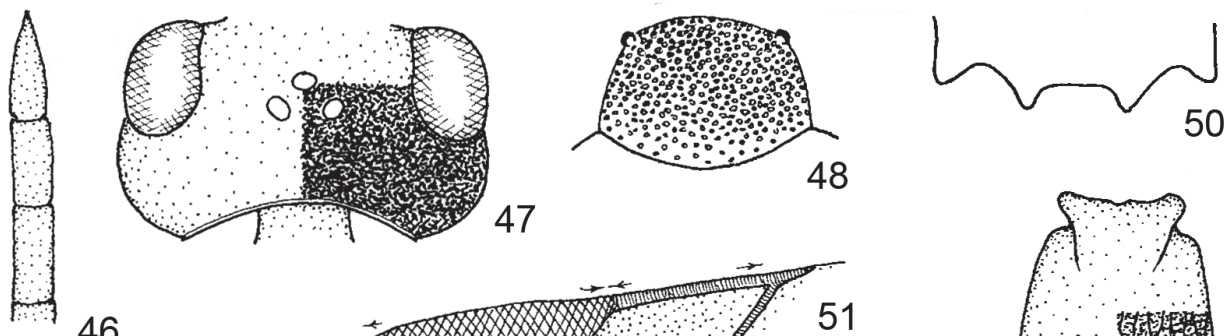

46

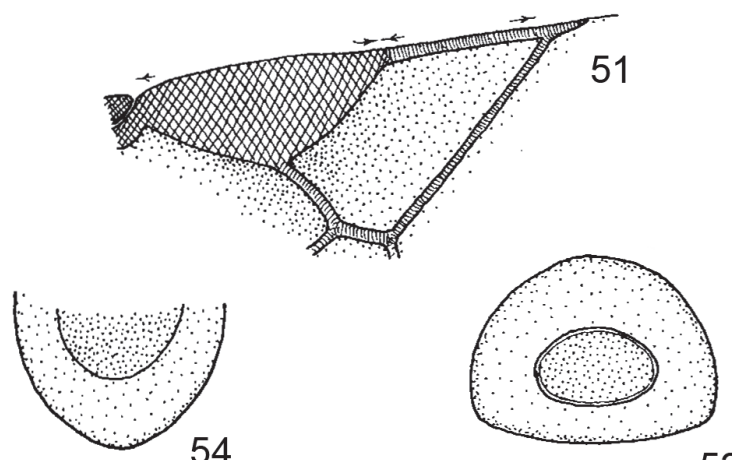

53

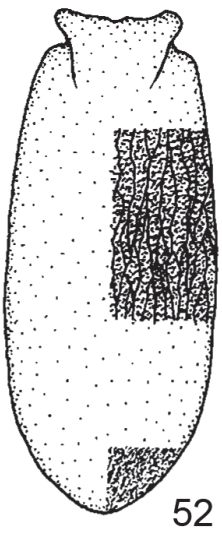

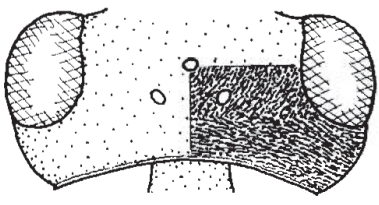

55

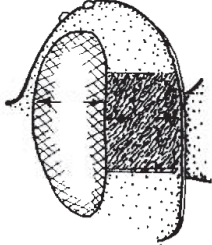

56

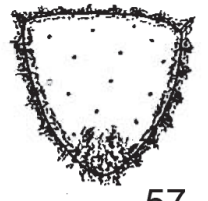

57

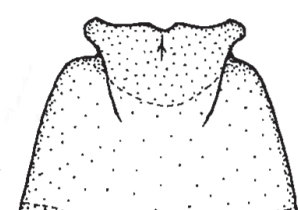

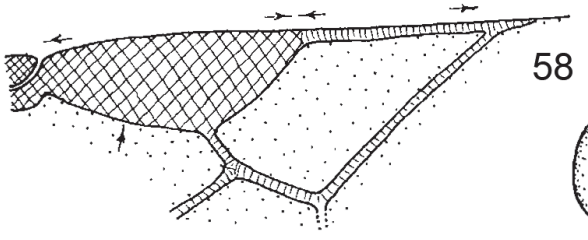

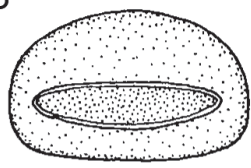

60

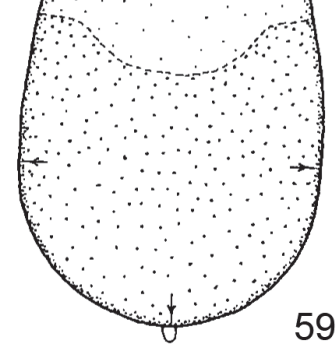

Figs 46-60. 46-54. Microchelonus bermus sp. n. (male holotype): $46=$ ultimate three flagellomeres, 47 = head in dorsal view with indication of its sculpture, $48=$ clypeus, $49=$ scutellum, 50 = propodeal carina in dorsal view, $51=$ distal part of right fore wing, $52=$ carapace in dorsal view with indication of its sculpture, 53 = apical foramen of carapace, $54=$ posterior third of carapace in ventral view. 55-60. Microchelonus blackburni (Cameron, 1886): $55=$ head in dorsal view with indication of its sculpture (q), $56=$ head in lateral view with indication of its sculpture $(+$ ) $), 57=$ scutellum $(+\phi \hat{\jmath}), 58=$ distal part of right fore wing $(\phi \hat{\jmath})$, 59 = carapace in dorsal view $(+), 60=$ apical foramen of carapace $(\delta)$. 
Male - Similar to the female. Body (2.3-)3-3.2 mm long. Antenna somewhat longer than head + mesosoma combined and with 23-24 antennomeres. Penultimate flagellomere 1.4-1.5 times as long as broad. Carapace in dorsal view less belly, 1.8 times as long as broad posteriorly, apically less rounded, striated (Fig. 62). Apical foramen of carapace wide-elliptic (or slit-like), five times as wide as high (Fig. 60). 29-30).

Hosts - Many Microlepidoptera species (see Shenefelt 1973: 877, МсСомв 1968:

Distribution - USA: Hawaii (type locality), Marquesas Islands. - Introduced: USA: Arizona, California, Florida, Texas; Costa Rica, Honduras, Mexico, Peru, Puerto Rico; India, Egypt.

Taxonomic position - In the key to the female Microchelonus species M. blackburni runs to M. angustus Papp, see couplets 76 (79) - 78 (77); to M. brasiliensis (Brues) and M. pectiniphorae (Cushman), see couplets 86 (85) - 90 (89); to M. johni (Marsh), see couplets 96 (99) - 98 (97). In the key to the male Microchelonus species M. blackburni runs to M. pectiniphorae (Cushman), see couplets $42(41)-44(43)$.

\section{Microchelonus bolsoni Papp, 1999 \\ (Figs 64-69)}

Microchelonus bolsoni Papp: 1999: 181 , type locality: Argentina, prov. Rio Negro, El Bolsón. - Holotype in HNHM; examined.

Emendated features to the original description (Papp l.c.) - Eye 1.6 times longer than temple, temple strongly rounded (or less receded, Fig. 64). Clypeus 2.1 times as wide below as high medially, its lower margin widely truncate (cf. Fig. 487). Fore wing: 3-SR slightly longer than r, SR1 straight (Fig. 68).Hind femur 2.5 times as long as broad medially (Fig. 67). Carapace in lateral view 2.3 times as long as high posteriorly.

Taxonomic position - In the key to the female Microchelonus species M. bolsoni runs to $M$. zobocus sp. n., see couplets $63(62)-65$ (64). In the original description M. bolsoni is related to $M$. topali Papp and M. brevis Tobias (Papp 1.c.).

\section{Microchelonus brasiliensis (Brues, 1912) (Figs 70-76, 88)}

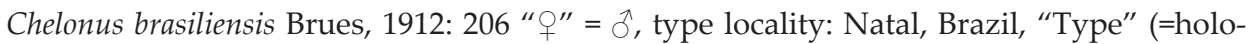
type) in Museum of Comparative Zoology, Cambridge (USA); examined.

Microchelonus brasiliensis (Brues): Shenefelt 1973: 878 (comb. n., literature up to 1912). PApp 1999: 183 (synonymization, redescription, taxonomic position), 2010: 189 (in key).

Chelonus (Chelonella) szepligetii Viereck, 1913: 360 , type locality: Pernambuco, Brazil, female holotype in USNM (one female paratype in MNB, locality: San Bernandine, Paraguay); examined, synonymization (PAPP l.c.). 

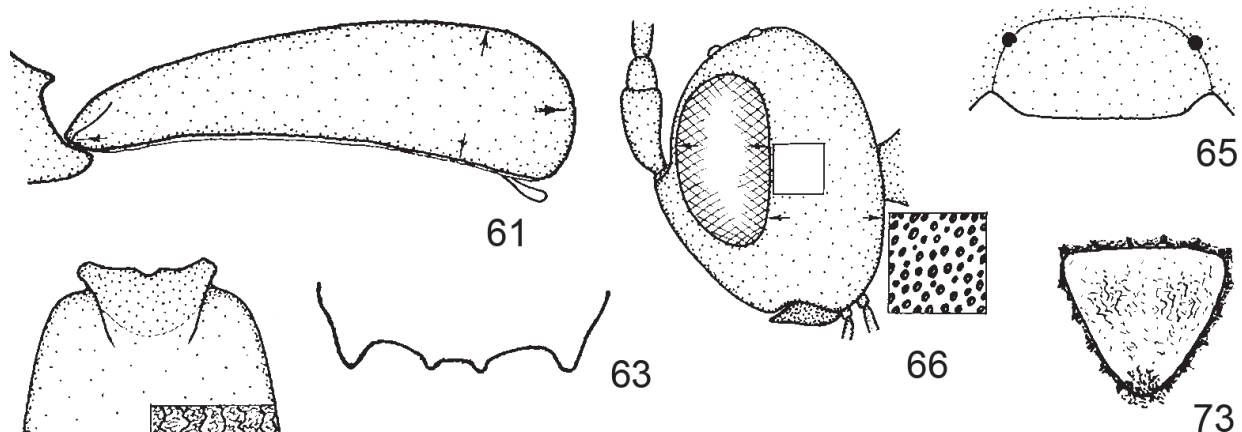

66

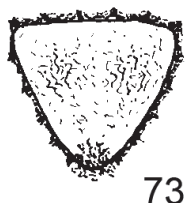

73
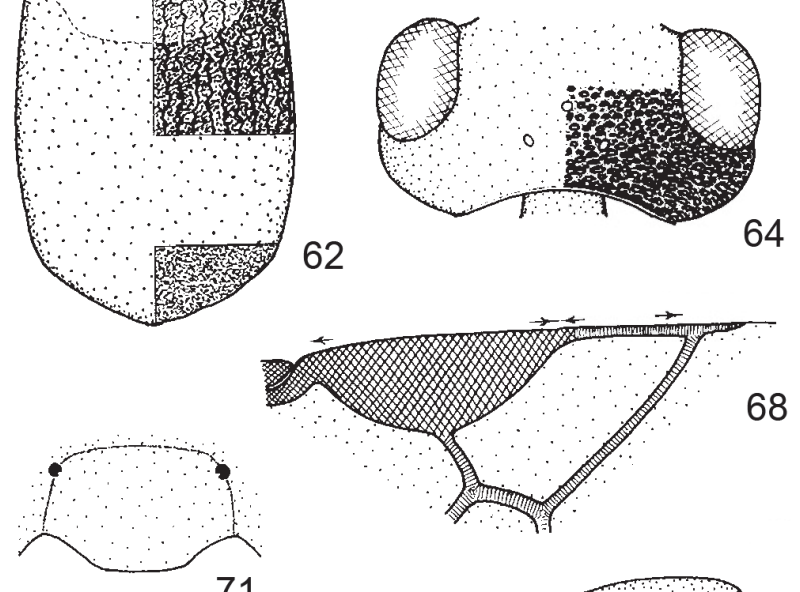

68

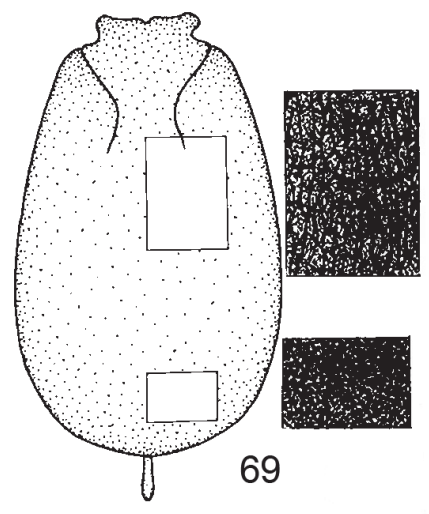

71
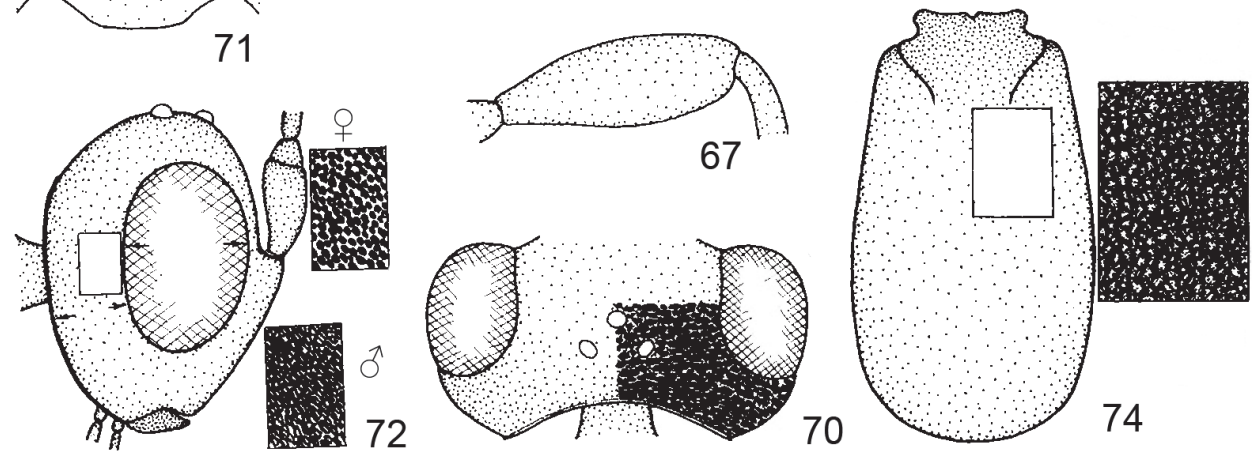

Figs 61-74. 61-63. Microchelonus blackburni (Cameron, 1886): 61 = carapace in lateral view $(+), 62$ = carapace in dorsal view with indication of its sculpture $\left({ }^{\pi}\right), 63$ = propodeal carina in dorsal view (†ð). 64-69. Microchelonus bolsoni Papp, 1999 (female holotype): 64 = head in dorsal view with indication of its sculpture, 65 = clypeus, $66=$ head in lateral view with indication of its sculpture, 67 = hind femur, $68=$ distal part of right fore wing, $69=$ carapace in dorsal view with indication of its sculpture. 70-74. Microchelonus brasiliensis (Brues, 1912): $70=$ head in dorsal view with indication of its sculpture $(+\hat{O}), 71=$ clypeus $(+\circ), 72=$ head in lateral view with indication of its sculpture $(\phi \hat{\phi} \hat{)}), 73=$ scutellum $(\dot{\phi} \hat{O}), 74=$ carapace in dorsal view with indication of its sculpture $(ð)$. 
Emendated features to the redescription (PAPp 1999: 183) - + . Body 2.7-2.9 mm long. Head in dorsal view almost twice (i.e. 1.9 times) as broad as long, eye 2.1 times longer than temple, temple receded, vertex strongly and almost confluently and elliptic subfoveolate (Fig. 70). Scutellum smooth and shiny to uneven, subrugulose, dull (Fig. 73). Fore wing: pterostigma 2.2 times as long as wide and 1.25 times longer than 1-R1, SR1 almost straight (Fig. 75 see arrows). Carapace in lateral view 2.8 times as long as high posteriorly (Fig. 76, see arrows). $-\delta$. Apical foramen of carapace elliptic and fairly large, 2-2.2 times as wide as high (Fig. 88).

Taxonomic position - In the key to the female Microchelonus species M. brasiliensis (Brues) runs to $M$. johni (Marsh), see couplets 80 (83) - 82 (81); to $M$. blackburni (Cameron) and M. pectiniphorae (Cushman), see couplets 86 (85) - 90 (89); to M. constrictus Papp, see couplets 92 (95) - 94 (93). In the key to the male Microchelonus species M. brasiliensis runs to M. kellieae (Marsh) and M. topali Papp, see couplets 47 (46) - 51 (50).

\section{Microchelonus buscki (Viereck, 1912) (Figs 77-87, 89-92)}

Chelonus (Chelonella) buscki Viereck, 1912: 618 +, type locality: “Montserrat, Trinidad", type series: ?two females in USNM.

Microchelonus buscki (Viereck): Shenefelt 1973: 878 (comb. n., literature up to 1913). Papp 2010: 157 (designation of female lectotype, redescription, distribution), 172 and 180 (in key); examined.

Material examined - Female lectotype and 194 females and 19 males from Costa Rica, Honduras, Panama and Peru (Papp 1.c.).

Emendated features to the redescription (Papp 1.c.) - 9. Body 3.5-4.5, usually 3.9-4.2 mm long. Flagellomeres long: proximo-distally attenuating and four to two times as long as broad (Fig. 87). Head in dorsal view 1.9-2.1 times as broad as long, temple strongly rounded (Fig. 78) to receded (Fig. 79). Clypeus 1.6 times as wide below as high medially (Fig. 80). Gena substriolated, one-fourth wider than eye (Fig. 81 see arrows). Scutellum scabrous (Fig. 82). Hind femur 2.6-2.8 times longer than broad somewhat distally from its middle (Fig. 84). Fore wing: pterostigma 2.5-2.7 times as long as wide and issuing $r$ distally from its middle, 3-SR twice to three times as long as $r, 1-R 1$ 0.7-0.9 times as long as pterostigma (Fig. 83). Carapace in dorsal view more or less evenly boadening antero-posteriorly, i.e. more or less pyriform, twice longer than broad posteriorly, striate to rugose, apically rugulose (Fig. 8586). Carapace in lateral view 2.6-2.8 times as long as high posteriorly, apically rounded (Fig. 89); apico-ventally incurved (Fig. 90). Carapace black, anteriorly with a pair of round (pale) yellow maculae (nom. f., Figs 85-86) or with transverse (pale) yellow band (var. gilvus).

o. Similar to the female. Body 3.8-4.2 mm long. Penultimate flagellomere three times as long as broad (Fig. 87). Carapace in dorsal view somewhat less broadening posteriorly, 2.3-2.4 times as long as broad posteriorly (Fig. 91). Apical foramen of carapace missing.

Taxonomic position - In the key to the female Microchelonus species $M$. buscki runs to M. effusus Papp and M. pyriformis Papp, see couplets 38 (43) - 42 
(41); to M. danzas sp. n. and M. pyriformis Papp, see couplets 113 (112) - 115 (114). - In the key to the male Microchelonus species M. buscki runs to M. effusus Papp and M. jamaicus sp. n., see couplets 27 (26) - 31 (30).
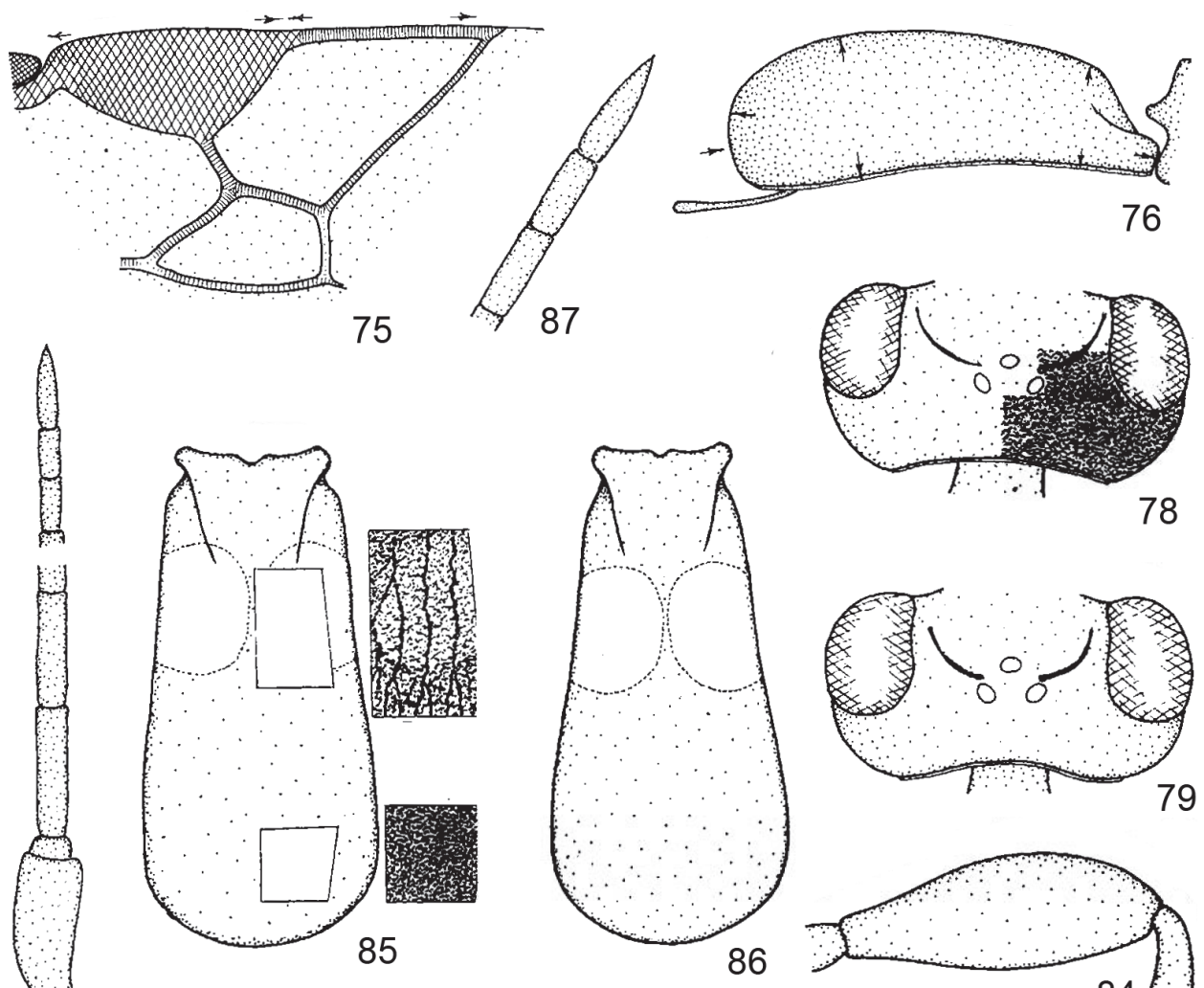

78

77
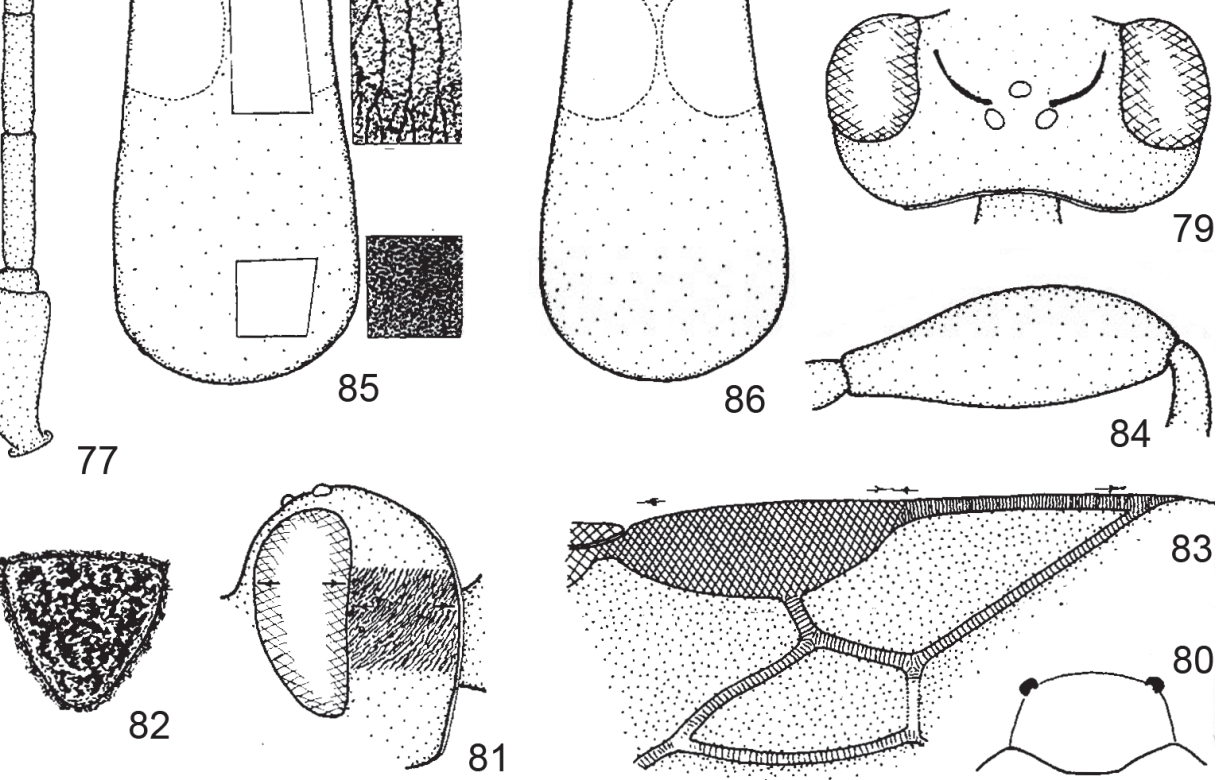

Figs 75-87. 75-76. Microchelonus brasiliensis (Brues, 1912): 75 = distal part of right fore wing (욱), 76 = carapace in lateral view. 77-87. Microchelonus buscki (Viereck, 1912) (female holotype: $78,81,84,85$; female: 77,79 ; female + male: $80,82,83$, 86; male: 87 ): 77 = scape, pedicel and proximal / distal parts of flagellomeres, $78=$ head in dorsal view with indication of its sculpture, $79=$ head in dorsal view, $80=$ clypeus, $81=$ head in lateral view with indication of its sculpture, $82=$ scutellum, $83=$ distal part of right fore wing, $84=$ hind femur, $85=$ carapace in dorsal view with indication of its sculpture, $86=$ carapace in dorsal view, $87=$ ultimate three flagellomeres. 


\section{Microchelonus cacumenus Papp, 2010 \\ (Figs 93-99)}

Microchelonus cacumenus Papp, 2010: 160 q, type locality: Honduras, Atlantida, Lancertilla, female holotype in ZMLU; examined.

Emendated features to the original description (Papp 1.c.) - 9 . Body $3 \mathrm{~mm}$ long. Penultimate flagellomere long, 1.6 times as long as broad (Fig. 93). Head in dorsal view less transverse, 1.7 times as broad as long, temple receded (Fig. 94). Clypeus 1.8 times as wide below as high medially, its lower margin very weakly convex (Fig. 95). Fore wing: pterostigma 2.3 times as long as wide, issuing $r$ distally from its middle, $1-R 1$ half as long as pterostigma, 3-SR twice longer than $r$ (Fig. 96). Carapace in dorsal view just twice longer than broad posteriorly, apically pointed, striated to less striated (Fig. 97). Carapace apicoventrally incurved as in Fig. 99; in lateral view almost evenly high, 3.4 times as long as high posteriorly (Fig. 98 see arrows).

Distribution - Honduras.

Taxonomic position - In the key to the female Microchelonus species M. cacumenus runs to $M$. parkeri Papp, see couplets 20 (21) - 21 (20); to M. candidus sp. n., see couplets 34 (35) - 36 (37). In the original description $M$. cacumenus is related to M. acutigaster (McComb) (PAPP 2010: 162-163) and M. parkeri Papp (PAPr 2010: 178).

\section{Microchelonus candidus sp. $\mathrm{n}$.}

(Figs 100-109)

Material examined (11 females) - (1) Female holotype and two female paratypes: Costa Rica, San José, Escazu, holotype (in USNM): 13-15 April 1988, two paratypes: 1-7 February 1988 (one paratype in ZMLU) and 2-13 May 1988 (one paratype in HNHM). (2) Five female paratypes: Costa Rica, Alajuela, Upala, 15 July 1990 and 11-20 April 1991 (two paratypes in USNM), 21-30 April 1991 (one paratype in HNHM), 21-31 July 1991 and 11-21 October 1991 (two paratypes in DEUU). (3) One female paratype (in DEUU): Costa Rica, Guanacastle, 3 km SE from Rio Naranjo, 17-20 November 1991. (4) One female paratype (in DEUU): Costa Rica, Guanacastle, 14 km S from Cañas, 1-22 June 1991. (5) One female paratype (in HNHM): Honduras, Atlantida, Lancetilla, Tela, taken with Malaise trap set up in lowland rain forest, 15 September 1995, leg. R. Cave. - The ten female type specimens from Costa Rica were taken by F. D. Parker.

Types condition - Holotype is in good condition: (1) glued directly to the pin by the anterior right side of mesosoma, (2) fore pair of legs partly less visible owing to the mounting, (3) no missing corporal part. Ten paratypic females are in good condition: (1) nine specimens from Costa Rica glued like the holotype, one specimen glued on card point, (2) flagelli partly more or less damaged (or missing).

Type depositories - Holotype and two paratypes are deposited in USNM, four paratypes in DEUU, one paratype in ZMLU and three paratypes in HNHM, Hym. Typ. No. 12230-12232.

Etymology - The new species received the Latin name "candidus" refering to its polished carapace. 
Description of the female holotype - Body $3.2 \mathrm{~mm}$ long. Antenna as long as head, mesosoma and two-thirds of carapace combined, with 16 antennomeres. Scape 2.5 times as long as broad apically, first flagellomere six times and penultimate flagellomere twice as long as broad (Fig. 101a), flagellum filiform. - Head in dorsal view transverse, twice as broad as long, eye twice longer than temple, temple receded (Fig. 102). OOL almost twice as long as POL, ocelli small. Eye in lateral view almost 1.9 times as high as wide, gena beyond eye clearly broadening ventrally and as broad as eye; polished with disperse hairpunctures (cf.
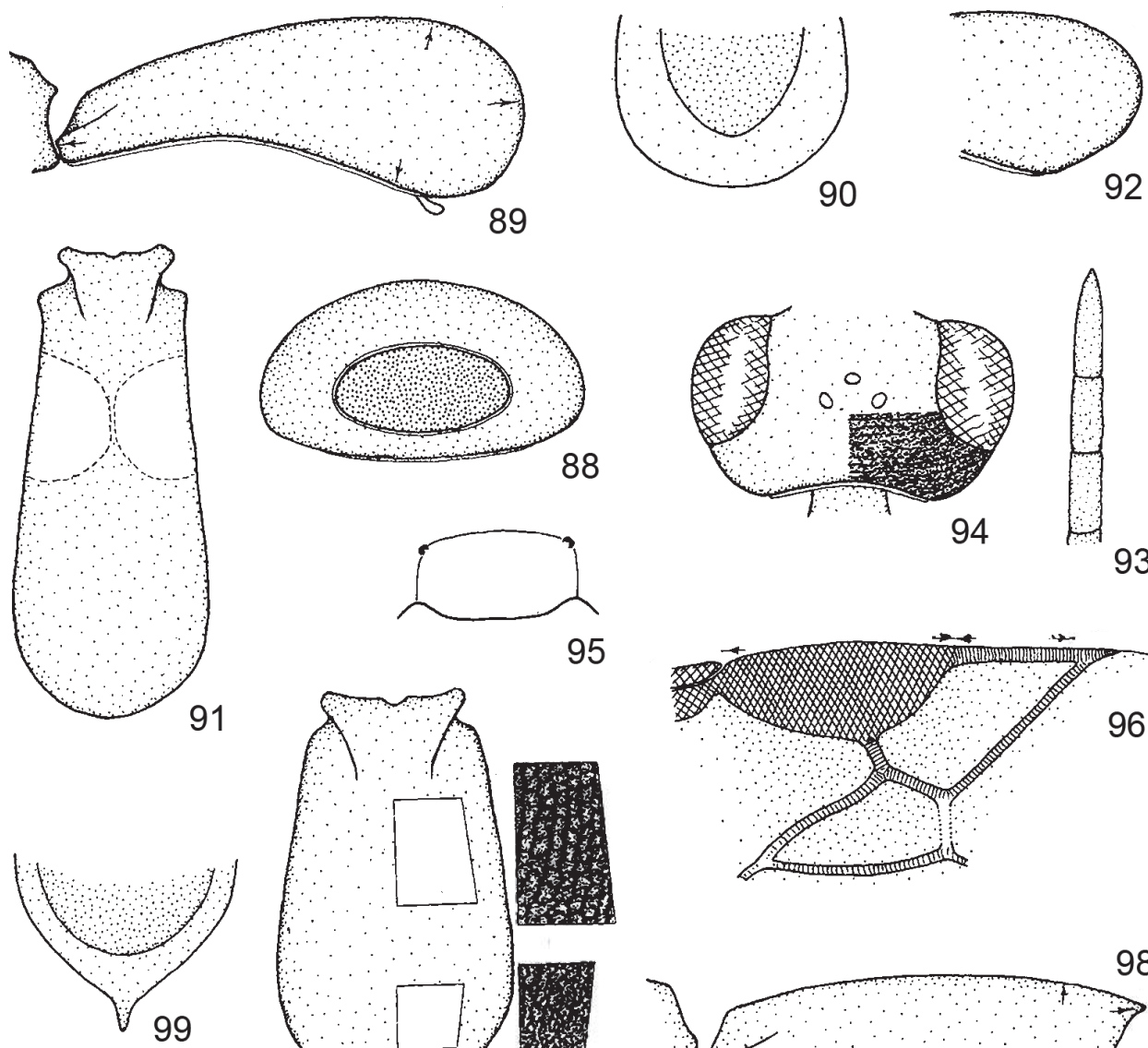

93
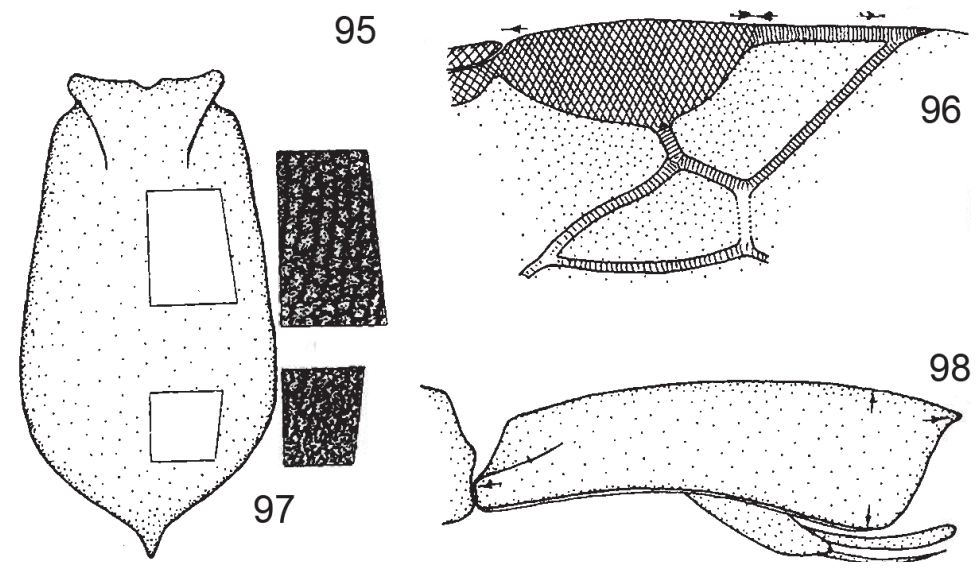

Fig. 88-99. 88. Microchelonus brasiliensis (Brues, 1912): 88 = apical foramen of male carapace. 89-92. Microchelonus buscki (Viereck, 1912) (female holotype: 89, 90; male: 91, 92): 89 = carapace in lateral view, $90=$ posterior third of carapace in ventral view, $91=$ carapace in dorsal view, 92 = posterior third of carapace in lateral view. 93-99. Microchelonus cacumenus Papp, 2010 (female holotype): 93 = ultimate three flagellomeres, $94=$ head in dorsal view with indication of its sculpture, 95 = clypeus, $96=$ distal part of right for wing, $97=$ carapace in dorsal view with indication of its sculpture, $98=$ carapace in lateral view, $99=$ posterior third of carapace in ventral view. 
Fig. 184). Clypeus one-fourth wider below than high medially, its lower margin convex (cf. Fig. 347), densely punctate, interpunctures shiny. Face twice as wide as high, transversely rugulose-punctate. Head above substriolate (Fig. 102).

Mesosoma in lateral view stout, somewhat longer than high. Mesoscutum rugo-rugulose, scutellum rugulo-uneven, mesopleuron rather rugose. Propodeum on its horizontal surface with an elongate areola basalis, otherwise areolated as in Fig. 103. Hind femur thin, 4.1 times as long as broad medially (Fig. 104). Hind basitarsus as long as tarsomeres 2-4 combined.

Fore wing somewhat shorter than body. Pterostigma 2.6 times as long as wide, issuing $r$ somewhat distally from its middle; $1-R 10.65$ times as long as pterostigma, $3-S R 1.4$ times longer than $r$, SR1 faintly bent (Fig. 105 see arrows).

Carapace in dorsal view 1.9 times as long as broad posteriorly, finely striate, its posterior (downvurved) fourth polished (Figs 100, 106). Carapace in lateral view curved, 3.4 times as long as high posteriorly, its apical fourth downcurved (Fig. 107, see arrows). Carapace apico-ventrally not incurved (Fig. 108). Ovipositor sheath short and concealed.

Ground colour of body black. Scape light reddish yellow, pedicel and flagellomeres 1-2 light reddish yellow darkening by fumous tint, flagellomeres 3-4 yellow, rest of flagellum black. Palpi pale yellow. Pronotum dark rusty, tegula brown. Carapace anteriorly brown to yellow. Legs tricoloured: coxae + trochanters 1-2 pale yellow, rest of legs 1-2 yellow with light brownish tint; hind leg brown to dark brown, trochanters, base of femur and proximal ring of tibia pale yellow. Wings feebly fumous around pterostigma, pterostigma itself light brown, parastigma pale yellow, veins brownish yellow to light brown.

Variable features of the ten female paratypes - Body 3.2-3.5 mm long. Penultimate flagellomere 1.8-2 times as long as broad (Fig. 101a-b). In lateral view gena beyond eye a bit wider than eye (cf. Fig. 184). Hind femur 4.1-4.5 times as long as broad. Fore wing: Pterostigma 2.8 times as long as wide, 1-R1 0.6-0.65 times as long as pterostigma (Fig. 109), SR1 straight to more or less bent. Light colour of carapace variable from faint brownish to lemon yellow.

Male and host unknown.

Distribution - Costa Rica, Honduras.

Taxonomic position - The new species, Microchelonus candidus, is closest to $M$. fulgens sp. n., they are very similar to each other and are separated by a few features keyed:

1 (2) Head in dorsal view somewhat more transverse, 2.1 times as broad as long, eye 2.5 times longer than temple (Fig. 227). Penultimate flagellomere cubic (cf. Fig. 134). Fore wing: pterostigma wide, 2.4 times as long as wide and issuing $r$ from its middle (Fig. 231). Dark colour of legs brown to blackish brown. $+: 3.1 \mathrm{~mm}$. - Costa Rica M. fulgens sp. n.

2 (1) Head in dorsal view somewhat less transverse, twice as broad as long, eye twice longer than temple (Fig. 102). Penultimate flagellomere 1.8-2 times as long as broad (Fig. 101a-b). Fore wing: pterostigma less wide, 2.6-2.8 times as long as wide and issuing $r$ distally from its middle (Fig. $105,109)$. Dark colour of legs light brown to brown / dark brown. O: 3.2-3.5 mm. - Costa Rica, Honduras

M. candidus sp. $n$. 
The new species is also near to M. latistigma sp. n. and M. exceptus sp. n., their distinction is presented in key couplets 4 (3) -8 (9), see the key to the female Microchelonus species.

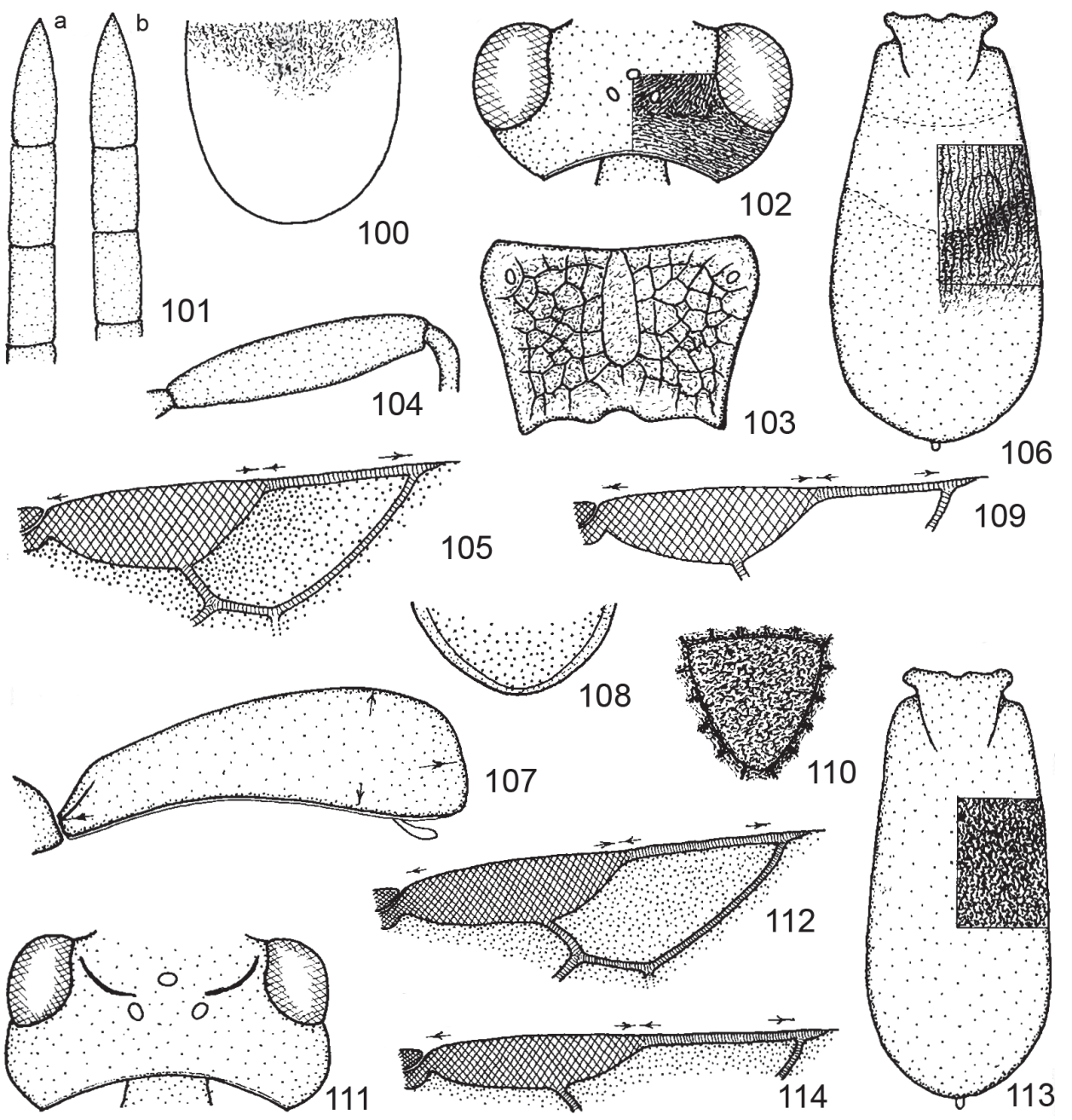

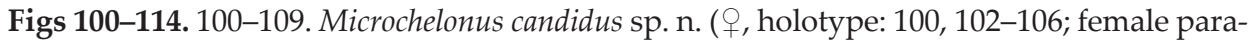
type: 108-109): 100 = posterior third of carapace in dorsal view with indication of its sculpture, $101=$ ultimate three flagellomeres of female holotype (a) and female (b), $102=$ head in dorsal view with indication of its sculpture, 103 = propodeum, $104=$ hind femur, $105=$ distal part of right fore wing, $106=$ carapace in dorsal view with indication of its sculpture, $107=$ carapace in lateral view, $108=$ posterior fourth of carapace in ventral view, $109=$ distal part of right fore wing. 110-114. Microchelonus carinatus (Provancher, 1881): $110=$ scutellum

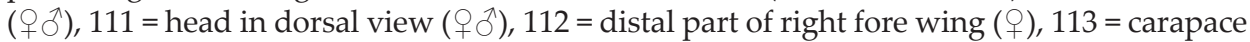
in dorsal view with indication of its sculpture $(+), 114=$ pterostigma $+1-R 1$ of fore wing $(\hat{\delta})$. 
Taxonomic remark - Propodeum of the Neotropical species of Microchelonus are roughly rugose to scabrous with a medio-transverse carina, carina itself with two pairs of denticules (Figs 38, 63, 144, 220). From this standard feature the propodeum of $M$. candidus sp. n. (together with further four species: M. curtulus sp. n., M. exceptus sp. n., M. fulgens sp. n. and M. latistigma sp. n.) deviates: medially with (long) areola basalis, otherwise areolate (Figs 103, $156,187)$. This deviating character may lead in the future to provoke a new subgeneric (or generic) rearrangement.
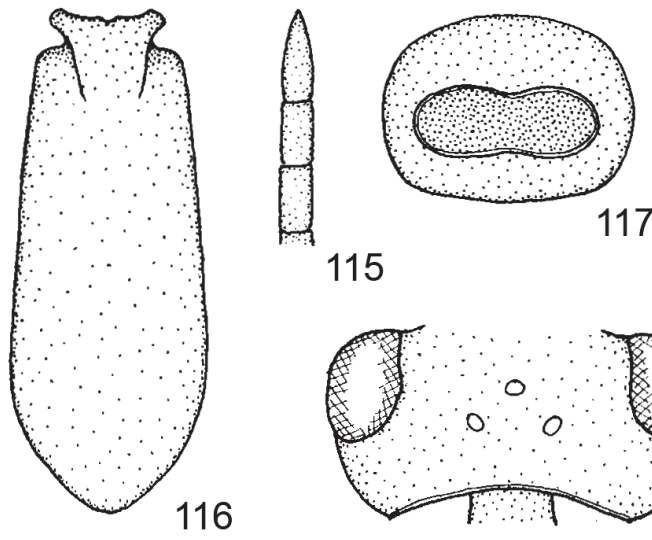

115
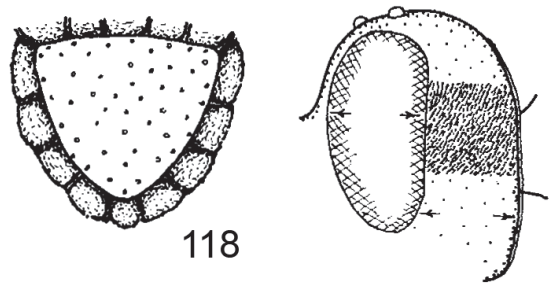

121
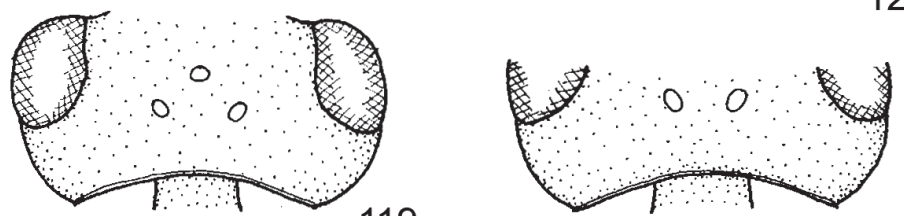

119

125

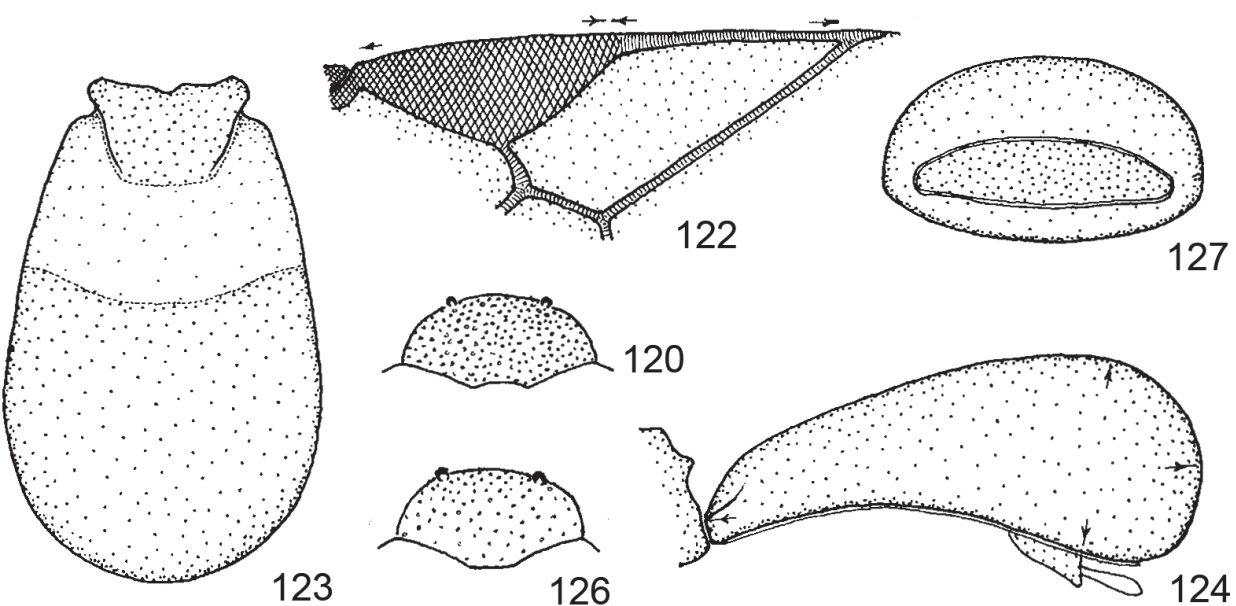

Figs 115-127. 115-117. Microchelonus carinatus (Provancher, 1881) (ふ) $)$ : 115 = ultimate three flagellomeres, $116=$ carapace in dorsal view, 117 = apical foramen of carapace. 118-127. Microchelonus cautus (Cresson, 1872): $118=$ scutellum (우), $119=$ head in dorsal view (), $120=$ clypeus (+), 121 = head in lateral view with indication of its sculpture ( + ), 122 = distal part of right fore wing $\left(+\oint^{\top}\right), 123$ = carapace in dorsal view $\left(+\oint^{\top}\right), 124$ = carapace in lateral view (ㅇ), 125 = temple in dorsal view $\left(\partial^{\Uparrow}\right), 126$ = clypeus $\left(\partial^{\Uparrow}\right), 127$ = apical foramen of carapace $\left(\partial^{\Uparrow}\right)$. 


\section{Microchelonus carinatus (Provancher, 1881) (Figs 110-117)}

Chelonus carinatus Provancher, 1881: 199 +, type locality: "presumed.....eastern Canada" (after МсСомв 1968: 35), "type" in Provincial Museum, Quebec; not examined.

Chelonus (Microchelonus) carinatus (Provancher): МсСомв 1968: 5, 7 (in key) and 34 (redescription, distribution) $\rightarrow$ ${ }^{\Uparrow}$.

Microchelonus carinatus (Provancher): SHEnefelt 1973: 878 (comb. n., literature up to 1968). PAPp 1999: 189, 2010: 175 (in keys).

Material examined $-1 q+1 \widehat{\jmath}$ (in HNHM, det. W. R. M. Mason): USA, New Jersey, Salt Marsh, Oceanville, 1950, leg. P. Springer.

Additional features to the redescription (McComb l.c.) - o . Body 4.5-6 mm long. Head in dorsal view transverse, 1.9 times as broad as long, temple swollen (i.e. head between temples somewhat broader than between eyes, Fig. 111). Scutellum densely rugulose (Fig. 110). Hind femur 3.1 times as long as broad medially (cf. Fig. 165). Fore wing: pterostigma 3.3 times as long as wide and issuing $r$ distally from its middle, 1-R1 0.7 times as long as pterostigma (Fig. 112, see arrows). Carapace in dorsal view elongate, 2.3 times as long as broad posteriorly, evenly broadening posteriorly, longitudinally rugulose (Fig. 113). Carapace in lateral view 4.4 times longer than high posteriorly, apically truncate. Body black, mandible and palpi reddish yellow.

${ }^{7}$. Similar to the female. Penultimate flagellomere twice longer than broad (Fig. 115). Fore wing: pterostigma usually narrow, four times as long as wide and issuing $r$ clearly distally from its middle (Fig. 114). Carapace in dorsal view more elongate, 2.5 times as long as broad and weakly broadening posteriorly (Fig. 116). Apical foramen of carapace three times as wide as high laterally, medially slightly narrowing (Fig. 117).

Distribution - Frequent in Canada and USA (including Florida). Supposedly occurring in Central America.

Taxonomic position - In the key to the female Microchelonus species $M$. carinatus runs to $M$. vissas sp. n., see couplets 50 (51) - 52 (53). In the key to the male Microchelonus species $M$. carinatus runs to $M$. refluus Papp, see couplets 18 (19) -19 (18) as well as to M. bermus sp. n., see couplets 22 (25) -24 (23).

\section{Microchelonus cautus (Cresson, 1872) (Figs 118-127)}

Chelonus cautus Cresson, 1872: 180 ô, type locality: Texas (USA), male lectotype in Academy of Natural Sciences, Philadelphia; not examined.

Chelonus (Microchelonus) cautus Cresson: МсСомв 1968: 10 (in key) and 36 (redescription) Microchelonus cautus (Cresson): SHenefelt 1973: 879 (comb. n., literature up to 1968).

Synonyms: Chelonus albobasilaris Ashmead, 1895; Chelonus nucleolus Viereck, 1905 (further details see in Shenefelt 1.c.).

Material examined $(1 q+2 \delta$ in USNM, det. Muesebeck) $-1 q+1$ : USA, Arizona, Elfrida. $1 \delta$ : USA, Texas, Presidio. 
Additional features to the redescription (McComb 1.c.) - 9 . Body 3.2-4 mm long. Penultimate flagellomere cubic, 1.1 times as long as broad (cf. Fig. 150). Head in dorsal view transverse, twice as broad as long, temple receded. Frons, vertex and occiput denselytransversely substriolate (cf. Fig. 55). Eye in lateral view twice as high as wide, gena evenly wide beyond eye and as wide as eye, finely-densely substriolate (Fig. 121). Clypeus almost twice as wide below as high medially. Lower margin medially concave, finely-densely punctulate (Fig. 120). Scutellum smooth, shiny, hairpunctured (Fig. 118). Fore wing: ptetostigma 2.3 times as long as wide, issuing $\mathrm{r}$ just distally from its middle, $1-\mathrm{R} 10.8-0.9$ times as long as pterostigma (Fig. 122). Carapace in dorsal view belly, 1.7 times longer than broad posteriorly, basally yellow (Fig. 123). Carapace in lateral view 2.4-2.5 times as long as broad posteriorly (Fig. 124 see arrows). Parategula ochre.

J. Similar to the female. Body 3-3.2 mm long. Temple in dorsal view rather rounded (Fig. 125). Penultimate flagellomere 1.2-1.3 times longer than broad. Clypeus less densely punctulate, interspunctures shiny (Fig. 126). Carapace in dorsal view belly, 1.7-1.8 times longer than boad posteriorly (Fig. 123). Apical foramen of carapace slit-like, four times wider than high (Fig. 127).

Distribution - USA (Arizona, Louisiana, Texas), Mexico (Baja California), “Central America".

Taxonomic position - In the key to the female Microchelonus species $M$. cautus runs to $M$. pectiniphorae (Cushman), see couplets 99 (96) - 101 (100). In the key to the male Microchelonus species $M$. cautus runs to M. blackburni (Cameron) and M. pectiniphorae (Cushman), see couplets 40 (45) - 44 (43).

\section{Microchelonus cavei Papp, 2010}

(Figs 128-132)

Microchelonus cavei Papp, 2010: 163 \& , type locality (seven female types): Honduras, Olancho, Caracasmas; (one female type:) Costa Rica, Alajuela, Upala; type depositories: female holotype and four female paratypes in MZLU, three female paratypes in HNHM.

Material examined - Female holotype and seven female paratypes, their two localties see above.

Emendated features to the original description (Papp 1.c.) - 9 . Body (2.2-)2.6-2.8 mm long. Penultimate flagellomere 1.7 times as long as broad (Fig. 128). Head in dorsal view transverse, 2-2.1 times as broad as long, eye 3.1-3.2 times longer than temple, temple receded (Fig. 129). Fore wing: pterostigma wide, 2.1-2 times as long as wide, issuing $r$ from (or just proximally from) its middle, 1-R1 0.7 times as long as pterostigma (Fig. 130). Carapace belly, 1.4-1.6 times as long as broad posteriorly, areolate-rugose (Fig. 131). Carapace in lateral view 3(-2.9) times as long as high posteriorly (Fig. 132, see arrows). Legs yellow, hind tibia distally brownish, trochanters (partly) whitish.

Distribution - Costa Rica, Honduras.

Taxonomic position - In the key to the female Microchelonuis species $M$. cavei runs to M. paululus (McComb), see couplets 127 (126) - 129 (128) (cf. 
Papp 2010: 165-166). In the original description M. cavei is also related to $M$. paululus (Papp 1.c.).
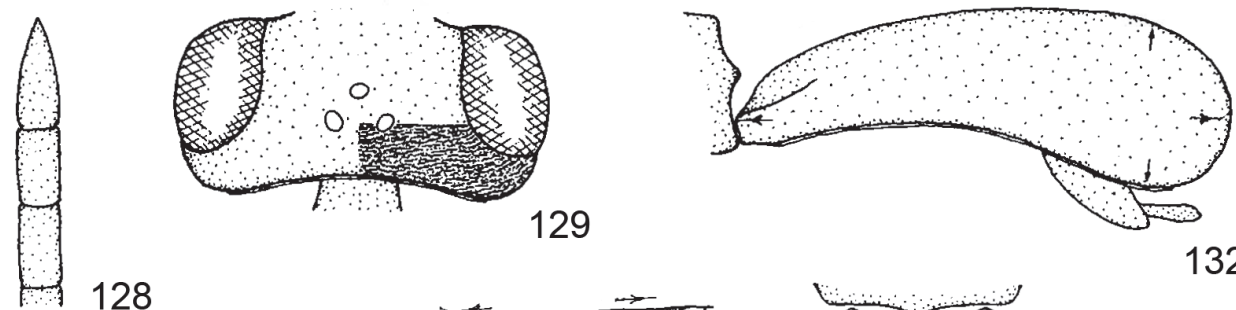

129

132

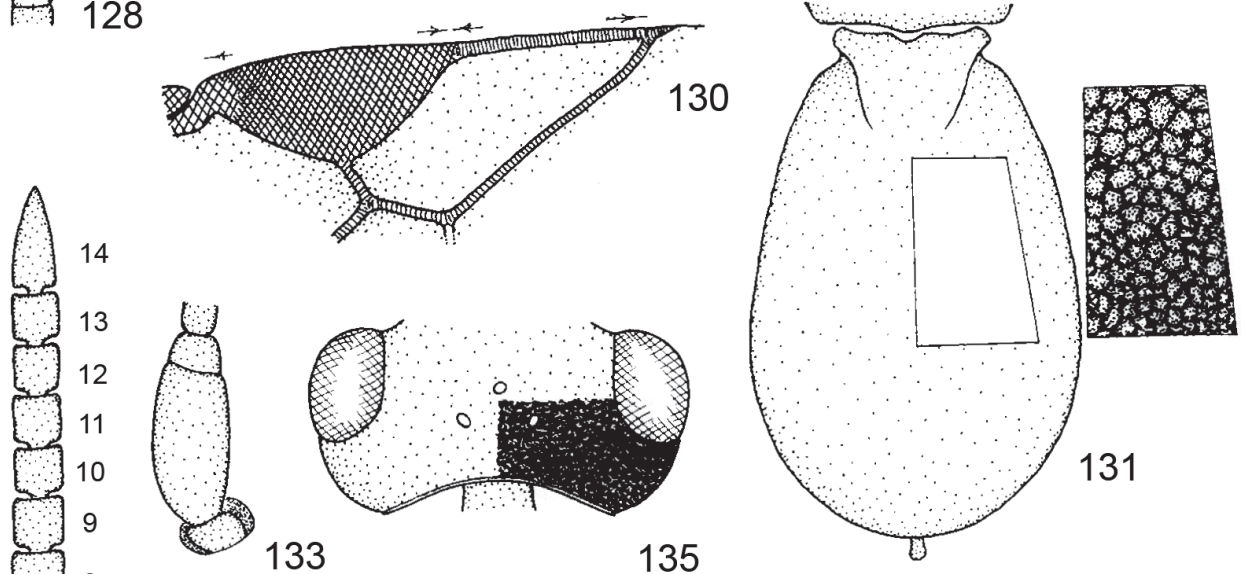

133

135

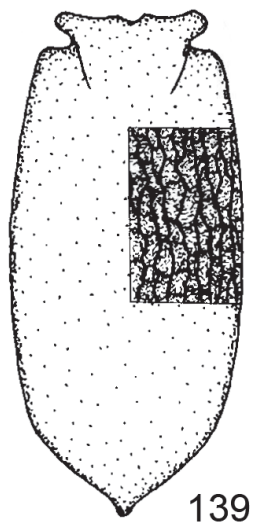

Figs 128-139. 128-132. Microchelonus cavei Papp, 2010 ( + , holotype): $128=$ ultimate three flagellomeres, 129 = head in dorsal view with indication of its sculpture, $130=$ distal part of right fore wing, 131 = carapace in dorsal view with indication of its sculpture, $132=$ carapace in lateral view. 133-138. Microchelonus constrictus Papp, 1999) (ㅇ, holotype): 133 = scape and pedicel, $134=$ flagellomeres $8-14,135=$ head in dorsal view with indication of its sculpture, $136=$ hind femur, $137=$ distal part of right fore wing, $138=$ carapace in dorsal view with indication of its sculpture. 139. Microchelonus curticarinulus sp. n. ( + ,holotype): $139=$ carapace in dorsal view with indication of its sculpture. 


\section{Microchelonus constrictus Papp, 1999 \\ (Figs 133-138)}

Microchelonus constrictus Papp, 1999: 185 ㅇ, type locality: Argentina, Buenos Aires, Ramos Mejia, female holotype and two female paratypes in HNHM; examined.

Emendated features to the original description (Papp l.c.) -o Body 3-3.3 mm long. Scape thick, 2.1 times as long as broad (Fig. 133). Eye in dorsal view one-third longer than temple, temple rounded (Fig. 135). Hind femur thick, 2.5 times as long as broad medially (Fig. 136). Fore wing: pterostigma 2.5 times as long as wide, issuing $r$ from its middle, $1-R 10.7$ times as long as pterostigma (Fig. 137). Carapace in dorsal view 1.9 times as long as broad just posteriorly from its middle, longitudinally strio-rugose, apically rugo-rugulose (Fig. 138).

Distribution - Argentina.

Taxonomic position - In the key to the female Microchelonus species $M$. constrictus runs to M. brasiliensis (Brues), see couplets 92 (95) - 94 (93). In the original description $M$. constrictus is related to $M$. paullus and $M$. townsendi (Viereck) (PApp 1999: 187).

\section{Microchelonus curticarinulus sp. $\mathrm{n}$.}

$$
\text { (Figs 139-153) }
$$

Material examined $(1+9 \hat{\jmath})$ - Female holotype: Costa Rica, Alajuela, $20 \mathrm{~km} S$ from Upala, 20-26 March1991, leg. F. D. Parker. Male paratype: Honduras, Yoro, Palo de Combo, $15^{\circ} 11^{\prime} \mathrm{N} / 87^{\circ} 39^{\prime} \mathrm{W}, 5$ August 1995 , leg. R. Cave. - Holotype is in good condition: (1) glued direct to the pin by the right side of mesosoma, (2) right fore wing missing. Paratype is in fairly good condition: (1) glued on card point by the right side of mesosoma, (2) left flagellum deficient: present flagellomeres 1-7. Holotype is deposited in HNHM, Hym. Typ. No. 12250; paratype in ZMLU.

Etymology - The new species received the name "curticarinulus" refering to the short carinule apico-dorsally on carapace (Fig. 147).

Description of the female holotype - Body $3.5 \mathrm{~mm}$ long. Antenna short, as long as head and mesosoma combined, with 16 antennomeres. Scape somewhat globose, 2.3 times as long as broad (Fig. 140). First flagellomere 3.6 times as long as broad, penultimate flagellomere almost 1.5 times longer than broad. - Head in dorsal view transverse, twice as broad as long, eye 1.9-2 longer than temple, temple receded (Fig. 141). OOL somewhat longer than POL (10:8). Eye in lateral view 1.8 times as high as wide, gena beyond eye broadening ventrally and just broader ventrally than eye, fairly dispersely to densely punctate, interpunctures longer to shorter than punctures (Fig. 142). Clypeus 1.8 times as wide below as high medially, its lower margin medially truncate, punctate: interpunctures shorter than punctures, subshiny (cf. Fig. 434). Face, frons, vertex and occiput transversely substriolate (Fig. 141).

Mesosoma in lateral view 1.4 times as long as high, scabrous. Mesoscutum with notaulix. Scutellum uneven-subrugulose (Fig. 143). Lateral pair of denticules of propodeal carina stronger than median pair (Fig. 144). Hind femur thick, 2.4 times as long as broad medially, hind tibia also thick: distally as broad as femur (Fig. 145 see arrows). Hind basitarsus as long as tarsomeres $2-4$ combined. 
Fore wing one-fourth shorter than body ( $2.6 \mathrm{~mm}$ long). Pterostigma wide, twice as long as wide, issuing $r$ from its middle, 3-SR 1.8 times as long as $r$ (11:6), SR1 straight, 1-R1 0.6 times as long as pterostigma (Fig. 146 see arrows).

Carapace in dorsal view 2.1 times as long as broad medially, posteriorly coniculeshape, fairly strongly striated with anastomoses, interstriations rugulose (Fig. 139); apico-
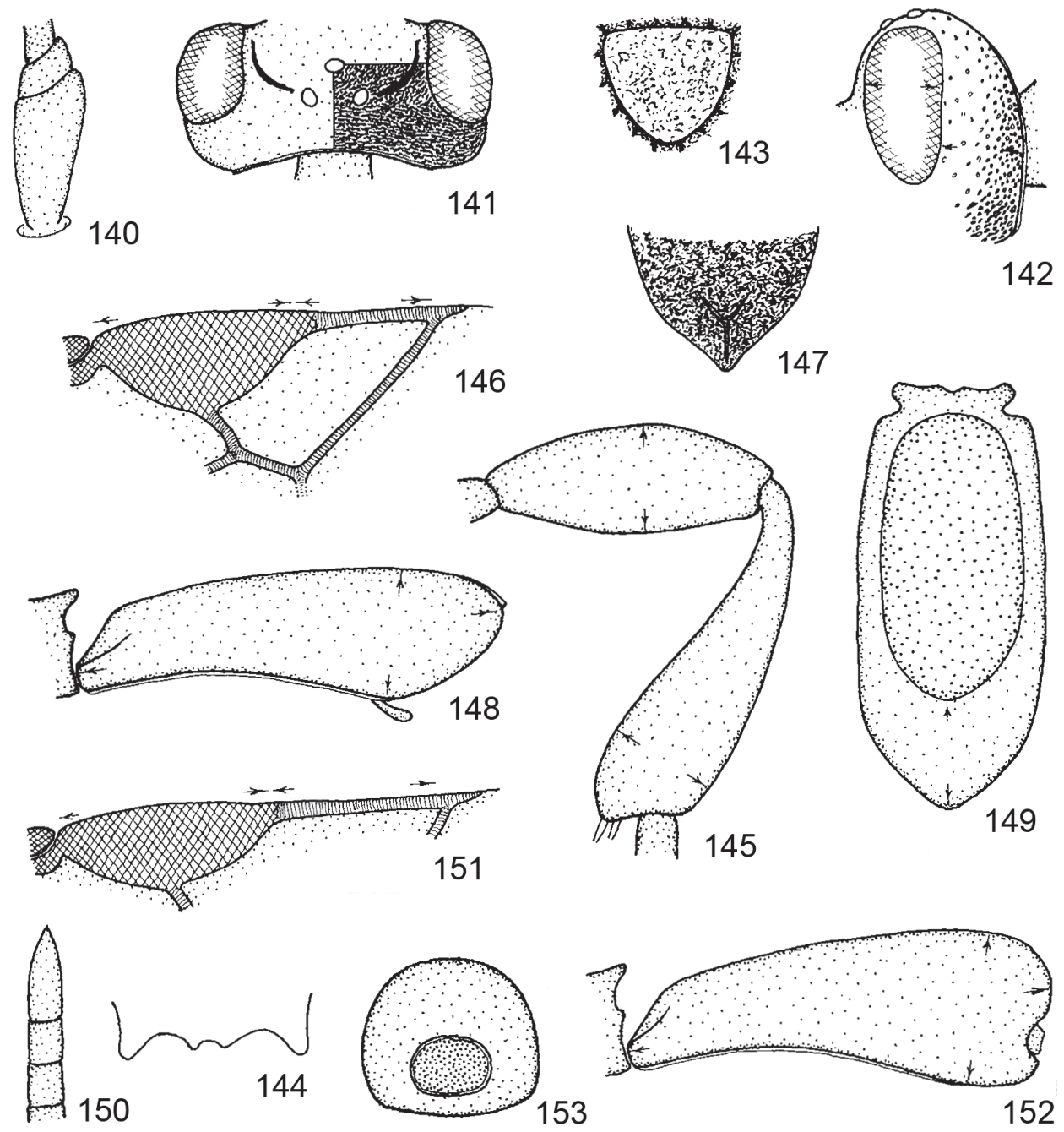

Figs 140-153. Microchelonus curticarinulus sp. n. (female holotype: 140-149, male paratype: 150-153): 140 = scape and pedicel, 141 = head in dorsal view with indication of its sculpture, $142=$ head in lateral view with indication of its sculpture, $143=$ scutellum, 144 = propodeal carina in dorsal view, 145 = hind femur + tibia, 146 = distal part of right fore wing, $147=$ posterior third of carapace in dorsal view, $148=$ carapace in lateral view, $149=$ carapace in ventral view, $150=$ ultimate three flagellomeres, $151=$ pterostigma $+1-R 1$ of right fore wing, 152 = carapace in lateral view, 153 = apical foramen of carapace. 
dorsally with a short and weak carinulus (Fig. 147). Carapace in lateral view 2.8 times as long as high posteriorly, its apical end incurved (Fig. 148 see arrows). Apico-ventral incurved part of carapace deep and about as long as hind first two tarsomeres (Fig. 149 see arrows). Carapace apically without foramen. Ovipositor sheath short, concealed.

Ground colour of body black. Scape and pedicel testaceous, flagellum brownish black. Palpi and tegula pale yellow. Legs yellow, coxae 1-2 brownish, coxa 3 black, hind fe-

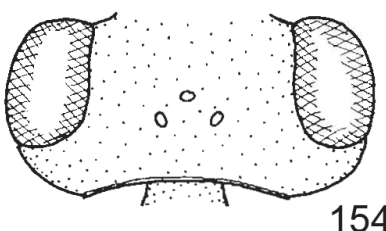

154

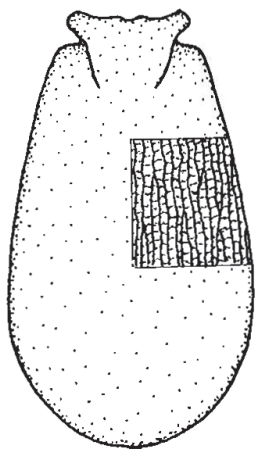

158

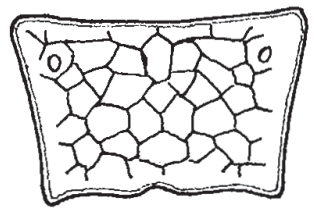

156

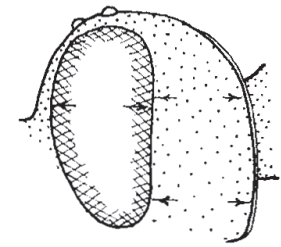

155
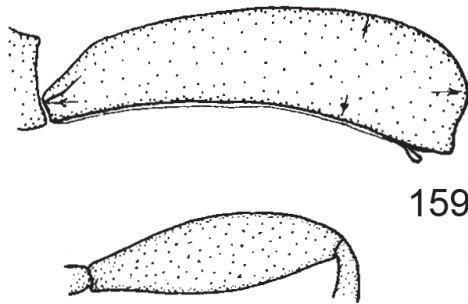

159

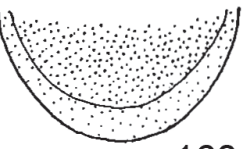

160
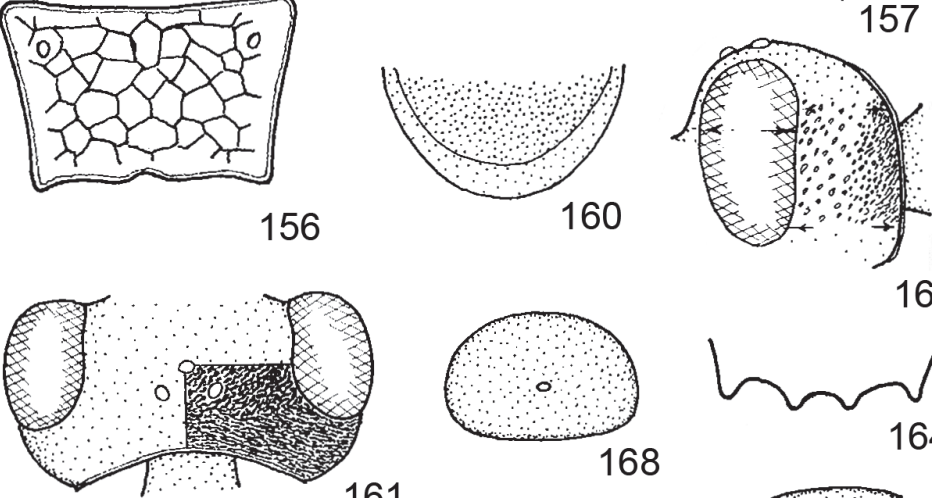

168

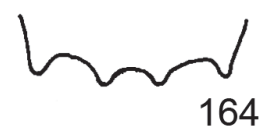

161
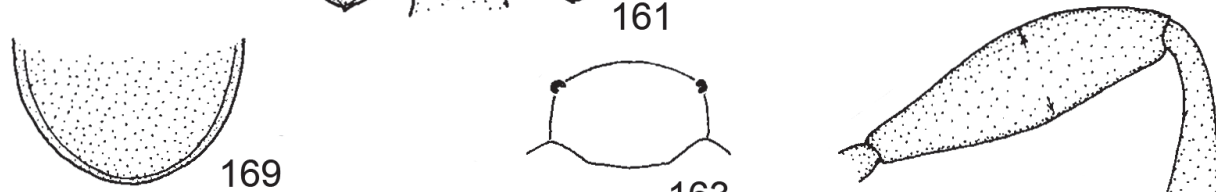

163
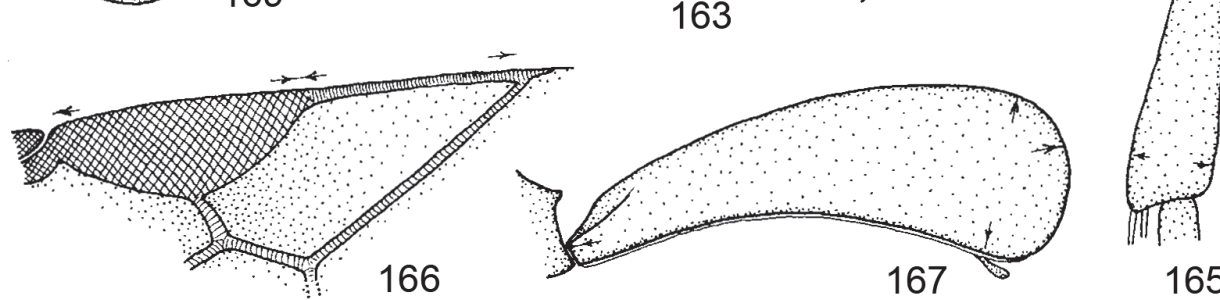

165

Figs 154-169. 154-160. Microchelonus curtulus sp. n. ( 9 , holotype): 154 = head in dorsal view, 155 = head in lateral view, $156=$ propodeum, $157=$ hind femur, $158=$ carapace in dorsal view with indication of its sculpture, $159=$ carapace in lateral view, $160=$ posterior fourth of carapace in ventral view. 161-169. Microchelonus danzas sp. n. (ㅇ, holotype): 161 $=$ head in dorsal view with indication of its sculpture, $162=$ head in lateral view with indication of its sculpture, 163 = clypeus, $164=$ propodeal carina in dorsal view, $165=$ hind femur + tibia, 166 = distal part of right fore wing, $167=$ carapace in lateral view, $168=$ apical foramen of carapace, $169=$ posterior fourth of carapace in ventral view. 
mur black, hind tibia apically dark brownish to blackish, tarsi straw yellow. Wings hyaline, pterostigma dark brown, veins yellow to ligh brownish.

Description of the male paratype - Similar to the female holotype. Body $3 \mathrm{~mm}$ long. Antenna as long as head, mesosoma and anterior fourth of carapace combined, with 20 antennomeres, penultimate flagellomere just cubic (11:10). Scutellum rugose. Hind femur thick, 2.5 times as long as broad medially, hind tibia as broad distally as femur (Fig. 145). Fore wing: pterostigma 2.5 times as long as wide, 1-R1 long: 0.8 times as long pterostigma (Fig. 151). Carapace apico-dorsally without carinulus. Apical foramen of carapace less elliptic, 1.6 times as wide as high (Fig. 153). Carapace in lateral view 2.6 times as long as high posteriorly (Fig. 152 see arrows). Ventral cavitiy of carapace as in Fig. 149.

Distribution - Costa Rica, Honduras.

Taxonomic position - The new species, M. curticarinulus, is closest to $M$. refluus Papp viewing their less strong sculpture of carapace (Figs 139, 390), apico-ventrally distinctly incurved carapace (Fig. 149) and hind leg dark coloured; distinction of their females is as follows:

1 (2) Carapace apico-dorsally with a short and less distinct carinulus (Fig. 147). Fore wing: pterostigma wide, twice as long as wide, 1-R1 0.6 times as long as pterostigma (Fig. 146). Scutellum uneven-subrugulose (Fig. 143). Temple in dorsal view strongly rounded, eye 2.5 times longer than temple, frons without bent carinulus (Fig. 141). Carapace without pair of maculae. + : 3.5 mm. - Costa Rica, Honduras M. curticarinulus sp. n.

2 (1) Carapace apico-dorsally without carinulus (Fig. 390). Fore wing: pterostigma less wide, 2.8(-3.3) times as long as wide, 1-R1 0.75 times as long as pterostigma (Fig. 389). Scutellum scabrous (Fig. 387). Temple in dorsal view rounded, eye 1.6 times longer than temple, frons with a bent carinulus between hind ocellus and eye (Fig. 384). Carapace with a pair of straw yellow maculae. + : 4.8-4.9 mm. - Honduras

M. refluus Papp, 2010

In the key to the female Microchelonus species M. curticarinulus runs to $M$. refluus Papp, M. sulcifera sp. n. and $M$. fodicus sp. n., see couplets 23 (32) - 31 (28). - In the key to male Microchelonus species it runs to M. avron sp. n. and M. topali Papp, see couplets 4 (9) - 8 (7).

\section{Microchelonus curtulus sp. $\mathrm{n}$.}

(Figs 154-160)

Material examined - Female holotype: Costa Rica, Cartago, near Tuis, 3000 feet, 16-22 July 1993, leg. W. J. Hanson. - Holotype is in good condition: (1) glued direct to the pin by the side side of head and mesosoma, (2) right gena (of head) and right side of mesosoma invisible owing to the mounting. Holotype is deposited in HNHM, Hym. Typ. No. 12233.

Etymology - The new species received the Latin name "curtulus" (=short) refering to the short alar vein 1-R1 (cf. Fig. 146). 
Description of the female holotype - Body $2.3 \mathrm{~mm}$ long. Antenna short, as long as head, mesosoma and half carapace combined, with 16 antennomeres. Scape 2.7 times as long as broad apically, first flagellomere 3.2 times as long as broad, penultimate 8-13 flagellomeres cubic (cf. Fig. 134). - Head in dorsal view transverse, twice as boad as long, eye 2.3 times longer than temple, temple receded (Fig. 154). OOL 1.5 times as long as POL. Eye in lateral view twice as high as wide, gena beyond eye faintly broadening ventrally, as wide as eye, polished (Fig. 155). Clypeus 1.6 times as wide below as high medially, its lower margin truncate, polished, laterally uneven (cf. Fig. 434). Face finely substriolate, shiny. Head above polished.

Mesosoma in lateral view 1.4 times as long as high. Mesoscutum, scutellum and mesopleuron rugose. Propodeum areolate-rugose, without transverse carina (Fig. 156). Hind femur 3.5 times as long as broad medially. Hind tibia thickening, distally as broad as femur (cf. Fig. 165). Hind basitarsus as long as tarsomeres $2-3$ combined.

Fore wing almost as long as body. Pterostigma 2.5 times as long as wide, issuing $r$ from its middle, 1-R1 short, half (0.5 times) as long as pterostigma, 3-SR just longer than $r$ (9:8), SR1 bent (cf Fig. 146).

Carapace in dorsal view 1.75 times as long as broad posteriorly, basally somewhat narrowing, longitudinally striated, its downcurved hind fourth polished (Fig. 158). Carapace in lateral view weakly curved, 3.8 times as long as high posteriorly, apico-ventrally with a very small tubercule (Fig. 159 see arrow). Carapace apico-ventrally somewhat incurved (Fig. 160). Ovipositor sheath short, concealed.

Body dark coloured. Scape and pedicel ochre, flagellum dark brown. Head dark brown, palpi brown. Mesosoma blackish brown, pronotum dark rusty. Carapace dark brown. Legs brown, hind coxa dark brown, fore leg ochre. Wings hyaline, pterostigma brown, veins light brown.

Male and host unknown.

Distribution - Costa Rica.

Taxonomic position - The new species, Microchelonus curtulus, is closest to M. fulgens sp. n., the distinction between the two species is presented in the key to the female Microchelonus species, see couplets 13 (10) - 15 (14). - Also near to M. politus sp. n., their separation see at M. politus.

\section{Microchelonus danzas sp. $n$. \\ (Figs 161-170)}

Material examined (2 우 $)$ - Female holotype and one female paratype: Costa Rica, Heredia, Chilamate, 18-23 August 1988, leg. W. J. Hanson. - Holotype is in good condition: (1) glued direct to the pin by its right meso- and metapleuron, (2) tarsi 1-2 somewhat less visible owing to the mounting. Paratype is in somewhat less good condition: (1) glued like holotype, (2) left antenna deficient: present first two flagellomeres, (3) alar venation somewhat less visible owing to the mounting. Holotype and paratype are deposited in HNHM, Hym. Typ. Nos 12251 (holotype) and 12252 (paratype).

Etymology - The new species received the latinized phantasy name "danzas".

Description of the female holotype - Body $4.2 \mathrm{~mm}$ long. Antenna nearly as long as body and with 18 antennomeres. Scape in lateral view three times as long as broad. Flagellomeres long, first flagellomere five times and penultimate flagellomere 2.3 times as long as 
broad (cf. Fig. 171), distal half of flagellum attenuating. - Head in dorsal view transverse, twice as broad as long, eye twice longer than temple, temple rounded (Fig. 161). OOL one-third longer than POL. Eye in lateral view almost 1.8 times as high as wide, gena beyond eye weakly broadening and somewhat wider than eye (Fig. 162 see arrows). Gena anteriorly finely punctate, interspaces greater than punctures and shiny, posteriorly finely substriated (Fig. 162). Clypeus almost 1.5 times as wide below as high medially, its lower margin just convex (Fig. 163). Face 1.6 times as wide as high, rugose; clypeus finely punctate, interspaces subshiny to dull. Malar space somewhat longer than basal width of mandible. Frons rugulose, vertex and occiput substriolate.

Mesosoma 1.25 times as long as high, scabrous. Notaulix distinct. Scutellum scabrous (cf. Fig. 387). Four denticules of transverse propoeal carina equal in size (Fig. 164). Hind femur 3.1 times as long as broad medially, hind tibia thickening distally and as broad as femur (Fig. 165 see arrows). Hind basitarsus as long as tarsomeres $2-4$ combined.

Fore wing about one-third shorter than body ( $3 \mathrm{~mm}$ long). Pterostigma 2.5 times as long as wide and issuing $r$ just distally from its middle, 3-SR twice longer than $r, S R 1$ straight, 1-R1 almost as long as pterostigma (35:40, Fig. 166).

Carapace in dorsal view twice longer than broad and weakly broadening posteriorly (i.e. nearly parallel-sided, longitudinally striated, interstriations crenulate-subcrenulate, its hind end (striolate-)rugose (Fig. 170), apically with a very small foramen (Fig. 168). Carapace in lateral view curved, 2.9 times as long as high posteriorly, its hind end rather rounded (Fig. 167 see arrows). Carapace apico-ventrally not incurved (Fig. 169). Ovipositor sheath about as long as hind tarsomeres 1-2 combined.

Body black. Scape, pedicel and flagellomeres 3-5 ochre yellow, rest of flagellum blackish to black. Palpi brown to light brown. Tegula blackish, parategula dark brown. Legs 1-2 light brown to brown, trochanters and tarsi yellow. Leg 3 blackish to black, trochanters and tarsus yellow. Wings subhyaline, around pterostigma brownish fumous. Pterostigma brown, veins rather light brown.

Description of the female paratype - Similar to the female holotype. Body $4.2 \mathrm{~mm}$ long. Vertex rather striated. Carapace 2.2 times as long as broad posteriorly. Carapace in lateral view 3.2 times as long as high posteriorly. Carapace apically without foramen.

Male ad host unknown.

Distribution - Costa Rica.

Taxonomic position - The new species, Microchelonus danzas, is closest to M. subplanus Papp as well as to M. buscki (Viereck and M. pyriformis Papp, their distinction see in the key-couplets $46(45)-48$ (47) as well as in the key couplets $113(112)-115$ (114) to the female Microchelonus species.

\section{Microchelonus effusus Papp, 2010 (Figs 171-178)}

Microchelonus effusus Papp, 2010: 166 우, type locality: Costa Rica, Alajuela, 20 km $S$ of Upala $(3 q+2 \delta$ paratypes from four other localities in Costa Rica, see Papp 1.c.), female holotype and one female paratype in USNM, two female and two male paratypes in HNHM; examined.

Additional features to the original description (Papp l.c.) - +. Body 3.5-4 mm long. Penultimate flagellomere 2.3-2.5 times as long as broad (Fig. 171). Head in dorsal view 1.9-2 
times as broad as long, eye twice longer than temple, latter rounded, vertex and occiput transversely substriolated (Fig. 172). Eye in lateral view somewhat wider than gena (18:16), gena finely substriolated (Fig. 173). Fore wing: pterostigma 2.2-2.3 times as long as wide and issuing $r$ either from its middle (cf. Fig. 151) or distally from its middle, 1-R1 almost as long as pterostigma (Fig. 174 see arrows). Carapace distinctly broadening posteriorly, 1.8 times as long as broad, areolate-rugose, apically rather transversely rugose (Fig. 175).

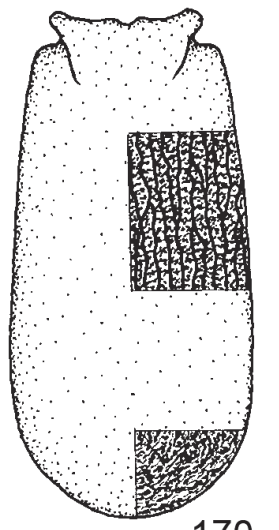

170

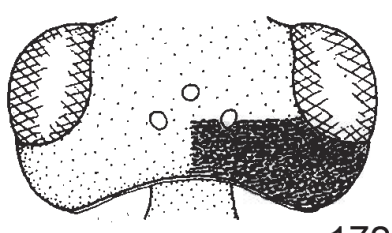

172

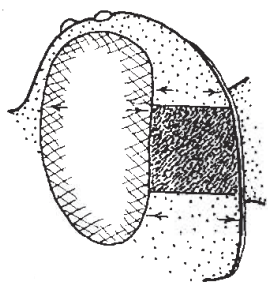

173
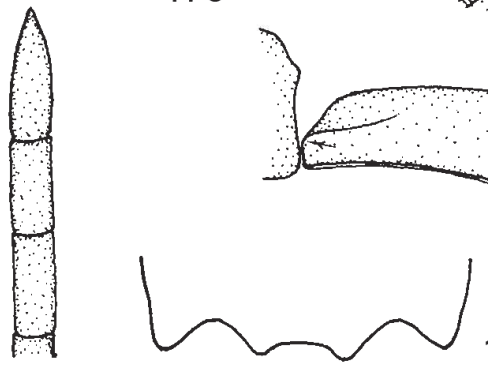

\section{0}

171
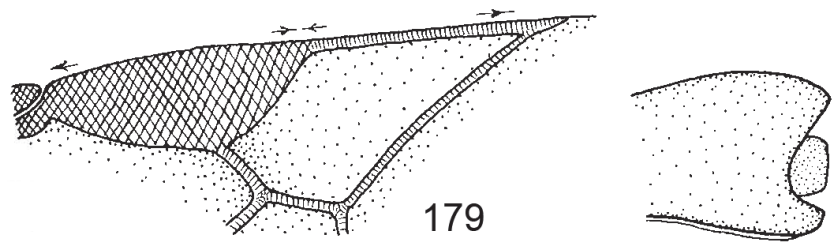

178

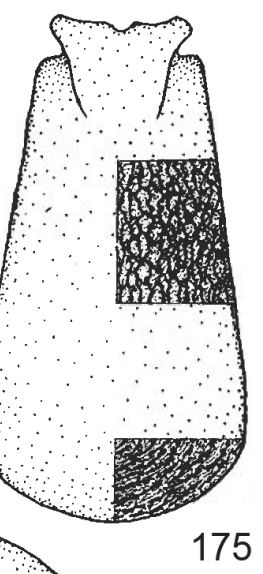

175

Fig. 170-181. 170. Microchelonus danzas sp. n. ( $($, holotype): 170 = carapace in dorsal view 171-178. Microchelonus effusus Papp, 2010 (female holotype: 172-174, 176; male paratype: 171, 175, 177-178): 171 = penultimate three flagellomeres, 172 = head in dorsal view with indication of its sculpture, $173=$ head in lateral view with indication of its sculpture, $174=$ distal part of right fore wing, $175=$ carapace in dorsal view with indication of its sculpture, $176=$ carapace in lateral view, $177=$ apical foramen of carapace, $178=$ posterior third of carapace in lateral view. 179-181. Microchelonus egregicolor (Viereck, 1905) (female): $179=$ distal part of right fore wing, 180 = propodeal carina in dorsal view, 181 = carapace in dorsal view with indication of its sculpture. 
Carapace in lateral view 2.6-2.7 times as long as high posteriorly, apically truncate (Fig. 176 see arrows).

7. Similar to the female. Apical foramen of carapace elliptic, 1.8 times as wide as high (Fig. 177). Apical end of carapace in lateral view as in Fig. 178.

Distribution - Costa Rica.

Taxonomic position - In the key to the female Microchelonus species M. effusus runs to M. buscki (Viereck) and M. pyriformis Papp, see couplets 38 (43) - 42 (41). In the key to the male Microchelonus species M. effusus runs to $M$. jamaicus sp. n., see couplets 29 (28) -31 (30). In the original description M. effusus is related to M. cephalanthi (McComb) and M. lavernae (Ashmead) (PAPP 2010: 168-169).

\section{Microchelonus egregicolor (Viereck, 1905)}

(Figs 179-181)

Chelonus egregicolor Viereck, 1905: 278 ๙े, type locality: USA, Kansas, Douglas county, 900 feet, "Type" (= holotype: “one specimen"), type in Snow Museum, University of Kansas, Lawrence; not examined.

Chelonus (Microchelonus) egregicolor Viereck: МсСомв 1968: 7 (in key) and 55 (redescription, distribution), 우 $\hat{0}$.

Microchelonus egregicolor (Viereck): SHENEFELt 1973: 883 (comb. n., literature up to 1968).

Material examined -1 (det. McComb, in HNHM): USA, North Caroline, Highlands, 21 August 1957, leg. L. A. Kelton.

Additional features to the redescription (McComb 1.c.) - 9 . Body 4.7-5.2 mm long. Penultimate flagellomere 1.8 times as long as broad (cf. Fig. 101b). Head in dorsal view 1.8 times as broad as long, temple somewhat swollen (cf. Fig. 47). Scutellum rugose (cf. Fig. 372). Propodeum: lateral pair of denticules more and middle pair of denticules less prominent (Fig. 180). Fore wing: pterostigma 2.5 times as long as wide, issuing $r$ distally from its middle, $1-R 1$ almost as long as pterostigma, SR1 bent inwards (Fig. 179). Carapace in dorsal view twice as long as broad and faintly broadening posteriorly, striated without anastomoses (Fig. 181).

Distribution - USA: widely distributed in many states.

Taxonomic position - Microchelonus egregicolor is closest to M. bermus, their distinction see at this species.

\section{Microchelonus exceptus sp. n.}

(Figs 182-191)

Material examined - Female holotype: Costa Rica, San José, Escazu, 28-31 May 1988, leg. F. D. Parker. - Holotype is in good condition: (1) glued direct to the pin by right gena and right propleuron; (2) right fore coxa + femur less visible owing to the mounting. Holotype is deposited in HNHM, Hym. Typ. No. 12234. 
Etymology - The new species received the name "exceptus" indicating its exceptional similarity to M. candidus sp. n.
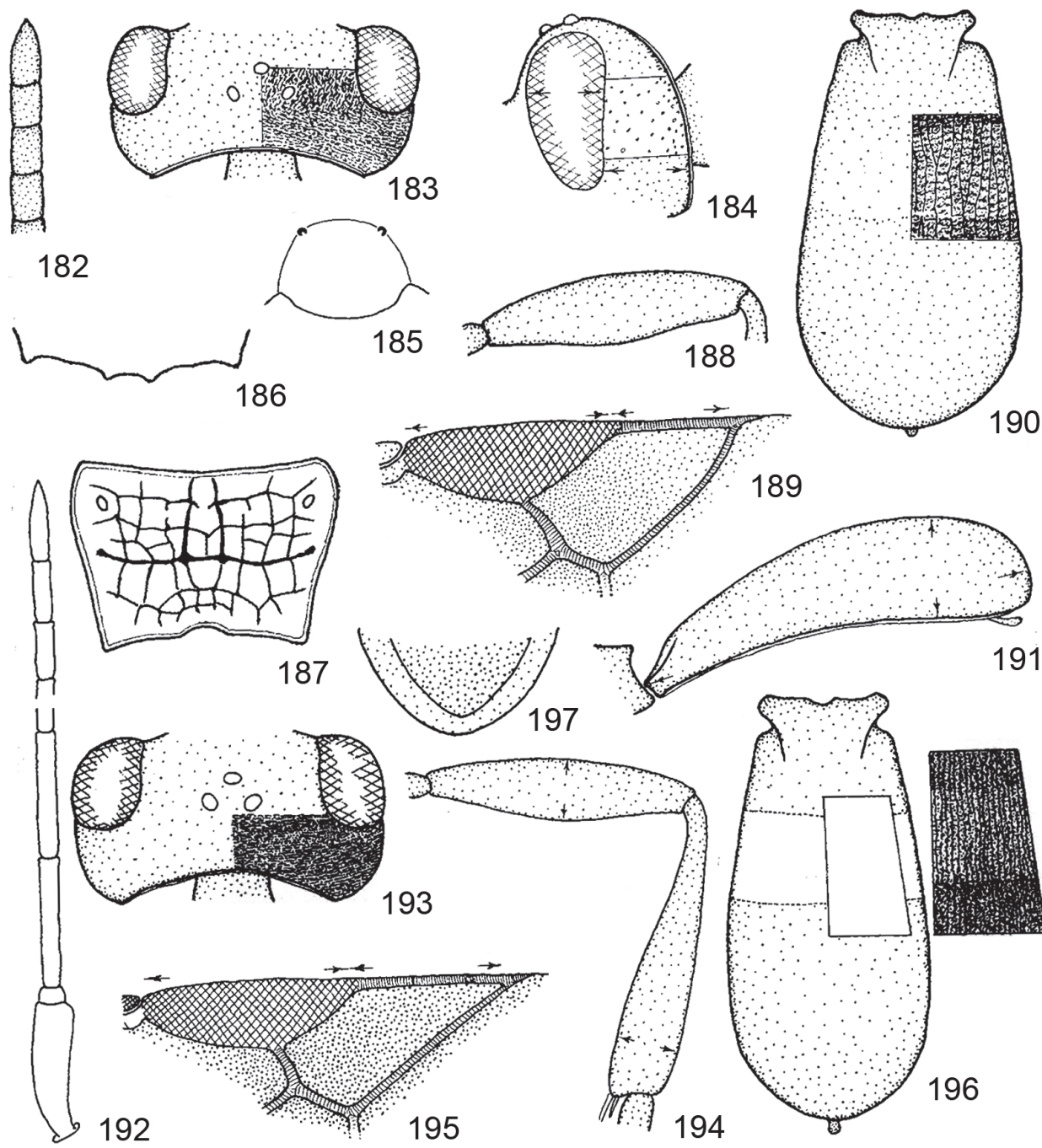

189
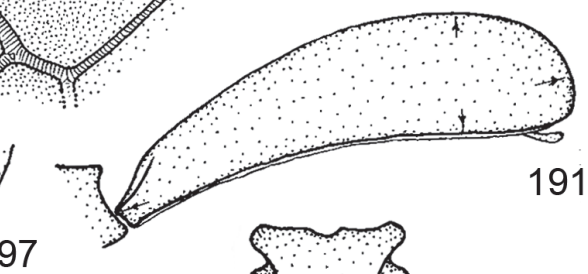

Figs 182-197. 182-191. Microchelonus exceptus sp. n. ( 9 , holotype): 182 = ultimate four flagellomeres, 183 = head in dorsal view with indication of its sculpture, $184=$ head in lateral view with indication of its sculpture, 185 = clypeus, 186 = propodeal carina in dorsal view, 187 = propodeum, 188 = hind femur, 189 = distal part of right fore wing, 190 = carapace in dorsal view with indication of its sculpture, 191 = carapace in lateral view. 192-197. Microchelonus fascis Papp, 2010 ( + , holotype): 192 = scape, pedicel and proximal / distal part of flagellomeres, $193=$ head in dorsal view with indication of its sculpture, $194=$ hind femur + tibia, 195 = distal part of right fore wing, 196 = carapace in dorsal view with indication of its sculpture, $197=$ posterior third of carapace in ventral view. 
Description of the female holotype - Body $3.6 \mathrm{~mm}$ long. Antenna shorter than body $(2.8$ $\mathrm{mm}$ long), and with 16 antennomeres. Scape globose, 2.3 times as long as broad (cf. Fig. 453). First flagellomere five times as long as broad apically, further flagellomeres shortening so that penultimate flagellomere subcubic, 1.3 times longer than broad (Fig. 182). - Head in dorsal view transverse, twice as broad as long, eye 1.3 times as long as temple, temple rounded (Fig. 183). OOL one-third longer than POL. Eye in lateral view twice as high as wide, gena beyond eye clearly broadening ventrally and just wider than eye, gena polished with hairpunctures (Fig. 184 see arrows). Clypeus 1.25 times as wide below as high medially, its lower margin convex (Fig. 185). Clypeus punctate, interpunctures shiny. Face densely rugulose, head above transverso-densely substriolate, dull.

Mesosoma in lateral view 1.4 times as long as high. Mesoscutum scabrous, scutellum roughly rugose (cf. Fig. 49). Propodeal carina with four small denticules (Fig. 186), propodeum on its horizontal surface with a median parallel-shaped areola basalis, otherwise areolated (Fig. 187). Hind femur 3.8 times as long as broad medially (Fig 188). Hind basitarsus as long as tarsomeres $2-4$ combined.

Fore wing shorter than body ( $2.9 \mathrm{~mm}$ long). Pterostigma 2.6 times as long as wide and isuing $r$ just distally from its middle, $r 1.4$ times longer than 3-SR, 1-R1 0.6 times as long as pterostigma (Fig. 189 see arrows).

Carapace in dorsal view 1.8 times as long as broad posteriorly, hind third of carapace polished (Fig. 190). Carapace in lateral view 3.8 times as long as high posteriorly, declivous behind (Fig. 191). Carapace apico-ventrally not incurved (cf. Fig. 108). Ovipositor sheath short, concealed.

Ground colour of body black. Scape and pedicel brownish. Flagellum black, third flagellomere apically and fourth flagellomere entirely straw yellow. Palpi light brownish. Tegula blackish. Carapace anteriorly and before its middle with a transverse lemon yellow band. Fore leg yellow, femur brown. Middle and hind legs black, trochanters, femora and tibiae basally straw yellow, tarsi dark with little yellowish pattern. Wings brownish fumous, pterostigma dark brown, parastigma lemon yellow. Veins yellow to brownish, brown.

Male and host unknown.

Distribution - Costa Rica.

Taxonomic position - The new species, Microchelonus exceptus, is closest to $M$. candidus considering their common features: long temple in dorsal view, short 1-R1 of fore wing and yellow ring of flagellum; the two species differ from each other by the following traits keyed:

1 (2) Penultimate flagellomere subcubic, 1.3 times longer than broad (Fig. 182). Propodeal carina with four small denticules (Fig. 186), horizontal part of propodeum with a subparallel-sided areola basalis (Fig. 187). Hind femur somewhat less thin, 3.8 times as long as broad (Fig. 188). Fourth flagellomere straw yellow. $+: 3.6 \mathrm{~mm}$. - Costa Rica

M. exceptus sp. n.

2 (1) Penultimate flagellomere long, 1.6 times longer than broad (Fig. 101b). Propodeal carina missing, propodeum itself areolated and with an elongated areola basalis (Fig. 103). Hind femur thin, 4.1-4.5 times as long as broad (Fig. 104). Flagellum basally brownish to yellow. $ๆ: 3.2-3.5 \mathrm{~mm}$. - Costa Rica

M. candidus sp. $\mathrm{n}$. 
In the key to the female Microchelonus species M. exceptus runs to M. politus sp. n. and M. tuberulus sp. n., see couplets 7 (2) -12 (11).

\section{Microchelonus fascis Papp, 2010 \\ (Figs 192-197)}

Microchelonus fascis Papp, 2010: 169 ㅇ, type locality: Honduras, Corbes, Parque Nacional Casuco, $5 \mathrm{~km} \mathrm{~N}$ from Buenos Aires, $15^{\circ} 29^{\prime} \mathrm{N} / 88^{\circ} 13^{\prime} \mathrm{W}$ (female holotype and 4 ㅇ paratypes; two further female paratypes from two localities in Honduras, see Papp l.c.); holotype and four female paratypes in ZMLU, two female paratypes in HNHM; examined.

Emendated features to the original description (Papp 1.c.) - + . Body 3.2-3.5 mm long. Flagellum long, first flagellomere six times and penultimate flagellomere 2.7-3.5 times as long as broad (Fig. 192). Head in dorsal view 1.9 times as broad as long, eye somewhat longer than temple (18:15), temple rounded, vertex and occiput substriolated (Fig. 193). Hind femur + tibia thin: femur 4.1 times as long as broad, tibia as broad as femur (Fig. 194 see arrows). Fore wing: pterostigma 2.8 times as long as wide, issuing $r$ distally from its middle, 1-R1 0.7-0.75 times as long as pterostigma, SR1 straight (Fig. 195). Carapace in dorsal view twice as long as broad posteriorly, apically rounded with fine and dense striolation (Fig. 196).

Distribution - Honduras.

Taxonomic position - In the key to the female Microchelonus species $M$. fascis runs to $M$. projectus sp. n., see couplets 53 (52) -55 (54). In the original description M. fascis is related to M. buscki (Viereck) (Papp 1.c).

\section{Microchelonus flavicoxa sp. $\mathrm{n}$.}

(Figs 198-209)

Material examined $(3$ 우) - Female holotype + one female paratype: Costa Rica, Cartago, near Tuis, 3000 m, 16-22 July 1993, leg. S. Keller (holotype) and W.J. Hanson (paratype). One female paratype: Costa Rica, Limon, 7 miles from North Guacimo, taken with Malaise trap, 22 February - 3 March 1988, leg. F. D. Parker. - Holotype is in good condition: (1) glued direct to the pin by its right mesopleuron, (2) ultimate right four (11-14) flagellomeres missing. Two paratypes are also in good condition: (1) glued like holotype, (2) one paratype: ultimate right and left two (13-14) flagellomeres missing. Holotype and two paratypes are deposited in the HNHM, Hym. Typ. No. 12235 (holotype) and 12236-12237. (paratypes).

Etymology - The species name flavicoxa refers to the yellow (middle) coxa.

Description of the female holotype - Body $3.5 \mathrm{~mm}$ long. Left antenna one-fourth shorter than body ( $3 \mathrm{~mm}$ long), with 16 antennomeres. First flagellomere four times and penultimate flagellomere 1.5 times as long as broad, flagellomeres 11-12 subcubic (14:11, Fig. 198). - Head in dorsal view transverse, twice as broad as long, eye almost twice (19:11) longer than temple, temple rounded (Fig. 199). OOL one-third longer than POL. Eye in lateral view 1.9 times as high as wide, gena beyond eye broadening ventrally and as wide as eye, fairly strongly substriated with anastomoses, subshiny (Fig. 200 see arrows). Clypeus 1.35 times as wide below as high medially, densely and distinctly punctate, its ventral margin 
just convex (Fig. 201). Face roughly rugose, vertex and occiput transverse, frons rather longitudinally and somewhat roughly substriated (Fig. 199).

Mesosoma in lateral view 1.35 times as long as high, scabrous. Notaulix indistinct. Scutellum with strong striae (Fig. 202). Hind femur thick, 2.9 times as long as broad medially, hind tibia also thick and distally as broad as femur (cf. Fig. 39 see arrows). Hind basitarsus as long as tarsomeres $2-4$ and one-third of 5 th tarsomere combined.

Fore wing clearly one-third shorter than body ( $2.7 \mathrm{~mm}$ long). Pterostigma 2.3 times as long as wide, isuing $r$ from its middle and just shorter than 3-SR (9:10), SR1 straight, 1-R1 long, 0.85 times as long as pterostigma (Fig. 204 see arrows).

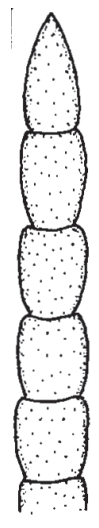

198
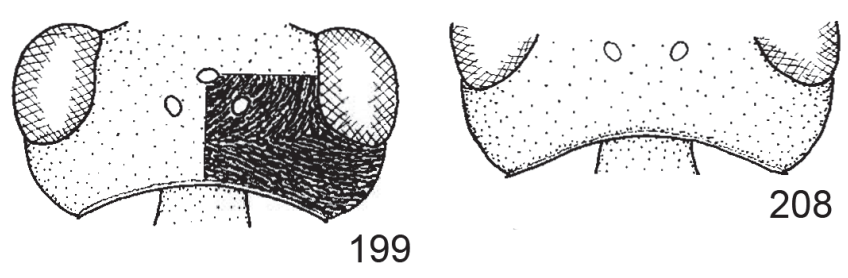

199
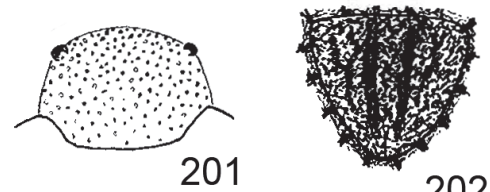

202
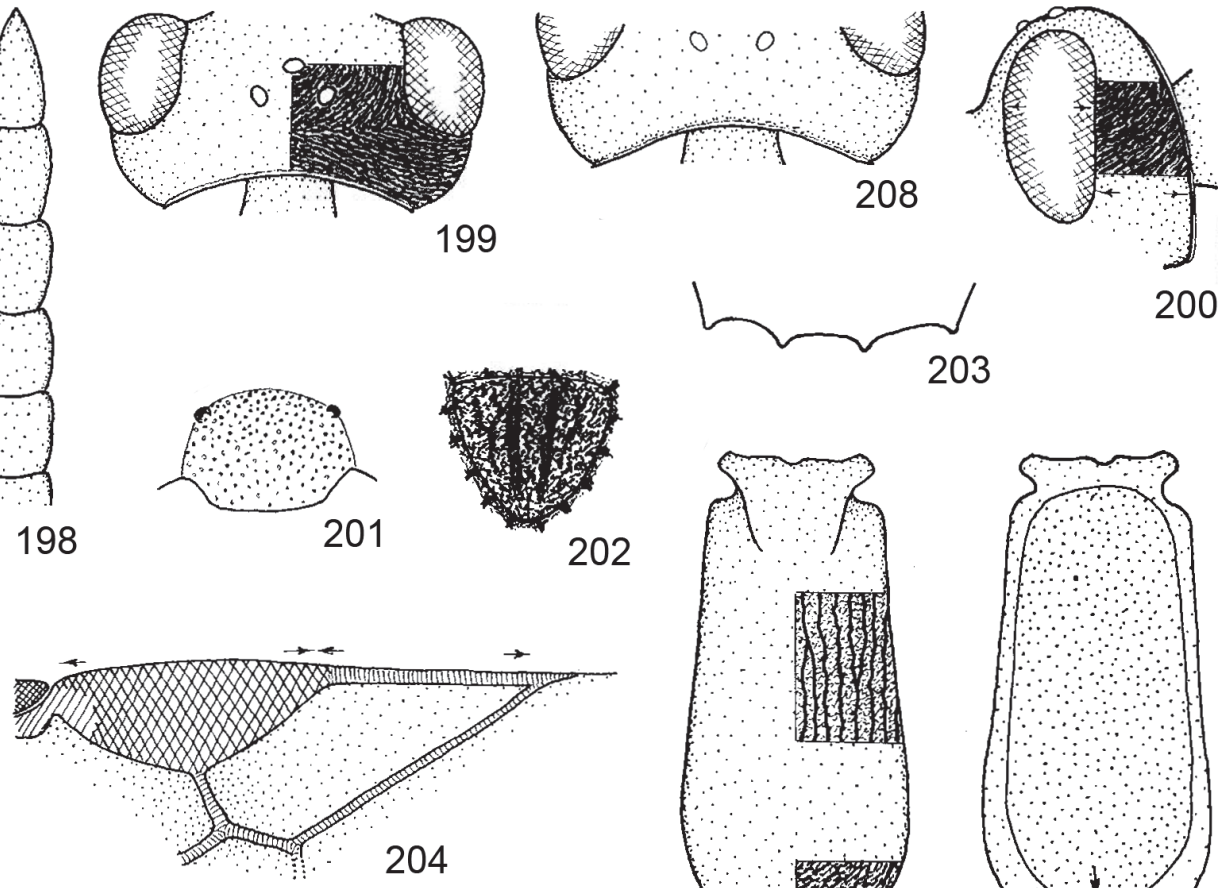

200
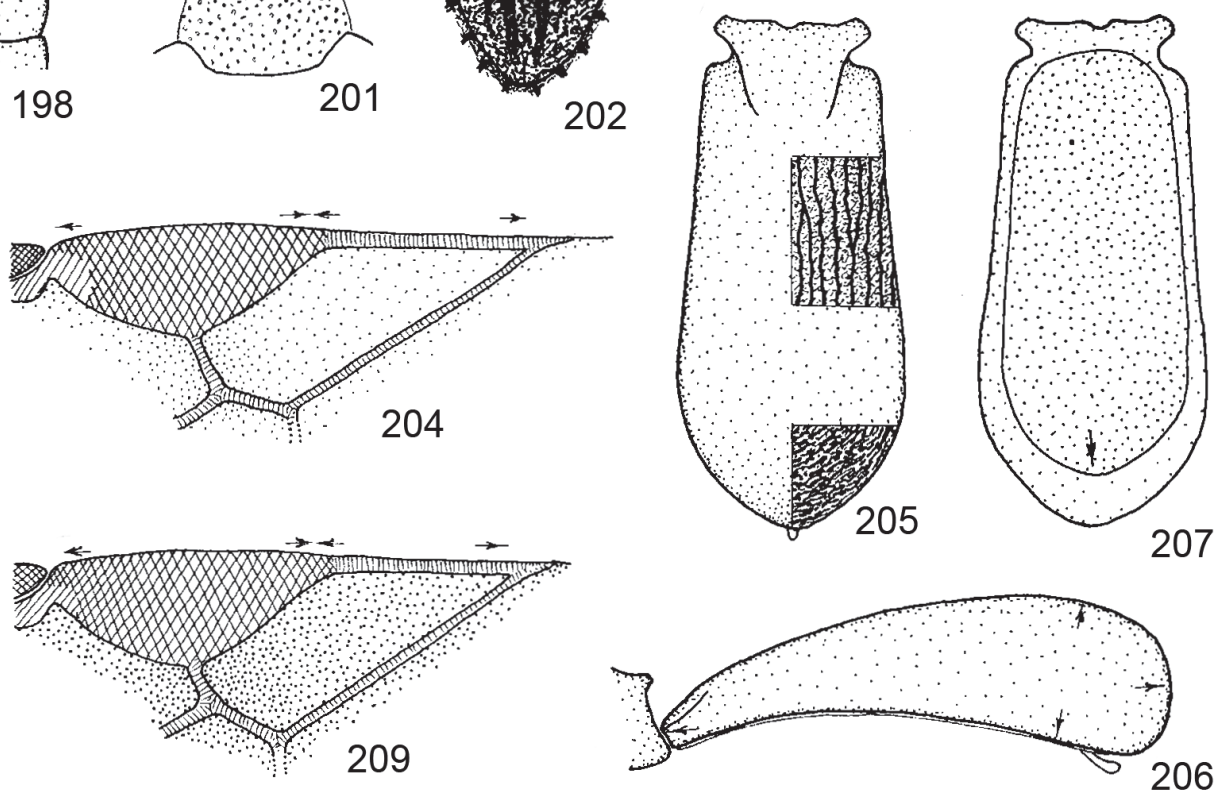

Figs 198-209. Microchelonus flavicoxa sp. n. (, holotype: 198-207, ᄋ, paratype: 208-209): $198=$ ultimate five flagellomeres, $199=$ head in dorsal view with indication of its sculpture, $200=$ head in lateral view with indication of its sculpture, 201 = clypeus, 202 = scutellum, 203 = propodeal carina in dorsal view, $204=$ distal part of right fore wing, 205 = carapace in dorsal view with indication of its sculpture, $206=$ carapace in lateral view, $207=$ carapace in ventral view, 208 = hind half of head in dorsal view, 209 = distal part of right fore wing. 
Carapace in dorsal view 2.1 times as long as broad, evenly and moderately broadening antero-posteriorly, apically rounded, longitudinally striated with little anastomoses, interstriations uneven, subshiny, its posterior fourth rugo-rugulose (Fig. 205). Carapace in
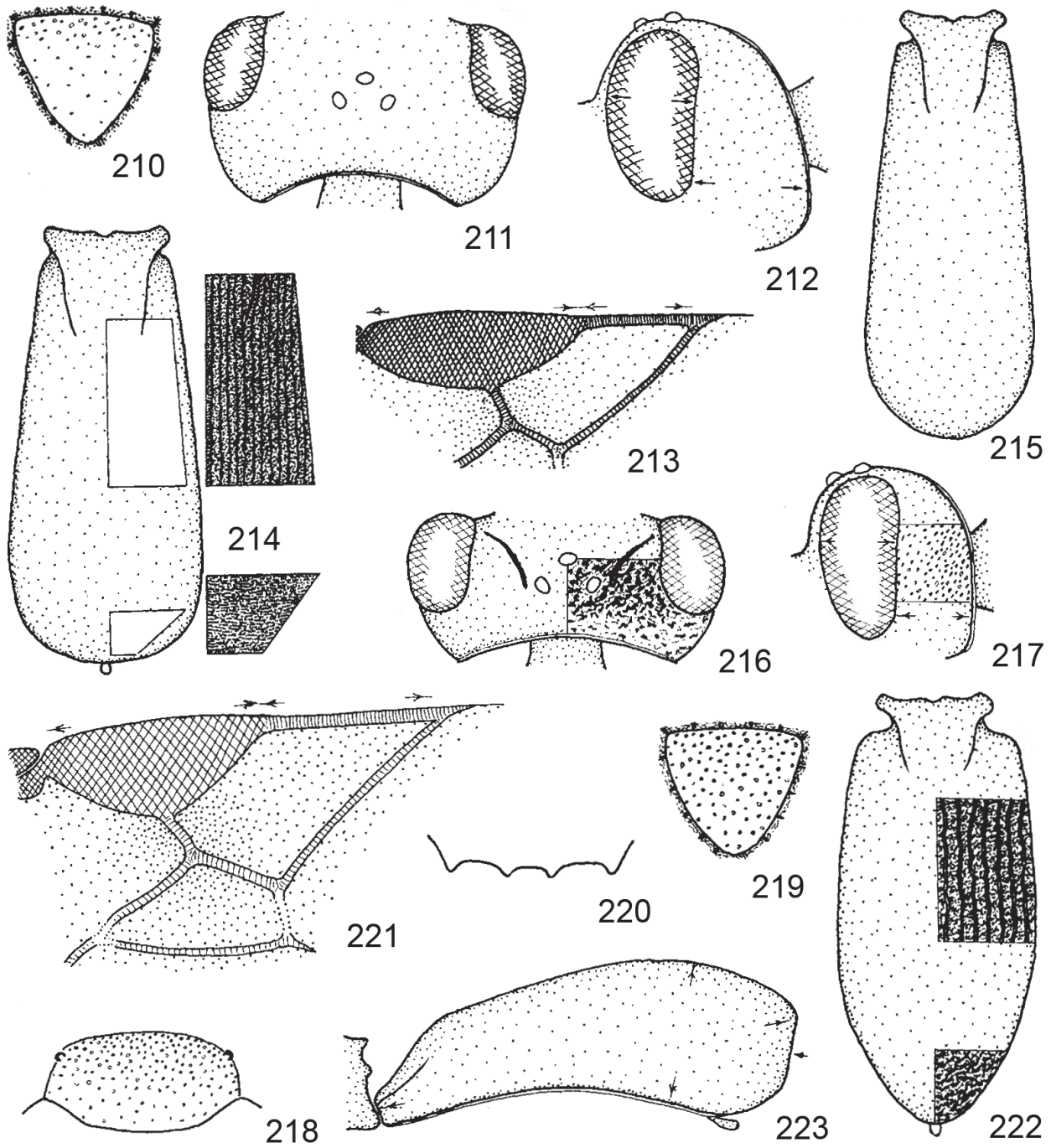

Figs 210-223. 210-215. Microchelonus flavopax Papp, 2010 (ㅇ, holotype: 211-212, 214, ㅇ, paratype: 210,0 , paratype: 213,215$): 210=$ scutellum, $211=$ head in dorsal view, $212=$ head in lateral view, 213 = distal part of right fore wing, 214 = carapace in dorsal view with indication of its sculpture, 215 = carapace in dorsal view. 216-223. Microchelonus fodicus sp. n. ( + , holotype): $216=$ head in dorsal view with indication of its sculpture, $217=$ head in lateral view with indication of its sculpture, $218=$ clypeus, $219=$ scutellum, $220=$ propodeal carina in dorsal view, 221 = distal part of right fore wing, $222=$ carapace in dorsal view with indication of its sculpture, $223=$ carapace in lateral view. 
lateral view 3.4 times as long high posteriorly, its hind end declivous (Fig. 206 see arrows). Carapace apico-ventrally somewhat incurved, i.e. ventral cavity of carapace nearly as long as carapace itself (Fig. 207 see arrow). Ovipositor sheath short, concealed.

Body black. Scape and pedicel yellow, flagellomeres 4-6 ochre. Palpi brownish. Tegula black, parategula brown. Fore coxa light brownish yelowish, middle coxa yellow, hind coxa black. Fore leg: trochanters yellow, femur brownish, tibia light brownish. Middle and hind legs: trochanters pale yellow, femora black, tibia blackish. Tarsi pale yellow with dark suffusion. Wings hyaline, pterostigma brown, basally yellow, veins light brown to brown.

Description of the two female paratypes - Similar to the holotype. Body $3 \mathrm{~mm}$ long (one paratype) and $4.2 \mathrm{~mm}$ (one paratype). Fore wing: $r$ and 3-SR equal in length (one paratype) or pterostigma 2.2 times as long as wide, $r$ half as long as $3-S R(5: 10), 1-R 10.75$ times as long as pterostigma (one paratype, Fig. 209 see arrows). Hind femur 2.6 times (one paratype) and 2.7 times (one paratype) as long as broad medially. Coxae 1-2 yellow (one paratype). Carapace in dorsal view 1.9 times (one paratype) and twice (one paratype) as long as broad posteriorly. Carapace apically without small foramen.

Male and host unknown.

Distribution - Costa Rica.

Taxonomic position - In the key to the Nearctic species of Microchelonus (МсСомв 1968) the new species, M. flavicoxa, runs to M. paululus (McComb) and M. cushmani (McComb), see key-couplet 76. The new species is nearest to $M$. hurdi (McComb), the distinction between them is presented (quotations after МсСомв 1968: 73-74):

1 (2) Scutellum "polished medially, rugulose along its lateral margins." Clypeus "sparsely and weakly punctate." Fore wing: 1-R1 short, 0.4 times as long as pterostigma. Carapace somewhat globose, 0.7 times as broad as long. Femora testaceous, flagellomeres $4-5$ black. $+2.6 \mathrm{~mm}$. - USA: California

M. hurdi (McComb, 1968)

2 (1) Scutellum with strong striae (Fig. 202). Clypeus densely and distinctly punctate (Fig. 201). Fore wing: 1-R1 long, 0.7-0.8 times as long as pterostigma (Figs 204, 209). Carapace not globose, $0.3-0.5$ times as broad as long (Fig. 205). Femore blackish to black, flagellomeres $4-5$ brownish yellowish. + : 3-4.2 mm. - Costa Rica

M. flavicoxa sp. $n$.

In the key to the female Microchelonus species M. flavicoxa runs to M. shenefelti (McComb), see couplets 130 (125) - 132 (131).

\section{Microchelonus flavopax Papp, 2010 \\ (Figs 210-215)}

Microchelonus flavopax Papp, 2010: 172 ổ, type locality: Ecuador, Napo, 5 km NE from El Chaco, female holotype and one male paratype in ZMLU, two female paratypes (1 $\rightarrow$ from Ecuador and 1 f from Costa Rica) in HNHM; examined. 
Emendated features to the original description (Papp 1.c.) - + . Body $4.3-4.5 \mathrm{~mm}$ long. Flagellum long, first flagellomere 3.2-3.3 times and penultimate flagellomere 1.7-1.8 times as long as broad. Head in dorsal view less transverse, 1.7 ties as broad as long, eye either as long as temple or just longer, temple rounded (Fig. 211). Gena in lateral view about onefourth wider than eye (Fig. 212 see arrows). Scutellum smooth, basally hairpunctate (Fig. 210). Fore wing: pterostigma 2.6 times as long as wide, isuing $r$ distally from its middle, $1-\mathrm{R} 1$ half ( 0.5 times) as long as pterostigma (Fig. 213 see arrows). Carapace in dorsal view 2.2 times as long as broad posteriorly, densely and parallel striated, apically transversely substriolated (Fig. 214).

3. Similar to the female. Body $4.1 \mathrm{~mm}$ long. Penultimate flagellomere 1.8 times as long as broad. Carapace in dorsal view 2.5 times as long as broad posteriorly (Fig. 215). Apical foramen of carapace missing.

Distribution - Costa Rica, Ecuador.

Taxonomic position - In the key to the female Microchelonus species $M$. flavopax runs to $M$. bolsoni Papp, M. turgoclarus Papp and M. zobocus sp. n., see couplets 59 (66) - 66 (59). In the key to the male Microchelonus species it runs to M. masoni (McComb) and M. zobocus sp. n., see couplets 34 (35) - 38 (37). In the original description $M$. flavopax is related to $M$. carinatus (Provancher) (PApr 2010: 175).

\section{Microchelonus fodicus sp. $n$.}

$$
\text { (Figs 216-226) }
$$

Material examined - Female holotype: Costa Rica, Alajuela, $20 \mathrm{~km} \mathrm{~S} \mathrm{from} \mathrm{Upala,} 11$ December 1990, leg. F. D. Parker. - Holotype is in good condition: (1) glued direct to the pin by its right mesopleuron, (2) distal part of left hind wing creased. Holotype is deposited in HNHM, Hym. Typ. No. 12238.

Etymology - The new species name "fodicus" has the meaning pricking refering to its parasitoid behavour.

Description of the female holotype - Body $5 \mathrm{~mm}$ long. Antenna short, as long as head + mesosoma combined and with 16 antennomeres. First flagellomere three times as long as broad, further flagellomeres shortening so that penultimate flagellomere subcubic: 1.2 times as long as broad. - Head in dorsal view transverse, 2.1 times as broad as long, eye 2.1 times longer than temple, temple strongly rounded (Fig. 216). OOL one-third longer than POL (12:8). Eye in lateral view twice as high as wide (31:15), gena beyond eye broadening ventrally and as wide as eye (Fig. 217 see arrows). Gena punctate, interpunctures as great as punctures, shiny (Fig. 217). Clypeus wide, 1.8 times as wide below as high medially, punctate above (finer than that of gena), punctation sparsing below, subshiny (Fig. 218). Face rugose, frons and vertex rugose, occiput subrugulose to smooth (Fig. 216).

Mesosoma in lateral view 1.6 times as long as high, scabrous. Notaulix distinct. Scutellum finely punctate, interspaces greater than punctures and subshiny (Fig. 219). Transverse carina of propodeum with four small denticules (Fig. 220). Hind femur thick, 2.6 times as long as broad medially (Fig. 224). Middle tibia with spinules (Fig. 225). Hind basitarsus as long as tarsomeres $2-4+$ half 5 th tarsomere combined. 
Fore wing shorter than body (3.5 mm long). Pterostigma wide, 2.1 times as long as wide, issuing $\mathrm{r}$ from its middle, 3-SR twice longer than $\mathrm{r}$ (13:6.5), SR1 weakly bent, 1-R1 0.8 times as long as pterostigma (Fig. 221).

Carapace in dorsal view 2.1 times as long as broad medially, apically coniculeshaped, with longitudinal sulciferous striations (similar to that of M. sulcifera sp. n.), interstriations crenulate (Fig. 222). Carapace in lateral view 2.8 times as long as high posteriorly, its hind end truncate (Fig. 223 see arrows). Carapace apically without foramen. Carapace apico-ventrally weakly incurved.

Ground colour of body black. Scape and pedicel testaceous. Palpi light brownish yellow. Tegula blackish. Fore leg pale testaceous, femur proximally brownish. Middle and hind legs blackish to black, coxae yellowish, tibiae basally and tarsi entirely straw yellow. Wings subhyaline, pterostigma brown, veins yellow to brownish.

Male and host unknown.

Distribution - Costa Rica.

Taxonomic position - The new species, M. fodicus, is closest to M. sulcifera sp. n. and $M$. townsendi (Viereck) considering their common features: strong corporal sculpture, sulciferous striations of carapace, 1-R1 almost as long as pterostigma, their distinction is presented in the key to the female Microchelonus species, see couplets 27 (26) - 30 (29).

\section{Microchelonus fulgens sp. n.}

(Figs 227-233)

Material examined - Female holotype: Costa Rica, San José, C. Nara, NE from Quepos, 16 July 1975, leg. J. W. Hanson. - Holotype is in good condition: (1) glued direct to the pin by left side of mesosoma, (2) left antenna deficient: scape, pedicel and flagellomeres 1-7 are present, (3) left wing pair less visible owing to the mounting. Holotype is deposited in HNHM, Hym. Typ. No. 12253.

Etymology - The new species received the Latin name "fulgens" (=glistening) refering to its polished carapace.

Description of the female holotype - Body $3.1 \mathrm{~mm}$ long. Right antenna as long as head, mesosoma and two-thirds of carapace combined, with 16 antennomeres. Scape three times as long as broad apically, first flagellomere six times and penultimate flagellomere subcubic: just longer than broad. - Head in dorsal view distinctly transverse, 2.1 times as broad as long, temple receded, eye 2.5 times longer than temple (Fig. 227). OOL 2.4 times as long as POL. Eye in lateral view twice as high as wide, gena beyond eye broadening ventrally so that eye 1.2 times wider than gena, gena itself polished with disperse hairpunctates (cf. Fig. 461 see arrows). Clypeus 1.5 times as wide below as high medially, its lower margin convex (Fig. 228), smooth and shiny with disperse hairpunctates. Face 1.6 times as wide as high, with more or less confluent punctation, subshiny. Head above with substriolation, dull (Fig. 227).

Mesosoma in lateral view 1.3 times as long as high. Mesoscutum, scutellum and mesopleuron rugose. Propodeum areolate, medially with a transverse though less distinct carina (Fig. 230). Hind femur 4.1 times as long as broad distally (Fig. 229). Hind basitarsus as long as tarsomeres $2-4$ combined. 

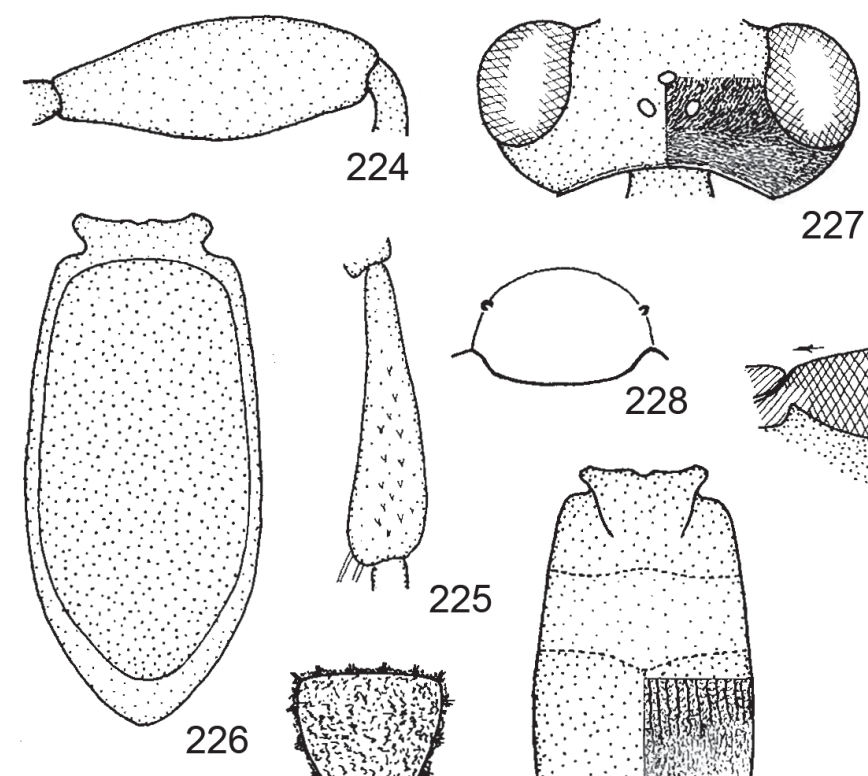

227

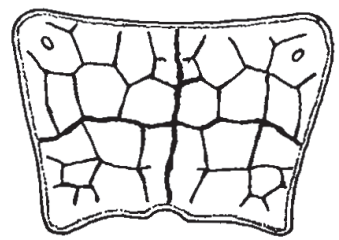

230
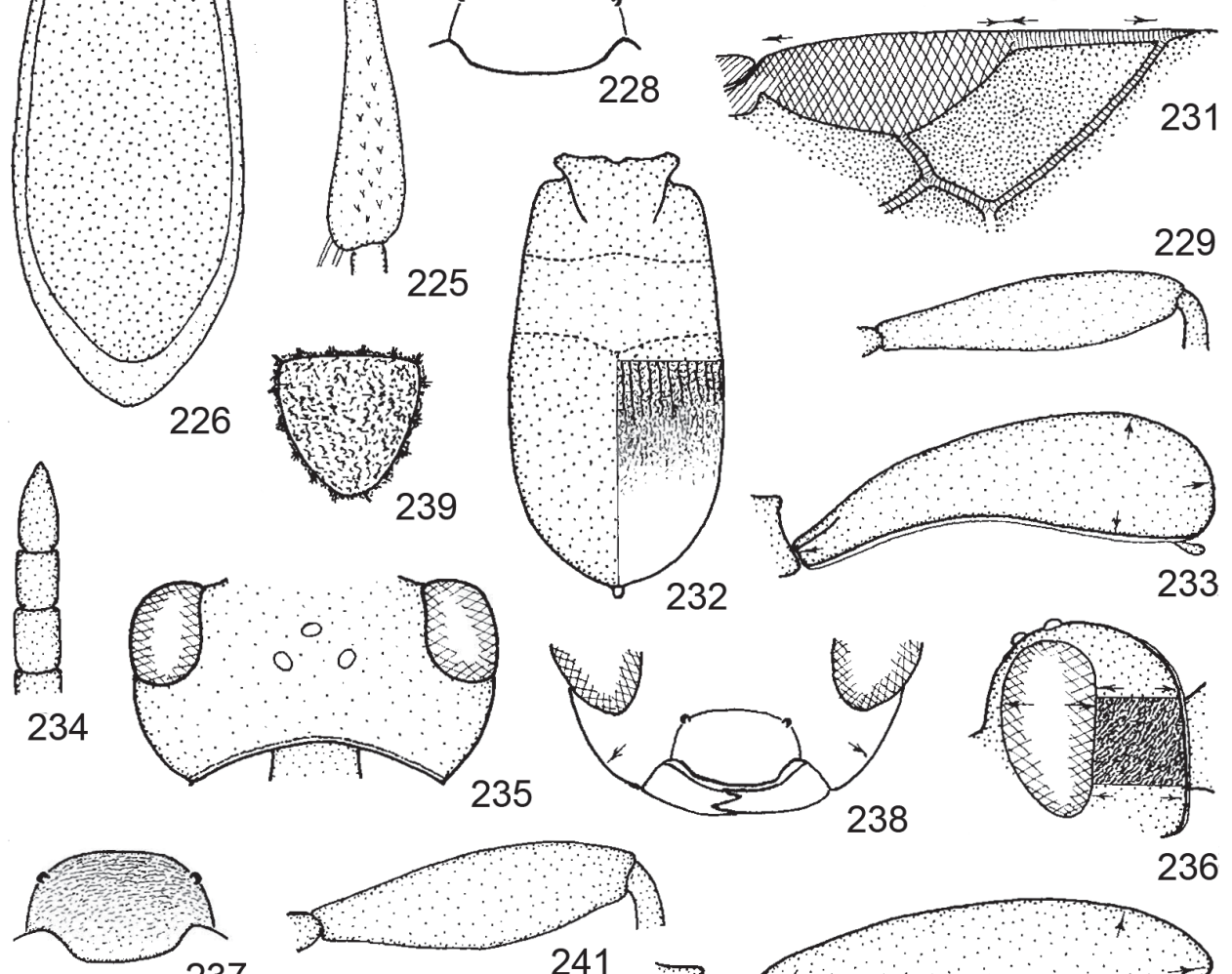

237
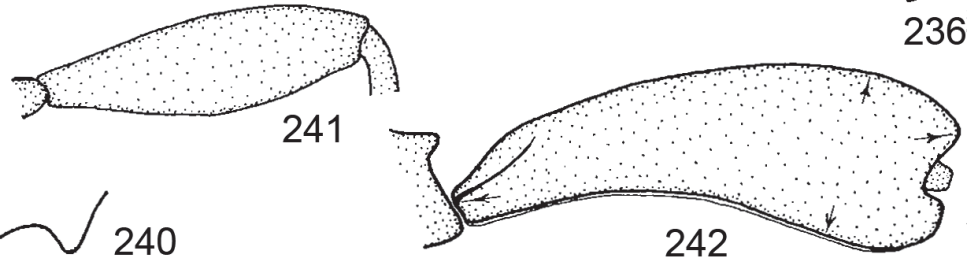

Figs 224-242. 224-226. Microchelonus fodicus sp. n. (ㅇ, holotype): 224 = hind femur, $225=$ middle tibia, 226 = carapace in ventral view. 227-233. Microchelonus fulgens sp. n. (q, holotype): 227 = head in dorsal view with indication of its sculpture, $228=$ clypeus, $229=$ hind femur, 230 = propodeum, 231 = distal part of right fore wing, 232 = carapace in dorsal view with indication of its sculpture, 233 = carpace in lateral view. 234-242. Microchelonus hebes sp. n. $(\hat{O}$, holotype): $234=$ ultimate three flagellomeres, $235=$ head in dorsal view, $236=$ head in lateral view with indication of its sculpture, 237 = clypeus, $238=$ ventral half of head in frontal view, $239=$ scutellum, $240=$ propdeal carina in dorsal view, $241=$ hind femur, 242 = carapace in lateral view. 
Fore wing somewhat shorter than body ( $2.9 \mathrm{~mm}$ long). Pterostigma 2.3 times as long as wide, issuing $r$ just distally from its middle, 1-R1 0.6 times as long as pterostigma, 3-SR slightly longer than (9:7), SR1 faintly bent (Fig. 231 see arrows).

Carapace in dorsal view twice longer than broad posteriorly, basally less narrowing, its striations similar to that of M. candidus (cf. Fig. 106, Fig. 232), its declivous hind part polished. Carapace in lateral view 3.6 times as long as high posteriorly, apically declivous (Fig. 233 see arrows). Carapace apico-ventrally just incurved (cf. Fig. 197).

Corporal colour similar to that of $M$. candidus. Flagellum black, flagellomeres 3-4 straw yellow. Tegula black. Dark colour of legs brown to blackish. Wings subhyaline, around pterostigma brownish fumous. Veins light brownish, parastigma yellow.

Male and host unknown.

Distribution - Costa Rica.

Taxonomic position - The new species, M. fulgens, is closest to $M$. candidus sp. n., they distinction see at this species. In the key to the female Microchelonus species $M$. fulgens runs to $M$. curtulus sp. n., see couplets $13(10)-15(14)$. Also near to $M$. latistigma sp. n., their distinction see at this species.

\section{Microchelonus hadrogaster (McComb, 1968)}

(Figs 246-253)

Chelonus (Microchelonus) hadrogaster McComb, 1968: 9 (in key) and 70 (description) $q$ ô, type locality: Mott, North Dakota, USA, holotype is deposited in USNM; not examined.

Microchelonus hadrogaster (McComb): SHEnefelt 1973: 888 (comb. n., literature up to 1968). PAPr 2010: 183 (in key).

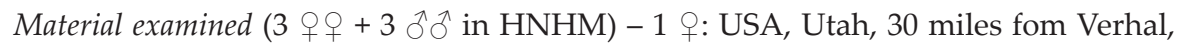
8400'. 1 क् : USA, Maine, Franklin county, Strong. $1++3 \hat{\jmath} \delta^{\lambda}$ : USA, Wyoming, Albany county, Medicine Bow National Forest, 5 miles from SW Lincoln Monument, meadow near mixed forest.

Additional features to the original description (McComb 1.c.) - q ô. Body 3-3.2 mm long. Antenna of male with 22-24 flagellomeres, penultimate flagellomere 1.6 times as long as broad (Fig. 246). Head in dorsal view transverse, 1.8 times as broad as long, eye somewhat longer than temple (18:15, Fig. 247). Eye in lateral view twice as high as wide, gena beyond eye wide, one-fourth wider than eye, somewhat strongly substriolated (Fig. 248 see arrows). Fore wing: pterostigma three times longer than wide, issuing $r$ clearly distally from its middle, 1-R1 half as long as pterostigma, SR1 bent outwards (Fig. 249 see arrows). Male carapace in dorsal view twice as long as broad medially, parallel-sided, striated (Fig. 250). Male carapace in lateral view three times as long as high posteriorly (Fig. 251 see arrows). Male carapace apico-ventrally with a pointed sulculus (Fig. 253). Apical foramen of male carapace elliptic, 1.4 times as wide as high. Scape and pedicel black.

Host unknown.

Distribution - USA: Idaho, North Dakota, Utah, Wyoming. 


\section{Microchelonus hebes sp. n.}

$$
\text { (Figs 234-245) }
$$

Material examined - Male holotype: Costa Rica, San José, San Pedro, UCR Campus, 1200 m a.s.l., 28 February 1997, leg. C. Hansson. - Holotype is in good condition: (1) glued on card point by the right side of its mesosoma, (2) tarsomeres $4-5$ of left hind leg missing, (3) right fore leg somewhat less visible owing to the mounting. Holotype is deposited in MZLU.

Etymology - The new species received the Latinized phantasy name "hebes".

Description of the male holotype - Body $2.7 \mathrm{~mm}$ long. Antenna one-sixth shorter than body ( $2.1 \mathrm{~mm}$ long) and with 19 antennomeres. First flagellomere just less than three times longer than broad (20:7), penultimate flagellomere subcubic (9:7, Fig. 234). - Head in dorsal view transverse, 1.8 times as broad as long, eye as long as temple, temple moderately rounded (Fig. 235). OOL one-third longer than POL (12:8). Eye in lateral view 1.9 times as high as wide, gena beyond eye as wide as eye and substriolate ((Fig. 236 see arrows). Clypeus 1.6 times as wide below as high medially, its lower margin faintly convex, transversely (sub)rugulose (Fig. 237). Malar space 1.4 times longer than basal width of mandible (Fig. 238). Cheek rounded, i.e. less convergent (Fig. 238). Face 1.5 times as wide as high, circularly striolated, dull. Head above (vertex + occiput) transversely substriolated (cf. Fig. 183).

Mesosoma in lateral view 1.4 times as long as high, scabrous. Notaulix distinct. Scutellum rugulose, dull (Fig. 239). Four denticules of propodeal carina small (Fig. 240). Hind femur 3.1 times as long as broad medially (Fig 241). Hind basitarsus as long as tarsomeres 2-3 combined.

Fore wing one-sixth shorter than body. Pterostigma wide, 2.2 times as long as wide, issuing $r$ from its middle, 3-SR almost 1.6 times longer than $r$, SR1 feebly bent, 1-R1 0.57 times as long as pterostigma (cf. Fig. 146).

Carapace in dorsal view nearly 1.9 times as long as broad medially, longitudinally and more or less parallel striated, interstriations crenulated, apically conicule-shaped (Fig. 243). Carapace in lateral view 2.9 times as long as high posteriorly, apically incurved (Fig. 242). Apical foramen of carapace less elliptic: 1.3 times as wide as high (Fig. 244). Apical incurved part of carapace as long as hind basitarsus and without a pair of sulcatuli (Fig. 245, see also Fig. 253).

Body black. Scape and pedicel rusty, dorsally with weak brownish suffusion. Palpi light brown. Tegula and parategula blackish brown to brown. Legs blackish brown to brown, femora apically, tibiae and tarsi entirely yellow, fore tarsus weakly brownish. Wings hyaline, pterostigma brown, veins light brown.

Female and host unknown.

Distribution - Costa Rica.

Taxonomic position - The new species, Microchelonus hebes, is nearest to M. avron sp. n., their distinction see at this species. Also near to M. hadrogaster (McComb), their common features are as follows: head in dorsal view less transverse, temple in dorsal view nearly as long as eye and moderately rounded (Figs 235, 247), carapace in dorsal view intermediate conicule- to cupole-shaped (Figs 243, 250), scutellum rugulose (Fig. 239); the two species differ by the following traits: 

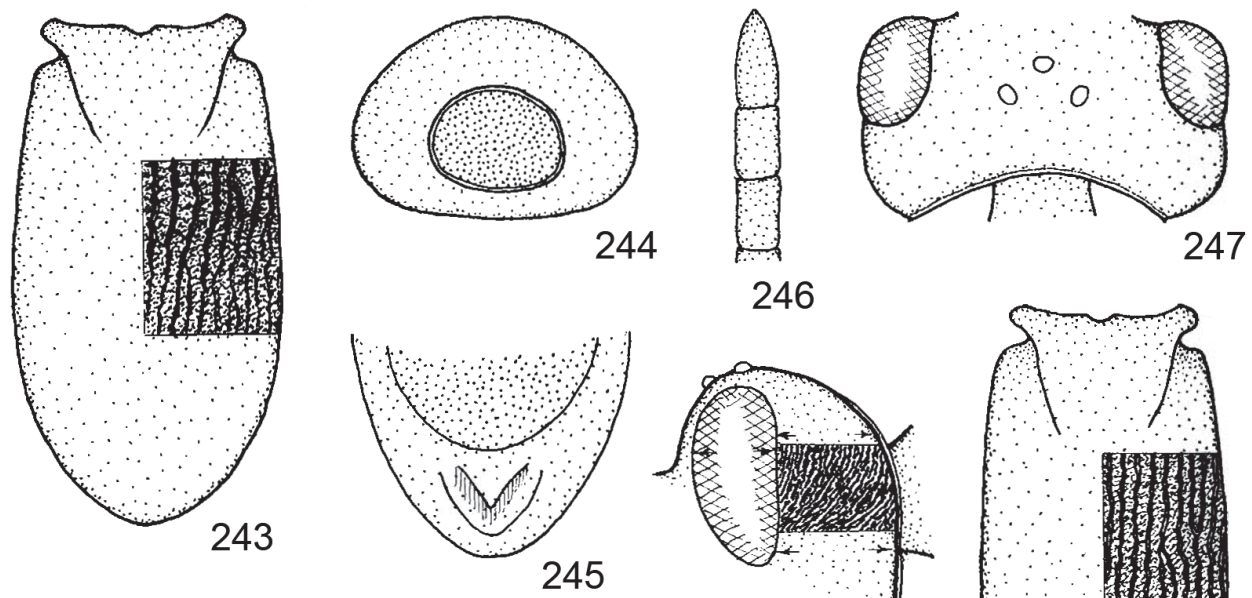

246
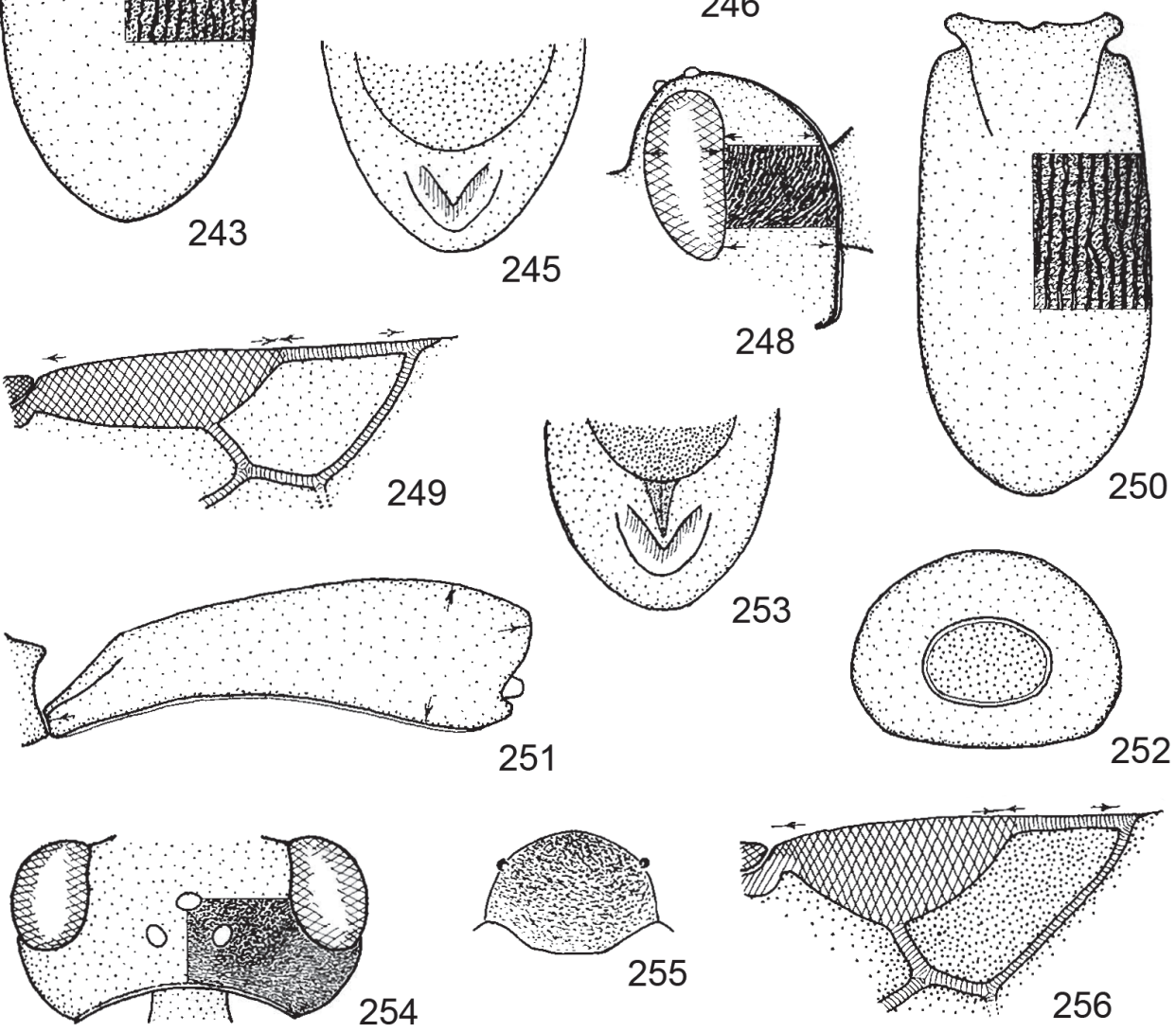

Figs 243-256. 243-245. Microchelonus hebes sp. n. ( $\hat{\jmath}$, holotype): 243 = carapace in dorsal view with indication of its sculpture, $244=$ apical foramen of carapace, $245=$ posterior third of carapace in ventral view. 246-253. Microchelonus hadrogaster (McComb, 1968) (ㅇ, đ): $246=$ ultimate three flagellomeres $(\hat{\jmath}), 247=$ head in dorsal view, $248=$ head in lateral view with indication of its sculpture, $249=$ distal part of right fore wing, $250=$ carapace in dorsal view with indication of its sculpture $\left({ }^{1}\right), 251$ = carapace in lateral view, $252=$ apical foramen of carapace $(\delta), 253$ = posterior third of carapace in ventral view. 254-256. Microchelonus jamaicus sp. n. ( $\hat{0}$, holotype): 254 = head in dorsal view with indication of its sculpture, 255 = clypeus, $256=$ distal part of right fore wing. 
1 (2) Gena in lateral view as wide as eye and finely substriolated (Fig. 236 see arrows). Head in dorsal view slightly less transverse, 1.7 times as broad as long, temple somewhat less rounded (Fig. 235). Antenna with 19 antennomeres, penultimate flagellomere subcubic (9:7, Fig. 234 see arrows). Fore wing: pterostigma twice as long as wide, issuing $r$ from its middle, $1-R 1$ somewhat longer: 0.6 times as long as pterostigma (cf. Fig. 146). Apico-ventral incurved part of carapace without an apically pointed sulculus (Fig. 245). Apical foramen of carapace less elliptic, 1.3 times as wide as high (Fig. 244). Scape and pedicel rusty. $\delta^{7}: 2.7 \mathrm{~mm}$. Costa Rica

M. hebes sp. n.

2 (1) Gena in lateral view 1.4 times as wide as eye and less finely substriolated (Fig. 248 see arrows). Head in dorsal view slightly more transverse, 1.8 times as broad as long, temple rounded (Fig. 247). Antenna with 22-24 antennomeres, penultimate flagellomere 1.6 times as long as broad (Fig. 246). Fore wing: pterostigma narrow, three times as long as wide, issuing $\mathrm{r}$ clearly distally from its middle, $1-R 1$ half as long as pterostigma (Fig. 249 see arrows). Apico-ventraly part of carapace with an apically pointed sulculus (Fig. 253). Apical foramen of carapace more elliptic, 1.5 times

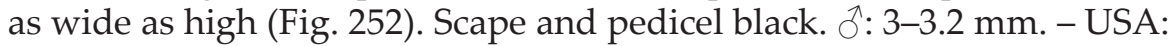
Idaho, North Dakota, Utah, Wyoming M. hadrogaster (McComb, 1968)

In the key to the male Microchelonus species M. hebes runs to M. jamaicus sp. n., see couplets $14(13)-16(15)$.

\section{Microchelonus jamaicus sp. n. \\ (Figs 254-262)}

Material examined - Male holotype: Jamaica, Hardwar Gap at Fairy Galdes Trail, 135 m a.s.l., 9 June 1989, leg. M. Sörensson et B. Martensson. - Holotype is in good condition: (1) glued on carp point by the left side of mesosoma and carapace, (2) left antenna deficient: with nine antennomeres (i.e. 14 distal flagellomeres missing), (3) right middle leg glued separately (in two parts). Holotype is deposited in ZMLU. collected.

Etymology - The new species received the country name ("jamaicus") where its was

Description of the male holotype - Body $3.2 \mathrm{~mm}$ long. Right antenna nearly as long as body and with 23 antennomeres. First flagellomere thrice (25:7) and penultimate flagellomere 2.5 times as long as broad. - Head in dorsal view transverse, twice as broad as long, eye almost twice longer than temple, temple rounded (Fig. 254). OOL one-third longer than POL. Eye in lateral view 1.9 times as high as wide, gena beyond eye not broadening ventrally and slightly less wide (15:17) than eye, substriolate (cf. Fig. 236). Clypeus subquadrate: 1.4 times as long below as high medially, its lower margin convex, transversely and densely rugulose, dull (Fig. 255). Malar space as long as basal width of mandible. Face 
1.6 times as wide as high, transversely-densely rugulose. Vertex and occiput rather transversely substriolate, dull (Fig. 254).

Mesosoma in lateral view 1.6 times as long as high, scabrous. Notaulix faintly distinct. Mesoscutum finely punctate and subshiny, scutellum basally subrugulose, otherwise haipunctate, shiny (Fig. 257). Four denticules of propodeal carina weakly prominent (cf. Fig. 220). Hind femur 3.5 times as long as broad medially (Fig. 258). Hind basitarsus as long as tarsomeres 2-4 combined.

Fore wing shorter than body, $2.7 \mathrm{~mm}$ long. Pterostigma 2.3 times as long as wide, issuing $r$ proximally from its middle, $r$ as long as $3-S R, S R 1$ straight, $1-R 1$ half as long as pterostigma (Fig. 256 see arrows).

Carapace in dorsal view 2.2 times as long as broad posteriorly, more or less parallel striated anteriorly, rugulose to subrugulose posteriorly, apically conicule-shaped (Fig. 259). Carapace in lateral view 3.2 times as long as high posteriorly, apically truncate (Fig. 260). Apical foramen of carapace wide, 2.7 times wider than high laterally (Fig. 261). Apical-ventral incurved part of carapace short, as long as hind second tarsomere (Fig. 262).

Body black, scape yellow, pedicel yellow with brownish suffusion, flagellum black. Palpi pale yellow. Tegula dark brown, parategula brown. Fore and middle legs yellow. Hind leg: coxa black, trochanters and base of femur yellow, rest of femur brown, tibia + tarsus blackish, tarsomeres ventrally yellowish. Wings hyaline, marginal cell brownish fumous. Pterostigma brown, veins feebly light brown.

Female and host unknown.

Distribution - Jamaica.

Taxonomic position - The new species, Microchelonus jamaicus, is closest to M. amelot sp. $\mathrm{n}$. considering their common features: scutellum smooth with hairpunctation (Fig 257) or punctures (Fig. 13), 1-R1 half as long as pterostigma (Figs 16, 256) and coxae 1-2 yellow; the distinctive traits of the two species are keyed:

1 (2) Temple in dorsal view rounded, eye almost twice longer than temple, vertex and occiput rather transversely substriolate (Fig. 254). Fore wing: pterostigma issuing $r$ proximally from its middle (Fig. 256). Gena in lateral view not broadening ventrally and slightly less wide than eye (cf. Fig. 236). Carapace less strongly striated (Fig. 259). Palpi pale yellow. $\delta^{7}$ : $3.2 \mathrm{~mm}$. - Jamaica

M. jamaicus sp. n.

2 (1) Temple in dorsal view receded, eye twice as long as temple, vertex and occiput rugose (Fig. 10). Fore wing: pterostigma issuing $r$ distally from its middle (Fig. 16). Gena in lateral view broadening ventrally and slightly wider than eye (Fig. 12 see arrows). Carapace strongly striated (Fig. 17). Palpi light brownish. . : $3.3 \mathrm{~mm}$. - Costa Rica

M. amelot sp. n.

The new species is similar to female M. projectus sp. n. considering their long antenna: flagellomeres 2.5-3 times longer than broad, carapace in dorsal view moderately broadening posteriorly (Figs 259, 376), black corporal colour 
and yellow fore and middle legs; the two species differ from each other as follows:

1 (2) Ocelli: OOL one-third longer than POL, in dorsal view temple rounded (Fig. 254). Fore wing: pterostigma issuing $r$ proximally from its middle, 1-R1 0.5 times as long as pterostigma (Fig. 256). Scutellum hairpunctate, smooth and shiny (Fig. 257). 0 : $3.2 \mathrm{~mm}$. - Jamaica M. jamaicus sp. n.

2 (1) Ocelli: OOL as long as POL, in dorsal view temple moderately rounded (Fig. 369). Fore wing: pterostigma issuing $r$ from its middle, 1-R1 0.8 times as long as pterostigma (Fig. 374). Scutellum rugose (Fig. 372)..$: 3.3$ mm. - Honduras

M. projectus sp. n.

In the key to the male Microchelonus species M. jamaicus sp. n. runs to $M$. hebes sp. n. and to M. refluus Papp, see couplets 14 (13) - 16 (15).

\section{Microchelonus johni (Marsh, 1979)}

(Figs 263-275)

Chelonus (Microchelonus) johni Marsh, 1979: 14 (description, Figs 7, 9) $9 \hat{\jmath}$, type locality: Palmira, Colombia, holotype is (and five female + six male paratypes are) deposited in USNM; examined 19 and $1 \delta$ paratypes.

Microchelonus johni (Marsh): PAPP 1999: 185, 191, 194 (in keys, comb. n.)

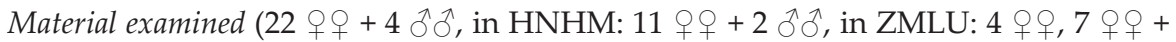

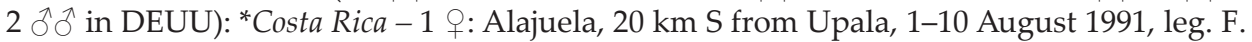
D. Parker; 8 우: San José, Escazu, 8 February 1987 (2 우) and 34 January - 13 May 1988 (6

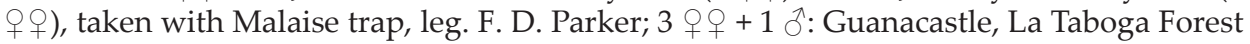
Research Station, 9 km SW from Cañas, taken with Malaise trap, 18 March - 30 April 1987 (3 우) and 17-27 February 1987 (1 え), leg. W. L. Rubink. 2 q : : Guanacastle, 14 km S from Cañas, taken with Malaise trap, 1-5 March and 7-10 October 1989, leg. F. D. Parker. 1 + 2 đ̊: Guanacastle, 3 km SE from Rio Naranjo, 12 November 1991 (1 of) and 1-25 April 1992

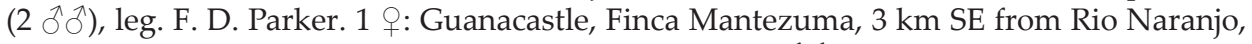
taken with Malaise trap, 2 May 1992, leg. F. D. Parker. 2 đo ${ }^{\lambda}$ : Guanacastle, S Cañas Experiment Station, taken with Malaise trap, 8-18 March 1988, leg. F. D. Parker. 1 q: Puntarenas, Quepos, 13 February 1987, leg. G. E. Bohart. *Honduras -1 ㅇ: LaCeiba, 25 February 1979, leg. G. E. Bohart. 1 o: Olancho, Catacamas, $15^{\circ} 50^{\prime} \mathrm{N} / 85^{\circ} 51^{\prime} \mathrm{W}$, taken with Malaise trap, 14 November 1995, leg. R. Cave. 2 우: Yoro, Palo de Comba, $15^{\circ} 11 \mathrm{~N} / 87^{\circ} 39^{\prime} \mathrm{W}$, taken with Malaise trap, 12 and 27 September 1995, leg. R. Cave. ${ }^{*}$ Mexico -1 : Baja California Norte, 10 km N from Punte Prieta, taken with Malaise trap, 20 March 1986, leg. R. R. Parmenter.

Additional features to the original description (Marsh 1.c.) - + . Body 3-3.2 mm long. Penultimate flagellomere 1.1-1.3(-1.6) times as long as broad (Fig. 263a-b). - Head in dorsal view transverse, twice as broad as long, eye 1.3 times longer than temple, temple rounded, frons-vertex-occiput finely substriolated (Fig. 264). Gena in lateral view 1.3 times wider than eye, substriolation as in Fig 265a-b. Cheek in frontal view slightly more rounded (i.e. 

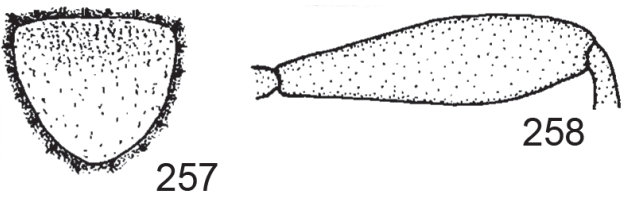

258

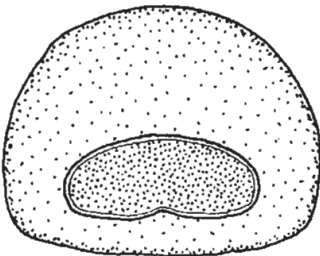

261

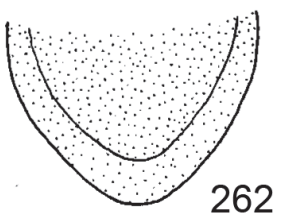

262

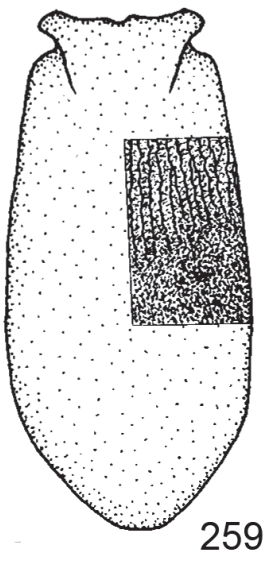

270
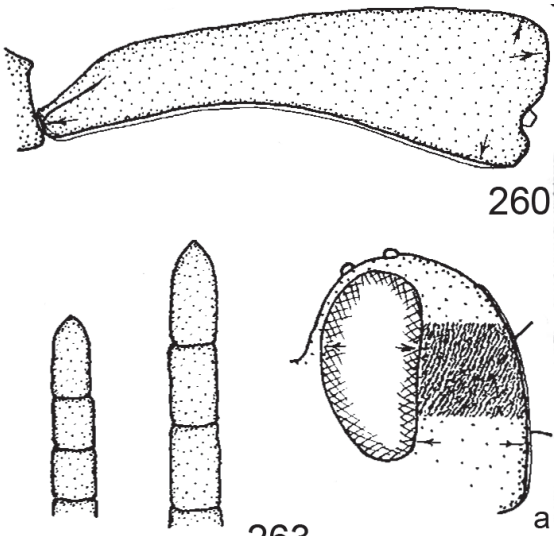

b
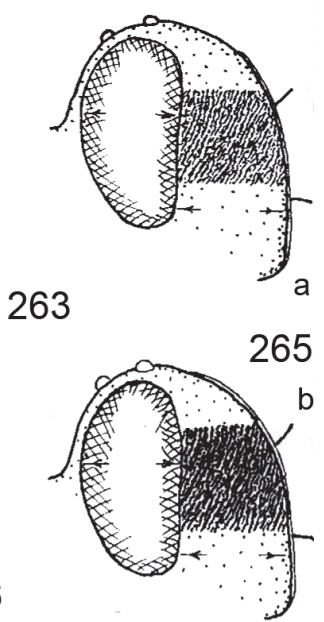

266

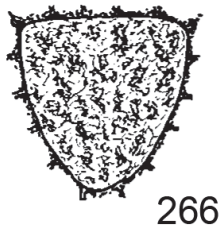

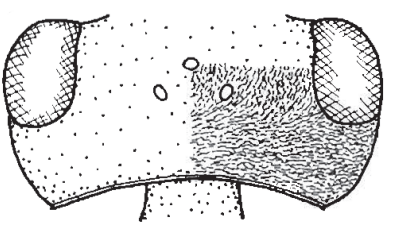
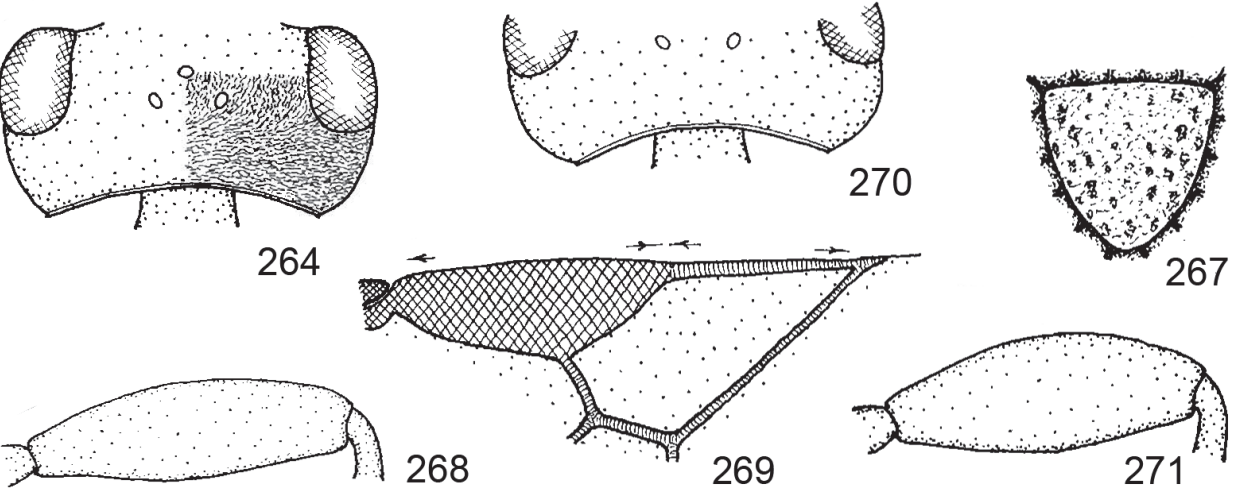

268

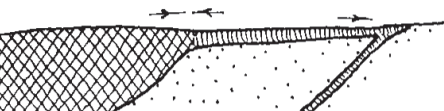

Figs 257-271. 257-262. Microchelonus jamaicus sp. n. (§ે, holotype): $257=$ scutellum, $258=$ hind femur, $259=$ carapace in dorsal view with indication of its sculpture, $260=$ carapace in lateral view, $261=$ apical foramen of carapace, $262=$ posterior third of carapace in ventral view. 263-271. Microchelonus johni (Marsh, 1979) (ㅇ, paratype: 263a, 264, 265a, 266, 268, 269;

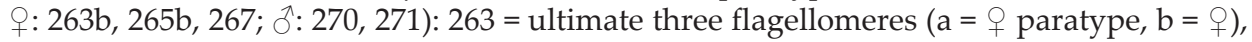
$264=$ head in dorsal view with indication of its sculpture, $265=$ head in lateral view with indication of its sculpture $(\mathrm{a}=q$, paratype, $\mathrm{b}=+), 266-267=$ scutellum $(266=q$, paratype, $267=$ + $), 268=$ hind femur, $269=$ distal part of right fore wing, $270=$ posterior half of head in dorsal view, 271 = hind femur. 
less converging, Fig. 272 see arrows). Scutellum variably smooth with hairpunctures (cf. Fig. 279), rugose (Fig. 266) to rugulose (Fig. 267). Hind femur 3.1-3.3 times as long as broad medially (Fig. 268). Fore wing: pterostigma 2.6(-2.1) times as long as wide, issuing $r$ distally from its middle, 1-R1 0.7-0.8 times as long as pterostigma (Figs 269, 273 see arrows). Carapace in dorsal view twice as long as broad posteriorly, striated with much anastomoses, apically transversely substriolated (Fig. 274). Carapace in lateral view 2.9 times as long as high posteriorly, apically truncate (cf. Fig. 306).

T. Similar to the female. Body $2.8-3.1 \mathrm{~mm}$ long. Temple in dorsal view slightly less rounded (Fig. 270). Hind femur 2.8 times as long as broad medially (Fig. 271). Fore wing: pterostigma wide, 2.1 times as long as wide (Fig. 273 see arrows). Apical foramen of carapace elliptic, 1.4-1.5 times as wide as high (Fig. 275).

Host - Scrobipalpula sp. (Lep., Gelechiidae).

Distribution - Colombia, ${ }^{*}$ Costa Rica, ${ }^{*}$ Honduras, ${ }^{*}$ Mexico.

Taxonomic position - According to the describer (Marsh 1.c.) it is similar to M. kellieae (Marsh). In the key to the female Microchelonus species M. johni runs to $M$. ormos sp. n., see couplets 68 (67) - 70 (69), to M. blackburni (Cameron), see couplets 96 (99) - 98 (97) as well as to M. angustus sp. n., M. phthorimaeae (Gahan) and M. topali Papp, see couplets 104 (109) - 109 (104). In the key to the male Microchelonus species it runs to M. kellieae (Marsh), see couplets 45(40) - 48 (49).

\section{Microchelonus kellieae (Marsh, 1979) comb. n. (Figs 276-284, 519)}

Chelonus (Microchelonus) kellieae Marsh, 1979: 14 오, type locality: Costa Rica, Cartago, female holotype (and 22 female +28 male paratypes) in USNM (paratypes also in University of California, Riverside).

Material examined $-1+2$ ô paratypes: Costa Rica, Cartago, ex gelechiid moth-larva (its food plant potato), 25 April 1973, leg. E. R. Oatman. 1 o: Costa Rica, Guanacastle, S. Cañas, Experiment Station, taken with Malaise trap, 8-18 March 1988, leg. F. D. Parker. 1 : Costa Rica, Guanacastle, LaTaboga Forest Research Station, taken with Malaise trap, 17-27 February 1987, leg. W. L. Rubink. 1 ऽ̊: *Honduras, Roatan Island, 27 February 1979, G. E. Bohart.

Additional features to the original description (Marsh 1.c.) - 9 . Body 3-3.2 mm long. Penultimate flagellomere 1.2-1.3 times as long as broad (cf. Fig. 263a). Temple in dorsal view moderately rounded (Fig. 276). Cheek in frontal view slightly less rounded (or slightly more converging, Fig. 278 see arrows). Head in lateral view: gena broadening ventrally and 1.2-1.3 (-1.4) times as wide as eye (Fig. 277 see arrows), substriolate, dull. Scutellum smooth with hairpunctures (Fig. 279) to uneven (Fig. 283). Hind femur 3.5 times as long as broad distally (Fig. 281). Fore wing: pterostigma 2.2 times as long as wide, issuing $r$ distally from its middle, 3-SR somewhat longer than $r, 1-R 1$ half as long as pterostigma (Fig. 280). Carapace in dorsal view belly, 1.8 times as long as broad medially, densely rugose, apically rugulose (Fig. 282).

J. Similar to the female. Body 2.6-3 mm long. Scutellum uneven (Fig. 283). Apical foramen of carapace elliptic, 2.6 times as wide as high (Fig. 284). 
Distribution - Costa Rica, ${ }^{*}$ Honduras, USA (California, introduced).

Taxonomic position - According to the describer (Marsh 1.c.) M. kellieae is similar to the Nearctic M. cosmopteridis (McComb). In the key to the female Microchelonus species M. kellieae runs to M. amelot sp. n., see couplets 72 (75) 74 (73). In the key to the male Microchelonus species it runs to M. johni Marsh), see couplets $45(40)-47(46)$.
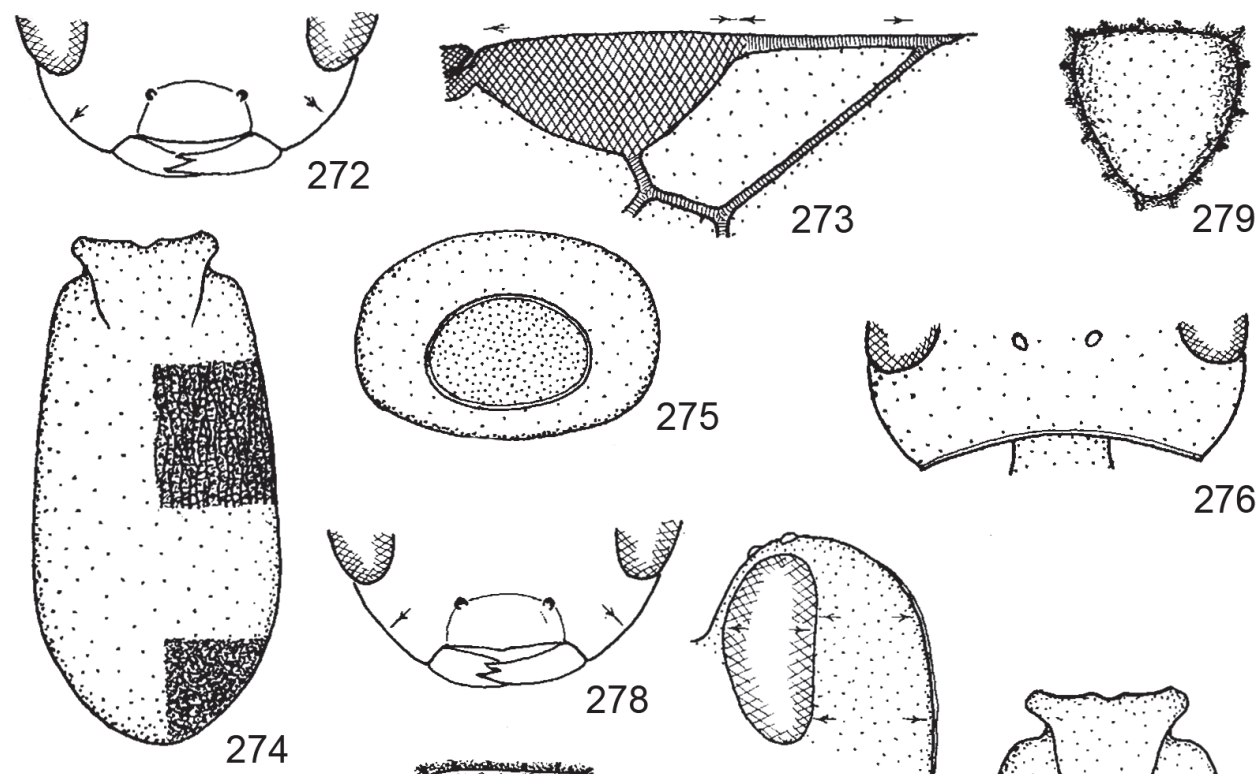

273

279
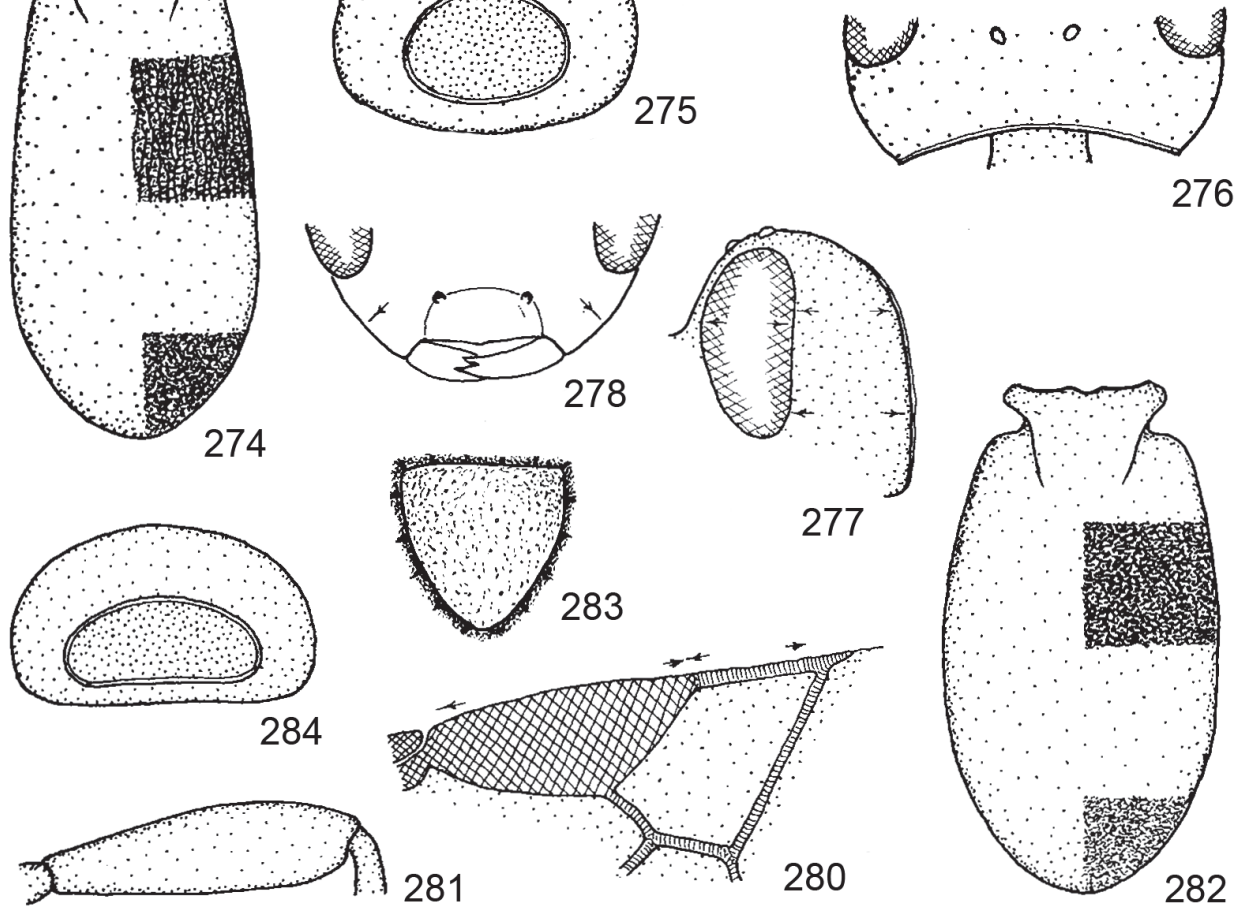

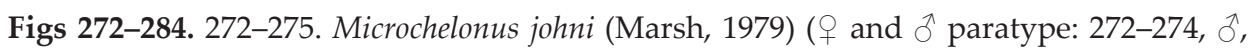
paratype: 275 ): 272 = ventral half of head in frontal view, 273 = distal part of right fore wing, $274=$ carapace in dorsal view with indication of its sculpture, $275=$ apical foramen of carapace. 276-284. Microchelonus kellieae (Marsh, 1979) (ㅇ, paratype: 276-282, ô, paratype: 283-284): 276 = posterior half of head in dorsal view, 277 = head in lateral view, 278 = ventral half of head in frontal view, $279=$ scutellum, 280 = distal part of right fore wing, $281=$ hind femur, 282 = carapace in dorsal view with indication of its sculpture, $283=$ scutellum, $284=$ apical foramen of carapace. 


\section{Microchelonus latistigma sp. n.}

(Figs 289-298)

Material examined - Female holotype: Costa Rica, Alajuela, $20 \mathrm{~km}$ S from Upala, 10 19 March 1991, leg. F. D. Parker. - Holotype is in good condition: (1) glued direct to the pin by the right side of mesosoma, (2) right fore leg somewhat less visible owing to the gluing. Holotype is deposited in HNHM, Hym. Typ. No. 12239.

Etymology - The species received the name "latistigma", refering to its wide pterostigma (Fig. 296).

Description of the female holotype - Body $2.6 \mathrm{~mm}$ long. Antenna almost as long as body (2.4 mm long) and with 16 antennomeres. Scape somewhat belly: thrice as long as broad proximally (Fig. 289). First flagellomere long, seven times as long as broad, further flagellomeres shortening so that penultimate flagellomere 1.25 times as long as broad. - Head in dorsal view transverse, 2.1 times as broad as long, eye 2.5 times longer than temple, temple receded (Fig. 290). OOL slightly longer than POL (10:9). Eye in lateral view 1.9 times as high as wide, gena beyond eye faintly broadening ventrally, less wide than eye, gena polished with very fine and disperse substriolae (Fig. 291). Clypeus 1.5 times as wide below as high medially, its lower margin truncate (Fig. 292). Face and clypeus coriaceoussubrugulose, subshiny, sculpture of clypeus slightly weaker. Head above densely subrugulose, subshiny (Fig. 290).

Mesosoma in lateral view stout, slightly (1.1 times) longer than high, scabrous-rugose. Scutellum densely rugo-rugulose (cf. Fig. 412). Transverse carina of propodeum less strong, with four small denticules (Fig. 293). Hind femur 3.5 times as long as broad medially (Fig. 294). Hind tibia thickening, distally as broad as femur (cf. Fig. 165). Hind basitarsus as long as tarsomeres 2-3 combined. Pair of spurs of hind tibia subequal (Fig. 295).

Fore wing one-sixth shorter than body ( $2.2 \mathrm{~mm}$ long). Pterostigma wide, 2.2 times as long as wide and issuing $r$ just distally from its middle, $r$ slightly longer than $3-S R$ (6:5), SR1 faintly bent, 1-R1 short: 0.7 times as long as pterostigma (Fig 296).

Carapace in dorsal view globose, 1.6 times as long as broad slightly posteriorly from its middle, anteriorly striated with little anastomoses, posteriorly densely rugulose, apically (i.e. declivous part) polished. Carapace in lateral view 2.9 times as long as high posteriorly, its hind end declivous (Fig. 298). Carapace apico-ventrally somewhat incurved (cf. Fig. 262). Ovipositor sheath short, concealed.

Ground colour of body black. Scape and pedicel yellow. Flagellum dark brown to blackish, flagellomeres 3-4 straw yellow. Palpi dark brownish. Tegula and fore half of carapace yellow. Legs brown to dark brown, with straw yellow to yellow pattern (coxae, trochanters, tibiae). Wings subhyaline, pterostigma brown, veins yellow to brownish, light brown.

Male and host unknown.

Distribution - Costa Rica.

Taxonomic position - The new species, Microchelonus latistigma, is closest to $M$. candidus sp. n. and M. exceptus sp. n., see the couplets of the key to the female Microchelonus species 4 (3) - 8 (9).

The new species is also near to $M$. fulgens $s p$. $n$. considering their common features: straw yellow ring of flagellum and temple in dorsal view receded (Figs 102, 290), the distinction between them is as follows: 

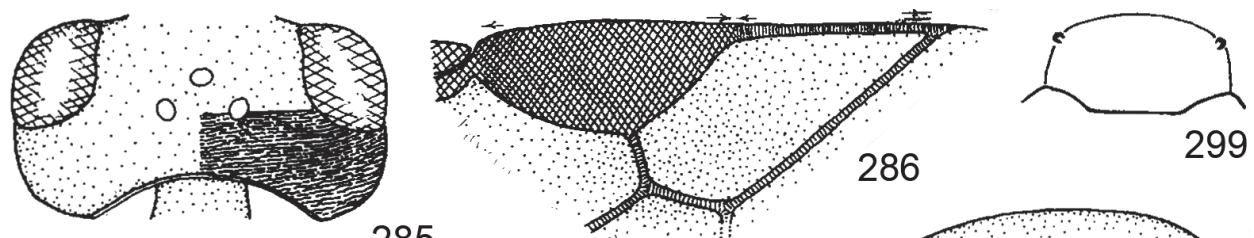

285
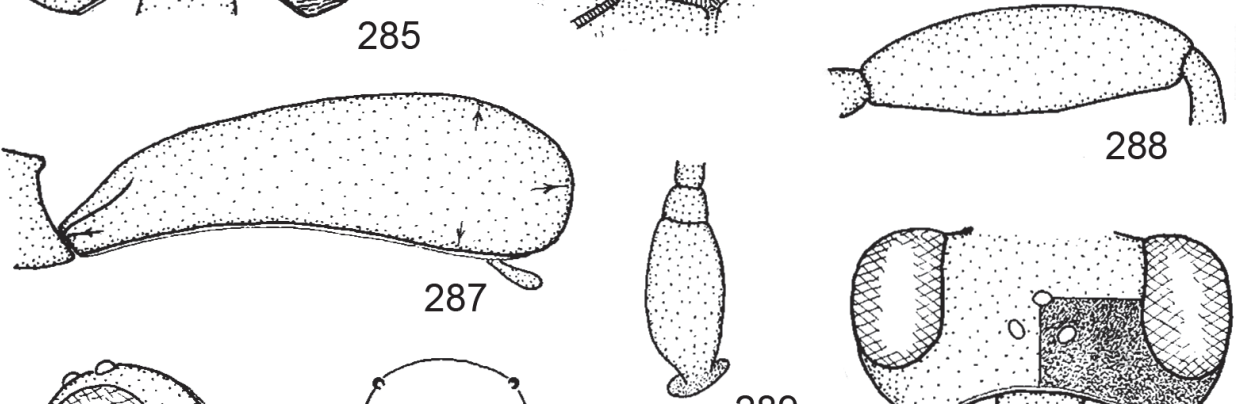

288

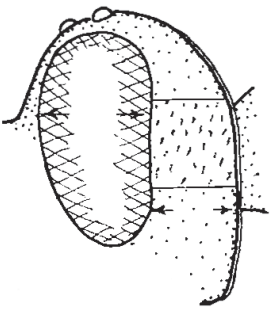

291

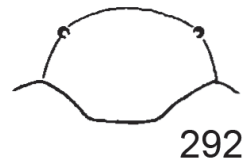

289

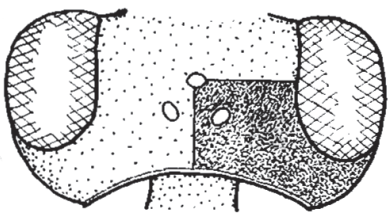

290
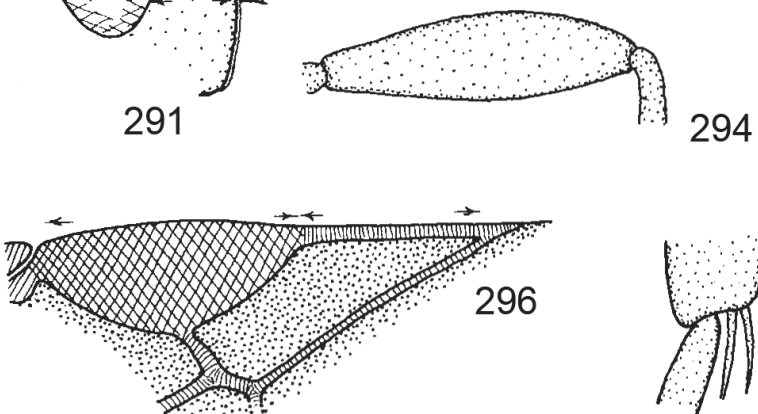

294
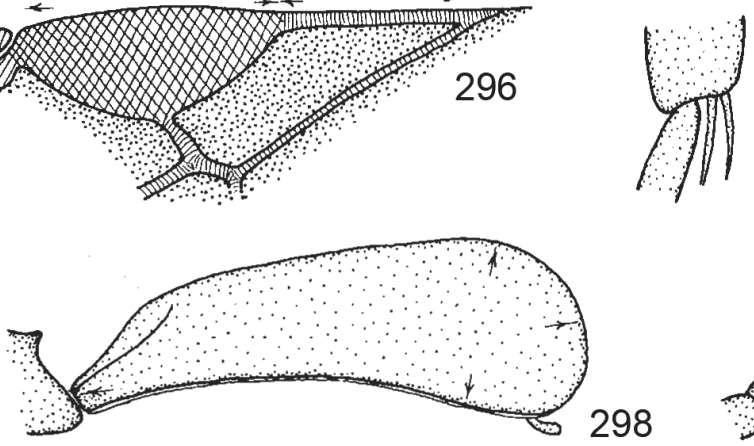

295

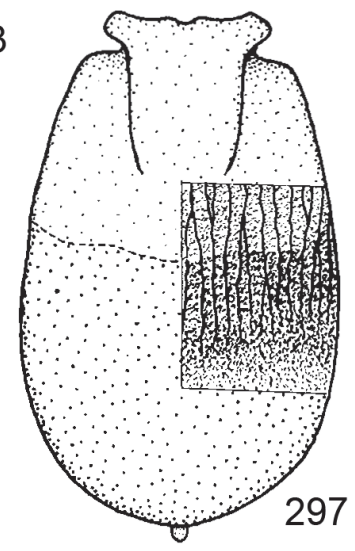

Figs 285-300. 285-288. Microchelonus lavernae (Ashmead, 1889) (†): 285 = head in dorsal view with indication of its sculpture, 286 = distal part of right fore wing, 287 = carapace in lateral view, 288 = hind femur. 289-298. Microchelonus latistigma sp. n. (†, holotype): $289=$ scape and pedicel in lateral view, $290=$ head in dorsal view with indication of its sculpture, 291 = head in lateral view with indication of its sculpture, 292 = clypeus, 293 = propodeal carina in dorsal view, 294 = hind femur, 295 = pair of spurs of hind tibia, 296 = distal part of right fore wing, $297=$ carapace in dorsal view with indication of its sculpture, $298=$ carapace in lateral view. 299-300. Microchelonus levigena sp. $n .(+$, holotype): $299=$ clypeus, $300=$ hind femur. 
1 (2) Fore wing: pterostigma wide, 2.2 times as long as wide, $1-R 10.7$ times as long as pterostigma (Fig. 296). Carapace in dorsal view globose, 1.6 times as long as broad just posteriorly (Fig. 297). Carapace in lateral view 2.9 times as long as high posteriorly, its hind end slightly less declivous (Fig. 298 see arrows). Hind femur 3.5 times as long as broad (Fig. 294). Ventral part of clypeus somewhat more produced (Fig. 292). Tegula yellow. + : $2.6 \mathrm{~mm}$. - Costa Rica

M. latistigma sp. $n$.

1 (1) Fore wing: pterostigma less wide, 2.3 times as long as wide, 1-R1 0.6 times as long as pterostigma (Fig. 231). Carapace in dorsal view less globose, twice as long as broad posteriorly (Fig. 232). Carapace in lateral view 3.4 times as long as high posteriorly, its hind end slightly more declivous (Fig. 233 see arrows). Hind femur 4.1 times as long as broad (Fig. 229). Ventral part of clypeus somewhat less produced (Fig. 228). Tegula black. o: $3.1 \mathrm{~mm}$. - Costa Rica

M. fulgens sp. n.

Furthermore, the new species is related to M. tuberulus sp. $n$. viewing their common features: wide pterostigma (Figs 296, 465), receded temple (Figs 290, 460), penultimate flagellomere 1.2 times longer than broad (Fig. 459), legs yellow; the two species are distinguished at M. tuberulus. In the key to the female Microchelonus species M. latistigma runs to M. candidus sp. n., see couplets $4(3)-6(5)$.

\section{Microchelonus lavernae (Ashmead, 1889)}

(Figs 285-288)

Chelonus lavernae Ashmead, 1889: 635 ô, type locality: USA, Kirkwood, Missouri, male holotype ("Type") in USNM; not examined.

Chelonus (Microchelonus) lavernae Ashmead: МсСомв 1968: 13 (in key) and 82 (૧人ે, comb. n., redescription, distribution).

Microchelonus lavernae (Ashmead): Shenefelt 1973: 890 (comb. n., literature up to 1968). PAPP 2010: 169 (in key).

Material examined - 1 + (det. W.R.M. Mason, in HNHM by exchange): Canada, Ontario, St. Davids, ex Mompha cloisella Clement, 23 VI 1933, G. G. Dustan.

Additional features to the redescription (McComb 1.c.) - 9 . Body 3.2-3.3 mm long. Antenna short, about as long as head and mesosoma combined. Penultimate flagellomere variably 1.2 times longer than broad to subcubic (10:9). Head in dorsal view transverse, 1.8-1.9 times as broad as long, eye 1.2-1.3 times as long as temple, temple rounded, vertex and occiput distinctly substriolated (Fig. 285). Scutellum rugose (cf. Fig. 372). Hind femur 2.9 times as long as broad medially (Fig. 288). Fore wing: pterostigma wide, 2.1-2.3 times as long wide, issuing $r$ distally from its middle, 1-R1 0.75 times as long as pterostigma, 3-SR one-third longer than $r$ (Fig. 286 see arrows). Carapace in dorsal view belly, 1.7-1.8 times 
as long as broad posteriorly, antero-posteriorly undulate striate to rugose (cf. Fig. 350). Carapace in lateral view 2.9-3 times as long as high posteriorly, apically declivous (Fig. 287 see arrows). Tegula blackish, parategula brown. Legs dark coloured, tibiae yellow to ochre.

Male not seen. - Host: Mompha cloisella Clement (Lep. Momphidae).

Distribution - Canada, USA.

Taxonomic position - Microchelonus lavernae is close to M. levigena sp. n., their distinction see at this (subsequent) species. In the key to the Nearctic species of Microchelonus it runs to M. burksi (McComb), see couplet 90 (МсСомв 1968: 13).

\section{Microchelonus levigena sp. $\mathrm{n}$.}

(Figs 299-314)

Material examined ( 3 우) - Female holotype: Peru, Junin, Satipo, taken with Malaise trap, 21-24 January 1984, leg. L. Huggert. - One female paratype: Honduras Atlantida, Lancetilla Tela, $15^{\circ} 43^{\prime} \mathrm{N} / 87^{\circ} 27^{\prime} \mathrm{W}$, taken with Malaise trap in lowland rain forest, 30 April 1995, leg. R. Cave. - One female paratye: Costa Rica, Alajuela, 20 km S from Upala, 20-26 March 1991, leg. F. D. Parker.

Types condition - Holotype is in good condition: (1) micropinned ventrally by mesosoma, (2) ultimate (14th) flagellomere of left antenna missing. Two female paratypes are also in good condition: (1) glued on card point by its right mesopleuron (from Honduras), (2) glued by its right mesosomal side direct to the pin and (3) right flagellomeres 13-14 missing (from Costa Rica).

Type depositories - Holotype and one paratype (from Honduras) are deposited in ZMLU, one paratype (from Costa Rica) in HNHM, Hym. Typ. No. 12240.

Etymology - The species name "levigena" refers to the shiny gena of the head.

Description of the female holotype - Body $3 \mathrm{~mm}$ long. Antenna short, about two-thirds length of body and with 16 antennomeres. Scape thrice and penultimate flagellomere 1.8 times as long as broad (Fig. 301). - Head in dorsal view transverse, clearly twice (60:29) as broad as long, eye 1.6 times longer than temple, temple receded (Fig. 302). OOL one-third longer than POL, ocelli small. Eye in lateral view almost 1.7 times as high as wide, gena beyond eye weakly broadening ventrally and as wide as eye, hairpunctate, interpunctures as large as to larger than punctures, polished (Fig. 303). Clypeus twice as wide below as high medially, its lower margin truncate (Fig. 299). Face 1.5 times as wide as high, transversely finely striate, clypeus finely punctate (similar to that of gena), shiny. Malar space 1.5 times longer than basal width of mandible. Vertex and occiput rather transversely substriolate.

Mesosoma in lateral view stout, 1.2 times as long as high, rugose to scabrous. Notaulix distinct. Scutellum rugose (cf. Fig. 82). Four denticules of propodeal carina small (cf. Fig. 293). Hind femur 2.6 times as long as broad medially (Fig. 300). Hind basitarsus as long as tarsomeres 2-3 and one-third of 4th tarsomere combined.

Fore wing one-third shorter than body, i.e. $2.1 \mathrm{~mm}$ long. Pterostigma wide, twice as long as wide, issuing $r$ from its middle, $r$ short: 3-SR 2.6 times longer than $r$, SR1 indistinctly S-form (or almost straight), 1-R1 0.75 times as long as pterostigma (Fig. 304).

Carapace in dorsal view 2.1 times as long as broad, moderately broadening posteriorly, longitudinally striated, interstriations rugulose (Fig. 305), hind third of carapace rugulose to uneven, dull. Hind end of carapace rounded. Carapace in lateral view 2.6 times as 

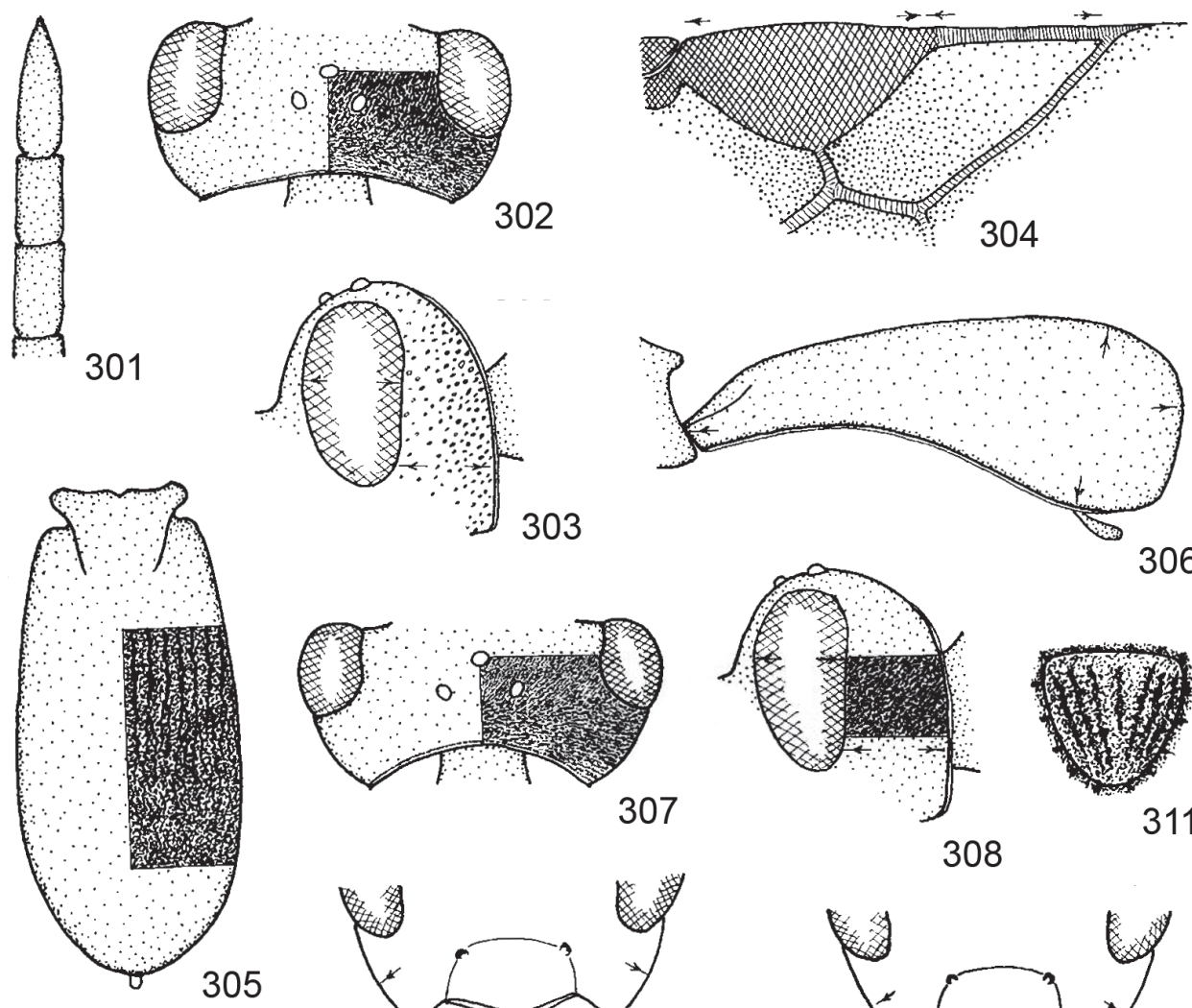

306

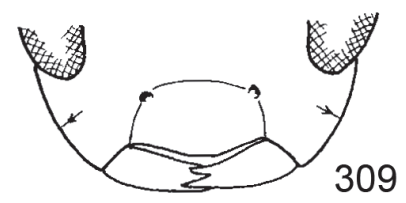

308
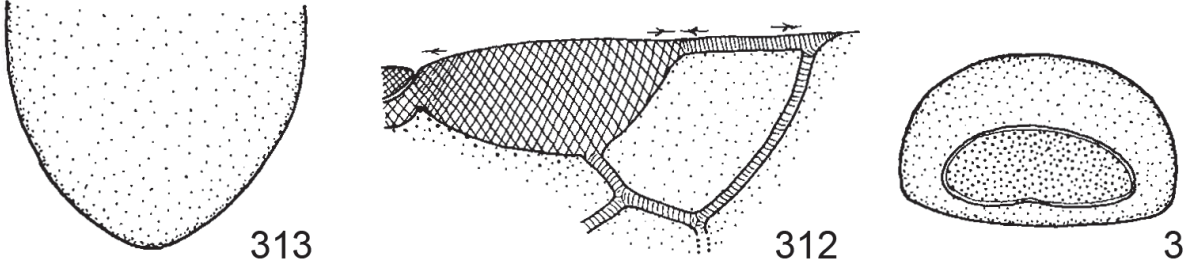

314

Figs 301-314. 301-306. Microchelonus levigena sp. n. (ㅇ, holotype): 301 = ultimate three flagellomeres, $302=$ head in dorsal view with indication of its sculpture, $303=$ head in lateral view with indication of its sculpture, $304=$ distal part of right fore wing, $305=$ carapace in dorsal view with indication of its sculpture, $306=$ carapace in lateral view. 307-314. Micro-

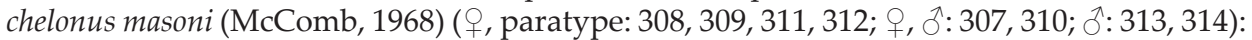
$307=$ head in dorsal view with indication of its sculpture, $308=$ head in lateral view with indication of its sculpture, 309-310 = ventral half of head in frontal view, $311=$ scutellum, $312=$ distal part of right fore wing, $313=$ posterior third of carapace in dorsal view, $314=$ apical foramen of carapace. 
long as high posteriorly, apically truncate (Fig. 306 see arrows). Carapace apico-ventrally incurved, incurved part as long as hind basitarsus (cf. Fig. 407). Ovipositor sheath short, concealed.

Body black. Antenna blackish, scape apically and pedicel faintly rusty. Palpi pale. Tegula blackish, parategula brown. Fore leg yellow, coxa and femur brownish. Middle leg: coxa black, trochanters and tarsus yellow, femur dark brown, tibia brownish yellowish. Hind leg: black (coxa) to blackish (femur + tibia), trochanters and tarsus yellow. Wings subhyaline, pterostigma dark brown, veins yellow to light brown, brown.

Description of the two female paratypes - Similar to the female holotype. Body $4 \mathrm{~mm}$ long. Penultimate flagellomere cubic (from Honduas). Fore wing: pterostigma 2.1 times as long as wide.

Male and host unknown.

Distribution - Costa Rica, Honduras, Peru.

Taxonomic position - The new species, Micochelonus levigena, is close to $M$. cavei Papp viewing their more or less sculptured scutellum, fairly thick hind femur and short corporal length; the two species differ from each other by the following traits:

1 (2) Carapace in dorsal view globose, 1.5 times as long as broad, areolaterugose (Fig. 131). Temple in dorsal view receded (Fig. 129). Gena substriolate (cf. Fig. 81). Fore wing: pterostigma 2.2-2.3 times as long as wide (Fig. 130). Carapace in lateral view 2.9 times as long as high posteriorly, apically rounded (Fig. 132 see arrows). Legs yellow with weak brownish pattern. Antenna proximally ochre yellow, distally darkening brown. $P$ : 2.2-2.8 mm. - Costa Rica

M. cavei Papp, 2010

2 (1) Carapace in dorsal view not globose, 2.1 times as long as broad, longitudinally striated (Fig. 305). Temple in dorsal view less receded (Fig. 302). Gena finely punctate, interpunctates polished (Fig. 303). Fore wing: pterostigma twice as long as wide (Fig. 304). Carapace in lateral view 2.6 times as long as high posteriorly, apically truncate (Fig. 306). Legs brown to black(ish) with less light coloured pattern. Antenna blackish. $+: 3.3$ mm. - Costa Rica, Honduras, Peru

M. levigena sp. $n$.

The new species runs to M. lavernae (Ashmead) with the help of McComb's key to the Nearctic species of Microchelonus; the two species are similar to each other, their distinction restricts to a few features:

1 (2) Temple in dorsal view somewhat less receded, eye 1.6 times longer than temple (Fig. 302). Fore wing: pterostigma wide, twice as long as wide, issuing $r$ from its middle (Fig. 304). Carapace in lateral view 2.6 times as long as high posteriorly, apically truncate (Fig. 306). Hind femur thick, 2.6 times as long as broad (Fig. 300). Notaulix distinct. Palpi pale, legs less dark coloured., : $3.3 \mathrm{~mm}$

M. levigena sp. n. 
2 (1) Temple in dorsal view rounded, eye 1.2-1.3 times longer than temple (Fig. 285). Fore wing: pterostigma less wide, 2.2-2.3 times as long as wide, issuing $r$ distally from its middle (Fig. 286). Carapace in lateral view 3.2 times as long as high posteriorly, apically rounded (Fig. 287). Hind femur less thick, 2.9 times as long as broad (Fig. 288). Notaulix weakly distinct to indistinct. Palpi brownish, legs more dark coloured. $q$ : $3.2-3.8 \mathrm{~mm}$ M. lavernae (Ashmead, 1889)

In the key to the female Microchelonus species M. levigena runs to M. masoni (McComb), see couplets 117 (118) - 119 (120).

\section{Microchelonus masoni (McComb, 1968) (Figs 307-316)}

Chelonus (Microchelonus) masoni McComb, 1968: 11 (in key) and 86 (description) $q \hat{o}$, type locality: USA, California, White Water, "Type" (=holotype; $3 q+4 \hat{\jmath}$ paratypes) in Canadian National Collection, Ottawa; not examined.

Microchelonus masoni (McComb): SHENefelt 1973: 891 (comb. n., literature up to 1968).

Material examined ( $3+2 \widehat{\partial}$ in HNHM by exchange) $-1 q$ paratype (Hym. Typ. No. 11732): USA, California, White Water, 17 March 1955, leg. et det W. R. M. Mason. $1+1$ J: Costa Rica, Guanacastle, S. Cañas, taken with Malaise trap, 7-10 March (1 ㅇ) and 18-22

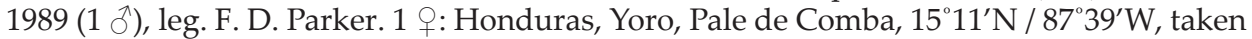
with Malaise trap, 5 August 1995, leg. R. Cave. 1 ' 1 : Honduras, Roatan Island, taken with Malaise trap, 27 February 1979, leg. G. E. Bohart.

Additional features to the original description (McComb l.c.)

Female paratype - Body $2.8 \mathrm{~mm}$ long. Penultimate flagellomere 1.6 times as long as broad. Head in dorsal view transverse, 2.1 times as broad as long, eye and temple almost equal in length, temple receded (Fig. 307). Eye in lateral view twice as high as wide, gena beyond eye slightly broadening ventrally and as wide as eye (Fig. 308 see arrows). Cheek in frontal view rounded, i.e. not converging (Fig. 309 see arrows). Scutellum striate-rugose (Fig. 311). Fore wing: pterostigma 2.1 times as long as wide and issuing $r$ distally from its middle, 3-SR 1.5 times longer than $r$, SR1 bent, 1-R1 half as long as pterostigma (Fig. 312). Carapace in dorsal view belly, 1.6 times as long as broad posteriorly, apically rounded, antero-posteriorly densely striate to rugose (Fig. 316).

+. Similar to the female paratype. Cheek in frontal view slightly less rounded i.e slightly more converging (Fig. 310 see arrows). Scutellum smooth to uneven-subrugulose (cf. Fig. 143). Fore wing: 1-R1 0.6 times as long as pterostigma (Fig. 315).

J. Similar to the female. Cheek in frontal view as in Fig. 310. Scutellum unevensubrugulose (cf. Fig. 143) to striate-rugose (Fig. 311). Fore wing: 1-R1 0.6 times as long as pterostigma (Fig. 315). Carapace apico-dorsally more rounded (or weakly pointed, Fig. 313). Apical foramen of carapace wide, 2.5-2.7 times as wide as high (Fig. 314).

Distribution $-{ }^{*}$ Costa Rica, ${ }^{*}$ Honduras, USA: California. 
Taxonomic position - In the key to the Nearctic species of Microchelonus it runs to M. elasmopalpi (McComb), see couplet 68 (МсСомв 1968: 11). In the key to the female species of Microchelonus it is close to M. levigena sp. n., see couplets 117 (118) -119 (120).

\section{Microchelonus mccombi sp. n.}

(Figs 497-507)

Material examined - Female holotype: Honduras, Olancho, Catacamas, $15^{\circ} 50^{\prime} \mathrm{N} / 85^{\circ}$ $51^{\prime} W$, taken with Malaise trap in lowland galary forest, 1 February 1996, leg. R. Cave. Holotype is in good condition: (1) glued on card point by its right mesopleuron, (2) left antenna missing, (3) middle pair of legs somewhat less visible owing to the mounting. Holotype is deposited in ZMLU.

Etymology - The new species is dedicated to Dr Charles Wight McComb (1930-2015), first reviser of the Nearctic species of Chelonus (Microchelonus) and describer of ninety new species in this genus.

Description of the holotype - Body $3 \mathrm{~mm}$ long. Antenna somewhat shorter than body (2.6 $\mathrm{mm}$ long) and with 16 antennomeres. First flagellomere long, 3.5 times as long as broad, further flagellomeres gradually shortening so that penultimate flagellomere 1.5 times as long as broad (Fig. 497). - Head in dorsal view transverse (Fig. 498), twice as broad as long, eye also twice longer than temple, temple receded. Ocelli small and elliptic, OOL somewhat longer than POL (10:8). Eye in lateral view 2.1 times as high as wide, gena beyond eye evenly wide and eye 1.3 times wider than gena, gena with thickening substriolation, subshiny (Fig. 499). Clypeus 1.7 times as wide below as high medially, its lower margin truncate (Fig. 501), rugulose (somewhat weaker than that of face). Face 1.9 times as wide as high, rugose (Fig. 500). Malar space as long as basal width of mandible. Vertex and occiput substriolate (Fig. 499).

Mesosoma in lateral view stout, 1.2 times as long as high, rugose to scabrous-areolate. Notaulix indistinct. Scutellum rugose (cf. Fig. 82). Transverse carina of propodeum distinct, its four denticules small (Fig. 502). Hind femur 2.9 times as long as broad medially (Fig. 503). Hind basitarsus as long as tarsomeres $2-4$ combined.

Fore wing about one-quarter shorter than body ( $2.3 \mathrm{~mm}$ long). Pterostigma wide, twice as long as wide, issuing $r$ from its middle, $r 1.4$ times as long as 3-SR, SR1 faintly Sform (or almost straight), 1-R1 long, 0.85 times as long as pterostigma (Fig. 504).

Carapace in dorsal view belly, 1.6 times as long as broad somewhat posteriorly, anteriorly somewhat less parallel striated, posteriorly densely rugo-rugulose, dull, apically rounded (Fig. 505). Carapace in lateral view 2.6 times as long as high posteriorly, apically declivous (Fig. 506). Carapace apico-ventrally slightly incurved, incurved part as long as third tarsomere of hind leg (Fig. 507).

Body black, anterior half of carapace pale yellow. Scape, pedicel and flagellomeres 1-3 yellow, flagellomeres 4-5 darkening and rest of flagellum blackish. Palpi pale yellow. Tegula brown, parategula yellow. Coxae 1-2 and trochanters 1-3 pale yellow, coxa 3 black; femori + tibiae + tarsi 1-2 yellow with brownish, brown pattern, hind femur black, tibia + tarsus brown, tibia basally pale yellow. Wings subhyaline, around pterostigma brownish fumous. Pterostigma blackish brown, veins yellow to brownish.

Male and host unknown. 


\section{Distribution - Honduras.}

Taxonomic position - The new species, Microchelonus mccombi, is closest to M. blackburni (Cameron) considering their common features: temple in dorsal view receded (Figs 55,498), carapace basally yellow, anteriorly striated and posteriorly densely rugo-rugulose (Figs 62, 505), 1-R1 of fore wing 0.75 times as long as pterostigma (Figs 58,504), scape and flagellum proximally more or less yellow; the two species are distinguished by the following traits:

1 (2) Scutellum smooth and shiny with a few fine punctures (Fig. 57). Fore wing: pterostigma less wide, 2.3-2.6 times as long as wide and issuing $\mathrm{r}$ distally from its middle (Fig. 58). Temple in dorsal view less receded (Fig. 55). Carapace in dorsal view broadest clearly posteriorly (Fig. 59 see arrows). Fore and middle coxae blackish. Parategula of fore wing brown. q: (2.3-)3-3.4 mm. - Widely distributed in the New and Old Worlds

M. blackburni (Cameron, 1886)

2 (1) Scutellum rugose (cf. Fig. 82). Fore wing: ptetrostigma wide, 2.2 times as long as wide and issuing $r$ from its middle (Fig. 504). Temple in dorsal view more receded (Fig. 498). Carapace in dorsal view broadest medially (Fig. 505). Fore and middle coxae pale yellow. Parategula of fore wing yellow.. : $3 \mathrm{~mm}$. - Honduras

M. mccombi sp. n.

The new species is also near to M. levigena sp. n. considering their finely sculptured gena (Figs 303, 499), temple in dorsal view more or less receded Figs 302,498 ) and scutellum rugose; the two species differ from each other by the following features:

1 (2) Carapace in dorsal view elongate, 2.1 times as long as broad posteriorly, its striations strong (Fig. 305). Temple in dorsal view less receded, eye 1.7 times longer than temple (Fig. 302). Hind femur thick, 2.5 times as long as broad (Fig. 300). Gena finely punctate, shiny (Fig. 303). Fore and middle coxae blackish brown; antenna blackish. $+: 3.3 \mathrm{~mm}$. - Peru

\section{M. levigena sp. n.}

2 (1) Carapace in dorsal view belly, 1.6 times as long as broad somewhat posteriorly, its striations less strong (Fig. 505). Temple in dorsal view more receded, eye twice longer than temple (Fig. 498). Hind femur less thick, 2.9 times as long as broad (Fig. 503). Gena thickening substriolate, subshiny (Fig. 499). Fore and middle coxae pale yellow, scape and flagellum proximally yellow. 0 : $3 \mathrm{~mm}$. - Honduras

M. mccombi sp. n.

In the key to the female Microchelonus species M. mccombi runs to M. cavei Papp and M. paululus (McComb), see couplets 126 (127) - 129 (128). 


\section{Microchelonus minimus (Cresson, 1873)}

(Figs 317-321)

Chelonus minimus Cresson, 1873 (1872): 181 q, type locality: USA, Texas, “Type” (=female lectotype designated by McComb l.c.) in Academy of Natural Sciences, Philadelphia; not examined.

Chelonus (Microchelonus) minimus Cresson: МсСомв 1968: 12 (in key) and 88 (redescription, distribution).

Microchelonus minimus (Cresson): SHENEFelt 1973: 892 (comb. n., literature up to 1968).

Taxonomic remark - In the U. S. National Museum of Natural History (Washington) there is a female specimen with four original labels: (first label) "Typus" (handwritten, less decipharable); (second label, printed) "Texas / Belfrage"; (third red label) "Type / No." (printed) "1431" (handwritten); fourth label is with the name Chelonus minimus Cresson det. Viereck ("Vier."); fifth label is with the actual name Microchelonus minimus (Cresson) (det. J. Papp 2010) (specimen examined).

Spontanous raises the question: Does this specimen belong to the typeseries? Worthy to note that the specimen is in a very poor condition: carapace entirely and legs partly missing, both flagelli with 11 flagellomeres (or antennae with 13 antennomeres). The taxonomic enigma is solved by Cresson's indication (1873: 181) that his description was based on "Two specimens" both females. Consequently the female lectotype belongs to the type-series and the second female is the female paralectotype specimen. I designated it accordingly. Its type locality is Texas (USA), coll. Belfrage, additionally I labelled it so.

Additional features to the redescription (McComb 1.c.) - . . Body $2.7 \mathrm{~mm}$ long. First flagellomere 3.5 times and penultimate flagellomere 1.6 times as long as broad. - Head in dorsal view less transverse, 1.8 times as broad as long, eye slightly longer than temple (17:15), temple rounded (Fig. 317). Mesosoma in lateral view 1.4 times as high as wide. Scutellum smooth and shiny. Transverse carina of propodeum distinct, its four denticules weak (cf. Fig. 293). Hind femur thick, 2.5 times as long as broad (cf. Fig. 300). Fore wing one-sixth shorter than body. Pterostigma 2.5 times as long as wide, issuing $r$ distally from its middle, $1-R 1$ short: 0.6 times as long as pterostigma, $r$ shorter than $3-S R$ (6:10, Fig. 319). Carapace in dorsal view 1.75 times as long as broad medially, densely rugose. Carapace in lateral view almost evenly high and apically perpendicularly truncate (Fig. 320). Antenna and body black, legs dark brown. Wings faintly brownish fumous.

${ }^{7}$. Similar to the female. Body $2.6 \mathrm{~mm}$ long. Scutellum smooth, shiny, apically subrugulose, dull, (Fig. 318). Hind femur 3.3 times as long broad. Apical foramen of carapace oval, twice wider than high (Fig. 321).

Host unknown.

Distribution - USA: Texas.

Taxonomic position - In the key to the Nearctic species of Microchelonus the species M. minimus runs to M. alius (McComb, 1968), see couplet 79. 

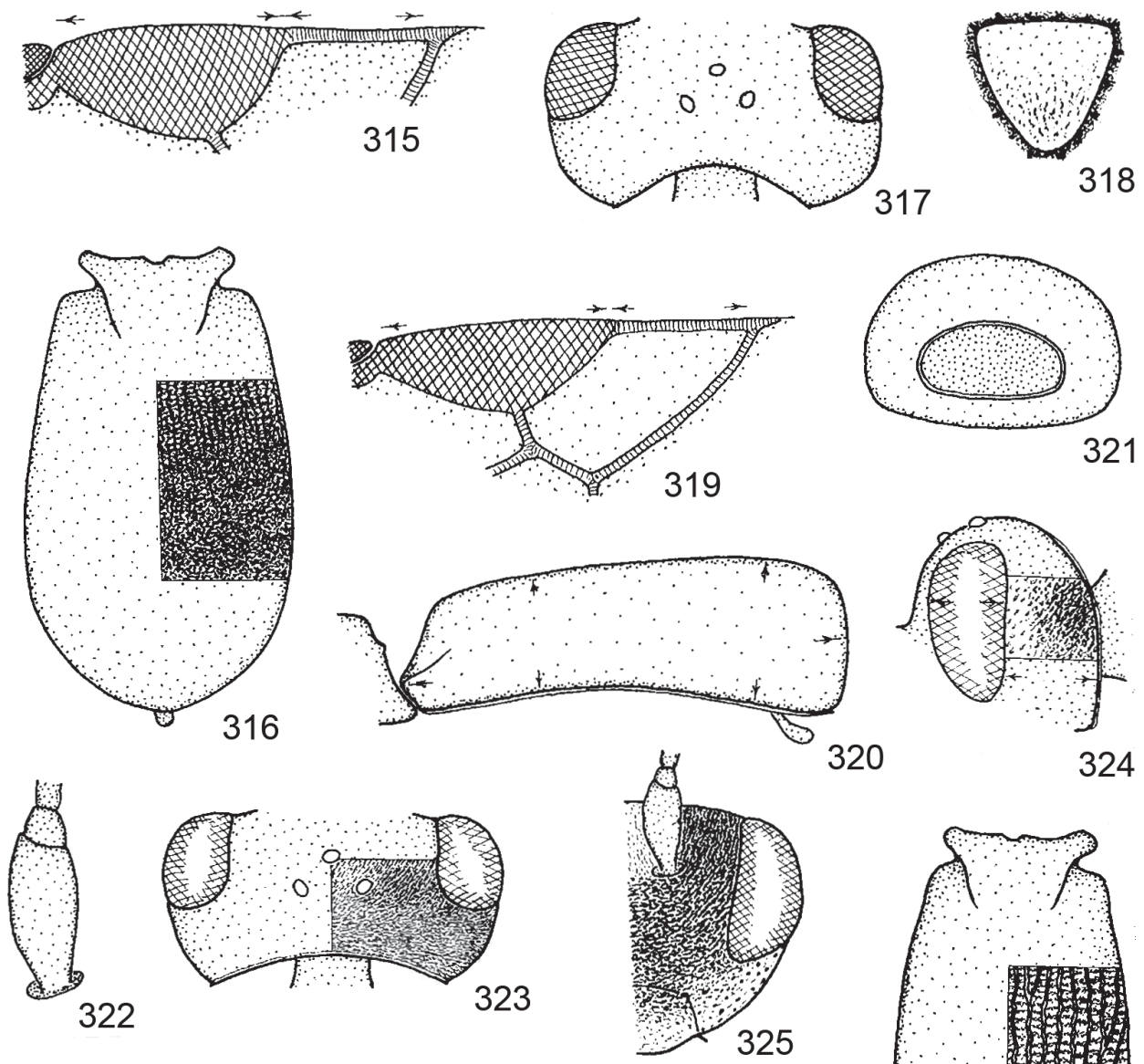

324
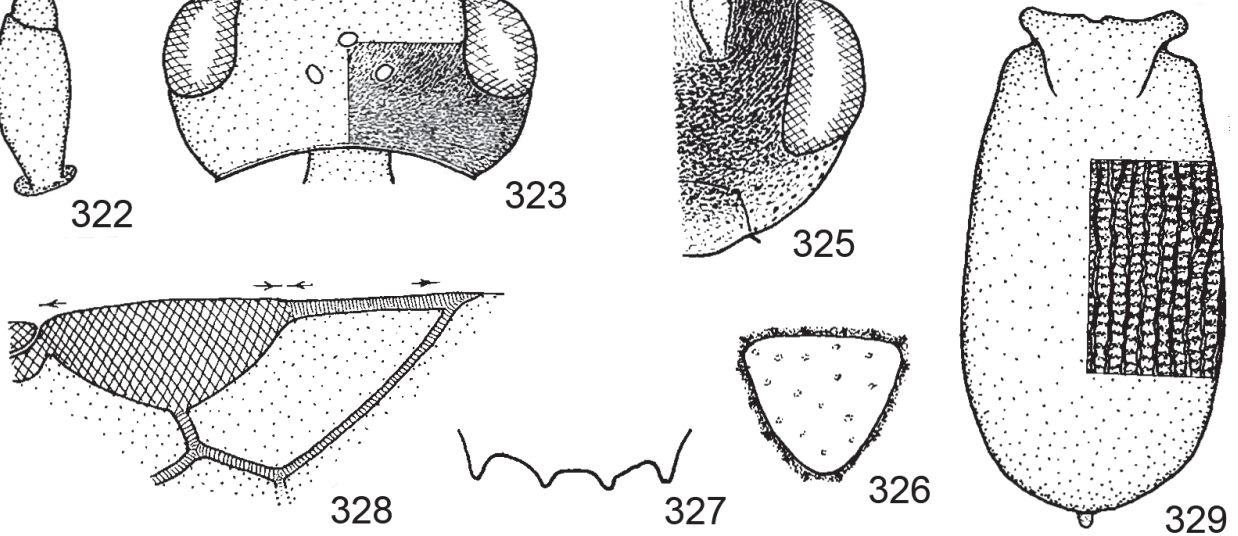

Figs 315-329. 315-316. Microchelonus masoni (McComb, 1968): 315 = pterostigma and 1-R1 of right fore wing $(\phi, \lambda), 316=$ carapace in dorsal view with indication of its sculpture $(q$, paratype). 317-321. Microchelonus minimus (Cresson, 1872) (ㅇ: 317, 319, 320; $0^{\top}: 318,321$ ): $317=$ head in dorsal view, $318=$ scutellum, $319=$ distal part of right fore wing, $320=$ carapace in lateral view, 321 = apical foramen of carapace. 322-329. Microchelonus ormos sp. n. ( + , holotype): 322 = scape and pedicel in lateral view, 323 = head in dorsal view with indication of its sculpture, $324=$ head in lateral view with indication of its sculptue, $325=$ right half of head in frontal view, $326=$ scutellum, $327=$ propodeal carina in dorsal view, $328=$ distal part of right fore wing, $329=$ carapace in dorsal view with indication of its sculpture. 
Microchelonus ormos sp. n.

(Figs 322-331)

Material examined - Female holotype: Costa Rica, San José, Escazu, 14-30 January 1988, leg. F. D. Parker. - Holotype is in good condition: (1) glued direct to the pin by its right mesosomal side, (2) left antenna deficient: ultimate six flagellomeres missing (i.e. present ten antennomeres), (3) right middle leg not visible: covered by glue. Holotype is deposited in HNHM, Hym. Typ. No. 12241.

Etymology - The new species rceived the latinized phantasy name "ormos".

Description of the female holotype - Body $2.7 \mathrm{~mm}$ long. Antenna one-third shorter than body (1.8 mm long). Scape in lateral view somewhat thick, 2.3 times as long as broad apically (Fig. 322). First flagellomere four times and penultimate flagellomere 1.5 times as long as broad. - Head in dorsal view transverse, twice as broad as long, eye 1.3 times longer than temple, temple faintly rounded (Fig. 323). OOL somewhat than POL, ocelli almost round. Eye in lateral view 2.1 times as high as wide, gena beyond eye moderately broadening ventrally and somewhat wider than eye (17:13), dispersely hairpunctate to subrugulose (Fig. 324). Clypeus almost 1.9 times as wide below as high medially, its lower margin widely truncate, densely subpunctate, dull. Malar space 1.8 times as long as basal width of mandible. Face 1.5 times as wide as high, rugulose (Fig. 325). Frons, vertex and occiput substriolate, subshiny to shiny (Fig. 323).

Mesosoma in lateral view 1.4 times as long as high, scabrous. Notaulix distinct anteriorly. Scutellum smooth, shiny, dispersely punctate (Fig. 326). Four denticules of propodeal carina small (Fig. 327). Hind femur 2.7 times as long as broad medially (cf. Fig. 300). Hind basitarsus as long as tarsomeres $2-3$ and half of tarsomere 4 combined.

Fore wing about one-fifth shorter than body ( $2.2 \mathrm{~mm}$ long). Pterstigma wide, 2.2 times as long as wide, issuing $r$ from its middle, 3-SR almost twice as long as $r$, SR1 very faintly bent, 1-R1 short: 0.6 times as long as pterostigma (Fig. 328).

Carapace in dorsal view 1.9 times as long as broad posteriorly, longitudinally striated with a few anastomoses, interstriations subcrenulated, hind fourth of carapace rather longitudinally rugose. Apical end of carapace in dorsal view rounded (Fig. 329). Carapace in lateral view thrice longer than high posteriorly, its apical end truncate (Fig. 330 see arrows). Carapace apico-ventrally slightly incurved (Fig. 331 see arrow). Ovipositor sheath short, concealed.

Ground colour of body black. Scape and pedicel testaceous, flagellum blackish. Palpi pale yellow. Tegula and parategula blackish to brown. Fore leg yellow, coxa with blackish pattern, femur brown. Middle leg yellow, coxa-trochanters-femur with brown(ish) tint. Hind leg black to blackish, basal half of tibia yellow, tarsus yellow with brownish suffusion. Wings hyaline, veins yellow to light brown.

Male and host unknown.

Distribution - Costa Rica.

Taxonomic position - The new species, Microchelonus ormos, is closest to $M$. kellieae (Marsh) considering their wide pterostigma (Figs 280, 328) and rounded temple in dorsal view (Figs 276, 323); the two species differ from each other by the features keyed: 
1 (2) Fore wing: pterostigma 2.2 times as long as wide, issuing $r$ from its middle, $r$ half as long as 3-SR (Fig. 328). Cheek in frontal view rounded as usually (cf. Fig. 272 see arrows). Carapace in dorsal view striated with few anastomoses, interstriations (sub)crenulated (Fig. 329). Palpi pale yellow. ㅇ: $2.7 \mathrm{~mm}$. - Costa Rica

M. ormos sp. $n$.

2 (1) Fore wing: pterostigma 2.3 times as long as wide, issuing $r$ distally from its middle, $r$ slightly shorter than 3-SR (Fig. 280). Cheek in frontal view rather converging (Fig. 278, see arrows). Carapace in dorsal view densely rugose (Fig. 282). Palpi blackish. + : 3-3.2 mm. - Costa Rica, ${ }^{*}$ Honduras M. kellieae (Marsh, 1979)

In the key to the female Microchelonus species the new species runs to $M$. johni (Marsh), see couplets 68 (67) - 70 (69).

\section{Microchelonus parkeri Papp, 2010}

(Figs 332-339)

Microchelonus parkeri Papp, 2010: 175 q ô, type locality: Costa Rica, San José, Escazu, female holotype (and $5++1 \delta$ paratypes taken in three localities Costa Rica) is (are) deposited in USNM (holotype + one female paratype), in DEUU (two female paratypes) and in HNHM (two female and one male paratypes); examined.

Chelonus (Microchelonus) murici Nascimento et Penteado-Dias, 2011: 512 +, type locality: São Paulo, São Carlos, Brazil, campus universidade, female holotype deposited in Departamento de Ecologia e Biologia Evolutiva da Universidade Federal de São Carlos; syn. n.

Taxonomic emendation - In the original description (PAPP 2010) the specific character of $M$. parkeri was omitted: the short, arcuate carinula on frons near to the compound eye (Fig. 6 in Nascimento \& Penteado-Dias 2011: 513; Fig. 335). This unique trait escaped my attention - a mistake of mine. Consequently the describer doubles rightly empasized this feature as specific distinction between M. murici and M. parkeri / M. cacumenus. In the key to female Microchelonus species (in the present paper) this is the first distinctive separation between M. cacumenus versus M. parkeri, see key-couplets 20 (21) - 21 (20).

Emendated features to the original description (Papp 1.c.) - +. Body 3.4-3.8 mm long. Penultimate three flagellomeres cubic, as long as broad (Fig. 336). Head in dorsal view less transverse, 1.7 times as broad as long, eye one-third longer than temple, latter strongly rounded, vertex and occiput rugose (Fig. 335). Clypeus almost twice as wide below as high medially, its lower part less produced, medially weakly concave (Fig. 338 see arrow). Fore wing: pterostigma 2.3-2.4 times as long as wide, issuing $r$ distally from its middle, $r$ short, 1-R1 0.7 times as long as pterostigma (Fig. 337). Carapace in dorsal view 2.2 times (holotype) and 2.4 times ( + paratype) as long as broad (Figs 332, 334). Carapace apico-ventrally incurved (Fig. 339). $-{ }^{2}$. Similar to the female. 

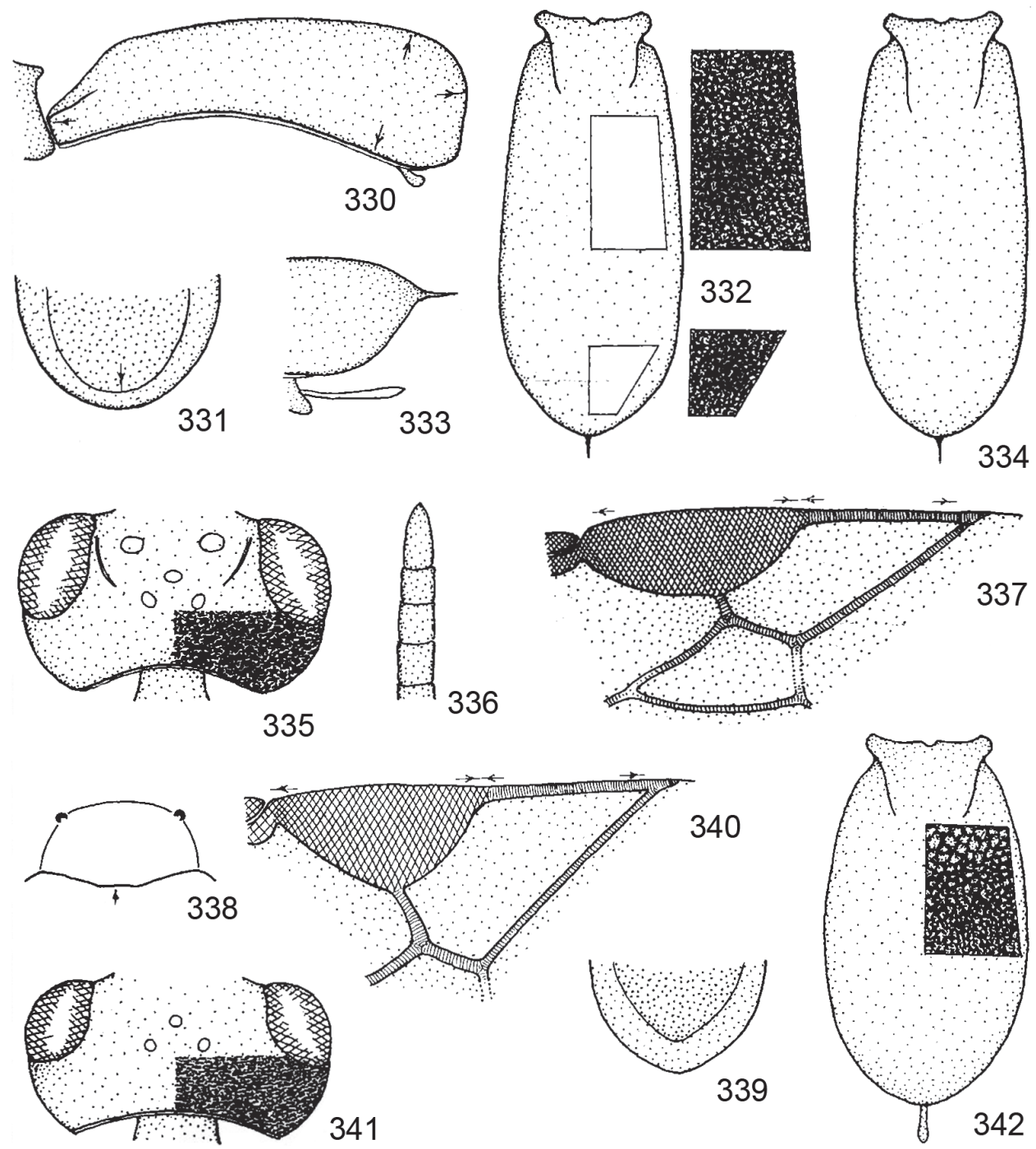

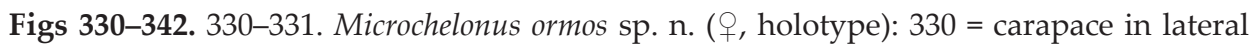
view, 331 = posterior third of carapace in ventral view. 332-339. Microchelonus parkeri Papp, 2010 ( + , holotype: 332, 333, 335, 337, 338; ㅇ, paratype: 334, 336, 339): 332 = carapace in dorsal view with indication of its sculpture, $333=$ posterior third of carapace in lateral view, $334=$ carapace in dorsal view, $335=$ head in dorsal view with indication of its sculpture, 336 = ultimate four flagellomeres, $337=$ distal part of right fore wing, $338=$ clypeus, $339=$ posterior third of carapace in ventral view. 340-342. Microchelonus paululus (McComb, 1968) (우, paratype): $340=$ distal part of right fore wing, $341=$ head in dorsal view with indication of its sculpture, 342 = carapace in dorsal view with indication of its sculpture. 
3. Similar to the female. Body $3.2 \mathrm{~mm}$ long. Antenna as long as head, mesosoma and half carapace combined. Fore wing: pterostigma 2.5 times as long as wide. Apical foramen of carapace missing.

Distribution - Brazil, Costa Rica.

Taxonomic position - In the original description (Papp 1.c.) as well as in the key to female Microchelonus species M. parkeri is closest to M. cacumenus Papp, see couplets 19 (18) - 21 (20). In the key to the male Microchelonus species $M$. parkeri stands alone within the species-group parkeri, see couplet 1 (2) (male is unknown for M. cacumenus).

\section{Microchelonus paululus (McComb, 1968)}

$$
\text { (Figs 340-342) }
$$

Chelonus (Microchelonus) paululus McComb, 1968: 11 (in key) and 92 (description) 90 , type locality: USA, Florida, Pasco county, Moon Lake, female holotype (and $60+3 \hat{\sigma}$ paratypes) in Canadian National Collection, Ottawa, 1 o paratype in HNHM (by exchange); examined the paratype in HNHM.

Microchelonus paululus (McComb): SHenefelt 1973: 895 (comb. n., literature up to 1968). Papp 1999: 187 (in key), 2010: 166 (in key).

Additional features to the original description (McComb l.c.) - + . Body 2.2-2.3 mm long. Penultimate 2-3 flagellomeres cubic: as long as broad (cf. Fig. 336). Head in dorsal view twice as broad as long, eye somewhat longer than temple (16:14), temple rounded, vertex and occiput rugulo-substriolated (Fig. 341). Scutellum (uneven to) rugulose, rugose (cf. Figs 73, 372). Hind femur 3.1 times as long as broad (cf. Fig. 403). Fore wing: pterostigma wide, 2-2.2 times as long as wide and issuing $r$ just distally from its middle, $r$ somewhat longer than 3-SR, 1-R1 0.6-0.7 times as long as pterostigma (Fig. 340). Carapace in dorsal view less belly, 1.7 times as long as broad about medially, apicallly rounded, areolaterugulose (Fig. 342). Legs yellow, hind tibia distally faintly brownish. Tegula brown.

J. Similar to the female. Body $4 \mathrm{~mm}$ long. Antenna with 19 antennomeres. Penultimate flagellomere 1.3 times as long as broad. Fore wing: pterostigma 2.3 times as long as wide. Apical foramen of carapace elliptic, 1.6 times as wide as high. Tegula yellow.

Host unknown.

Distribution - USA: Florida, ${ }^{*}$ Costa Rica.

Taxonomic position - According to the describer M. paululus stands close to M. cushmani (McComb) (McComb l.c.). In the key to the female Microchelonus species M. paululus runs to M. cavei Papp, see couplets 127 (126) - 129 (128).

\section{Microchelonus pectiniphorae (Cushman, 1931)}

(Figs 343-352)

Chelonus (Chelonella) pectiniphorae Cushman, 1931: 11 오, type locality: Korea, Mokpo, "Type" and "several series" (McComb l.c.) in USNM. 
Chelonus (Microchelonus) pectiniphorae (Cushman): МсСомв 1968: 10 (in key) and 94 (redescription, distribution, hosts).

Microchelonus pectiniphorae (Cushman): SHenefelt 1973: 895 (comb. n., hosts, literature up to 1968). PApp 1999: 192 (in key), 2010: 190 (distribution).

Material examined -7 우 and $1 \delta$ from three localities in Costa Rica (details in PAPP 2010).

Additional features to the redescription (McComb l.c.) - + . Body 3-3.6 mm long. Penultimate flagellomere 1.3 times longer than broad to cubic. Head in dorsal view transverse, 2-2.1 times as broad as long, eye 1.5-1.6 times as long as temple, temple receded to rounded, vertex and occiput substriolate (Figs 343-344). Clypeus 1.4 times as wide as high, its lower margin truncate (Fig. 347). Eye in lateral view narrow, 2.5 times as high as wide, gena beyond eye one-third wider than eye, substriolate (Fig. 346). Scutellum smooth and shiny with hairpunctures, at most (and exceptionally) uneven-subrugulose. Hind femur 2.5-2.6 times as long as broad medially (cf. Figs 84, 136). Fore wing: perostigma 2.5-2.6 times as long as wide, issuing $r$ distally from its middle, $r$ and 3-SR equal in length or 3-SR somewhat longer, 1-R1 0.7 ti mes as long as pterostigma (Figs 348-349 see arrows). Carapace in dorsal view belly, 1.7-1.8 times as long as broad posteriorly, apically rounded, undulate striated to rugo-rugulose (Fig. 350). Carapace in lateral view apically rounded as in Fig. 351.

万. Similar to the female. Temple in dorsal view receded (Fig. 345). Carapace in dorsal view 1.9-2 as long as broad. Apical foramen of carapace slit-like, $4-5$ times as wide as high (Fig. 352).

Distribution - Widely distributed in the eastern Palaearctic, Nearctic and Neotropical Regions.

Taxonomic position - According to the redescriber (McComb l.c.) M. pectiniphorae is "very close" to M. blackburni (Cameron). In the key to the female and male Microchelonus species it runs also to M. blackburni (Cameron), see couplets $88(87)-90(89)$ and $42(41)-44(43)$, respectively.

\section{Microchelonus peruensis (Shenefelt, 1973)}

(Figs 353-359)

Chelonus sobrinus Szépligeti, 1904 (nec Haldeman, 1849): 194 §̊, type locality: Peru, Mercapata, male holotype in HNHM, examined.

Chelonus szepligetii Viereck, 1912: 620 (new name for Ch. sobrinus Szépligeti nec Dalla TORRE, 1898): 420.

Chelonus peruensis Shenefelt, 1973 (new name for Ch. sobrinus Szépligeti and Ch. szepligetii (Viereck): 862.

Microchelonus peruensis (Shenefelt): PAPP 1999: 187 (comb. n., redescription, closest ally).

Emendated features to the redescription (Papp 1.c.) - 0 . Body $4.1 \mathrm{~mm}$ long. Head in dorsal view almost twice as broad as long (/031), eye almost 1.4 times as long as temple, latter rounded, vertex and occiput substriolate (Fig. 353). Cheek converging (Fig. 357 see ar- 

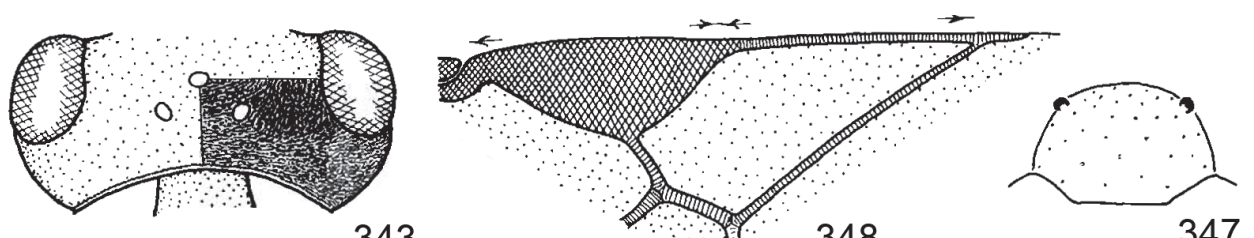

343

348

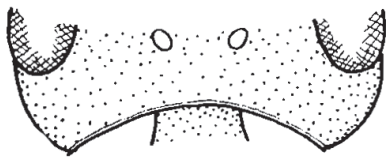

344
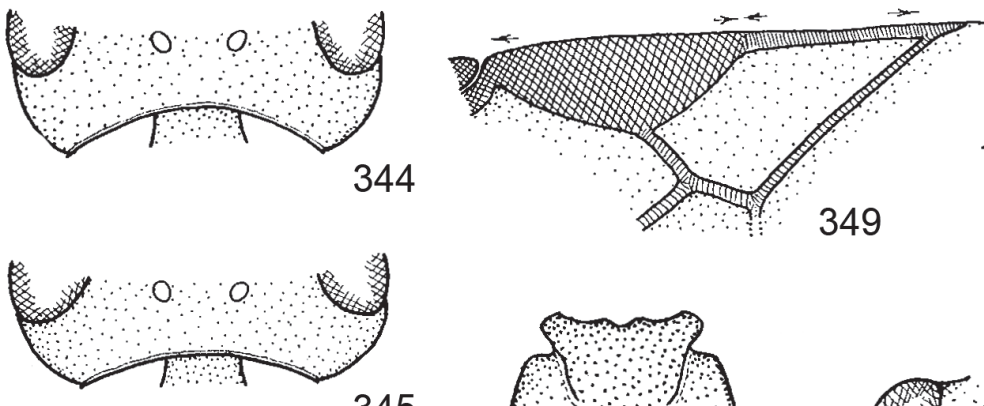

345
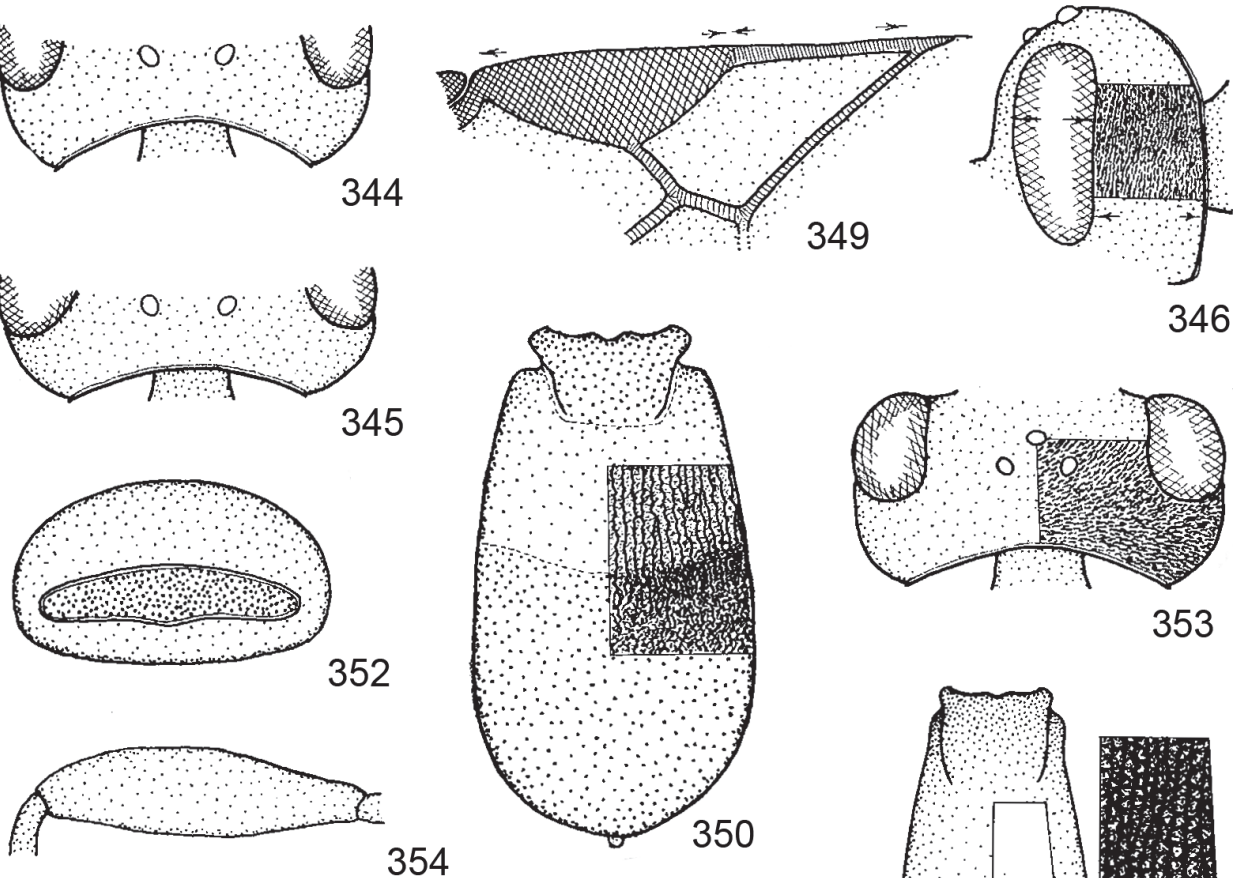

354
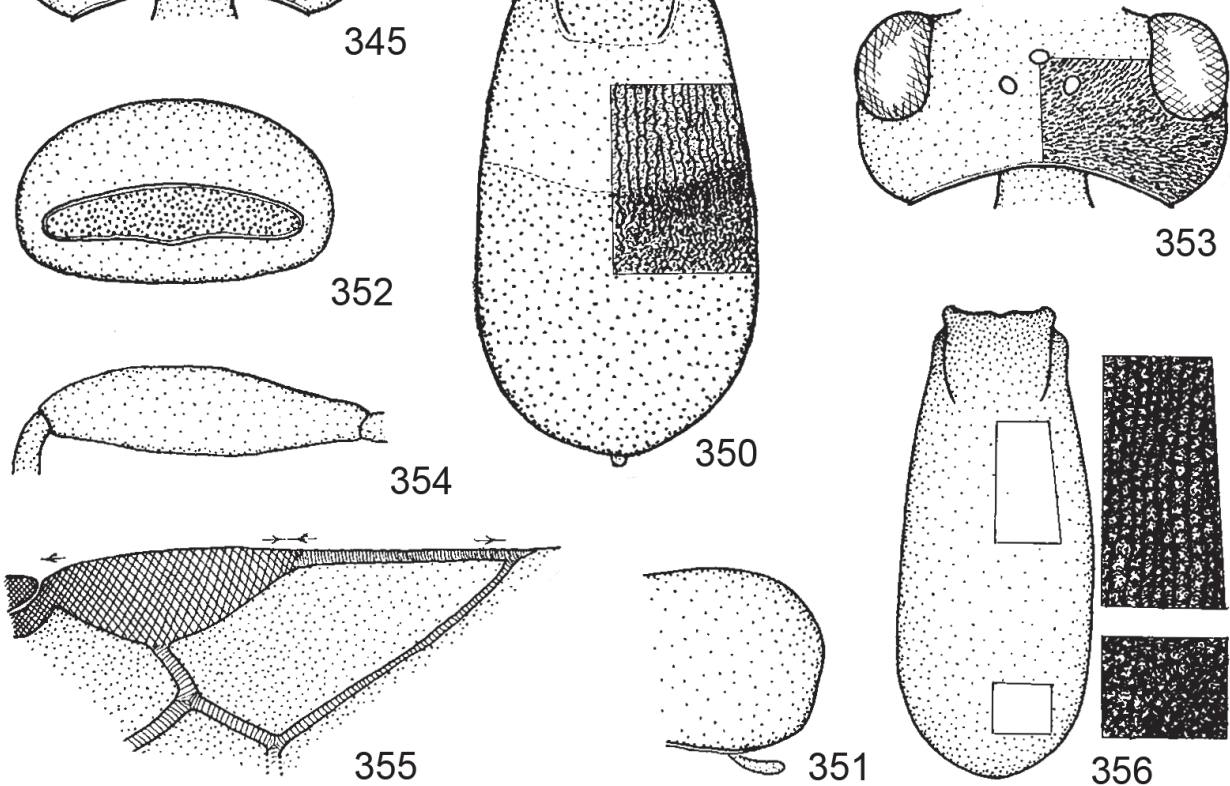

Figs 343-356. 343-352. Microchelonus pectiniphorae (Cushman, 1931) (ㅇ, §’: 343, 346, 347350; $9: 344,351 ; 0: 345,352): 343$ = head in dorsal view with indication of its sculpture, 344-345 = posterior half of head in dorsal view, $346=$ head in lateral view with indication of its sculpture, 347 = clypeus, $348-349=$ distal part of right fore wing, $350=$ carapace in dorsal view with indication of its sculpture, $351=$ posterior third of carapace in lateral view, 352 = apical foramen of carapace. 353-356. Microchelonus peruensis (Shenefelt, 1973) ( 0 , holotype): 353 = head in dorsal view with indication of its sculpture, $354=$ hind femur, $355=$ distal part of right fore wing, 356 = carapace in dorsal view with indication of its sculpture. 
rows). Scutellum longitudinally rugose (cf. Fig. 202). Hind femur 3.5 times as long as broad distally (Fig. 354). Fore wing: pterostigma 2.6 times as long as wide, issuing $r$ proximally from its middle, 1-R1 almost as long as pterostigma (35:40), 3-SR 1.7 times longer than $r$ (Fig. 355). Carapace in dorsal view elongate-form, 2.4 times as long as broad posteriorly, fairly densely striated, behind areolate-rugose (Fig. 356). Carapace in lateral view 3.4 times as long as broad posteriorly (Fig. 358 see arrows). Apical foramen of carapace 2.1 times as wide as high (Fig. 359). Fore wing proximo-distally hyaline to subfumous.

Distribution - Peru.

Taxonomic position - In the redescription M. peruensis is related to M. carinatus (Provancher) (Papp 1.c.). In the key to the male Microchelonus species it runs to $M$. paululus (McComb), M. projectus sp. n. and M. shenefelti, see couplets $61(62)-66(65)$.

\section{Microchelonus phthorimaeae (Gahan, 1917)}

(Figs 508-518)

Chelonus phthorimaeae Gahan, 1917: 199 ${ }_{+} \widehat{\jmath}$, type locality: USA, Colorado, Rocky Ford, female(?) "Type" in USNM; not examined.

Chelonus (Microchelonus) phthorimaeae Gahan: МсСомв 1968: 11 (in key) and 97 (redescription, distribution, hosts).

Microchelonus phthorimaeae (Gahan): SHenefelt 1973: 896 (comb. n., hosts, literature up to 1968).

Material examined -1 (det. W.R.M. Mason, in HNHM by exchange): Canada, Ontario, Pt. Pelee, 25 June 1927, leg. F. P. Ide.

Additional features to the redescription (McComb 1.c.) - 9 . Body $2.9 \mathrm{~mm}$ long. Antenna about as long as head and mesosoma combined and with 16 antennomeres. First flagellomere 2.7 times and penultimate flagellomere 1.8 times as long as broad (Fig. 508). Head in dorsal view transverse, 2.1 times as broad as long, eye 1.5 times longer than temple, temple reced-rounded (Fig. 509). Ocelli almost round, OOL slightly longer than POL (12:10). Eye in lateral view 1.8 times as high as wide, gena beyond eye wider than eye (17:15), substriolate (Fig. 510). Clypeus 2.1 times as wide below as high medially, its lower margin faintly convex, hairpunctate and shiny (Fig. 511). Frons. vertex, and occiput finely substriolate as in Fig. 509. Mesosoma in lateral view 1.6 times as long as high, scabrous. Notaulix indistinct. Scutellum densely punctate (Fig. 512), or rugulose, medially shiny to punctate (McComb l.c.). Propodeal carina distinct, its latetral pair of denticules prominent, median pair small (Fig. 513). Hind femur 3.3 times as long as broad medially (Fig. 514), hind tibia distally almost as broad as femur (14:16). Fore wing: pterostigma 2.3 times as long as wide, issuing $r$ clearly distally from its middle, $r$ and $3-S R$ equal in length (7:7), SR1 straight, 1-R1 0.6 times as long as pterostigma (Fig. 515). Carapace in dorsal view almost 1.8 times as long as broad posteriorly, apically rounded, logitudinally rugose (Fig. 516). Carapace in lateral view 2.9 times as long as high posteriorly, apically declivous to truncate (Fig. 517). Carapace apico-ventrally slightly incurved, incurved part about as long as hind third tarsomere (Fig. 518 see arrows). Ovipositor sheath short, concealed, as long as hind 
tarsomeres 1-3 combined. Ground colour of body black. Antenna black. Femora apically and tibiae entirely brownish yellow or testaceous. Wings weakly subhyaline, pterostigma brown, veins yellow to light brownish.

Male known, not seen.

Hosts - Anthrips rancidella Herrich-Schäffer, Gnorimoschema gudmanella Walsingham, Kieferia glochinella Zeller, Phthorimaea operculella Zeller (Lep. Gelechiidae), Ancylis comptana Frölich (Lep. Tortricidae) (Shenefelt 1.c.). duced).

Distribution - USA (widely ranged), Mexico (introduced), Bermuda Islands (intro-

Taxonomic position - According to the redescriber (McComb l.c.) M. phthorimaeae is "rather similar" to M. empherus (McComb). The species M. phthorimaeae is closest to M. kellieae (Marsh) considering their common features: temple in dorsal view more or less rounded (Figs 276, 509), short 1-R1 (Figs $280,515)$ and black corporal colour; the two species differ from each other keyed:

1 (2) Scutellum smooth with hairpunctures, subshiny to shiny (Fig. 279), or uneven, dull (Fig. 283). Penultimate flagellomere short, 1.2-1.3 times as long as broad (cf. Fig. 263a). Carapace in lateral view apically rounded (Fig. 519). Cheek in frontal view rather converging (Fig. 278 see arrows). Scape rusty to reddish yellow. + : 3-3.2 mm. - Costa Rica, *Honduras M. kellieae (Marsh, 1979)

2 (1) Scutellum densely punctate (Fig. 512), or rugulose to punctate. Penultimate flagellomere less short, 1.7 times as long as broad (Fig. 508). Carapace in lateral view apically declivous to truncate (Fig. 517 see arrows). Cheek in frontal view rounded as usually (cf. Fig. 272 see arrows). Scape blackish brown. + : 2.6-3.3 mm. - USA, Mexico, Bermuda

M. phthorimaeae (Gahan, 1917)

In the key to the female Microchelonus species $M$. phthorimaeae runs to $M$. angustus Papp and M. topali Papp, see couplets 104 (109) - 108 (107).

\section{Microchelonus polites sp. $\mathrm{n}$.}

$$
\text { (Figs 360-367) }
$$

Material examined - Female holotype: Costa Rica, Alajuela, $20 \mathrm{~km} \mathrm{~S} \mathrm{from} \mathrm{Upala,} \mathrm{10-21}$ May 1991, leg. F. D. Parker. - Holotype is in good condition: (1) glued directly to the pin by its right meso- and metapleuron, (2) right meso- and metapleuron invisible owing to the mounting, (3) left hind leg missing (except coxa and trochanters). Holotype is deposited in HNHM, Hym. Typ. No. 12242.

Etymology - The new species received the Latin name "polites" (= nice) referring to its polished corporal parts: gena and carapace apically. 


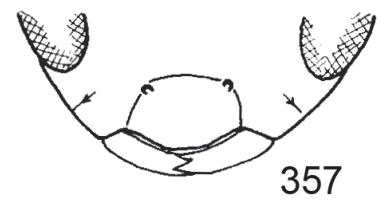

357
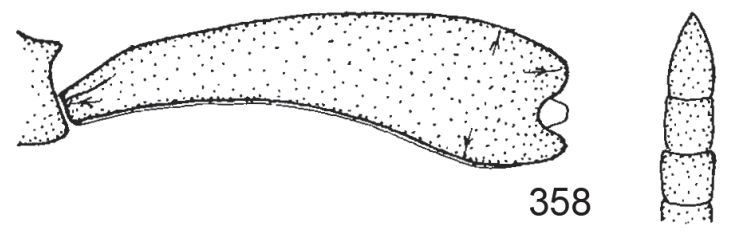

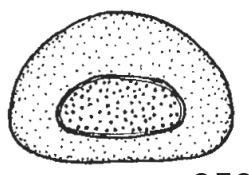

359

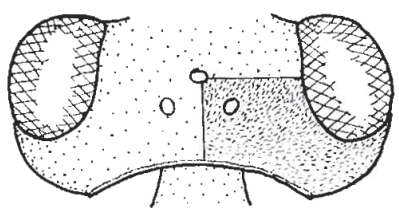

361

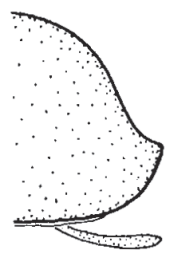

358
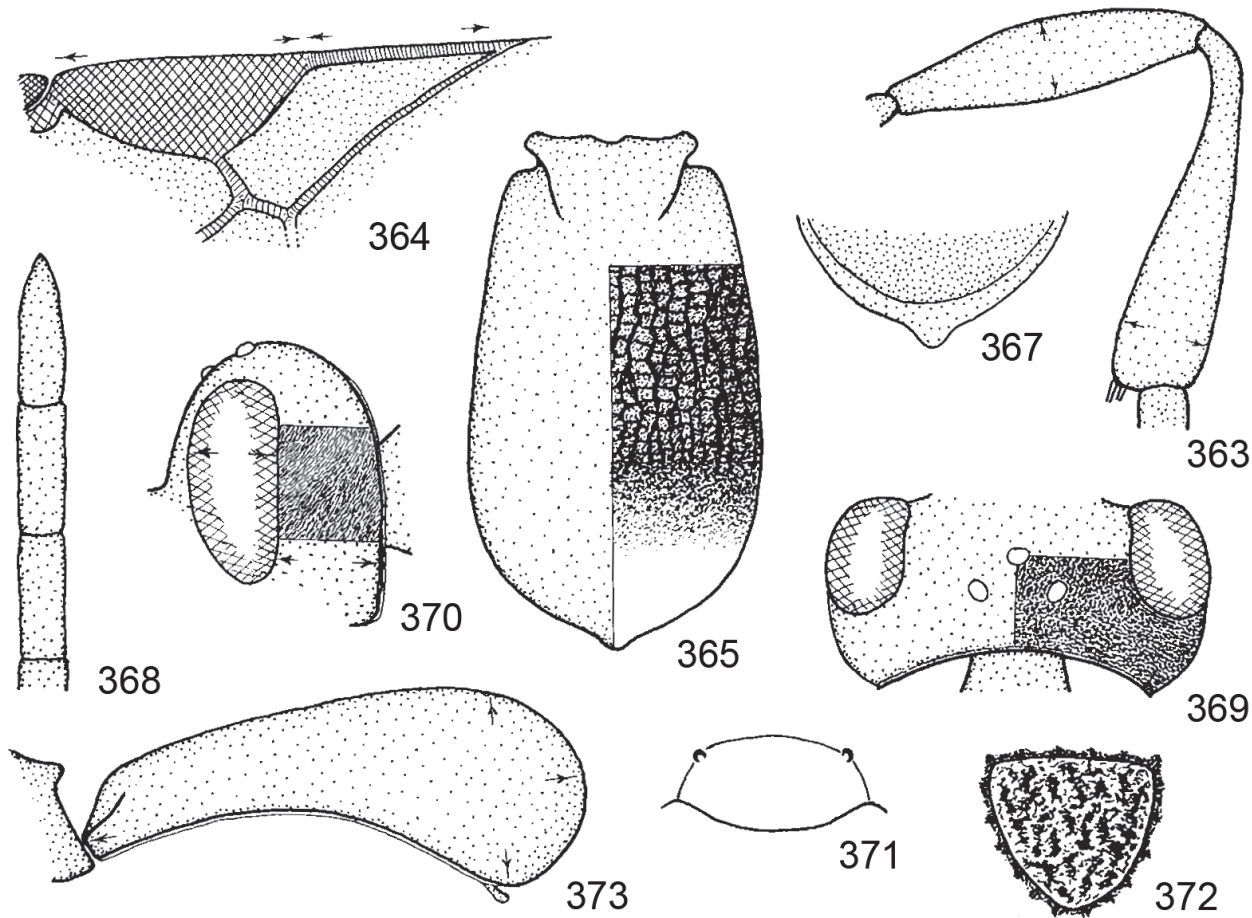

366

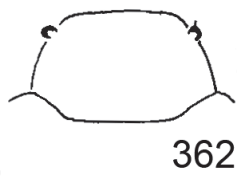

363

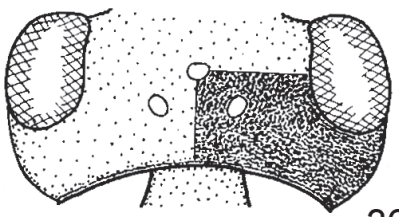

365

369

Figs 357-373. 357-359. Microchelonus peruensis (Shenefelt, 1973) ( $ఓ$, holotype): $357=$ ventral half of head in frontal view, $358=$ carapace in lateral view, $359=$ apical foramen of carapace. $360-367$. Microchelonus polites sp. n. ( + , holotype): $360=$ ultimate three flagellomeres, $361=$ head in dorsal view with indication of its sculpture, $362=$ clypeus, $363=$ hind femur + tibia, $364=$ distal part of right fore wing, $365=$ carapace in dorsal view with indication of its sculpture, $366=$ hind end of carapace in lateral view, $367=$ hind end of carapace in ventral view. 368-373. Microchelonus projectus sp. n. ( 9 , holotype): $368=$ ultimate three flagellomeres, $369=$ head in dorsal view with indication of its sculpture, $370=$ head in lateral view with indication of its sculpture, 371 = clypeus, 372 = scutellum, 373 = carapace in lateral view. 
Description of the female holotype - Body $2.7 \mathrm{~mm}$ long. Antenna just shorter than body and with 16 antennomeres. Scape thickening, twice as long as broad distally (cf. Fig. 322). First flagellomere five times as long as broad, further flagellomeres shortening so that penultimate flagellomere cubic (Fig. 360). - Head in dorsal view transverse, twice as broad as long, eye thrice longer than temple, temple receded (Fig. 361). OOL somewhat longer than POL, ocelli elliptic. Eye in lateral view high, 2.1 times as high as wide, gena beyond eye broadening ventrally: as wide as eye (cf. Fig. 217). Gena polished. Clypeus 1.7 times as wide below as high medially, ventrally protruding and widely truncate (Fig. 362). Face and clypeus rather transversely subrugulose-rugulose (clypeus somewhat weaker), subshiny. Head above transversely substriolate, subshiny (Fig. 361).

Mesosoma in lateral view stout, 1.2 times as long as high. Mesosoma scabrous-rugose, scutellum roughly rugose (cf. Fig. 387). Transverse carina of propodeum with small four denticules (cf. Fig. 293). Hind femur 3.8 times as long as broad medially, hind tibia thickening: distally somewhat broader than femur (Fig. 363, see arrows). Hind basitarsus as long as tarsomeres $2-3$ and half of 4 th tarsomere combined. Outer spur of hind tibia short and slightly shorter than half basitarsus, inner spur missing.

Fore wing almost as long as body (2.6 mm long). Pterostigma 2.5 times as long as wide, issuing $r$ distally from its middle, veins relatively thick, $3-S R$ and $r$ equal in length, SR1 slightly bent inwardly, 1-R1 0.7 times as long as pterostigma (Fig. 364).

Carapace in dorsal view somewhat globose, 1.7 times as long as broad posteriorly, anteriorly longitudinally striated with anastomoses, interstriations subcrenulated, posteriorly densely rugulose, apically (or its declivous part) polished (Fig. 365). Carapace in lateral view 3.2 times as long as high posteriorly, apically declivous and with a tubercule ventrally (Fig. 366). Carapace apico-ventrally weakly incurved (Fig. 367 see arrow). Ovipositor sheath about as long as hind basitarsus.

Ground colour of body black. Scape and pedicel yellow, first flagellomere brownish, 2nd flagellomere brownish to yellowish, 3rd and 4th flagellomeres yellow, rest of flagellum blackish. Palpi brownish to light bownish. Carapace fully black. Legs yellow, coxae 2-3 straw yellow, proximal 3/4th of femora and tibiae distally with brownish pattern. Wings subhyaline, pterostigma brown, veins light brown to brownish.

Male and host unknown.

Distribution - Costa Rica.

Taxonomic position - The new species, Microchelonus polites, is close to $M$. curtulus sp. n. viewing their short 1-R1, cubic penultimate flagellomere and entirely black carapace; the distinctive traits between them are as follows:

1 (2) Head substriolate, subshiny (Fig. 361). Carapace in lateral view apically with a tubercule (Fig. 366). Fore wing: pterostigma issuing $r$ distally from its middle, 1-R1 0.7 times as long as pterostigma, SR1 bent inwardly (Fig. 364). Flagellum with a yellow ring (on flagellomeres 3-4). ㅇ: $2.7 \mathrm{~mm}$. Costa Rica

M. polites sp. n.

2 (1) Head polished (Fig. 154), face very finely striolate. Carapace in lateral view with a very small tubercule (Fig. 159). Fore wing: pterostigma issuing $r$ from its middle, 1-R1 0.5 times as long as pterostigma, SR1 almost straight (i.e. indistinctly S-form, cf. Fig. 146). Flagellum evenly blackish. † $2.3 \mathrm{~mm}$. - Costa Rica

M. curtulus sp. n. 
In the key to the female Microchelonus species the new species runs to $M$. tuberulus sp. n., see couplets 10 (13) - 12 (11).

\section{Microchelonus projectus sp. $\mathrm{n}$. (Figs 368-377)}

Material examined $(1++1 \precsim)$ - Female holotype: Honduras, Yoro, Palo de Comba, $15^{\circ} 11^{\prime} \mathrm{N} / 87^{\circ} 39^{\prime} \mathrm{W}$, taken with Malaise trap in mid-elevation secondary forest, 31 August 1995, leg. R. Cave. One male paratype: Honduras, Atlantida, Lancetilla Tela, $15^{\circ} 43^{\prime} \mathrm{N} /$ $87^{\circ} 27^{\prime} \mathrm{W}$, taken with Malaise trap in lowland forest, 31 August 1995, leg. R. Cave.

Types condition - Holotype is in good condition: (1) glued on card point by the right side of mesosoma and carapace, (2) right middle leg less visible owing to the mounting. One paratype is in fairly good condition: (1) glued on card point by the right side of mesosoma, (2) right hind leg less visible owing to the mounting, (3) left antenna missing.

Type depositories - Holotype is deposited in ZMLU and paratype in HNHM, Hym. Typ. No. 12243.

Etymology - The new species name refers to the excessive (= projectus) richness in species of the genus Microchelonus.

Description of the female holotype - Body $3.3 \mathrm{~mm}$ long. Antenna nearly as long as body (3 mm long), with 16 antennomeres. Scape in lateral view thrice as long as broad, flagellomeres long, first flagellomere thrice and penultimate flagellomere 2.5 times as long as broad (Fig. 368). - Head in dorsal view transverse, twice (60:31) as broad as long, eye 1.5 times longer than temple, temple rounded (Fig. 369). POL as long as OOL (9:10). Eye in lateral view twice as high as wide, gena beyond eye less broadening ventrally and 1.2 times as wide as eye, substriolate and subshiny (Fig. 370). Clypeus twice as wide below as high medially, lower margin of clypeus convex (Fig. 371), with confluent punctation, subshiny to dull. Face and vertex densely rugulose, occiput transversely substriolate (Fig. 369).

Mesosoma in lateral view 1.5 times as long as high, scabrous, notaulix distinct, lateral lobe of mesoscutum densely rugulose. Scutellum rugose (Fig. 372). Hind femur thick, 2.6 times as long as broad medially, hind tibia distally less broad than femur (14:19, Fig. 375 see arrows). Hind basitarsus as long as tarsomeres $2-4$ and half of 5 th tarsomere combined.

Fore wing shorter than boidy (2.6 mm long). Pterostigma 2.3 times as long as wide, issuing $r$ from its middle, $r$ twice as long as $3-S R, 1-R 10.7$ times as long as pterostigma, SR1 bent inwardly (Fig. 374 see arrows).

Carapace in dorsal view 1.9 times as long as broad posteriorly, antero-posteriorly striate, scabrous to rugose, apically rounded (Fig. 376). Carapace in lateral view 2.7 times as long as high posteriorly, apically rounded (Fig. 373 see arrows). Carapace apico-ventrally incurved, ventral cavity of carapace nearly as long as carapace itself (Fig. 37 see arrow). Ovipositor sheath short, concealed.

Body black. Scape, pedicel and flagellomeres 1-2(-3) yellow to yellowish, rest of flagellum darkening greyish-brownish, ventrally rather ochre. Palpi straw yellow. Tegula light brownish, parategula yellow. Fore leg yellow, coxa basally brownish. Middle leg yellow, coxa and distal end of tibia brownish. Hind leg yellow, coxa black, femur dark brown, tibia apically blackish. Every tarsus pale yellow, distally faintly brownish.Wings hyaline, pterostigma brown, veins yellow to light brownish to blackish.

Description of the male paratype - Similar to the female holotype. Body $3.7 \mathrm{~mm}$ long. Antenna as long as head, mesosoma and half of carapace combined, with 22 antennomeres. 
Penultimate flagellomere 1.6 times as long as broad. Fore wing: pterostigma wide, twice as long as wide, issuing $r$ just distally from its middle. Carapace in dorsal view twice as long as broad posteriorly (Fig. 376). Apical foramen of carapace wide oval, 2.5 times as wide as high. Legs yellow, hind femur entirely and hind tibia apically faintly brownish.

Distribution - Honduras.

Taxonomic position - The new species, Microchelonus projectus, runs to $M$. cephalanthi (McComb) with the help of the key to the Nearctic species of $\mathrm{Mi}$ crochelonus (МсСомв 1968), the amplified differentation of the two species is as follows (male of $M$. cephalanthi unknown):

1 (2) Penultimate three flagellomeres long, (almost) three times as long as broad (Fig. 368). Fore wing: pterostigma 1.25 times longer than $1-R 1, r$ twice as long as 3-SR (Fig. 374 see arrows). Carapace black. $+3.3 \mathrm{~mm}$. Honduras

M. projectus sp. n.

2 (1) Penultimate three flagellomeres short, somewhat longer than broad (Fig. 11 in МсСомв 1968: 133). Fore wing: pterostigma and 1-R1 equal in length, $r$ and 3-SR also equal in length (Fig. 88 in МсСомв 1968: 141). Carapace ferrugineous. $+: 2.8 \mathrm{~mm}$. - USA (Texas)

M. cephalanthi (McComb, 1968)

In the key to the female Microchelonus species $M$. projectus runs to $M$. fascis Papp, see couplets 53 (52) - 55 (54).

\section{Microchelonus pyriformis Papp, 2010}

(Figs 378-383)

Microchelonus pyriformis Papp, 2010: 178 +, type locality: Honduras, Yoro, Palo de Comba, female holotype (+ one female paratype) in ZMLU, two female paratypes in HNHM (from Costa Rica); examined.

Emendated features to the original description - + . Body 5-5.5 mm long. Penultimate flagellomere (1.8-)2.5-3 times as long as broad (Fig. 378). Head in dorsal view 1.9-2 times as broad as long, eye 1.3-1.4 times longer than temple, temple rounded, vertex and occiput transversely rugose (Fig. 379). Eye in lateral view fairly narrow, 2.5 times as high as wide, gena beyond eye broadening so that ventrally almost 1.4 times wider than eye (cf. Fig. 12 see arrows). Clypeus 1.6 times as wide below as high medially, ventrally produced (Fig. 380). Scutellum carinate-form rugose (cf. Fig. 202), or longitudinally rugose. Hind femur 2.6-2.8 times as long as broad (cf. Fig. 375). Fore wing: pterostigma 2.7-2.9 times as long as wide, issuing $r$ distally from its middle, 1-R1 0.7 times as long as pterostigma, 3-SR about twice longer than $r$ (Fig. 381). Carapace in dorsal view pyriform broadening posteriorly, strongly striated, interstriations crenulated (Fig. 382). Carapace in lateral view 2.7-2.8 times as long as high posteriorly, apically truncate (Fig. 383 see arrows). Carapace anterolaterally with a pair of yellow maculae. Wings brownish fumous. 
Male and host unknown.

Distribution - Costa Rica, Honduras.
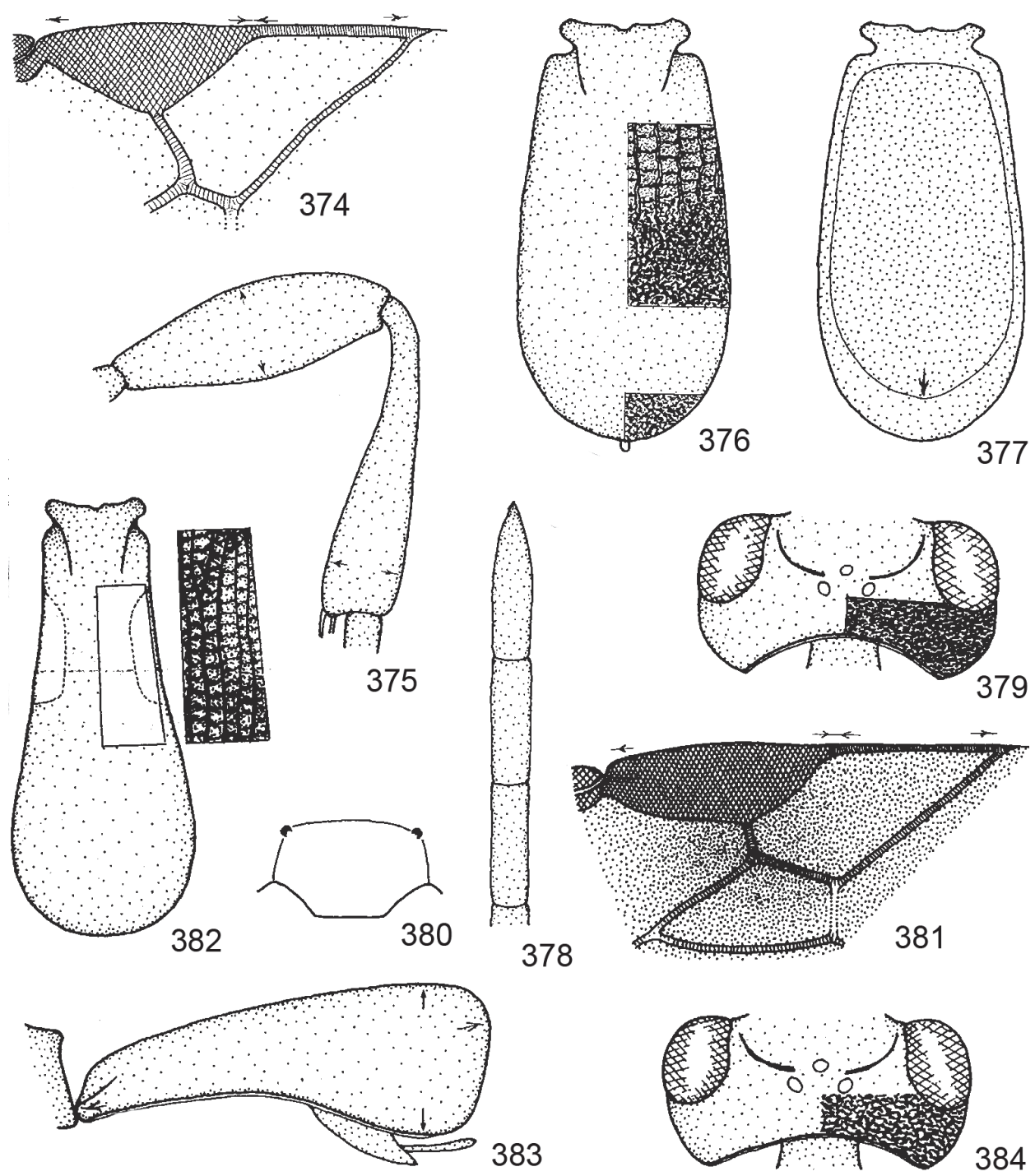

384

Figs 374-384. 374-377. Microchelonus projectus sp. n. (q, holotype): $374=$ distal part of right fore wing, $375=$ hind femur + tibia, 376 = carapace in dorsal view with indication of its sculpture, 377 = carapace in ventral view. 378-383. Microchelonus pyriformis Papp, 2010 (우, holotype): $378=$ ultimate three flagellomeres, $379=$ head in dorsal view with indication of its sculpture, 380 = clypeus, $381=$ distal part of right fore wing, 382 = carapace in dorsal view with indication of its sculpture, 383 = carapace in lateral view. 384 . Microchelonus refluus Papp, 2010 ( + , holotype): head in dorsal view with indication of its sculpture. 
Taxonomic position - In the original description of M. pyriformis is related to (Papp l.c.) as well as in the key to the female Microchelonus species it runs to M. buscki (Viereck) and to M. buscki (Viereck) + M. effusus sp. n., see couplets $38(43)-42$ (41) and $113(112)-114$ (115), respectively.

\section{Microchelonus refluus Papp, 2010 (Figs 384-392)}

Microchelonus refluus Papp, 2010: 180 우, type locality: Honduras, Yoro, Palo de Comba, $15^{\circ} 11^{\prime} \mathrm{N} / 87^{\circ} 39^{\prime} \mathrm{W}$, female holotype (and two female paratypes) in ZMLU, one female + one male paratypes in HNHM (paratypes taken in type locality); examined.

Emendated features to the original description (Papp 1.c.) - + . Body 4.8-4.9 mm long. Penultimate flagellomere subcubic, 1.1 times as long as broad. Head in dorsal view twice as broad as long, eye 1.3 times longer than temple, temple rounded, vertex and occiput transversely rugulo-rugose, frons with a pair of arcuate carinulae between hind ocelli and compound eyes (Fig. 384). Clypeus 1.3 times as wide as high, ventrally produced (Fig. 386). Eye in lateral view 2.1-2.3 times as high as wide, gena beyond eye broadening so that ventrally 1.2 times wider than eye (Fig. 385 see arrows). Scutellum roughly rugose or scabrous (Fig. 387). Hind femur 2.6-2.9 times as long as broad medially, hind tibia 0.8 times as broad as femur (Fig. 388 see arrows). Fore wing: pterostigma 2.8-3 times as long as wide, issuing $r$ from its middle (Fig. 389 see arrows) or slightly distally, 1-R1 0.7 times as long as pterostigma, 3-SR 2-2.2 times longer than $r$. Carapace in dorsal view 2.4-2.6 times as long as broad medially, apically pointed, longitudinally striated with anastomoses (Fig. 390). Carapace in lateral view 3.2 times as long as high posteriorly, apically inclivous truncate (Fig. 391 see arrows). Carapace apico-ventrally deeply incurved (cf. Fig. 407). Antero-lateral pair of maculae of carapace straw yellow.

J. Similar to the female. Body $4 \mathrm{~mm}$ long. Penultimate flagellomere 1.8 times as long as broad. Head in dorsal view 1.9 times as broad as long. Hind femur thrice as long as broad. Fore wing: 1-R1 0.85 times as long as pterostigma. Carapace in dorsal view evenly broad, 2.6 times as long as broad and apically pointed (Fig. 392). Apical foramen of carapace very small and round, hardly distinct.

Host unknown.

Distribution - Honduras.

Taxonomic position - In the original description $M$. refluus is related to $M$. hadrogaster (McComb) (Papp 2010: 183). In the key to the female Microchelonus species it runs to M. curticarinulus sp. n., see couplets 24 (25) - 26 (27).

\section{Microchelonus rubescus Papp, 2010}

(Figs 393-397)

Microchelonus rubescus Papp, 2010: 183 , type locality: Costa Rica, Heredia, LaSelva Research Institute, holotype deposited in HNHM, examined.

Emendated features to the original description (Papp 1.c.) - . . Body $3.6 \mathrm{~mm}$ long. Penultimate flagellomere cubic (cf. Fig. 398). Head in dorsal view 2.1 times as broad as long, eye 
2.1 times longer than temple, temple rounded, vertex and occiput transversely substriolate (Fig. 393). Eye in lateral view 1.3 times wider than gena, gena ventrally with somewhat weakening substriolation (Fig. 394 see arrows). Scutellum rugose (cf. Fig. 412). Fore wing: pterostigma 2.5 times as long as wide, issuing $r$ distally from its middle, $1-R 1$ as long as

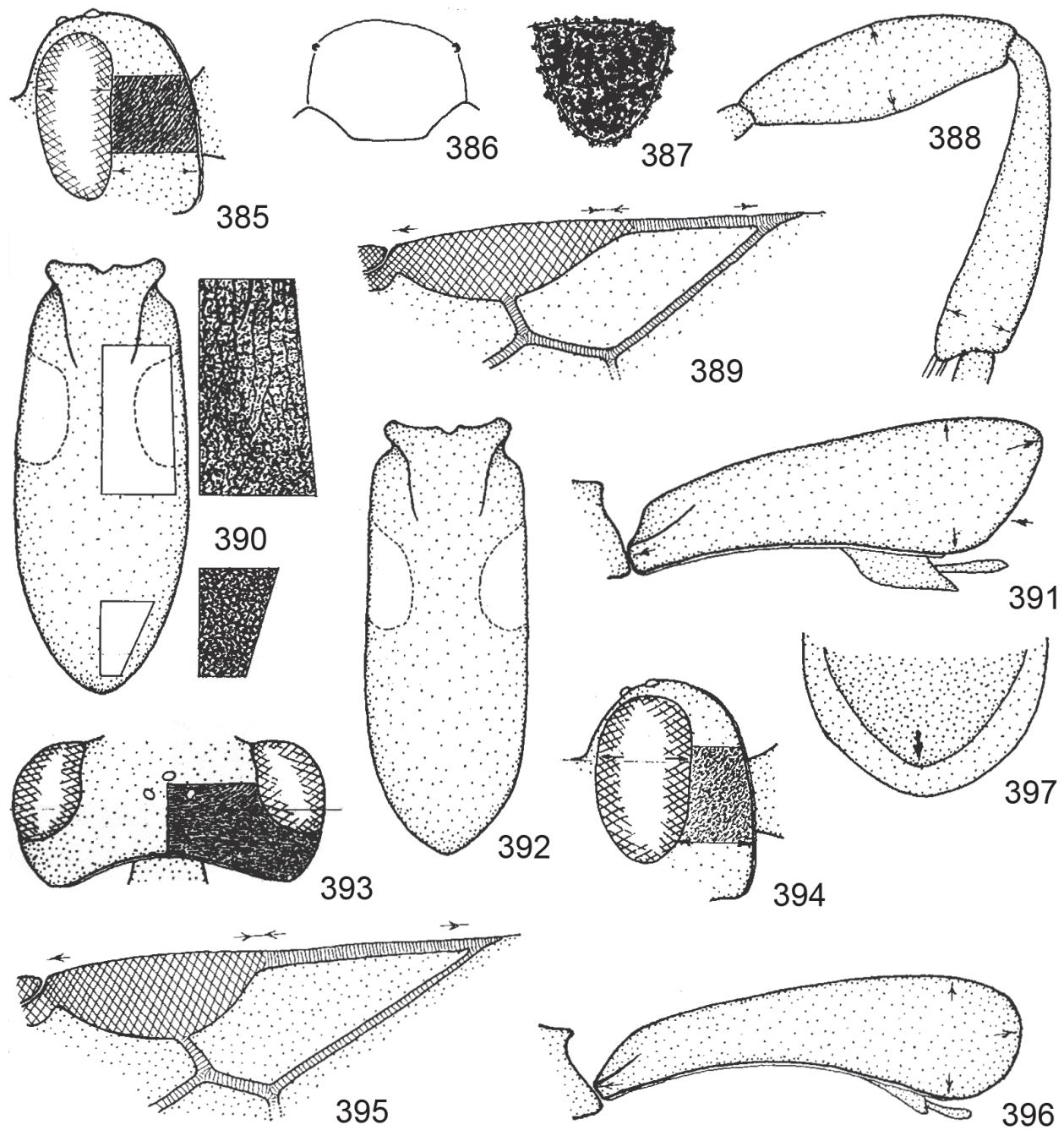

Figs 385-397. 385-392. Microchelonus refluus Papp, 2010 ( + , holotype: 388-391; + , holotype +1 , paratype: 386,392 ; + , paratype: 385,387$): 385=$ head in lateral view with indication of its sculpture, 386 = clypeus, 387 = scutellum, $388=$ hind femur + tibia, $389=$ distal part of right fore wing, $390=$ carapace in dorsal view with indication of its sculpture, $391=$ carapace in lateral view, 392 = carapace in dorsal view. 393-397. Microchelonus rubescus Papp, 2010 ( 9 , holotype): 393 = head in dorsal view with indication of its sculpture, $394=$ head in lateral view with indication of its sculpture, 395 = distal part of right fore wing, $396=$ carapace in lateral view, $397=$ posterior third of carapace in ventral view. 
pterostigma, 3-SR about 1.7 times longer than $r$ (Fig. 395). Carapace in dorsal view belly, 1.7 times as long as broad posteriorly, apically rounded, parallel striated, apically densely rugulose (cf. Fig. 316). Carapace in lateral view flattened, 3.3 times as long as high posteriorly, apically rounded (Fig. 396 see arrows). Carapace apico-ventrally weakly incurved (Fig 397). Proximal half of antenna ochre, distal half darkening brown. Mesosoma testaceous.

Male unknown.

Distribution - Costa Rica.

Taxonomic position - In the original description M. rubescus is related to (Papp 1.c.) and in the key to the female Microchelonus species it runs to M. ruficollis (Viereck), see couplets 121 (124) -123 (122).

\section{Microchelonus ruficollis (Viereck, 1912) (Figs 398-410)}

Chelonus (Chelonella) ruficollis Viereck, 1912: $618+\hat{\jmath}$, type locality: Brazil, Bonito province,

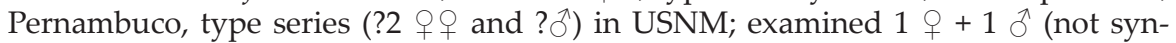
types).

Microchelonus ruficollis (Viereck): SHenefelt 1973: 901 (comb. n., literature up to 1913). PAPP 2010: 184 (in key), 187 (6 figures) and 190 (faunistics).

Material examined (in HNHM) - 1 o: Costa Rica, Guanacastle, S. Cañas, 1-3 February 1989, leg. F. D. Parker. 1 đ̊: Costa Rica, Aljuela, 20 km S from Upala, 1-20 November 1990, leg. F. D. Parker. Both specimens taken with Malaise trap.

Redescription of M. ruficollis based on one female and one male - + . Body 4.3-4.5 mm long. Antenna somewhat longer than head and mesosoma combined and with 16 antennomeres. First flagellomere 3.3 times, further flagellomeres gradually shortening so that penultimate 3-4 flagellomeres cubic (Fig. 398). - Head in dorsal view transverse, twice as broad as long, eye 1.5 times longer than temple, temple rounded (Fig. 399). Ocelli small, OOL one-third longer than POL. Eye in lateral view 1.8 times as long as wide, gena beyond eye broadening ventrally and here as wide as eye, substriolate and subshiny (Fig. 400 see arrows). Clypeus 1.7 times as wide below as high medially, its lower margin medially truncate (Fig. 401), uneven-subrugulose and subshiny. Face densely rugo-rugulose, vertex and frons transversely and densely rugose (Fig. 399).

Mesosoma in lateral view stout, 1.2 times as long as high, rugose. Notaulix anteriorly distinct. Scutellum rugose (cf. Fig. 372). Propodeum areolate-rugose, its transverse carina with four and evenly large denticules (Fig. 402). Hind femur 1.9 times as long as broad medially (Fig. 403), tibia distally somewhat less wide than femur (15:17). Hind basitarsus as long as tarsomeres $2-4$ combined.

Fore wing about one-fourth shorter than body (3.2 mm long). Pterostigma wide, 2.6 times as long as wide, issuing $r$ distally from its middle, 3-SR almost 1.6 times longer than $r, 1-R 10.7$ times as long as pterostigma.

Carapace in dorsal view 2.1 times as long as broad medially, anteriorly striated with anastomoses, posteriorly densely rugulose (Fig. 405). Carapace in lateral view flattened, 3.5 times as long as high posteriorly (Fig. 406 see arrows). Carapace apico-ventrally deeply incurved (Fig. 407 see arrow), i.e. ventral cavity of carapace shorter than carapace itself. 

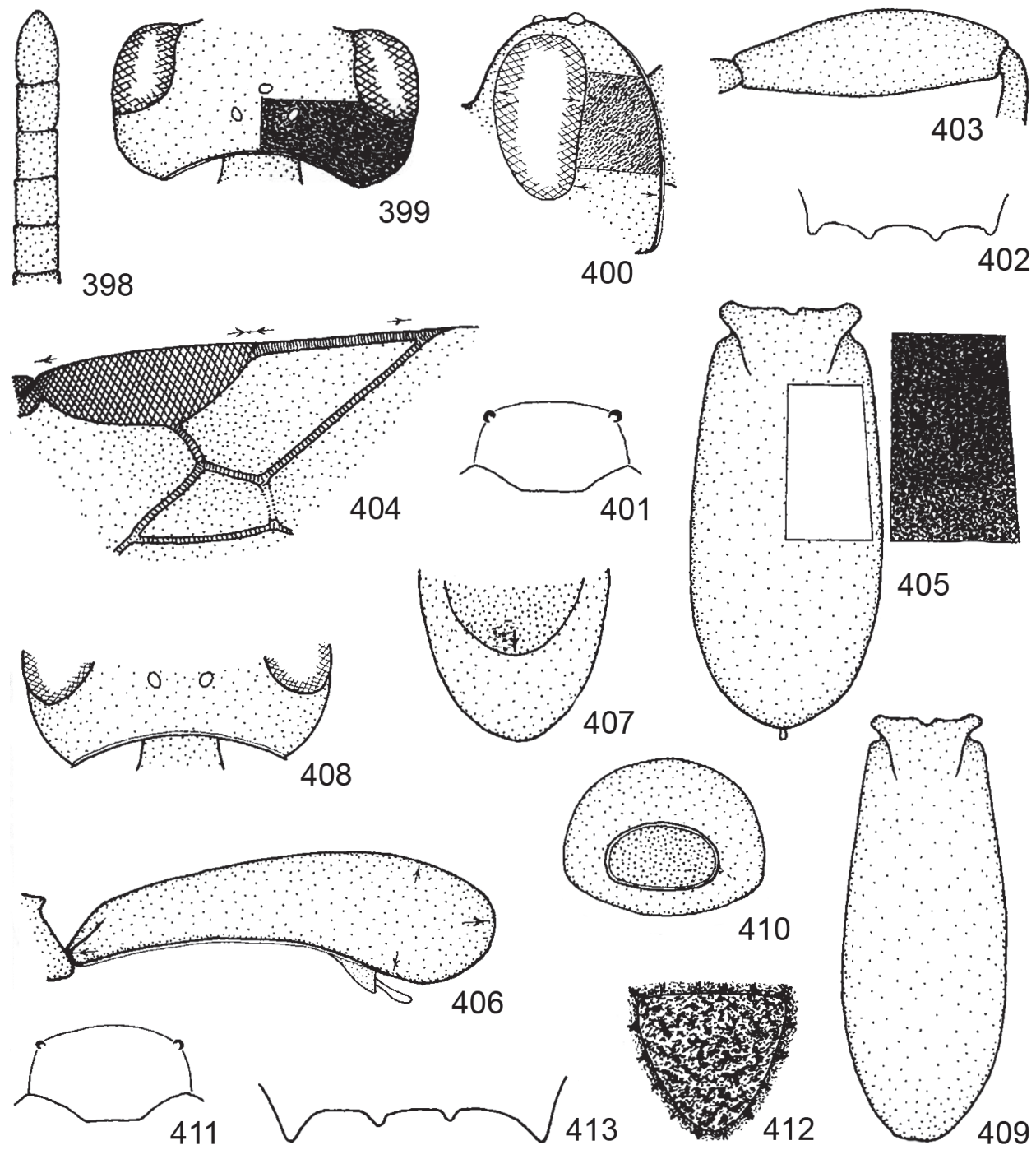

408
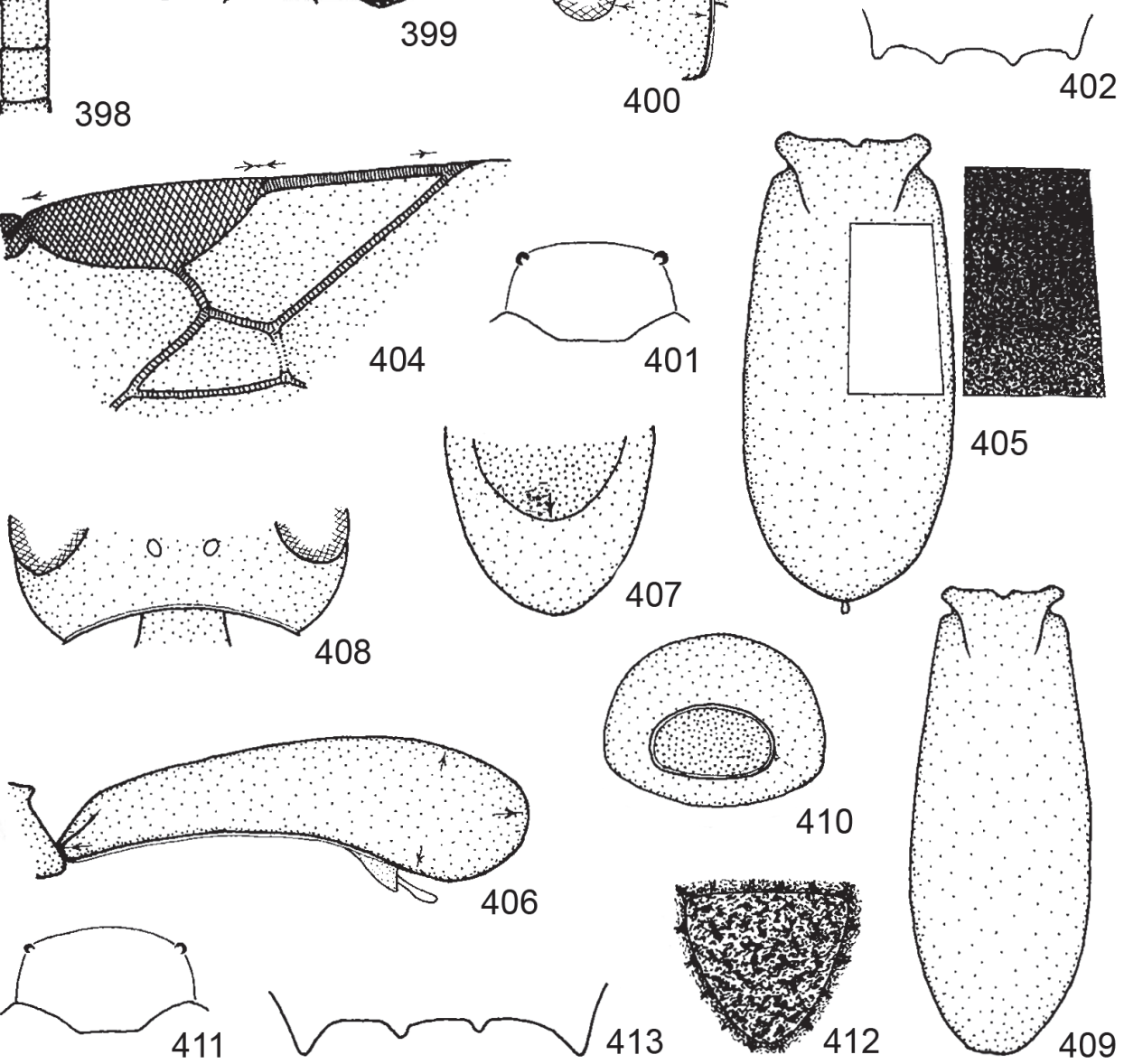

Figs 398-413. 398-410. Microchelonus ruficollis (Viereck, 1912) (: 398-400, 404-407; ㅇ, ô: 401-403; ô: 408-410): 398 = ultimate five flagellomeres, $399=$ head in dorsal view with indication of its sculpture, $400=$ head in lateral view with indication of its sculpture, $401=$ clypeus, 402 = propodeal carina in dorsal view, $403=$ hind femur, $404=$ distal part of right fore wing, 405 = carapace in dorsal view with indication of its sculpture, 406 = carapace in lateral view, $407=$ posterior third of carapace in ventral view, $408=$ posterior half of head in dorsal view, 409 = carapace in dorsal view, 410 = apical foramen of carapace. 411-413. Microchelonus shenefelti (McComb, 1968) (q, paratype): 411 = clypeus, 412 = scutelum, $413=$ propodeal carina in dorsal view. 
Body tricoloured. Scape reddish yellow, pedicel brownish, flagellum blackish. Head black, palpi pale yellow. Mesosoma testaceous, scutellum, propodeum and posterior half of mesosternum black. Carapace black with a pair of small testaceous maculae. Legs yellow. Middle femur faintly brownish, hind femur brownish black, basally yellow. tarsi pale yellow. Wings evenly subfumous, pterostigma dark brown, veins proximo-distally light brownish to brownish.

7. Similar to the female. Body $5 \mathrm{~mm}$ long. Antenna as long as three-fourths length of body and with 19 antennomeres. First flagellomere 3.3 times, further flagellomeres shortening so that penultimate flagellomere twice as long as broad (cf. Fig. 171). Temple in dorsal view receded (Fig. 399). Mesosoma 1.4 times as long as high. Fore wing: pterostigma wider, 2.1 times as long as wide, 1-R1 0.85 times as long as pterostigma (Fig. 404). Carapace elongate, 2.5 times as long as broad posteriorly, apically somewhat conicule-shape (Fig. 409), its striation and rugosity somewhat stronger than those of the female. Apical foramen of carapace oval: 1.6 times as wide as high (Fig. 410). Scape black. Ventral half of mesosoma black. Testacous coloured: mesoscutum, scutellum, metanotum and upper part of mesopleuron.

Distribution - Brazil, ${ }^{*}$ Costa Rica.

Taxonomic position - In the key to the female as well as to the male $\mathrm{Mi}$ crochelonus species $M$. ruficollis runs to $M$. rubescus Papp and to M. subplanus Papp, see couplets 121 (124) - 123 (122) and 54 (53) -57 (58), respectively.

\section{Microchelonus shenefelti (McComb, 1968) (Figs 411-418)}

Chelonus (Microchelonus) shenefelti McComb, 1968: 10(in key) and 116 (description) $q$ ơ, type locality: USA, Wisconsin, Port Angeles, female holotype (five female + one male paratypes) in Shenefelt Collection, Department of Entomology, University of Wisconsin, Madison (USA); two female paratypes examined (male not seen).

Microchelonus shenefelti (McComb): Shenefelt 1973: 903 (type locality: "Port Angeles, Washington" emendation, comb. n., literature up to 1968).

Material examined (two female paratypes) - "Port Angeles, Washington state", Mt. Pleasent district, sweeping Lathyrus torreyi, 18 July 1945, leg. R. D. Shenefelt.

Additional features to the original description (McComb l.c.) - + . Body 3.4-3.5 mm long. Antenna about three-fourths as long as body and with 16 antennomeres. Head in dorsal view 1.9-2 times as broad as long, eye as long as temple, temple rounded (Fig. 414). Ocelli faintly elliptic, small, POL slightly shorter than OOL (9-12-13). Eye in lateral view twice as high as wide, gena beyond eye just less wide (15:16) than eye (Fig. 415 see arrows). Clypeus less wide, 1.6-1.7 times as wide below as high medially (Fig. 411). Head above transversely substriolate, subshiny. Face more or less transversely subrugulose, subshiny. Clypeus hairpunctate, shiny.

Mesosoma in lateral view stout, 1.2 times as long as high, rugose to scabrous, mesoscutum medially rugulose-punctate. Scutellum rugose (Fig. 412). Propodeal carina distinct, lateral pair of denticules greater than middle pair (Fig. 413). Hind femur 3.3 times as long as broad medially (cf. Fig. 268). Hind tibia distally somewhat less broad than femur. Hind basitarsus as long as tarsomeres 2-4 combined. 

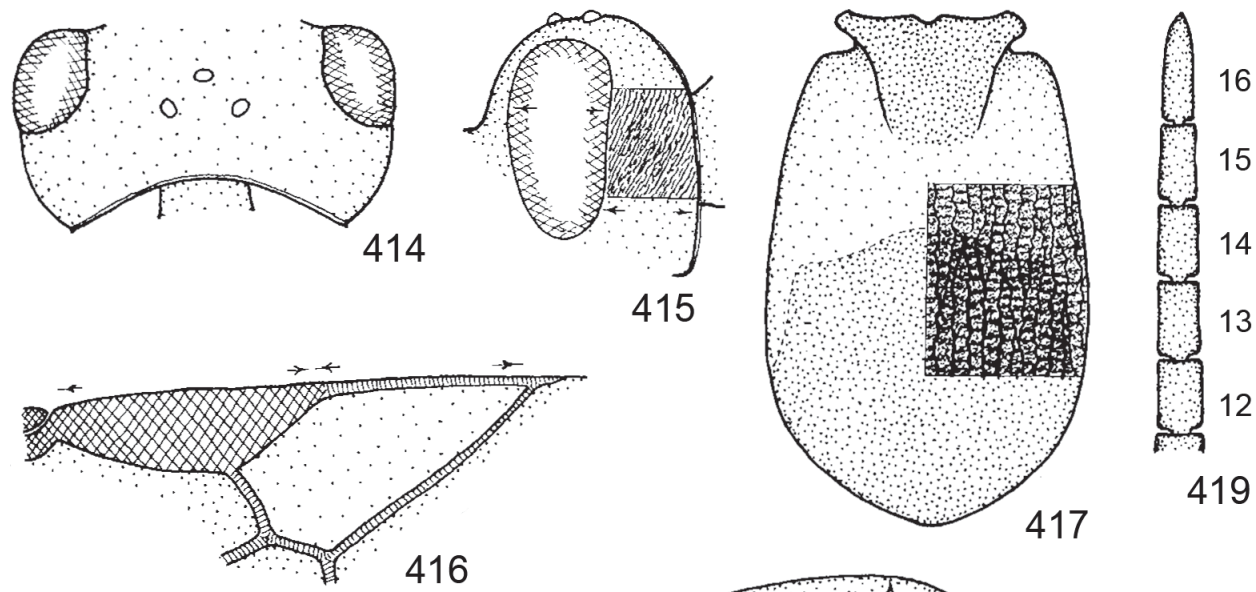

417
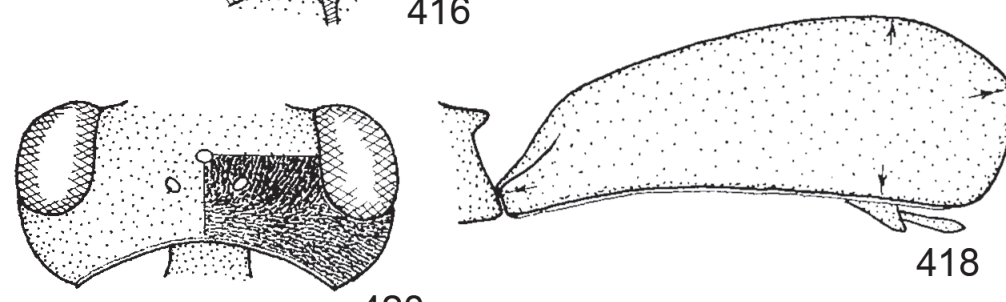

420
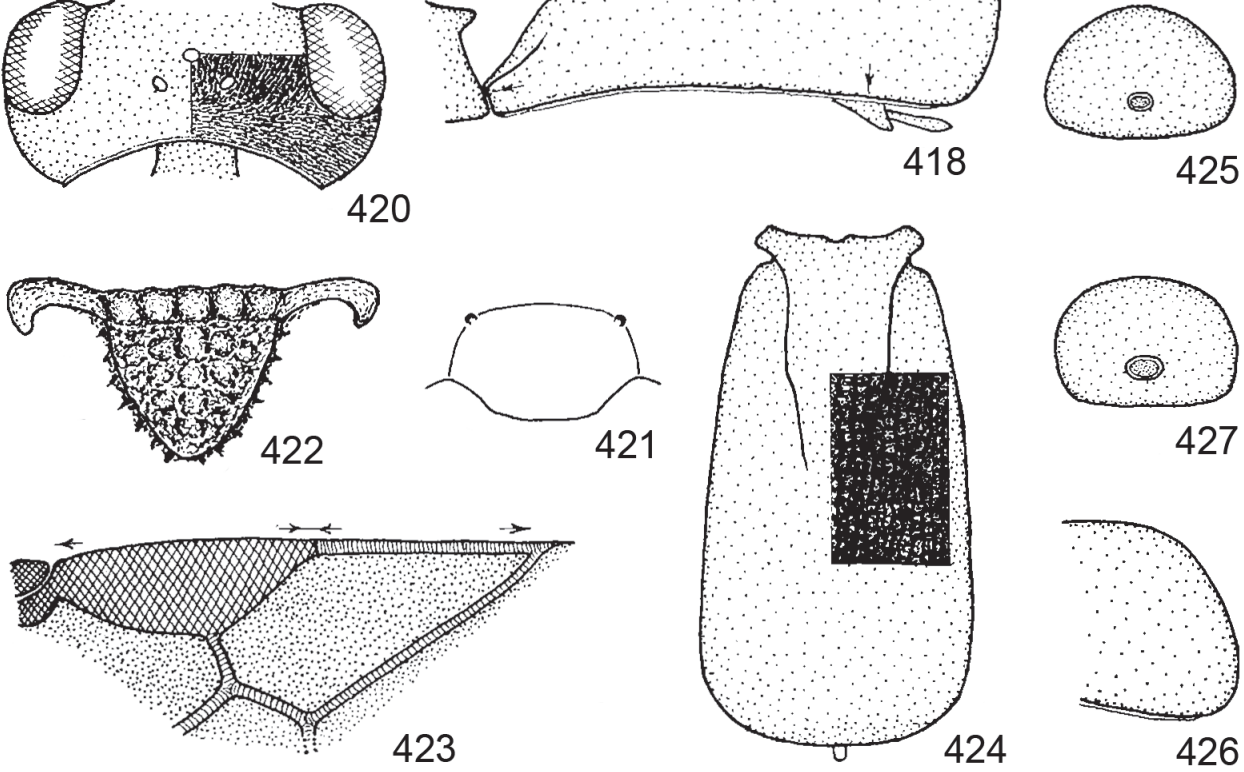

Figs 414-427.414-418. Microchelonus shenefelti (McComb, 1968) ( 9 , paratype): $414=$ head in dorsal view, $415=$ head in lateral view with indication of its sculpture, $416=$ distal part of right fore wing, $417=$ carapace in dorsal view with indication of its sculpture, $418=$ carapace in lateral view. 419-427. Microchelonus subplanus Papp, 1999 (ㅇ, holotype: 419-425; I. paratype: 426-427): $419=$ ultimate five flagellomeres, $420=$ head in dorsal view with indication of its sculpture, 421 = clypeus, $422=$ scutellum, $423=$ distal part of right fore wing, $424=$ carapace in dorsal view with indication of its sculpture, $425=$ apical foramen of carapace, 426 = posterior end of carapace in lateral view, 427 = apical foramen of carapace. 
Fore wing one-fourth shorter than body (2.5-2.6 mm long). Pterostigma narrow, twice as long as wide, issuing $r$ clearly distally from its middle. $1-R 1$ somewhat shorter than pterostigma (35:40), 3-SR just shorter than $r$ (Fig. 416 see arrows).

Carapace in dorsal view belly, 1.6 times as long as broad posteriorly, fairly densely striated, interstriations crenulated, apically rugulose-rugose. Carapace in lateral view 2.6-2.7 times as long as high posteriorly (Fig. 418 see arrows). Carapace apico-ventrally somewhat incurved.

Ground colour of body black. Antenna black. Palpi brownish yellow. Tegula dark brown to brownish. Carapace anteriorly lemon yellow, laterally extending to posteriorly (Fig. 417). Legs blackish, yellow: femur apically, tibiae 1-3 and fore tarsus, tarsi 2-3 dark fumous. Wings hyaline, pterostigma opaque brown, veins proximo-distally yellow to light brownish.

$\widehat{\delta}$ (features after McComb l.c.) - Body $3.4 \mathrm{~mm}$ long. Antenna as long as body and with 22 antennomeres. Apical foramen of carapace small, oval, twice wider than high, i.e. its width two-thirds of the hind basitarsus.

Host unknown.

Distribution - USA (Washington), ?Mexico.

Taxonomic position - In the original description (McComb 1.c.) Microchelonus shenefelti is related to $M$. fulgidus (McComb). In the key to the female Microchelonus species it runs to M. flavicoxa sp. n., see couplets 130 (125) - 132 (131).

\section{Microchelonus subplanus Papp, 1999 \\ (Figs 419-431)}

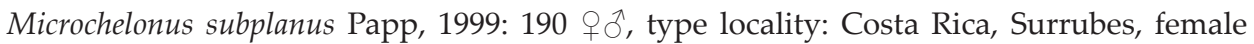
holotype (and one male paratype: Honduras, Yoro, Palo de Comba). Female holotype and male paratype are deposited in HNHM; examined.

Material examined - 1 q: Costa Rica, Alajuela, 20 km S from Upala, 17 September 1990, leg. F. D. Parker.

Emendated features to the original description (Papp 1.c.) - 9 . Body $3.3 \mathrm{~mm}$ long. Ultimate flagellomeres long, penultimate flagellomere twice longer than broad (Fig. 419). Head in dorsal view transverse, 2.1 times as broad as long, eye 1.6 times longer than tempe (Fig. 420). Eye in lateral view twice as high as wide, gena beyond eye shiny and its punctation antero-posteriorly thickening (cf. Fig. 303). Clypeus 1.7 times as wide below as high medially, its lower margin faintly convex (Fig. 421). Fore wing: pterostigma 2.6 times (holotype, Fig. 423) and 2.3 times (1 +, Fig. 429) as long as wide, 1-R1 almost, 0.85 times, as long as pterostigma. Carapace in dorsal view 1.9 times as long as broad posteriorly, apically rounded (Fig. 424). Carapace in lateral view 2.7 times as long as high posteriorly (Fig. 428 see arrows). Apical foramen of female carapace very small and elliptic (Fig. 425).

$\widehat{\delta}$. Penultimate flagellomere short, 1.6 times as long as broad. Fore wing: pterostigma 2.6 times as long as wide and issuing $r$ from its middle (Fig. 430). Carapace in dorsal view somewhat less broadening posteriorly, twice as long as broad (Fig. 431). Carapace in lateral view apically slightly more declivous (Fig. 426). Apical foramen of male carapace somewhat greater than that of female, elliptic: twice as wide as high (Fig. 427).

Distribution - Costa Rica. 
Remark - One male paratype (locality Honduras 12 September 1995) proved to be not representing the species M. subplanus - hence it is deleted from the type-series of this species. Seemingly this male is near to M. brasiliensis (Brues).

Taxonomic position - In the original description (Papp l.c.) it is related to M. johni (Marsh) and M. pectiniphorae (Cushman). In the key to the female Microchelonus species M. subplanus runs to M. danzas sp. n., see couplets 46 (45) -48 (47); in the key to the males it runs to M. bermus sp. n. and M. ruficollis (Viereck), see couplets 54 (53) -59 (60).

\section{Microchelonus sulcifera sp. $n$.}

(Figs 432-440)

Material examined ( 4 + + ) - Female holotype and two female paratypes: Costa Rica, 20 km S from Upala, 10-21 May 1991 (holotype), 8 November 1990 (one paratype) and 21-31 July 1991 (one paratype), all three types leg F. D. Parker. One female paratype: Honduras, Atlantida, Lancetilla Tela, $15^{\circ} 43^{\prime} \mathrm{N} / 87^{\circ} 27^{\prime} \mathrm{W}, 30$ May 1995, leg. R. Cave.

Types condition - Holotype is in good condition: glued direct to the pin by the right side of the mesosoma. Paratypes are also in good condition: (1) glued direct to the pin by the right side of the mesosoma (two paratypes from Costa Rica), and glued on card point by right side of the mesosoma (one paratype from Honduras), (2) missing: left hind leg (one paratype from Costa Rica), tarsus of middle right leg and tarsomeres $4-5$ of middle left leg (one paratype from Honduras).

Type depositories - Holotype and two paratypes are deposited in HNHM, Hym. Typ. Nos 12244 (holotype) and 12245-12246 (paratypes); one paratype is in ZMLU.

Etymology - The new species received the name "sulcifera" indicating the fairly strong sulciferous striation of the carapace (Fig. 438).

Description of the female holotype - Body $4.2 \mathrm{~mm}$ long. Antenna short, as long as head + mesosoma combined ( $2.7 \mathrm{~mm}$ long), with 16 antennomeres. Scape 2.2 times as long as broad, first flagellomere 3.3 times longer than broad, further flagellomeres shortening so that penultimate flagellomere cubic. - Head in dorsal view transverse, distinctly twice as broad as long, eye twice longer than temple, temple receded (Fig. 432). OOL one-third longer than POL (11:8). Eye in lateral view 1.9 times as high as wide, gena beyond eye clearly broadening ventrally and somewhat wider than eye (18:16), punctate, interspunctures smooth and shiny (Fig. 433). Clypeus twice as wide below as high medially, ventrally produced, its lower margin convex, evenly punctate, interpunctures more or less greater than punctures, dull (Fig. 434). Face rugose, frons transversely striated, vertex and occiput substriolate (Fig. 432).

Mesosoma in lateral view 1.5 times as long as high, scabrous. Notaulix distinctly crenulated. Scutellum smooth, hairpunctate, subshiny (cf. Fig. 219). Middle tibia with a few spinules (Fig. 435). Hind femur thick, 2.8 times as long as broad medially, hind tibia slightly less broad distally than femur with spinules (Fig. 436). Hind basitarsus somewhat longer than tarsomeres $2-4$ combined.

Fore wing short, one-third shorter than body ( $3 \mathrm{~mm}$ long). Pterostigma wide, 2.2 times as long as wide, issuing $r$ just distally from its middle, 3-SR 1.4 times longer than $r$, SR1 straight, 1-R1 almost as long as (35:40) pterostigma (Fig. 437). 

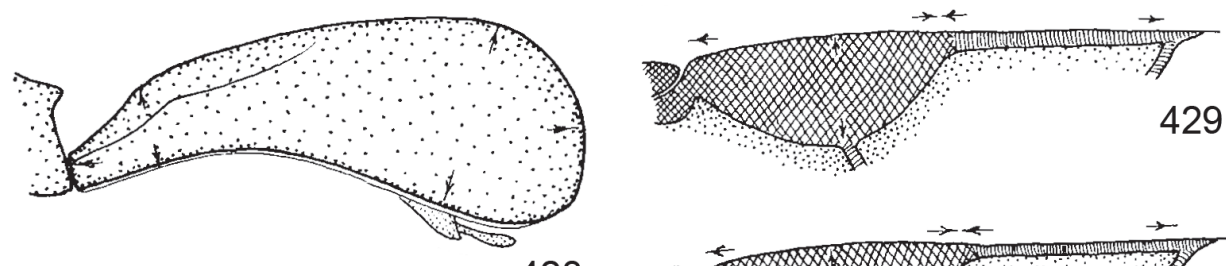

428
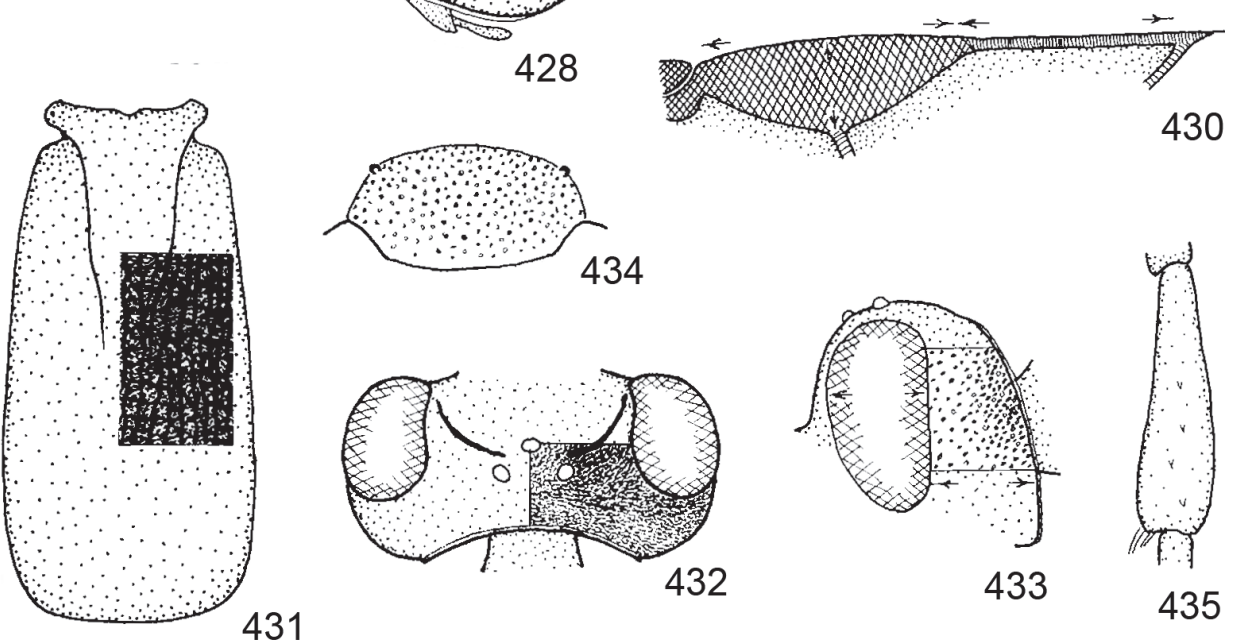

433

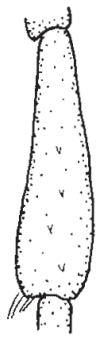

431
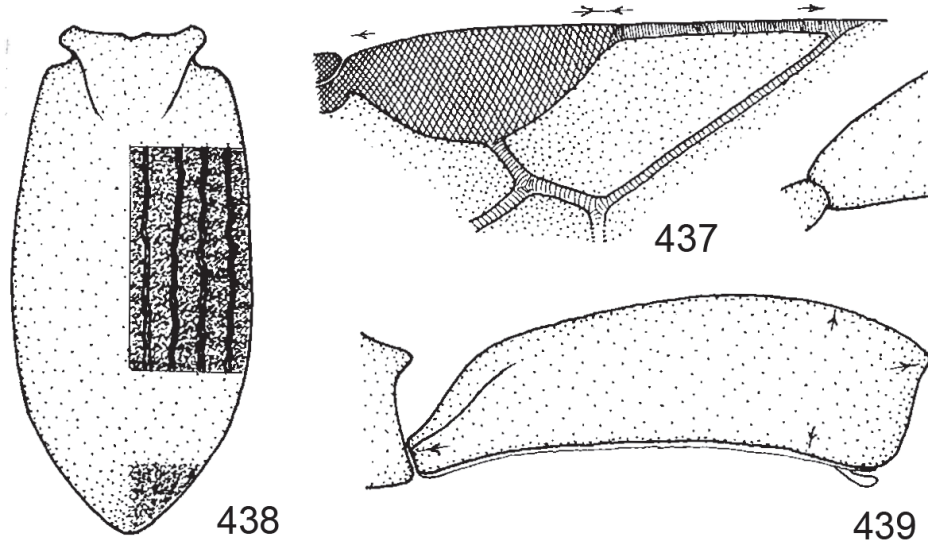

Figs 428-439. 428-431.Microchelonus subplanus Papp, 1999 (ㅇ, holotype: 428; $\widehat{\jmath}$, paratype: 430-431; ㅇ: 429): 428 = carapace in lateral view, $429-430=$ pterostigma $+1-R 1$ of right fore wing, $431=$ carapace in dorsal view. 432-439. Microchelonus sulcifera sp. n. ( $q$, holotype: 432, 434, 436-437, 439; $ᄋ$, paratype: $433,435,438$ ): 432 = head in dorsal view with indication of its sculpture, 433 = head in lateral view with indication of its sculpture, $434=$ clypeus, 435 = middle tibia, 436 = hind femur + tibia, 437 = distal part of right fore wing, 438 = cara-

pace in dorsal view with indication of its sculpture, $439=$ carapace in lateral view. 
Carapace in dorsal view 2.1 times as long as broad about medially, apically conicule-shape, with longitudinal sulciferous striationes, interstriations subcrenulated (Fig. 438). Carapace in lateral view 3.2 times as long as high posteriorly, its hind end somewhat obliquely truncate (Fig. 439 see arrows). Carapace apically with a small foramen (Fig. 440). Carapace apico-ventrally weakly incurved (cf. Fig. 197). Ovipositor short, concealed.

Ground colour of body black. Scape and pedicel testaceous, flagellum blackish. Palpi pale yellow. Tegula brownish. Legs testaceous, hind coxa black, hind tibia apically blackish, tarsi straw yellow. Wings hyaline, pterostigma dark brown, veins yellow to light brownish.

Description of the three female paratypes - Similar to the female holotype. Body 4-4.2 mm long. Penultimate flagellomere subcubic: slightly longer than broad (2 o $q)$. Fore wing: 1-R1 0.7 times as long as pterostigma ( 1 , cf. Fig. 137). Carapace in dorsal view 2.5-2.6 times as long as broad.

Male and host unknown.

Distribution - Costa Rica, Honduras.

Taxonomic position - The new species, Microchelonus sulcifera, is closest to $M$. fodicus sp. n., M. refluus Papp and M. townsendi (Viereck) viewing their strong sculpture and long 1-R1; their distinction is presented in the key to the female Microchelonus species, see couplets 25 (24) - 31 (28).

\section{Microchelonus topali Papp, 1999 \\ (Figs 441-452)}

Microchelonus topali Papp, 1999: 192 우, type locality: Argentina, prov. Rio Negro, El Bolsón, Mt. Piltriquitron, $700 \mathrm{~m}$, female holotype and three female + fifteen male paratypes in HNHM; examined.

Emendated features to the original description (Papp 1.c.) - 9. Body 2.8-3 mm long. Head above: vertex and occiput transversely substriated (Fig. 441). Gena punctate, punctation fairly strong and thickening posteriorly, interpunctures polished (Fig. 442). Face striolated (Fig. 443). Scutellum variably distincly punctate (Fig. 444) to finely punctate (Fig. 445), interpunctures shiny. Fore wing: 1-R1 0.6-0.7 times as long as pterostigma. Carapace undulate striated, interstriations rugulose, apically rounded (Fig. 447).

${ }^{7}$. Similar to the female. Body 2.6-2.9 mm long. Gena punctate, punctation less strong than that of female, interpunctures shiny (Fig. 448). Hind femur 3.1-3.3 times as long as broad medially (Fig. 450). Fore wing: 1-R1 0.7-0.85 times as long as pterostigma. Carapace in dorsal view 1.8-1.9(-2) times as long as broad about medially, its sculpture less strong than that of the female, striations less undulate (Fig. 451). Apical foramen of carapace oval, 2.2-2.5 times as wide as high (Fig. 452). Tarsi brownish.

Distribution - Argentina.

Taxonomic position - In the original description M. topali is related to $M$. johni (Marsh) and M. masoni (McComb) (Papp l.c.). In the key to the female Microchelonus species M. topali runs to M. johni (Marsh) and M. ormos sp. n., see couplets 66 (59) - 70 (69) as well as to M. angustus Papp and M. phthorimaeae 

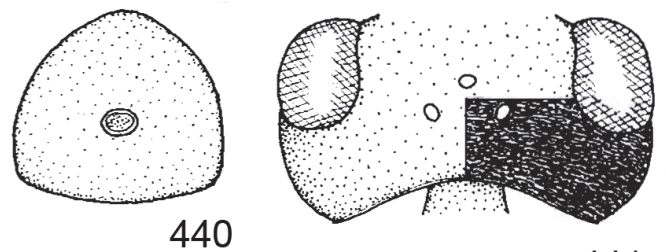

441
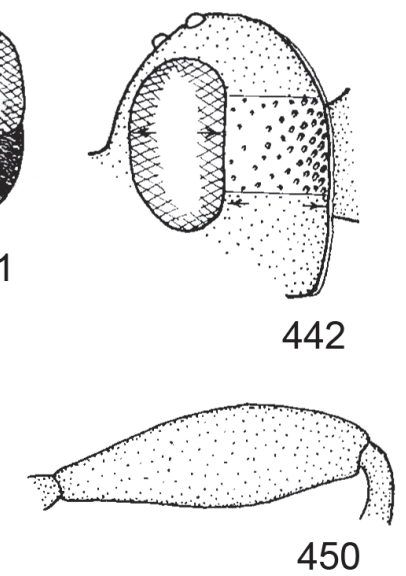

442
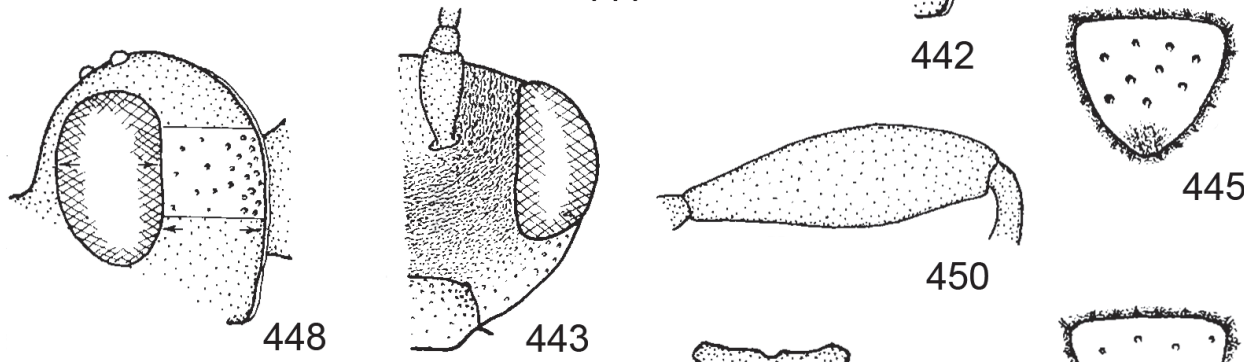

445
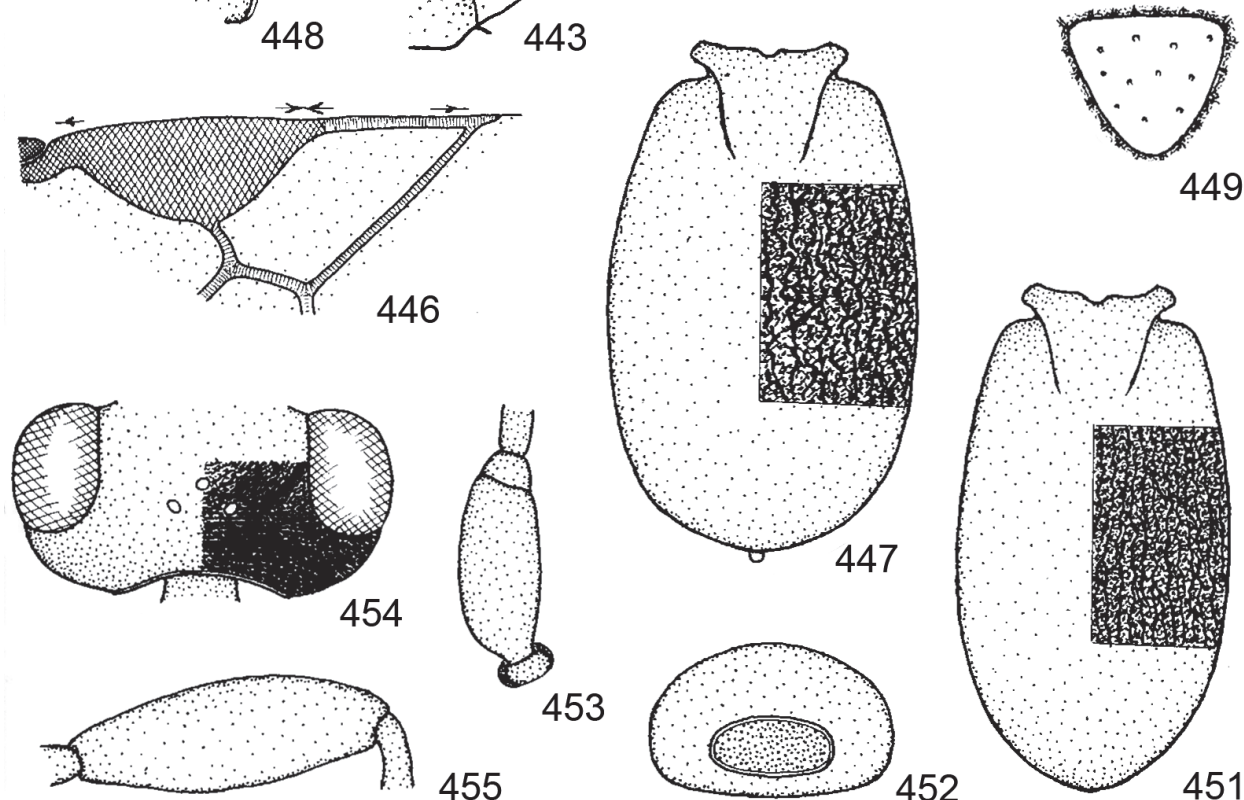

444

455
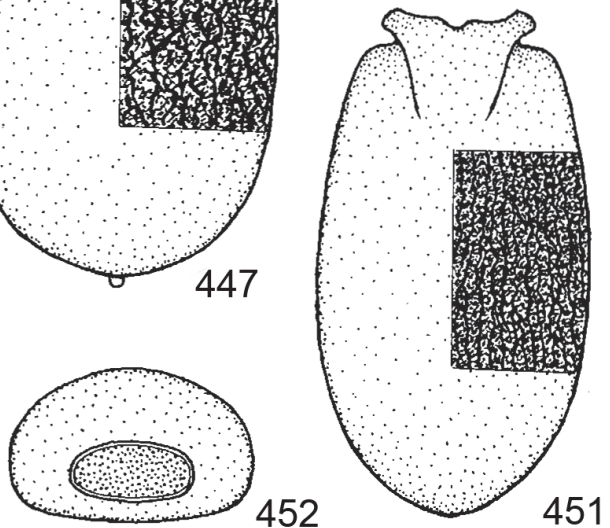

Figs 440-455. 440. Microchelonus sulcifera sp. n. ( $\odot$, holotype): $440=$ apical foramen of carapace. 441-452. Microchelonus topali Papp, 1999 (ㅇ, holotype: 441-444, 446-447; $ᄋ$ and $\hat{\delta}$ paratype: 445 ; $\hat{\partial}$, paratype: $448-452): 441=$ head in dorsal view with indication of its sculpture, $442=$ head in lateral view with indiction of its sculpture, $443=$ right half of head in frontal view, $444-445=$ scutellum, $446=$ distal part of right fore wing, $447=$ carapace in dorsal view with indication of its sculpture, $448=$ head in lateral view with indication of its sculpture, $449=$ scutellum, $450=$ hind femur, $451=$ carapace in dorsal view with indication of its sculpture, 452 = apical foramen of carapace. 453-455. Microchelonus townsendi (Viereck, 1912) (+): 453 = scape and pedicel in lateral view, $454=$ head in dorsal view with indication of its sculpture, $455=$ hind femur. 
(Gahan), see couplets 104 (109) - 108 (107); in the key to the males it runs to $M$. curticarinulus sp. n., see couplets 6 (5) - 8 (7), and to M. brasiliensis (Brues), see couplets $49(48)-51(50)$.

\section{Microchelonus townsendi (Viereck, 1912) (Figs 453-458)}

Chelonus (Chelonella) townsendi Viereck, 1912: 619 , type locality: Peru, Department of Piura, female holotype in USNM; examined.

Microchelonus townsendi (Viereck): SHENEFelt 1973: 906 (comb. n., literature up to 1913). PAPp 1999: 195 (redescription, taxonomic position).

Emendated features to the redescription (Papp l.c.) - 9 . Body $2.9 \mathrm{~mm}$ long. Scape 2.1 times as long as broad medially (Fig. 453). Flagellomeres 9-13 gradually shortening: 9th flagellomere 1.7 times and 13th (or penultimate) flagellomere 1.2 times as long as broad. Fig. 456). Eye in dorsal view twice longer than temple. Frons with a bent carinula between eye and ocellar field, head above densely substriolated (Fig. 454). Hind femur 2.8 times as long as broad medially (Fig. 455). Carapace in dorsal view with strong and somewhat undulate striations, twice longer than broad about medially, apically somewhat coniculeshape (Fig. 457). Apical foramen of carapace very small, round (Fig. 458). - ô not seen.

Distribution - Peru.

Taxonomic position - In the key to the female Microchelonus species $M$. townsendi runs (in refluus-group) to M. sulcifera sp. n., see couplets 28 (31) - 30 (29), (in blackburni-group) to M. blackburni, M. brasiliensis and M. pectiniphorae, see couplets $84(91)-90(89)$.

\section{Microchelonus tuberulus sp. $n$.}

(Figs 459-469)

Material examined - Female holotype: Costa Rica, Heredia, Chilamate, 18-23 August 1988, leg. W. J. Hanson. - Holotype is in good condition: glued direct to the pin by the right side of mesosoma. Holotype is deposited in HNHM, Hym. Typ. No. 12254; examined.

Etymology - The new species received the name "tuberulus" after the tubercule on the apical end of the carapace (Figs 466-468).

Description of the female holotype - Body $3.1 \mathrm{~mm}$ long. Antenna somewhat shorter than body ( $2.8 \mathrm{~mm}$ long) and with 16 antennomeres. Scape slightly globose, 2.8 times as long as broad (cf. Fig. 322). First flagellomere 5.7 times as long as broad, further flagellomeres shortening so that penultimate flagellomere subcubic, 1.25 times as long as broad (Fig. 459). - Head in dorsal view transverse, 2.1 times as broad as long, eye 2.5 times longer than temple, temple receded (Fig. 460). OOL almost twice as long as POL. Eye in lateral view 1.9 times as high as wide, gena beyond eye broadening ventrally and here as wide as eye, polished with hairpunctures (Fig. 461). Clypeus 1.3 times as wide below as high medially, its lower margin truncate (Fig. 462), subpunctate, shiny. Face more or less confluently punctate, subshiny. Frons with transverse substriolation, vertex and occiput hairpunctate, shiny (Fig. 460). 
Mesosoma in lateral view 1.2 times as long as high, scabrous-rugose, mesoscutum uneven and postero-medially scabrous. Scutellum rugose (cf. Fig. 372). Transverse carina of propodeum with four small denticules (Fig. 463), horizontal part of propodeum medial-
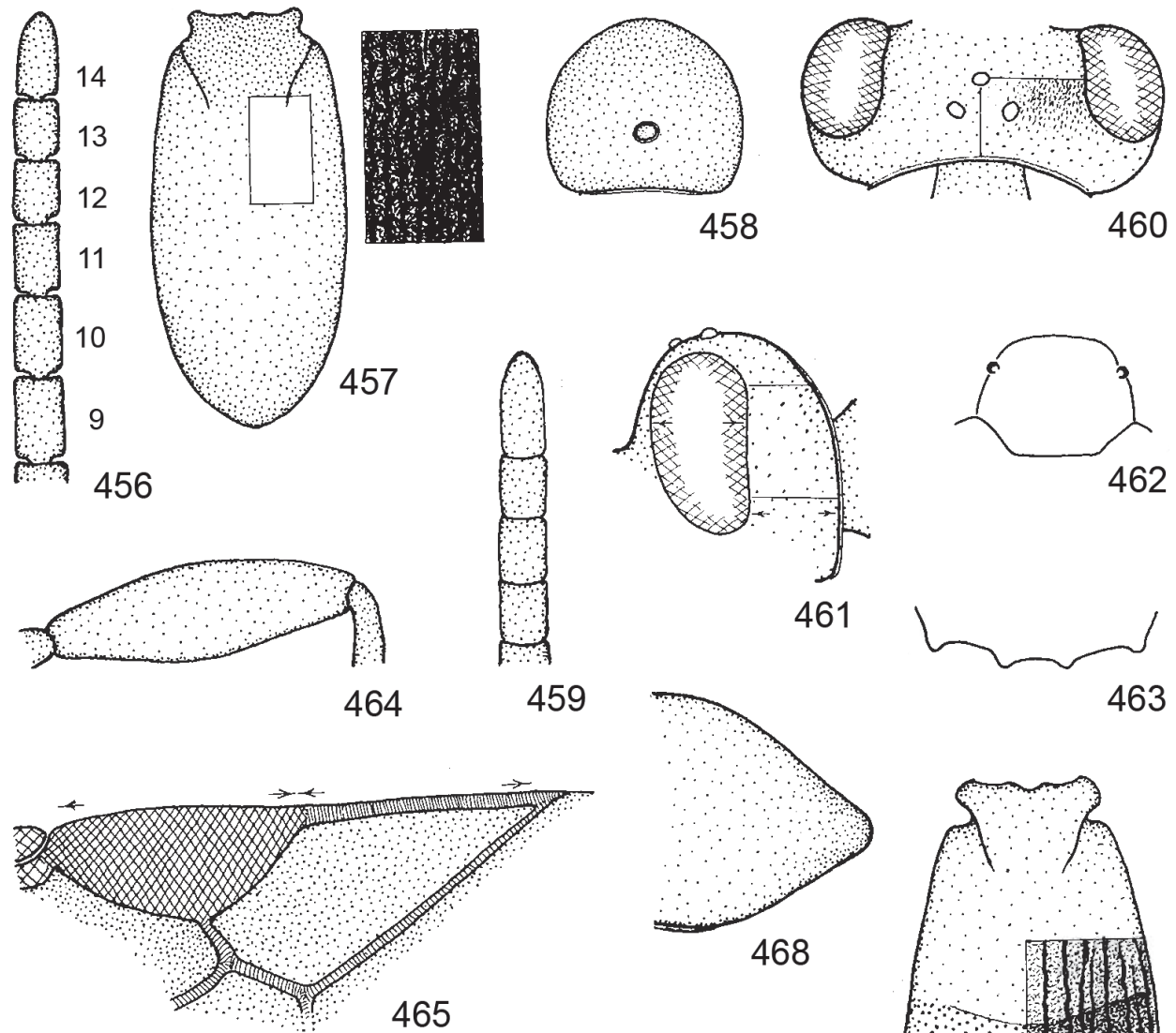

463
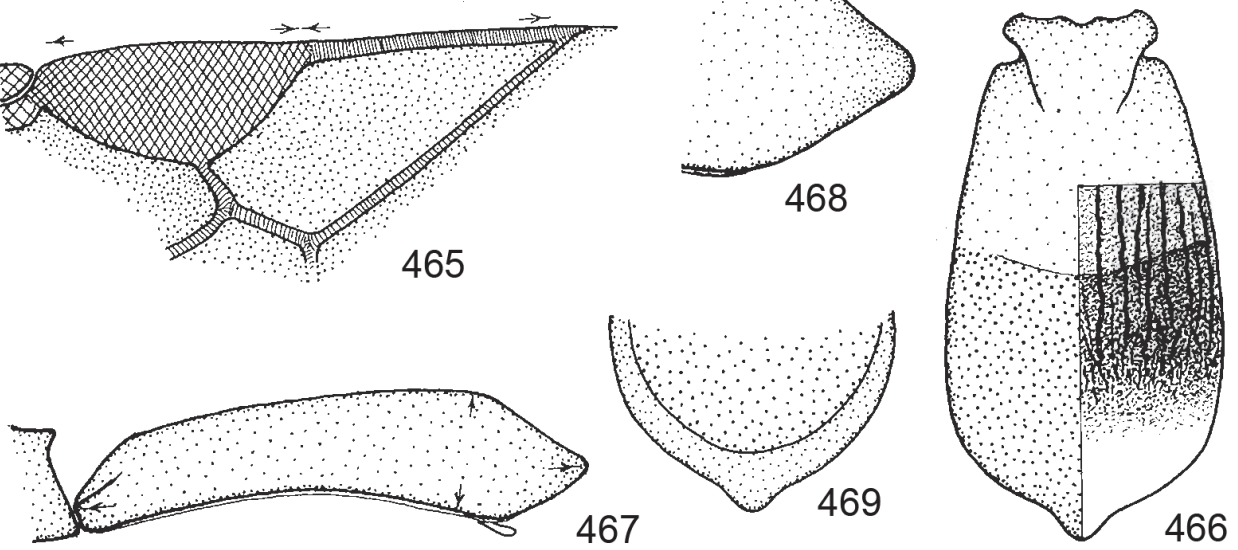

Figs 456-469. 456-458. Micrchelonus townsendi (Viereck, 1912) (q): 456 = ultimate six flagellomeres, $457=$ carapace in dorsal view with indication of its sculpture, $458=$ apical foramen of carapace. 459-469. Microchelonus tuberulus sp. n. (ㅇ, holotype): $459=$ ultimate four flagellomeres, $460=$ head in dorsal view with indication of its sculpture, $461=$ head in lateral view with indication of its sculpture, 462 = clypeus, 463 = propodeal carina in dorsal view, $464=$ hind femur, $465=$ distal part of right fore wing, $466=$ carapace in dorsal view with indication of its sculpture, $467=$ carapace in lateral view, $468=$ posterior third of carapace in lateral view, $469=$ posterior third of carapace in ventral view. 
ly with a wide oval-shaped areola (cf. Fig. 103). Hind femur somewhat thick, 3.1 times as long as broad medially (Fig. 464). Hind basitarsus almost as long as tarsomeres $2-4$ combined.

Fore wing shorter than body ( $2.7 \mathrm{~mm}$ long). Pterostigma wide, 2.1 times as long as wide and issuing $r$ distally from its middle, 3-SR twice as long as $r, S R 1$ straight, $1-R 1$ as long as pterostigma (Fig. 465 see arrows).

Carapace in dorsal view somewhat belly, 1.8 times as long as broad posteriorly, longitudinally striated with weak transverse (sub)striolation, striolation without anastomoses; posteriorly (beyond yellow colour) with weakening striolation, apically (i.e. its declivous part) polished and here with a tubercule (Fig. 466). Carapace in lateral view four times as long as high posteriorly, apically with a tubercule (Fig. 467 see arrows, 468). Carapace apico-ventrally slightly incurved (Fig. 469).

Ground colour of body black. Scape, pedicel and flagellomeres 1-4 yellow, flagellomeres 3-4 darkening brownish, rest of flagellum brownish black. Palpi brown. Tegula black. Anterior half of carapace straw yellow. Legs yellow, hind tibia apically brownish. Wings subhyaline, pterostigma brown, veins yellow to brownish.

Male and host unknown.

Distribution - Costa Rica.

Taxonomic position - The new species, Microchelonus tuberulus, is close to M. latistigma sp. n. viewing their common traits: pterostigma wide: 2.1-2.2 times as long as wide (Figs 296, 465), temple in dorsal view receded (Figs 290, 460), penultimate flagellomere somewhat longer than broad (Fig. 459) and legs yellow; their distinction is presented as follows:

1 (2) Carapace apically without tubercule, its hind end declivous (Fig. 298). Fore wing: 1-R1 0.6 times as long as pterostigma (Fig. 296). Hind femur 3.5 times as long as broad (Fig. 294). Antenna black, flagellomeres 3-4 with straw yellow ring. . $: 2.6 \mathrm{~mm}$. - Costa Rica M. latistigma sp. n.

2 (1) Carapace apically with tubercule (Figs 467, 468). Fore wing: 1-R1 as long as pterostigma (Fig. 465). Hind femur 3.1 times as long as broad (Fig. 464). Proximal half of antenna yellow, rest of flagellum brownish black. $:$ : $3.1 \mathrm{~mm}$. - Costa Rica

M. tuberulus sp. n.

In the key to the female Microchelonus species M. tuberulus runs to $M$. polites sp. n., see couplets 10 (13) - 12 (11).

\section{Microchelonus turgoclarus Papp, 2010 (Figs 470-475)}

Microchelonus turgoclarus Papp, 2010: 186 +, type locality: Ecuador, Pichin, Rio Pisque, 5 km North from Guallabamba, female holotype in ZMLU; examined.

Emendated features to the original descrition (Papp l.c.) - 9 . Body $2.7 \mathrm{~mm}$ long. Eye in dorsal view as long as temple. Gena beyond eye broadening ventrally and almost 1.3 times wider than eye, polished and antero-posteriorly hairpunctate to substriolated (Fig. 
471). Face fairly densely punctate, interpunctures polished (Fig. 472). Scutellum polished and dispersely hairpunctate. Fore wing: pterostigma 2.1 times as long as wide, 1-R1 0.7 times as long as pterostigma (Fig. 473). Carapace in dorsal view 1.6 times as long as broad
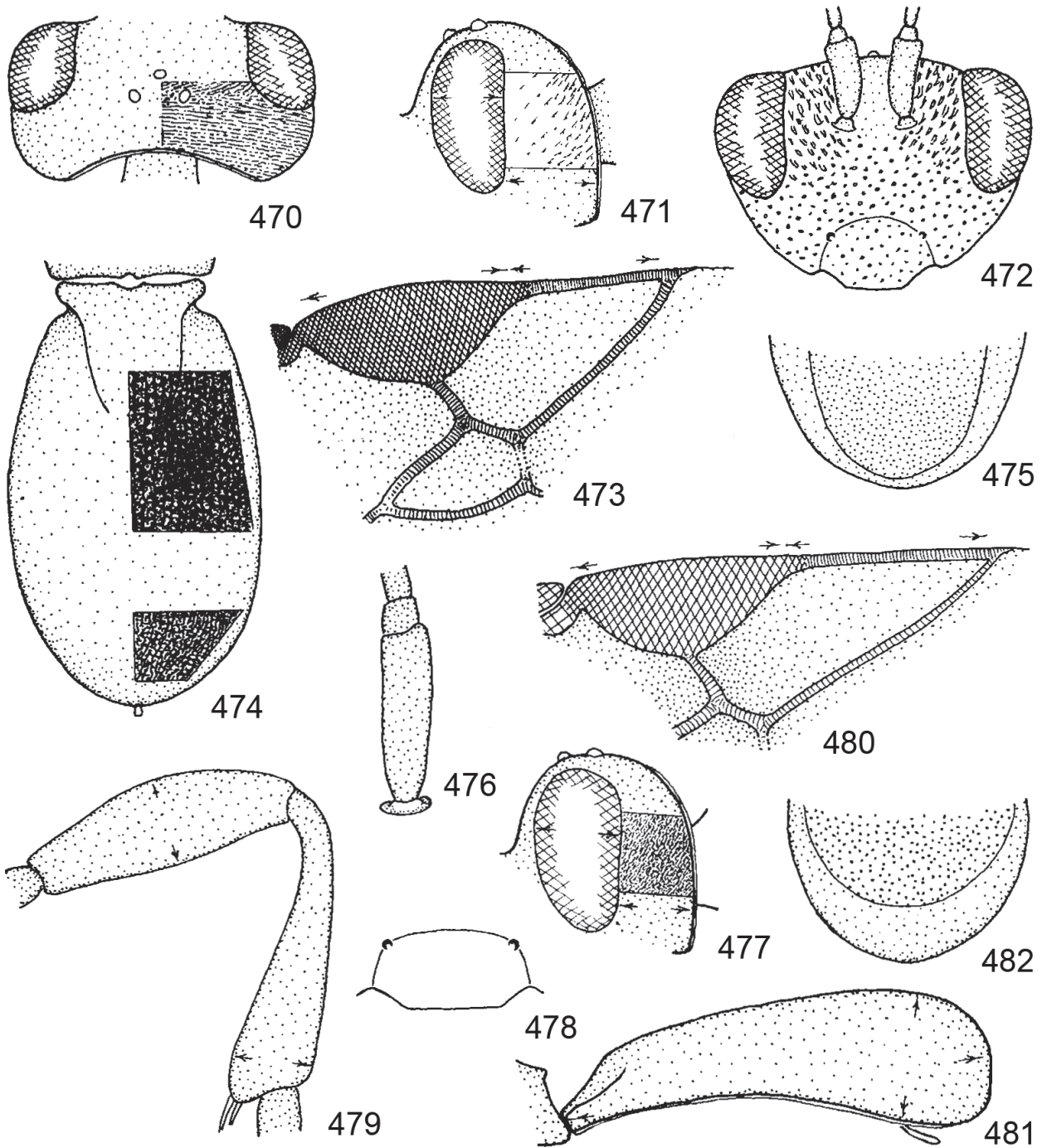

Figs 470-482. 470-475. Microchelonus turgoclarus Papp, 2010 (q, holotype): $470=$ head in dorsal view with indication of its sculpture, $471=$ head in lateral view with indication of its sculpture, 472 = head in frontal view, $473=$ distal part of right fore wing, $474=$ carapace in dorsal view with indication of its sculpture, $475=$ posterior third of carapace in ventral view. 476-482. Microchelonus vissas sp. n. ( 9 , holotype): $476=$ scape and pedical in lateral view, $477=$ head in lateral view with indication of its sculpture, $478=$ clypeus, $479=$ hind femur + tibia, $480=$ distal part of right fore wing, $481=$ carapace in lateral view, $482=$ posterior third of carapace in ventral view. 
medially, densely striated, transverse crenulation fairly strong (Fig. 474). Carapace apicoventrally just incurved (Fig. 475). Legs black(ish) to brown, tibiae 1-2 with yellow pattern.

Distribution - Ecuador.

Taxonomic position - In the original description $M$. turgoclarus is related to M. brasiliensis (Brues) (Papp 1.c.). M. turgoclarus is also close to $M$. danzas sp. n., the distinction between the two species is as follows:

1 (2) Face fairly densely punctate, interpunctures polished (Fig. 472). Fore wing: pterostigma wide, 2.1 times as long as wide, $1-R 10.7$ times as long as pterostigma (Fig. 473 see arrows). Carpace in dorsal view belly, 1.6 times as long as broad medially (Fig. 474). Flagellum black. + : 2.7 mm. Ecuador

M. turgoclarus Papp, 2010

2 (1) Face rugose (cf. Fig. 325). Fore wing: pterostigma less wide, 2.5 times as long as wide, 1-R1 almost as long as pterostigma (Fig. 166 see arrows). Carapace in dorsal view not belly, evenly broadening posteriorly (Fig. 170). Flagellum blackish, flagellomeres 3-5 ochre yellow. $+: 4.2 \mathrm{~mm}$. Costa Rica

M. danzas sp. n.

In the key to the female Microchelonus species $M$. turgoclarus runs to $M$. flavopax Papp, see couplets 59 (66) - 62 (63).

\section{Microchelonus vissas sp. $n$.}

(Figs 476-483)

Material examined - Female holotype: Costa Rica, San José, Escazu, 25-29 July 1988, leg. F. D. Parker. - Holotype is in good condition: (1) glued directly to the pin by its right mesopleuron, (2) right antenna deficient: present scape, pedicel and flagellomeres 1-2. Holotype is deposited in HNHM, Hym. Typ. No. 12247.

Etymology - The new species received the latinized phantasy name "vissas".

Description of the female holotype - Body $3 \mathrm{~mm}$ long. Antenna shorter than body (2.5 $\mathrm{mm}$ long) and with 16 antennomeres. Scape thrice as long as broad (Fig. 476). First flagellomere six times and penultimate flagellomere twice as long as broad (cf. Fig. 301). - Head in dorsal view transverse, twice as broad as long (60:29), eye 2.2 times longer than temple, temple receded (cf. Fig. 460). OOL = POL. Eye in lateral view 1.8 times as high as wide, gena beyond eye less broadening ventrally, 0.8 times as wide as eye, substriolate-rugulose and subshiny (Fig. 477 see arrows). Clypeus twice as wide below as high medially, its lower margin truncate (Fig. 478), subrugulose, dull. Face more or less transversely subrugulose (slightly stronger than that of clypeus). Vertex and occiput transversely substriolate, subshiny. Clypeus and face with silvery pubescent.

Mesosoma in lateral view stout, 1.2 times as long as high, scabrous, notaulix distinct. Scutellum roughly rugose (cf. Fig. 82). Hind femur 2.9 times as long as broad medially; hind tibia almost four times longer than broad distally and just less broad (16:17) than femur (Fig. 479 see arrows). Hind basitarsus as long as tarsomeres $2-4$ combined. 
Fore wing shorter than body (2.7 mm long). Pterostigma wide, 2.1 times as long as wide and issuing $r$ from its middle, faintly bent and somewhat longer (8:6-7) than 3-SR, SR1 feebly S-form, 1-R1 as long as pterostigma (Fig. 480 see arrows).

Carapace in dorsal view somewhat globose, 1.7 times as long as broad posteriorly, longitudinally and finely striated with few anastomoses, apically rounded (Fig. 483). Carapace in lateral view 3.2 times as long as high posteriorly, apically declivous (Fig. 481 see arrows). Carapace apico-ventrally weakly incurved (Fig. 482). Carapace apically without foramen. Ovipositor sheath short, concealed.

Body black, carapace antero-medially with a yellow macula. Scape and pedicel light brownish with darkening suffusion. Flagellum blackish. Palpi dark. Tegula dark brown, parategula brown. Legs 1-2 yellow with less dark pattern. Leg 3 black to blackish, yellow: trochanters, base of femur and tibia. Tarsi 2-3 dark fumous. Wings subhyaline, pterostigma brown, veins yellow to light brown.

Male and host unknown.

Distribution - Costa Rica.

Taxonomic position - The new species, Microchelonus vissas, is close to $M$. aperon sp. n. viewing their similar fore wing venation (Figs 32, 480), short corporal length and yellow coloured legs with much dark pattern; the two species are differentiated by the following features:

1 (2) Gena beyond eye less broadening ventrally, somewhat less wide than eye (14:17), substriolate-rugulose and subshiny (Fig. 477 see arrows). Fore wing: pterostigma 2.1 times as long as wide and $1-R 1$ as long as pterostigma (Fig. 480). Carapace in lateral view apically declivous (Fig. 481). Carapace in dorsal view anteriorly yellow. $+: 3 \mathrm{~mm}$. - Costa Rica

M. vissas sp. n.

2 (1) Gena beyond eye broadening ventrally and as wide as eye, shiny to polished and posteriorly substriolated (Fig. 28). Fore wing: Pterostigma 2.3 times as long as wide and 1-R1 0.8 times as long as pterostigma (Fig. 32). Carapace in lateral view apically obliquely incurved ventrally (Fig. 34 see arrows). Carapace in dorsal view anteriorly black. $+: 3 \mathrm{~mm}$. - Costa Rica

M. aperon sp. $n$.

In the key to the female Microchelonus species M. vissas runs to M. carinatus (Provancher) and M. fascis Papp, see couplets 49 (44) - 54 (55).

\section{Microchelonus zobocus sp. $\mathrm{n}$. \\ (Figs 484-496)}

Material examined $(1 q+1$ đ) - Female holotype: Costa Rica, Guanacaste, LaTaboga Forest Research, 9 km SW from Cañas, 23-30 April 1987, leg. W. L. Rubin. One male paratype: Costa Rica, Guanacasta, 14 km S from Cañas, 10 May 1989, leg. F. D. Parker.

Types condition - Holotype is in good condition: (1) glued direct to the pin by the right side of the mesosoma, (2) right legs 1-2 less visible owing to the mounting. Male paratype 
is also in good condition: (1) glued like the holotype, (2) left antenna deficient: flagellomeres 11-16 missing, (3) right eye and fore leg hardly visible owing to the mounting.

Type depository - Holotype and paratype are deposited in the HNHM, Hym. Typ. Nos 12248 (holotype) and 12249 (paratype).

Etymology - The new species received the latinized phantasy name "zobocus".

Description of the female holotype - Body $2.2 \mathrm{~mm}$ long. Antenna about as long as head and mesosoma combined and with 16 antennomeres. First flagellomere 2.5 times as long as broad apically, penultimate flagellomere cubic: as long as broad (Fig. 484). - Head in dorsal view conspicuously transverse, 2.3 times as broad as long, eye 2.2 times longer than temple, temple receded (Fig. 485). OOL somewhat (11:10) longer than POL, ocelli almost round. Eye in lateral view 1.9 times as high as wide, gena beyond eye broadening ventrally and here as wide as eye, finely substriolate, subshiny (Fig. 486 see arrows). Clypeus 2.1 times as wide below as high medially, its lower margin truncate (Fig. 487), rather dispersely subpunctate. Malar space twice longer than basal width of mandible. Face 2.8 times as wide as high, finely substriolate, shiny (similar to gena). Vertex and occiput transversely substriolate (Fig. 485).

Mesosoma in lateral view 1.4 times as long as high, mesoscutum rugose, otherwise scabrous. Notaulix anteriorly less distinct, posteriorly indistinct. Scutellum smooth, polished with few hairpunctures (cf. Fig. 449). Propodeal carina: lateral pair of denticules distinct, medial pair of denticules small (Fig. 488). Hind femur 2.8 times as long as broad medially (Fig. 489). Hind basitarsus as long as tarsomeres 2-3 and half of tarsomere 4 combined.

Fore wing one-fifth shorter than body (40:50, $1.8 \mathrm{~mm}$ long). Pterostigma wide, 2.1 times as long as wide and issuing $r$ from its middle, $r$ long: 1.7 times longer than $3-S R, S R 1$ faintly bent, 1-R1 0.6 times as long as pterostigma (Fig. 490).

Carapace in dorsal view somewhat belly, 1.6 times as long as broad posteriorly, densely and undulate striated with much anastomoses, apically rounded (Fig. 491), rugulose and without foramen. Carapace in lateral view less high posteriorly, 2.8 times longer than high, apically rounded (Fig. 492). Carapace apico-ventrally somewhat incurved (see arrow), cavity of carapace as in Fig. 493. Ovipositor sheath long, nearly as long as hind tarsus.

Ground colour of body black. Antenna blackish, scape faintly rusty suffused. Palpi straw yellow. Tegula blackish, parategula brown. Legs dark coloured: coxae blackish, femora brown, tibiae 1-2 straw yellow, tibia 3 basally yellow, tarsi pale yellowish with faint brownish tint. Wings hyaline, pterostigma brown, veins yellow to yellowish brownish.

Description of the male paratype - Similar to the female holotype. Body $2.4 \mathrm{~mm}$ long. Antenna somewhat longer than head and mesosoma combined. Penultimate flagellomere 1.3 times as long as broad. Head in dorsal view 2.3 times as broad as long, temple somewhat more receded (Fig. 494). Fore wing: pterostigma twice as long as wide, $1-R 1$ almost 0.7 times as long as pterostigma (Fig. 495). Carapace in dorsal view slightly less belly, 1.7 times as long as broad posteriorly. Apical foramen of carapace oval: 1.4 times as wide as high (Fig. 496).

Host unknown.

Distribution - Costa Rica. 
Taxonomic position - The new species, Microchelonus zobocus, is in the key to the female Microchelonus species the member of the blackburni-group and runs to M. bolsoni Papp, see couplets 63 (62) - 65 (64).

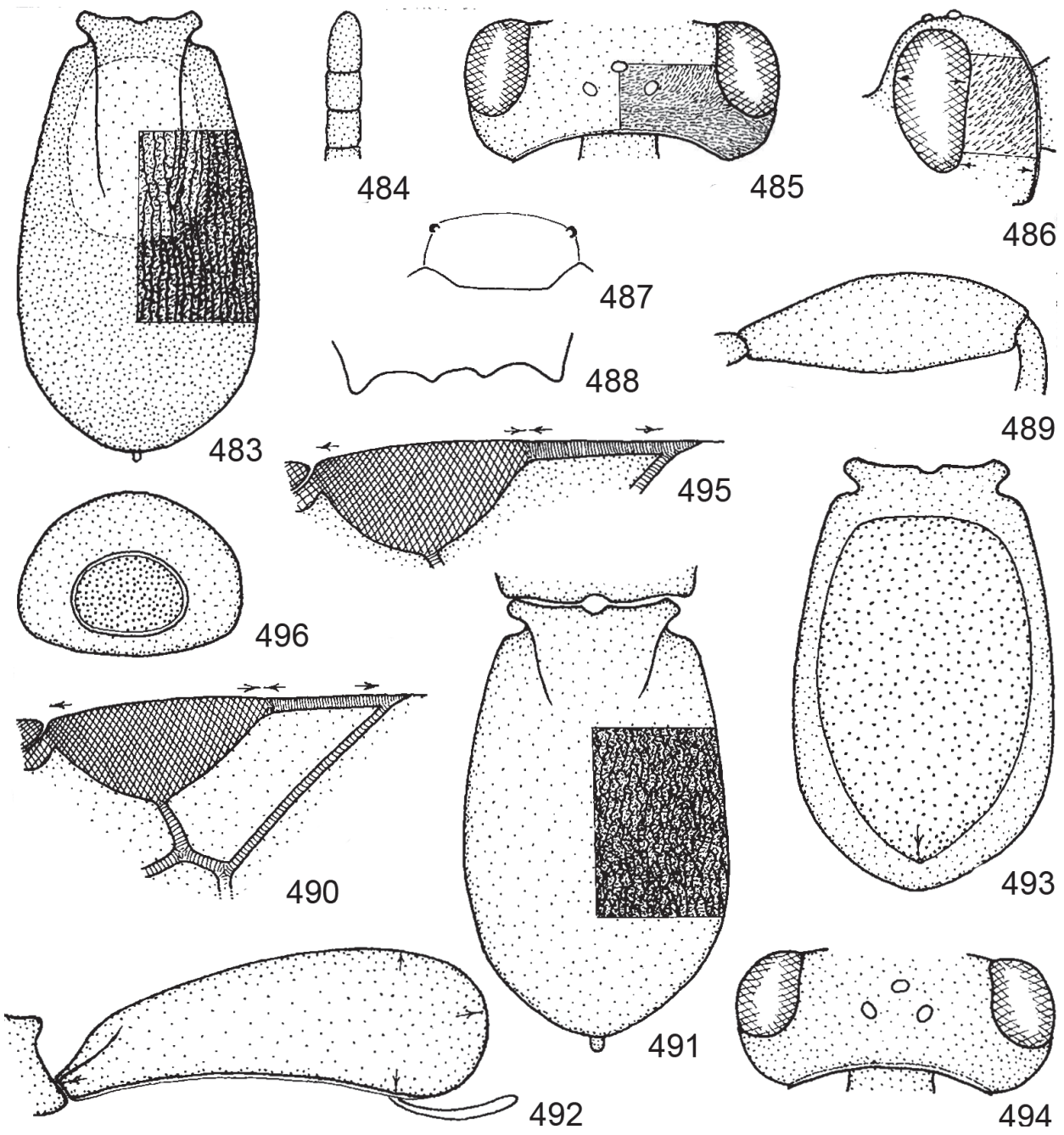

Figs 483-496. 483. Microchelonus vissas sp. n. ( 9 , holotype): 483 = carapace in dorsal view with indication of its sculpture. 484-496. Microchelonus zobocus sp. n. (9, holotype: 484-493; o, paratype: 494-496): $484=$ ultimate three flagellomeres, $485=$ head in dorsal view with indication of its sculpture, $486=$ head in lateral view with indication of its sculpture, $487=$ clypeus, $488=$ propodeal carina in dorsal view, $489=$ hind femur, $490=$ distal part of right fore wing, 491 = carapace in dorsal view with indication of its sculpture, $492=$ carapace in lateral view, $493=$ carapace in ventral view, $494=$ head in dorsal view, $495=$ pterostigma and 1-R1 of right fore wing, 496 = apical foramen of carapace. 


\section{KEY TO THE NEOTROPICAL MICROCHELONUS SPECIES Females}

1 (16) Posterior third (or declivous hind part) of carapace polished (Figs 100, 232,365 ), at most (very weakly) uneven, polished to shiny (or subshiny) (candidus species-group).

2 (7) Penultimate flagellomeres 10-13 at least 1.2-1.3 times longer than broad (Fig. 101a-b). Fore wing: 1-R1 0.65-0.75 times as long as pterostigma (Figs 105, 296).
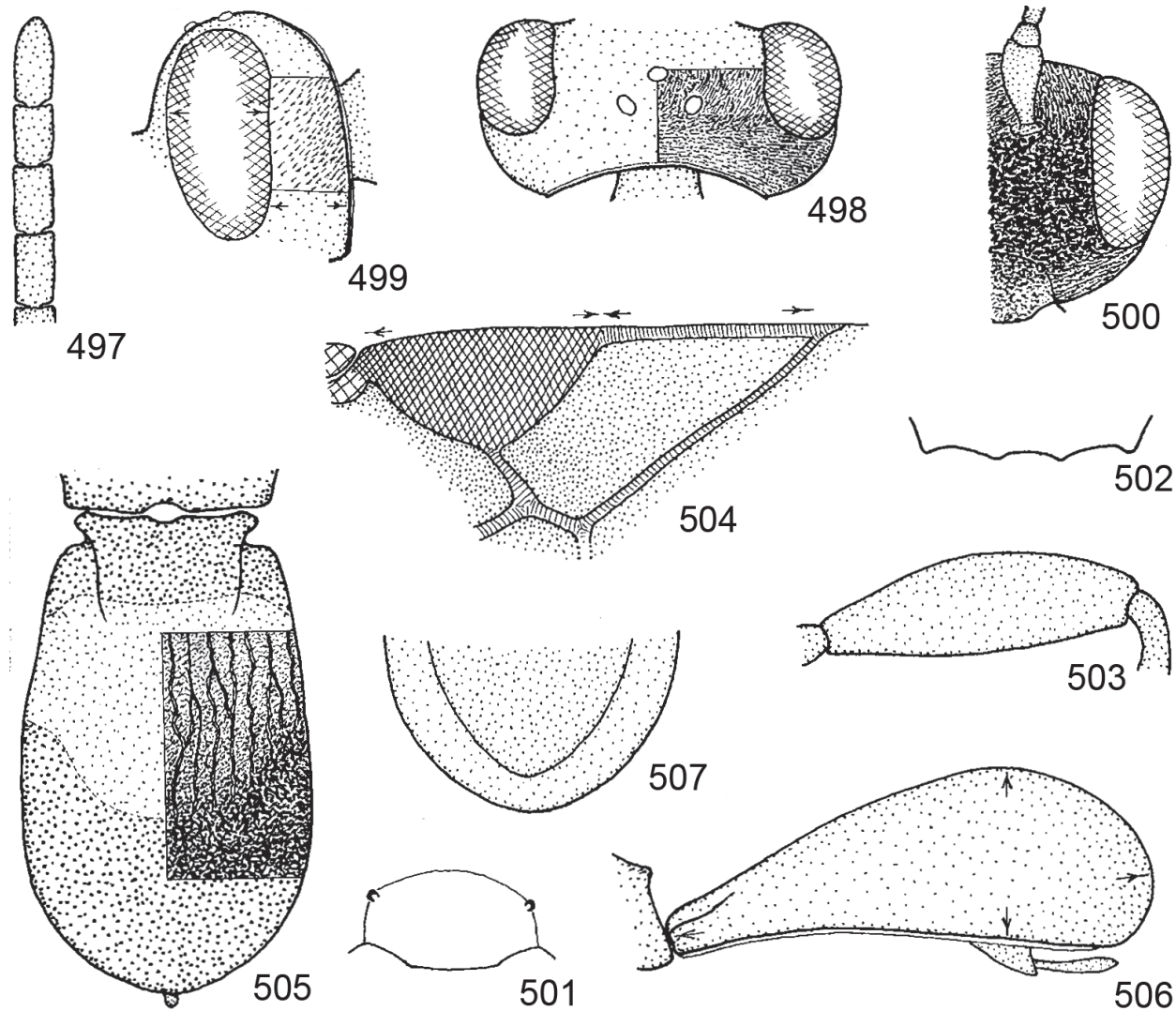

Figs 497-507. Microchelonus mccombi sp. n. (, , holotype): 497 = ultimate four flagellomeres, 498 = head in dorsal view with indication of its sculpture, $499=$ head in lateral view with indication of its sculpture, $500=$ right half of head in frontal view, $501=$ clypeus, $502=$ propodeal carina in dorsal view, 503 = hind femur, $504=$ distal part of right fore wing, $505=$ carapace in dorsal view with indication of its sculpture, 506 = carapace in lateral view, $507=$ posterior third of carapace in ventral view. 
3 (4) Carapace apically with a tubercule (Fig. 466-469), further features see at couplets 12 (11).

M. tuberulus sp. n.

4 (3) Carapace apically without tubercule (Figs 106-107, 297-298).

5 (6) Fore wing: pterostigma wide, 2.3 times as long as wide, 1-R1 0.6 times as long as pterostigma, $r$ slightly longer than 3-SR (Fig. 296). Temple in dorsal view slightly more receded, about 0.3 times as long as eye (Fig. 290). Carapace in dorsal view globose: 1.6 times as long as broad, anteriorly striated (Fig. 297).

M. latistigma sp. $\mathrm{n}$.

6 (5) Fore wing: pterostigma less wide, 2.6-3 times as long as wide, 1-R1 0.65 times as long as pterostigma, $r$ shorter than $3-S R$ (Fig. 105). Temple in dor-
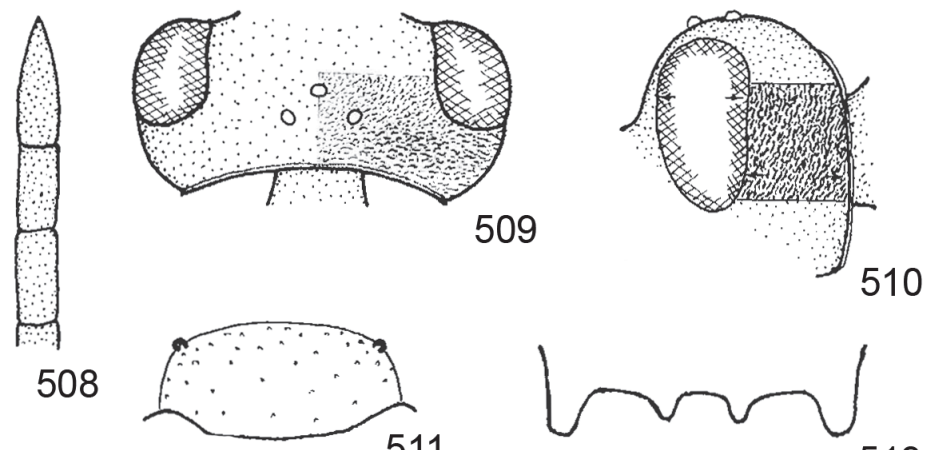

511

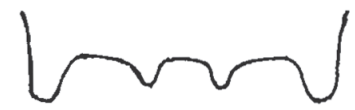

513
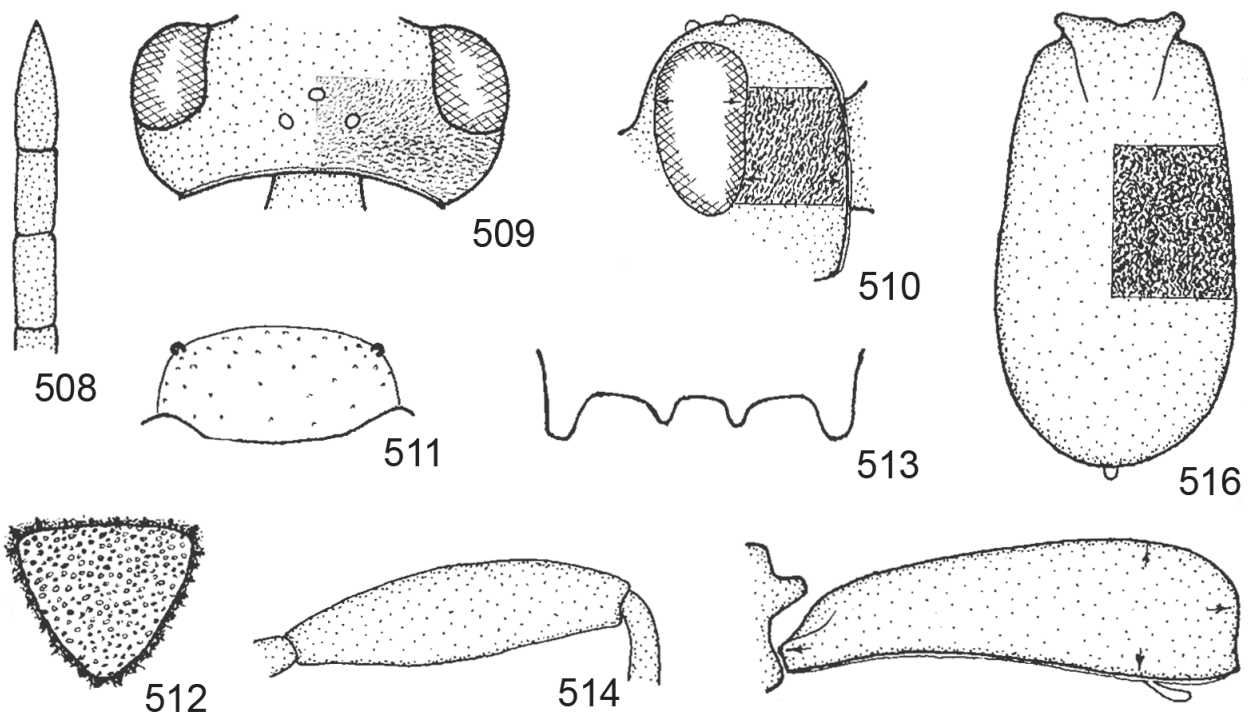

517
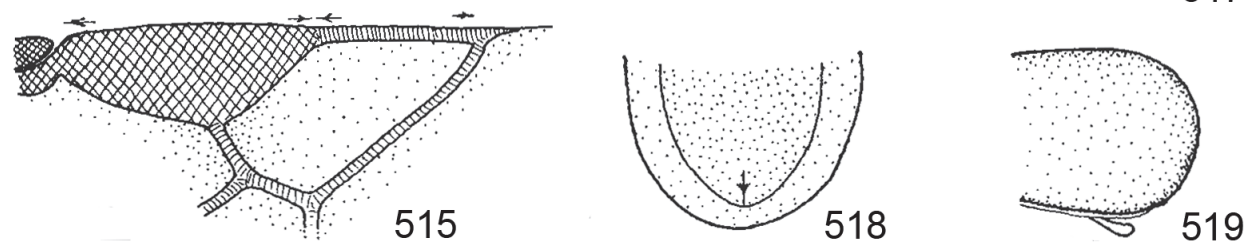

Figs 508-519. 508-518. Microchelonus phthorimaeae (Gahan, 1917) (): $508=$ ultimate three flagellomeres, $509=$ head in dorsal view with indication of its sculpture, $510=$ head in lateral view with indication of its sculpture, $511=$ clypeus, $512=$ scutellum, $513=$ propodeal carina in dorsal view, $514=$ hind femur, $515=$ distal part of right fore wing, $516=$ carapace in dorsal view with indication of its sculpture, $517=$ carapace in lateral view, $518=$ posterior third of carapace in ventral view. 519. Microchelonus kellieae (Marsh, 1979): posterior third of carapace in lateral view. 
sal view slightly less receded, about 0.5 times as long as eye (Fig. 102). Carapace in dorsal view less globose, 1.9 times as long as broad, anteriorly finely striated (Fig. 106). + : 3.2-3.5 mm. - Costa Rica M. candidus sp. n.

7 (2) Penultimate flagellomeres 10-13 subcubic to cubic: slightly longer to as long as broad (Figs 182, 360, 459). Fore wing: $1-R 1$ variably 0.5 to as long as pterostigma (Figs 189, 231, 364, 465).

8 (9) Temple in dorsal view long and rounded, almost as long as eye (Fig. 183). Fore wing: 1-R1 0.6 times as long as pterostigma (Fig. 189). Hind femur thin, 3.8 times as long as broad (Fig. 188). Carapace in dorsal view 1.8 times as long as broad, anteriorly striolate with few anastomoses (Fig. 190). Carapace anteriorly with a lemon yellow band. $+: 3.6 \mathrm{~mm}$. - Costa Rica

M. exceptus sp. n.

9 (8) Temple in dorsal view short and receded, at most half as long as eye (Figs $154,227,361,460)$.

10 (13) Carapace in dorsal view apically with tubercule (Figs 365, 466); in lateral view flattened (Fig. 467). Antenna proximally and legs more or less yellow.

11 (12) Tubercule in lateral view ventrally at apical end of carapace (Fig. 366). Fore wing: 1-R1 0.7 times as long as pterostigma, pterostigma itself 2.5 times as long as wide, $3-S R$ and $r$ equal in length (Fig. 364 see arrows). Carapace in dorsal view somewhat globose, 1.7 times as long as broad, its striation undulate (Fig. 365). Carapace entirely black. + : $2.7 \mathrm{~mm}$. Costa Rica

M. polites sp. n.

12 (11) Tubercule in lateral view medially at apical end of carapace (Figs 467468). Fore wing: $1-R 1$ as long as pterostigma, pterostigma itself 2.1 times as long as wide, $3-S R$ twice as long as $r$ (Fig. 465 see arrows). Carapace in dorsal view less globose, 1.8 times as long as broad, its striation not undulate (Fig. 466). Carapace anteriorly yellow, posteriorly black. $+: 3.1 \mathrm{~mm}$. - Costa Rica

M. tuberulus sp. $n$.

13 (10) Carapace in dorsal view apically without tubercule (Figs 158, 232); in lateral view less flattened (Figs 159, 233). Scape ochre, legs dark coloured.

14 (15) Fore wing: $1-R 1$ short, half (0.5 times) as long as pterostigma, SR1 bent (cf. Fig. 146 see arrows). Gena in lateral view faintly broadening ventrally, as wide as eye (Fig. 155 see arrows). Carapace in dorsal view belly, 1.7 times as long as broad, anteriorly more narrowing, striated with little anastomoses (Fig. 158); in lateral view apically somewhat 
less declivous (Fig. 159 see arrows). Flagellum and carapace entirely black. : $2.3 \mathrm{~mm}$. - Costa Rica

M. curtulus sp. n.

15 (14) Fore wing: 1-R1 long, 0.6 times as long as pterostigma, SR1 faintly bent (Fig. 231 see arrows). Gena in lateral view broadening ventrally, eye 1.2 rimes wider than gena (cf. Fig. 461 see arrows). Carapace in dorsal view not belly, twice as long as broad, anteriorly less narrowing, parallel striated (Fig. 232); in lateral view apically declivous (Fig. 233). Flagellomeres 3-4 with straw yellow ring. Carapace anteriorly yellow. +: $3.1 \mathrm{~mm}$. - Costa Rica

M. fulgens sp. n.

16 (1) Posterior third (or declivous hind part) of carapace sculptured: distinctly uneven to rugulose, rugose, scabrous, dull (Figs 7, 25, 147, 170, $332,438,474)$.

17 (22) Carapace in dorsal (or ventral) view apically with a more or less pointed spine (Figs 7, 9, 97, 99, 332-334). Carapace in lateral view inwardly truncate apically (Figs 8, 98, 333) (parkeri species-group).

18 (19) Head in dorsal view twice as broad as long, temple receded, vertex and occiput somewhat less densely substriolate (Fig. 1). Carapace in lateral view apically acute, anteriorly striated (Fig. 7); in ventral view apically deeply incurved, this part as long as hind tarsomeres 1-3 combined (Fig. 9). Fore wing: 1-R1 almost as long as pterostigma (Fig. 6 see arrows). Face rugulo-rugose (Fig. 3). Legs testaceous. $+.3 .3 \mathrm{~mm}$. - Costa Rica

M. acutulus sp. n.

19 (18) Head in dorsal view 1.7-1.8 as broad as long (Figs 94, 335). Carapaca in dorsal view apically pointed (Figs 97, 332); in ventral view apically hardly incurved, this part about as long as hind second tarsomere (Figs 99, 339).

20 (21) Frons with a pair of short carinuli between hind ocellus and eye, vertex and occiput rugose, temple strongly rounded (Fig. 335). Fore wing: 1-R1 long, 0.7 times as long as pterostigma (Fig. 337 see arrows). Carapace in dorsal view cylindric-shape, 2.2-2.4 times as long as broad, fairly roughly rugose (Figs 332, 334). Penultimate three flagellomeres cubic (Fig. 336). Fore femur stramineous. O: 3.4-3.8 mm. - Brazil, Costa Rica (=Ch. (M.) murici Nascimento et Penteado-Dias, 2011 syn. n.). M. parkeri Papp, 2010 *

21 (20) Frons without a pair of short carinuli, vertex and occiput substriolate, temple receded (Fig. 94). Fore wing: $1-R 1$ half (0.5 times) as long

* For synymization see Taxonomic emendation in Microchelonus parkeri Papp 
as pterostigma (Fig. 96 see arrows). Carapace in dorsal view less cylindric-shape, 1.9 times as long as broad, distinctly striated (Fig. 97). Penultimate flagellomere 2.6 times as long as broad (Fig. 93). Face femur brown. . $3 \mathrm{~mm}$. - Honduras

M. cacumenus Papp, 2010

22 (17) Carapace in dorsal (or ventral) view apically not spine-like pointed, i.e. either more or less rounded (Figs 25, 59, 74, 85-86, 181, 350) or conicule-shape (Figs 139, 222, 390, 438).

23 (32) Posterior third of carapace in dorsal view conicule-shape (Figs 139, $222,390,438)$. Antenna short, shorter than body, penultimate flagellomere subcubic to cubic, i.e. at most 1.2 times longer than broad (Fig. 150). A pair of arcuate carinuli present on frons between hind ocellus and eye (Figs 141, 216, 384, 432, 454) (refluus species-group).

24 (25) Carapace in dorsal view apically with a short carinulus (Fig. 147). Apical end of carapace in lateral view inwardly truncate (Fig. 148 see arrows), i.e. carapace ventrally deeply incurved: ventral aperture of carapace clearly shorter than carapace itself (Fig. 149 see arrows). Fore wing: pterostigma twice (Fig. 146 see arrows) to 2.5 times (Fig. 151 see arrows) as long as wide, issuing $r$ from its middle. Scutellum unevensubrugulose (Fig. 143). Tegula pale yellow or brown. Legs yellow with brownish pattern. + : $3.5 \mathrm{~mm}$. - Costa Rica, Honduras

M. curticarinulus sp. $\mathrm{n}$.

25 (24) Carapace in dorsal view apically without a short carinulus; either with (Fig. 440) or without a small foramen.

26 (27) Carapace in lateral view apically inclivous, i.e. deeply incurved (Fig. 391 see outer arrow); in ventral view aperture of carapace shorter than carapace itself (cf. Fig. 149 see arrows). Vertex and occiput of head rugulo-rugose (Fig. 384). Fore wing: pterostigma rather narrow, 2.8-3 times as long as wide, 1-R1 0.7 times as long as pterostigma (Fig. 389 see arrows). Scutellum scabrous (Fig. 387). Carapace basally with a pair of straw yellow maculae. + : 4.8-4.9 $\mathrm{mm}$. (See also couplets 111 (116) - 112 (113)) - Honduras

M. refluus Papp, 2010

27 (26) Carapace in lateral view apically truncate (Figs 223, 439 see outer arrow), in ventral view aperture of carapace almost as long as carapace itself (cf. Fig. 377 see arrow).

28 (31) Carapace apically with a small foramen (Figs 440, 458). Vertex and occiput substriolated (Figs 432, 454). 
29 (30) Carapace in dorsal view apically pointed cupole-shape, its striations sulciform (Fig. 438). Temple in dorsal view somewhat less receded (Fig. 432). Legs reddish yellow with little darkening suffusion, tarsi straw

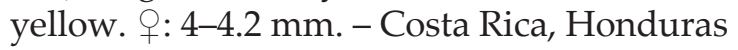

M. sulcifera sp. $n$.

30 (29) Carapace in dorsal view apically less pointed cupole-shape, its striations somewhat undulate (Fig. 457). Temple in dorsal view somewhat more receded (Fig. 454). Legs testaceous, femora + tibiae 2-3 brownish, tarsi brownish fumous. $+: 3 \mathrm{~mm}$. (A member of the blackburni-group, see couplets $84(91)-86(85))$. - Peru M. townsendi (Viereck, 1912)

31 (28) Carapace apically without a small foramen. Vertex rugose, occiput subrugulose to smooth (Fig. 216). Middle tibia with spinules (Fig. 225). Fore wing: 3-SR twice longer than $r$, SR1 faintly bent (Fig. 221 see arrows). Legs brown to black(ish) with little yellow pattern. $\circ: 5 \mathrm{~mm}$. - Costa Rica

M. fodicus sp. $\mathrm{n}$.

32 (23) Posterior third of carapace in dorsal view rounded or cupole-shape (Figs 25, 59, 74, 85-86, 181, 350). Antenna variably short to long. A pair of arcuate carinuli present on frons between hind ocellus and eye only in a few species.

33 (56) Antenna long, penultimate flagellomere 2.5-3 times longer than broad (Figs 26, 77, 192, 368, 378, 419). (effusus species-group).

34 (35) Carapace in dorsal view apically pointed (Fig. 97); in lateral view apically truncate below its pointed end (Fig. 98). Fore wing: 1-R1 half as long as pterostigma (Fig. 96 see arrows). A member of candidus-group, for further traits see couplets 20 (21) - 21 (20). M. cacumenus Papp, 2010

35 (34) Carapace in dorsal view not pointed apically (Fig. 85-86, 382); in lateral view apical end of carapace either rounded (Fig. 89 see arrows) or truncate (Fig. 383 see arrows).

36 (37) Posterior third (or declivous hind part) of carapace polished (Fig. 100). Fore wing: pterostigma 2.6-3 times as long as wide and issuing $r$ distally from its middle (Fig. 105). Penultimate flagellomere 1.8-2 times longer than broad (Fig. 101a-b). A member of candidus-group, for further traits see couplets $5(6)-6$ (5). M. candidus sp. $n$.

37 (36) Carapace entirely sculptured, its posterior third rugulose to rugose (Figs 33, 85, 170).

38 (43) Carapace in dorsal view pyriform: anteriorly less, posteriorly more broadening (Figs 86, 175, 382). 
39 (40) Eye in lateral view somewhat less narrow, 1.8-2 times as high as wide, gena somewhat less wide than eye (Fig. 173 see arrows). Carapace in dorsal view almost evenly broadening posteriorly (Fig. 175). Scutellum rugulose (cf. Fig. 266). Temple strongly rounded, vertex and occiput densely rugulo-substriolated (Fig. 172). Legs lemon yellow, antenna proximally yellow. + : 3.5-4 mm. - Costa Rica M. effusus sp. n.

40 (39) Eye in lateral view narrow, 2.1-2.5 times as high as wide, gena somewhat wider than eye (Fig. 81 see arrows). Scutellum scabrous (Fig. 82, 202). Legs more or less dark coloured.

41 (42) Temple in dorsal view rounded, eye 1.3-1.4 times longer than temple (Fig. 379). Clypeus ventrally more produced (Fig. 380). Carapace in dorsal view pyriform, densely and strongly striated (Fig. 382). Scutellum with strong longitudinal rugae (cf. Fig. 202). Legs dark brown to black with little yellow pattern. + : 5-5.5 mm. - Costa Rica, Honduras M. pyriformis Papp, 2010

42 (41) Temple in dorsal view receded, eye 1.7-2 times longer than temple (Figs 78-79). Clypeus ventrally less produced (Fig. 80). Carapace in dorsal view less pyriform (Figs 85-86), less densely and weakly striated (Fig. 85). Scutellum scabrous (Fig. 82). Legs brown to black with much yellow pattern. : : (3.6-)3.9-4.2(-4.6) mm. - ${ }^{*}$ Costa Rica, ${ }^{*}$ Honduras, *Panama, *Peru, Trinidad and Tobago M. buscki (Viereck, 1912)

43 (38) Carapace in dorsal not pyriform, antero-posteriorly (almost) evenly broadening (Figs 113, 175, 196, 376, 424) or globose (Figs 33, 483).

44 (49) Gena polished, its fine substriolation (Fig. 28) or hairpunctation (cf. Fig. 303) posteriorly crowded.

45 (46) Scutellum smooth (with hairpunctures) and shiny (Fig. 29). Carapace in dorsal view somewhat globose, apically rounded (Fig. 33); in lateral view less thickening posteriorly (Fig. 34 see arrows). Head in dorsal view 1.8 times as broad as long, temple slightly less rounded (Fig. 27). Carapace apically without foramen. Fore and middle legs yellow. $\circ: 3$ mm. - Costa Rica

M. aperon sp. n.

46 (45) Scutellum either areolate-like sculptured (Fig. 422) or scabrous (cf. Fig. 82). Carapace apically with a very small foramen (Figs 168, 425).

47 (48) Carapace in dorsal view broad, 1.9 times as long as broad, its posterior end weakly rounded (Fig. 424). Fore wing: pterostigma issuing $r$ distally from its middle (Fig. 423). Head in dorsal view 2.1 times as broad as long (Fig. 420). Clypeus 1.7 times as wide as high (Fig. 421). Flagel- 
lum entirely black(ish). o: 3.3 mm. - Costa Rica, Honduras

M. subplanus Papp, 1999

48 (47) Carapace in dorsal view less broad, 2-2.2 times as long as broad, its posterior end rounded (Fig. 170). Fore wing: pterostigma issuing $r$ from its middle (Fig. 166). Head in dorsal view twice as broad as long (Fig. 161). Clypeus 1.5 times as wide as high (Fig. 163). Flagellomeres 3-5 with ochre ring, otherwise flagellum black(ish). $+: 4.2 \mathrm{~mm}$. - Costa Rica

M. danzas sp. n.

49 (44) Gena substriolated, dull (Figs 370, 477).

50 (51) Temple in dorsal view slightly swollen, eye somewhat longer than temple, frons with a pair of arcuate carinuli (Fig. 111). Fore wing: pterostigma narrow, 3.3 times as long as wide and issuing $r$ distally from its middle (Fig. 112 see arrows). Carapace in dorsal view elongate, 2.3 times as long as broad, longitudinally rugulose (Fig. 113). Fore and middle femora (frequently hind femur too) testaceous. o : 4.5-6 mm. Canada, USA including Florida M. carinatus (Provancher, 1881)

51 (50) Temple in dorsal view not swollen, eye longer than temple, frons without a pair of carinuli (Figs 193, 369, cf. 460). Fore wing: pterostigma variably less wide to wide (Figs 195, 374, 480 see arrows).

52 (53) Temple in dorsal view receded, eye 2.2 times longer than temple (cf. Fig. 460). Fore wing: pterostigma wide, 2.1 times as long as wide, 1-R1 as long as pterostigma, 3-SR somewhat shorter than $r$ (Fig. 480 see arrows). Carapace in dorsal view globose, 1.7 times as long as broad, finely striated (Fig. 483), antero-medially with a yellow macula. $\circ: 3$ mm. - Costa Rica

M. vissas sp. n.

53 (52) Temple in dorsal view rounded, eye less than twice as long as temple (Figs 193, 369). Carapace in dorsal view not globose (Figs 196, 376).

54 (55) Fore wing: pterostigma narrow, 2.8 times as long as wide, issuing $r$ distally from its middle, $r$ shorter than 3-SR (Fig. 195). Carapace densely and finely striated (Fig. 196). Hind femur thin, 4.1-4.5 times as long as broad, hind tibia as broad distally as femur (Fig. 194 see arrows). Carapace before its middle with a whitish yellow band, middle(!) coxa + trochanter also whitish yellow. : 3.2-3.5 mm. - Honduras

M. fascis Papp, 2010

55 (54) Fore wing: pterostigma wide, 2.3 times as long as wide, issuing $r$ from its middle, $r$ longer than 3-SR (Fig. 374). Carapace strongly striated (Fig. 376). Hind femur thick, 2.6 times as long as broad, hind tibia less 
broad distally than femur (Fig. 375 see arrows). Carapace black, legs yellow with little brownish pattern. + : $3.3 \mathrm{~mm}$. - Honduras

M. projectus sp. n.

56 (33) Antenna not long, penultimate flagellomere cubic to at most twice longer than broad (Figs 20, 77, 128, 198, 263a-b, 301, 398, 456, 497).

57(102)Scutedllum smooth and shiny with disperse hairpunctures (Figs 29, $57,118,279,445)$, or with fine punctures (Fig. 13, 23, 326, 444), or faintly uneven, somewhat dull (Fig. 73) (blackburni species-group).

58 (71) Gena polished with posteriorly crowded hairpunctures/punctures (Figs 66, 442) or with substriolation (Figs 28, 324, 471, 486).

59 (66) Face finely sculptured: (sub)punctulated to substriolated, interpunctures polished (Fig. 472).

60 (61) Head in dorsal view less tansverse, 1.7(-1.8) times as broad as long, eye as long as temple, latter rounded, head above polished (Fig. 211). Gena with hairpunctures. Penultimate flagellomere 1.7-1.8 times as long as broad (cf. Fig. 128). Carapace in dorsal view evenly broadening posteriorly, 2.1-2.2 times as long as broad and with parallel striations (Fig. 214). Fore wing: pterostigma less wide: $2.6-2.7$ times as long as wide (Fig. 213 see arrows). Prothorax and anterior two-thirds of carapace yellow. o: 4.3-4.5 mm. - Costa Rica, Ecuador M. flavopax Papp, 2010

61 (60) Head in dorsal view transverse, twice as broad as long, eye (slightly) longer than temple (Figs 64, 470, 485). Gena with punctures or substriolations (Figs 66, 471, 486). Carapace in dorsal view more or less globose (Figs 69, 474, 491). Fore wing: pterostigma wide, 2.1-2.5 times as long as wide (Figs 68, 473, 490 see arrows).

62 (63) Face rather dispersely subpunctulate to punctulate, interpunctures polished (Fig. 472). Gena finely substriolated, shiny (Fig. 471). Carapace in dorsal view belly, 1.6 times as long as broad, its longitudinal striations with anastomoses (Fig. 474), apico-ventrally not incurved (cf. Fig. 169). Fore wing: pterostigma 2-2.2 times as long as wide, 1-R1 0.7 times as long as pterostigma (Fig. 473). Body dark coloured. o : 2.8 mm. - Ecuador

M. turgoclarus Papp, 2010

63 (62) Face rather densely substriolate or rugulose, shiny. Two dark coloured species.

64 (65) Head in dorsal view conspicuously transverse, 2.3 times as broad as long, temple receded and 0.4 times as long as eye, vertex and occiput substriolated (Fig. 485). Gena substriolated, shiny and as wide as eye 
(Fig. 486 see arrows). Fore wing: 1-R1 0.7 times as long as pterostigma (Fig. 495 see arrows). Penultimate flagellomere cubic: as long as broad (Fig. 484). Undulate striations of carapace relatively (compared to $M$. bolsoni) weak (Fig. 491). o: 2.2 mm. - Costa Rica M. zobocus sp. n.

65 (64) Head in dorsal view transverse, 1.9-2 times as broad as long, temple rounded and 0.6 times as long as eye, vertex and occiput densely and distinctly punctate (Fig. 64). Gena also punctate, shiny and somewhat wider than eye (Fig. 66 see arrows). Fore wing: 1-R1 half as long as pterostigma (Fig. 68 see arrows). Penultimate flagellomere subcubic, 1.1-1.2 times as long as broad (cf. Fig. 263a). $+: 2.8$ mm. - Argentina

M. bolsoni Papp, 1999

66 (59) Face substriolated to rugulose (Figs cf. 3, 325, 443).

67 (68) Head in dorsal view less transverse, 1.8 times as broad as long (Fig. 441). Carapace in lateral view apically rounded (cf. Fig. 34); in dorsal view globose, 1.7 times as long as broad and with undulate striations (Fig. 447). Scutellum with variable punctures (Figs 444-445, 449). Fore wing: pterostigma 2.3 times as long as wide, 1-R1 0.6 times as long as pterostigma (Fig. 446). Tibiae 1-3 ochre yellow. ․ : 2.8-3 mm. - Argentina, ${ }^{*}$ Honduras

M. topali Papp, 1999

68 (67) Head in dorsal view transverse, twice as broad as long (Figs 204, 323). Carapace in lateral view apically more or less truncate (Fig. 330); in dorsal view 1.9-2 times as long as broad (Figs 274, 329).

69 (70) Fore wing: pterostigma issuing $r$ distally from its middle, 1-R1 0.7-0.8 times as long as pterostigma (Figs 269, 273 see arrows). Scape less belly (cf. Fig. 133). Carapace undulate striated with anastomoses (Fig. 274). Scutellum variably almost smooth to rugulose (rugose), shiny to dull (Figs 266-267). o: 3-3.1 mm. - Colombia, Costa Rica, Honduras

M. johni (Marsh, 1979)

70 (69) Fore wing: pterostigma issuing $r$ from its middle, 1-R1 0.6 times as long as pterostigma (Fig. 328 see arrows). Scape belly (Fig. 322). Carapace parallel striated (Fig. 329). Scutellum smooth with hairpunctures, shiny (Fig. 326). o: 2.7 mm. - Costa Rica M. ormos sp. n.

71 (58) Gena substriolated of variable strength (Figs 12, 56, 72, 121, 265a-b, 346), or strongly punctate (Fig. 22).

72 (75) Fore wing: 1-R1 short, 0.5-0.55 times as long as pterostigma (Figs 16, 280).

73 (74) Temple in dorsal view receded, vertex and occiput rugose (Fig. 10). Fore wing: pterostigma somewhat less wide, 2.7 times as long as wide 
(Fig. 16 see arrows). Cheek in frontal view less converging as usually (cf. Fig. 272 see arrows). Scape and pedicel testaceous, flagellomeres 1-4 darkening testaceous. $+: 3.3 \mathrm{~mm}$. - Costa Rica M. amelot sp. n.

74 (73) Temple in dorsal view rounded (Fig. 276), vertex and occiput substriolated (cf. Fig. 323). Fore wing: pterostigma wide, 2.2 times as long as wide (Fig. 280 see arrows). Cheek in frontal view somewhat more converging (Fig. 278 see arrows). Scape, pedicel and first flagellomere testaceous with brownish tint. + : 3-3.2 mm. - Costa Rica, ${ }^{*}$ Honduras, USA: California (introduced) M. kellieae (Marsh, 1979)

75 (72) Fore wing: 1-R1 long, at least 0.7 times as long as pterostigma (Figs 24, $58,75,122,137,269,348-349$ see arrows).

76 (79) Fore wing: pterostigma narrow, at most 2.8 times as long as wide (Fig. 24 see arrows).

77 (78) Fore wing: pterostigma unusually narrow, 3.3 times as long as wide, its proximalinner margin concave Fig. 24 see perpendicular arrow). Gena strongly punctate (Fig. 22). Carapace in dorsal view apically rounded, subareolate-rugose (Fig. 25). Legs yellow, hind tibia distally brownish. Tegula yellow. $\odot: 3.1 \mathrm{~mm}$. - Argentina

M. angustus Papp, 1999

78 (77) Fore wing: pterostigma narrow, 2.8 times as long as wide, its proximal inner margin convex as usually (cf. Fig. 58 see perpendicular arrow). Carapace in dorsal view apically less rounded, somewhat undulate striated (Fig. 62). Legs lemon yellow with brown tint. Tegula black. Carapace basally straw yellow. + : (2.3-)3-3.4 mm. - USA (Texas, Hawaii), Mexico. Introduced: Australia, Egypt, Fiji, Puerto Rico

M. blackburni (Cameron, 1886)

79 (76) Fore wing: pterostigma wide, at least 2.5 times as long as wide (Figs $58,75,122,137,269,273,348-349)$.

80 (83) Gena evenly and more or less densely punctate, interpunctures shiny (Fig. 72).

81 (82) Temple in dorsal view rounded, vertex and occiput finely substriolated (Fig. 264). Further details see at couplets 96 (99) - 98 (97).

M. johni (Marsh, 1979)

82 (81) Temple in dorsal view receded, vertex and occiput strongly and almost confluently elliptic-punctate (Fig. 70). Further details see at couplets $86(85)-87(88)$.

M. brasiliensis (Brues, 1912)

83 (80) Gena substriolated and dull (Figs 56, 121, 265a-b, 346), or rugo-rugulose (Figs 72 ${ }^{\lambda}, 135$ ). 
84 (91) Temple in dorsal view receded, eye twice longer than temple (Figs 70, 345).

85 (86) Frons with an arcuate carinulus between hind ocellus and eye; frons, vertex and occiput fairly strongly substriolated (Fig. 454). Flagellum beads-like: each flagellomere somewhat separated (Fig. 456). Hind femur 2.9 times as long as broad (Fig. 455). Carapace in dorsal view twice longer than broad with somewhat undulate strong striations (Fig. 457). Scape, pedicel and first flagellomere testaceous, rest of flagellum darkening. $+: 3 \mathrm{~mm}$. - Peru

M. townsendi (Viereck, 1912)

86 (85) Frons without arcuate carinulus, vertex and occiput substriolated (Figs 55, 343), or strongly punctate (Fig. 70).

87 (88) Vertex and occiput strongly and almost confluently elliptic-punctate (Fig. 70). Carapace in lateral view 2.8 times as long as high posteriorly (Fig. 76 see arrows), in dorsal view subareolate-rugose (Fig. 74). Carapace entirely black. \%: 2.7-2.8 mm. - Brazil, *Costa Rica, *Honduras, *Paraguay M. brasiliensis (Brues, 1912)

88 (87) Vertex and occiput substriolated (Figs 55, 343).

89 (90) Carapace in lateral view flattened, 3.3-3.6 times as long as broad, apically rounded (Fig. 61 see arrows). Gena just, 1.1 times, wider than eye (Fig. 56). Striations of carapace less dense (Fig. 62). Carapace basally rather whitish yellow. ㅇ: (2.3-)3-3.4 mm. - Distribution see at couplets 78 (77).

M. blackburni (Cameron, 1886)

90 (89) Carapace in lateral view not flattened, 2.6-2.8 times as long as high posteriorly (cf. Fig. 124 see arrows), apically less rounded (Fig. 351). Gena 1.3-1.4 times wider than eye (Fig. 346). Striations of carapace dense (Fig. 350). Carapace basally rather yellow. o : 3-3.5 mm. - East Palaearctic and Nearctic Regions, Mexico (introduced)

M. pectiniphorae (Cushman, 1931)

91 (84) Temple in dorsal view strongly rounded to rounded, eye less than twice longer than temple (Figs 55, 70, 119, 135, 264, 343-344).

92 (95) Vertex and occiput with strong sculpture: punctured or rugose (Figs 70, 135).

93 (94) Fore wing: pterostigma issuing $r$ distally from its middle (Fig. 75). Hind femur and tibia equally broad (cf. Fig. 145 see arrows). Vertex and occiput strongly almost confluently elliptic-punctate (Fig. 70). Subareolate-rugose sculpture of carapace relatively less strong (Fig. 
74). Scape and pedicel testaceous. + : 2.7-2.9 mm. - Brazil, *Costa Rica, *Honduras, *Paraguay M. brasiliensis (Brues, 1912)

94 (93) Fore wing: pterostigma issuing $r$ from its middle (Fig. 137). Hind femur and tibia unequally broad (cf. Fig. 165 see arrows). Vertex and occiput rugose (Fig. 135). Subareolate-rugose sculpture of carapace relatively strong (Fig. 138). Scape, pedicel and flagellomeres 1-2(-3) testaceous. + : 3-3.3 mm. - Argentina

M. constrictus Papp, 1999

95 (92) Vertex and occiput with fine substriolation (Figs 55, 264, 343).

96 (99) Carapace in lateral view less high posteriorly, i.e. somewhat flattened (Figs 61, cf. 481 see arrows).

97 (98) Carapace in lateral view 2.9-3 times as long as high posteriorly, apically rather truncate (cf. Fig. 481). Hind femur 3.1-3.3 times as long as broad medially (Fig. 268). Striations of carapace as in Fig. 274. Scutellum variably smooth to rugulose (Figs 266-267). Carapace entirely black. . : 3-3.1 mm. - Distribution see at couplet 69 (70)

M. johni (Marsh, 1979)

98 (97) Carapace in lateral view 3.4-3.6 times as long as high posteriorly, apically rather rounded (Fig. 61 see arrows). Hind femur 2.9-3 times as long as broad distally (cf. Fig. 450). Striations of carapace as in cf. Fig. 62. Carapace black, basally whitish yellow. o : (2.3-)3-3.4 mm. - Distribution see at couplet 78 (77).

M. blackburni (Cameron, 1886)

99 (96) Carapace in lateral view high posteriorly, 2.5-2.6 times as long as high (Fig. 124 see arrows).

100 (101) Fore wing: pterostigma issuing $r$ from its middle, 1-R1 0.8-1 times as long as pterostigma (Fig. 122 see arrows). Hind femur less thick, 2.9 times as long as broad (cf. Fig. 403). Carapace basally whitish yellow. Parategula ochre. + : 3.2-3.4 mm. - USA, Mexico, "Central America" M. cautus (Cresson, 1872)

101 (100) Fore wing: pterostigma issuing $r$ distally from its middle, 1-R1 0.7 times as long as pterostigma (Fig. 349 see arrows, exceptionally as long as pterostigma (Fig. 348 see arrows). Hind femur thick, 2.5-2.6 times as long as broad (cf. Figs 84, 136). Carapace basally yellow. Parategula brown. . : 3-3.5 mm. - Distribution see at couplet 90 (89).

M. pectiniphorae (Cushman, 1931)

102 (57) Scutellum rugose to scabrous (Figs 82, 202, 266, 311, 387, 412), or strongly punctate (Figs 23, 444, 512), or rugulose (Figs 266-267). (ruficollis species-group). 
103 (110) Scutellum either strongly punctate (Figs 23, 444, 512), or rugulose (Figs 266-267).

104 (109) Scutellum strongly punctate (Figs 23, 444, 512).

105 (106) Fore wing: pterostigma unusually narrow, 3.3 times as long as wide (Fig. 24 see horizontal arrows), its antero-inner margin faintly concave (Fig. 24 see perpendicular arrow). Gena strong, dense and elliptic-form punctation (Fig. 22). A member of the blackburni-group, see couplet 77 (78). M. angustus Papp, 1999

106 (105) Fore wing: pterostigma wide, 2.2-2.3 times as long as wide, its antero-inner margin convex as usually (Figs 446, 512 see arrows). Gena with other sculpture (Figs 442, 510).

107 (108) Scutellum dispersely punctate, interpunctures greater than punctures (Figs 444-445). Gena antero-posteriorly with thickening punctures, interpunctures polished (Fig. 442). Hind femur 3.3 times as long as broad (Fig. 450). Temple in dorsal view rounded. Substriolation above head stronger (Fig. 441). Wings hyaline (to subhyaline). o: 2.8-3 mm. - Argentina M. topali Papp, 1999

108 (107) Scutellum densely punctate, interpunctures smaller than punctures (Fig. 512). Gena substriolated (Fig. 510). Hind femur 3.1 times as long as broad (Fig. 514). Temple in dorsal view receded-rounded; substriolation of vertex and occiput less strong (Fig. 509). Wings weakly subhyaline. + : 2.6-3.3 mm. - USA, Mexico (introduced)

M. phthorimaeae (Gahan, 1917)

109 (104) Scutellum rugulose (Figs 266-267). Gena substriolate of variable strength (Fig. 265a-b). Member of the blackburni-group, see couplet 97 (98).

M. johni (Marsh, 1979)

110 (103) Scutellum rugose to scabrous (Figs 82, 387, 412), or with strong longitudinal rugae (Figs 202, 311).

111 (116) Three deviating species transitional between species-groups ruficollis and effusus / refluus.

112 (113) Carapace in dorsal view apically conicule-shape (Fig. 390). Frons with a pair of arcuate carinuli (Fig. 384). Scutellum scabrous (Fig. 387). A member of refluus-group, see couplet 26 (27).

M. refluus Papp, 2010

113 (112) Carapace in dorsal view apically rounded (Figs 170, 382). Frons without a pair of carinuli. Penultimate flagellomere 1.8-2 times as long as broad. 
114 (115) Carapace in dorsal view pyriform (Fig. 382). Gena substriolate (cf. Fig. 265b). Temple in dorsal view rounded (Fig. 379). Two species of the effusus-group, see couplets 40 (39) - 42 (41).

M. buscki (Viereck, 1912) and M. pyriformis Papp, 2010

115 (114) Carapace in dorsal view pyriform (Fig. 170). Gena with posteriorly crowded hairpunctation (cf. Fig. 303). Temple in dorsal view strongly rounded (Fig. 161). A member of the effusus-group, see couplet 48 (47).

M. danzas sp. $\mathrm{n}$.

116 (111) Species clearly representing the ruficollis-group: scutellum rugose to scabrous (Figs 202, 311, 387, 412).

117 (118) Fore wing: 1-R1 short, half (0.5 times) as long as pterostigma, SR1 bent (Fig. 312). Cheek in frontal view less converging, i.e. more rounded (Fig. 309 see arrows). Temple in dorsal view receded (Fig. 307). Scutellum striate-rugose (Fig. 311), or rugose (cf. Fig. 266). Mesosoma black. + : 2.8-3 mm. - USA (California), *Costa Rica, *Honduras M. masoni (McComb, 1968)

118 (117) Fore wing: $1-R 1$ long, at least 0.6 times, usually $0.7-0.8$ times, as long as pterostigma (Figs 130, 209, 304, 395, 404, 416). Cheek in frontal view converging (cf. Fig. 278 see arrows).

119 (120) Gena with posteriorly somewhat crowded punctation, interspaces polished (Fig. 303). Fore wing: pterostigma wide, twice as long as wide, issuing $r$ from its middle (Fig. 304). Carapace in lateral view 2.6 times as long as high posteriorly, its hind end truncate (Fig. 306). Trochanters and tarsi yellow, otherwise legs brown to blackish. P: $3.3 \mathrm{~mm}$. - Peru

M. levigena sp. $n$.

120 (119) Gena substriolate, dull (Figs 200, 394, 400, 415). Fore wing: pterostigma less wide, at most 2.3 times as long as wide (Figs 209, 395, 404, 416).

121 (124) Mesosoma at least partly testaceous.

122 (123) Temple in dorsal view rounded, eye 1.5 times longer than temple (Fig. 399). Carapace apico-ventrally deeply incurved, incurved part as long as hind basitarsus (Fig. 407 see arrow). Substriolation of vertex + occiput slightly rougher (Fig. 399). Gena relatively wide (Fig. 400 see arrows). Mesosoma partly testaceous, scutellum and propodeum black. + : 3.5-4.5 mm. - Brazil, Costa Rica

M. ruficollis (Viereck, 1912) 
123 (122) Temple in dorsal view receded, eye 2.3 times longer than temple (Fig. 393). Carapace apico-ventrally less deeply incurved, incurved part as long as second tarsomere of hind tarsus (Figs. 397 see arrow). Substriolation of vertex + occiput slightly less rough (Fig. 393). Gena relatively less wide (Fig. 394 see arrows). Mesosoma entirely testaceous. + : $3.6 \mathrm{~mm}$. - Costa Rica

M. rubescus Papp, 2010

124 (121) Mesosoma entirely black.

125 (130) At least fore and middle legs yellow, hind leg more or ess darkening. Fore wing: pterostigma $2-2.2$ times as long as wide (Figs 130, 340, 504).

126 (127) Carapace in lateral view high, 2.6 times as long as high and gradually declivous posteriorly (Fig. 506 see arrows). Gena antero-posteriorly with somewhat thickening substriolation, subshiny (Fig. 499). Carapace in dorsal view belly, 1.6 times as long as broad, anteriorly with somewhat less parallel striations, posteriorly rugo-rugulose (Fig. 505). Legs 1-2 yellow, coxae pale yellow, leg 3 blackish brown to brown, tibia basally pale yellow. Scape, pedicel and flagellomeres 1-3 yellow. Anterior half of carapace pale yellow. $\circ$ : $3 \mathrm{~mm}$. - Honduras

M. mccombi sp. n.

127 (126) Carapace in lateral view less high, 3-3.4 times as long as high and declivous posteriorly (Fig. 132). Gena substriolate (cf. Fig. 121). Sculpture of carapace other (Figs 131, 342).

128 (129) Temple in dorsal view rounded, eye somewhat longer than temple (Fig. 341). Fore wing: pterostigma issuing $r$ just distally from its middle (Fig. 340). Carapace in dorsal view less belly, 1.7-1.8 times as long as broad, its areolation somewhat weaker (Fig. 342). Trochanters yellow. . : 2.2-2.3 mm. - USA (Florida), ${ }^{*}$ Costa Rica M. paululus (McComb, 1968)

129 (128) Temple in dorsal view receded, eye 3.1-3.2 times longer than temple (Fig. 129). Fore wing: pterostigma issuing $\mathrm{r}$ from its middle (Fig. 130). Carapace in dorsal view belly, 1.4-1.6 times as long as broad, its areolation somewhat stronger (Fig. 131). Trochanters (partly) whitish. ㅇ: 2.2-2.8 mm. - Costa Rica, Honduras M. cavei Papp, 2010

130 (125) Legs brown to black with more or less yellow pattern. Fore wing: pterostigma 2.2-3 times as long as wide (Figs 204, 209, 416).

131 (132) Gena beyond eye less broadening ventrally, its substriolation less strong (Fig. 415). Temple in dorsal view rounded (Fig. 414). Fore 
wing: pterostigma narrow, three times as long as wide, issuing $r$ distally from its middle (Fig. 416). Carapace in dorsal view belly, 1.6 times as long as broad, its striation less strong and rather less parallel with anastomoses (Fig 417). Carapace in lateral view 2.6-2.7 times as long as high (Fig. 418 see arrows). Carapace basally with yellow band. Flagellum black. Middle and hind trochanters black. P: 3.4-3.5 mm - USA (Washington), ?Mexico (introduced)

M. shenefelti (McComb, 1968)

132 (131) Gena beyond eye distinctly broadening ventrally, its substriaion strong (Fig. 200). Temple in dorsal view strongly rounded (Fig. 199). Fore wing: pterostigma wide, 2.2-2.3 times as long as wide, issuing $r$ from its middle (Fig. 204, 209). Carapace in dorsal view less belly, 1.9-2.1 times as long as broad, its striation strong and rather parallel with little anastomoses (Fig. 205). Carapace in lateral view 3.4 times as long as high (Fig. 206). Carapace entirely black. Flagellum black(ish), flagellomeres (4-)5-6 ochre. Middle and hind trochanters pale yellow. + : 3-4.2 mm. - Costa Rica

M. flavicoxa sp. n.

\section{Males}

1 (2) Carapace in dorsal view apically with a pointed spine (Figs 332-334) and inwardly truncate (Fig. 333). (parkeri species-group). Frons with a pair of short and arcuate carinuli between hind ocellus and eye (Fig. 335). Body with fairly rough rugosity (Fig. 332, 335). Carapace in dorsal view 2.2-2.5 times as long as broad, cylindric-form (Figs 332-334). Fore and middle legs stramineous. ${ }^{\lambda}: 3.2 \mathrm{~mm}$. - Costa Rica (= Chelonus (Microchelonus) murici Nascimento et Penteado-Dias, 2011, syn. n.)

M. parkeri Papp, $2010^{* *}$

2 (1) Carapace in dorsal (as well as in ventral) view apically not spine-like pointed, i.e. ending either conicule-shape (Figs 41, 44, 116, 139, 149, 243, 259, 392, 409), or rounded (cupole-shape) (Figs 62, 74, 91, 123, 175, 274, 350, 491).

3 (20) Carapace in dorsal view apically conicule-shape in variable form (Figs 41, 44, 116, 139, 149, 245, 259, 392, 409) (refluus species-group).

4 (9) Temple in dorsal view receded, eye about twice longer than temple (Figs 35, 141). Fore wing: pterostigma 2.5 times as long as wide (Figs 40, 151). Hind femur and tibia evenly thick (Figs 39, 145).

* For synonymization see Taxonomic emendation in Microchelonus parkeri Papp. 
5 (6) Temple in dorsl view constricted receded, vertex + occiput weakly substriolated (Fig. 35). Gena with posteriorly crowded substriolation (Fig. 37). Hind femur thin, 3.1 times as long as broad (Fig. 39). Fore wing: pterostigma issuing $r$ distally from its middle, 1-R1 0.7 times as long as pterostigma (Fig. 40 see arrows). Apical foramen of carapace nearly round: slightly wider (15:12) than high (Fig. 43). Tarsi pale yellow. $\widehat{~}$ : $2.3 \mathrm{~mm}$. - Costa Rica

M. avron sp. n.

6 (5) Temple in dorsal view rounded receded (Fig. 141, cf. Fig. 384), vertex + occiput substriolated (Fig. 141). Gena with posteriorly thickening punctation (Figs 142, 442).

7 (8) Apical foramen of carapace less elliptic, 1.6 times as wide as high (Fig. 153). Hind femur thick, 2.5 times as long as broad (Fig. 145). Striation of carapace somewhat strong, less parallel and with much anastomoses (cf. Fig. 139). Tarsi straw yellow. $\widehat{\delta}: 3 \mathrm{~mm}$. - Costa Rica

\section{M. curticarinulus sp. $n$.}

8 (7) Apical foramen of carapce elliptic, 2.2-2.5 times as wide as high (Fig. 452). Hind femur thin, 3.1-3.3 times as long as broad (Fig. 450). Striations of carapace less strong, parallel and with little anastomoses (Fig. 451). Tarsi brownish. $\delta^{7}: 2.6-2.9 \mathrm{~mm}$. (A member of the blackburnigroup, here inserted owing to its sometimes apically rather coniculeshape carapace, see couplets 49 (48) - 51 (50). - Argentina

M. topali Papp, 1999

9 (4) Temple in dorsal view rounded, eye about as long as temple (Figs 111, 235), or about 1.5 times longer than temple (Figs 254, 384, 399).

10 (11) Mesoscutum, scutellum, metanotum and upper part of mesopleuron testaceous. Carapace in dorsal view cylindric, 2.5 times as long as broad (Fig. 409), its anterior two-thirds strongly striated (Fig. 405). Carapace apico-ventrally deeply incurved, this part as long as hind tarsomeres 1-2 combined (Fig. 407 see arrow). Fore wing: pterostigma wide, 2.1 times as long as wide (cf. Fig. 312). Gena finely substriolated, shiny. $5 \mathrm{~mm}$. (A member of the ruficollis-group, see couplets 54 (53) - 56 (55). - Brazil, *Costa Rica

M. ruficollis (Viereck, 1912)

11 (10) Mesosoma entirely black.

12 (17) Fore wing: 1-R1 short, half (0.5 times) as long as pterostigma, issuing $r$ not distally (cf. Fig. 146, Fig. 256), or distally from its middle (Fig. 315). Frons laterally without a pair of carinuli. 
13 (14) Cheek in frontal view less converging ventrally (Fig. 310 see arrows). Clypeus wide, about twice wider below than high medially (Fig. 310). Fore wing: pterostima issuing $r$ clearly distally from its middle (Fig. 315 see arrows). Apical foramen of carapace oval, 2.5-2.7 times as long as high (Fig. 314). Legs blackish brown to brown, tibiae 1-2 yellow. o: $2.3-2.5 \mathrm{~mm}$. (The apically conicule-shape carapace is exceptional in this species (Fig. 313), usually rounded (Fig. 316); a member of the blackburni-group, see couplets 36 (39) - 38 (37). - USA (California), Costa Rica, Honduras

M. masoni (McComb, 1968)

14 (13) Cheek in frontal view converging ventrally as usually (Fig. 238 see arrows). Clypeus less wide, 1.4-1.6 times as wide below as high medially (Figs 237, 255). Fore wing: pterostigma issuing $r$ about from its middle (cf. Fig. 146, Fig. 256).

15 (16) Eye in dorsal view as long as temple, i.e. temple relatively less rounded (Fig. 235). Scutellum rugulose, dull, (Fig. 239). Fore wing: pterostigma issuing $r$ from its middle, 1-R1 0.57 times as long as pterostigma (cf. Fig. 146 see arrows). Clypeus less subquadrate, 1.6 times as wide below as high medially, its rugulosity weakening ventrally (Fig. 237), dull to subshiny. Fore and middle legs blackish brown to brown, tibiae yellow. $\widehat{~}$ : $2.7 \mathrm{~mm}$. - Costa Rica

M. hebes sp. n.

16 (15) Eye in dorsal view 1.5 times as long as temple, i.e. temple relatively more rounded (Fig. 254). Scutellum hairpunctate, shiny, basally subrugulose (Fig. 257). Fore wing: pterostigma issuing $r$ proximally from its middle, 1-R1 0.5 times as long as pterostigma (Fig. 256 see arrows). Clypeus subquadrate, 1.4 times as wide below as high medially, almost evenly rugulose (Fig. 255). Fore and middle legs (pale) yellow with little brownish tint on middle tibia. $0: 3.2 \mathrm{~mm}$. See also couplets $29(28)$ - 31 (30) - Jamaica

M. jamaicus sp. $n$.

17 (12) Fore wing: 1-R1 long, 0.7-0.85 times as long as pterostigma, issuing $r$ varaibly distally from its middle (Figs 114, 389). Frons laterally with a pair of arcuate (and weak) carinuli (Fig. 384). Carapace in dorsal view cylindrinc, 2.6 times as long as broad (Fig. 392).

18 (19) Eye in dorsal view 1.3 times longer than temple, temple rounded as usually (i.e. not swollen, Fig. 384). Fore wing: pterostigma wide, 2.8 times as long as wide and issuing $r$ just distally from its middle (Fig. 389). Apical foramen of carapace very small and round (hardly distinct). Carapace black, anteriorly with a pair of maculae. $\delta^{\top}: 4 \mathrm{~mm}$. Honduras

M. refluus Papp, 2010 
19 (18) Eye in dorsal view as long as temple, temple swollen, i.e. head in dorsal view between temples somewhat broader than between eyes (Fig. 111). Fore wing: pterostigma narrow, four times as long as wide and issuing $r$ clearly distally from its middle (Fig. 114). Apical foramen of carapace wide, thrice as wide as high laterally (Fig. 117). Carapace entirely black. $\delta^{\top}: 4.5 \mathrm{~mm}$. (A member of effusus-group, see couplets 22 (25) - 24 (23, distribution see there). M. carinatus (Provancher, 1881)

20 (3) Carapace in dorsal view apically cupole-shape or rounded (Figs 62, 74, 91, 123, 175, 274, 350, 491).

21 (32) Penultimare flagellomere 2.1-2.5 times longer than broad (Figs 46, 87, $115,171)$ (effusus species-group).

22 (25) Temple in dorsal view swollen, i.e. head between temples somewhat broader than between eyes (Figs 47, 111).

23 (24) Fore wing: pterostigma narrow, four times as long as wide, issuing $r$ clearly distally from its middle, (Fig. 114). Carapace in dorsal view elongate, 2.5 times as long as broad, longitudinaly rugulose (Figs 113, 116). Gena beyond eye evenly broad (cf. Fig. 37). Apical foramen of carapace wide, thrice wider than high (medially somewhat tightening, Fig. 117). Fore femur + tibia yellow. $\delta^{\top}: 5 \mathrm{~mm}$. - Widely distributed in Canada and USA including Florida. See also couplet 19 (18).

M. carinatus (Provancher, 1881)

24 (23) Fore wing: pterostigma wide, 2.3 times as long as wide, issuing $r$ from its middle (Fig. 51). Carapace in dorsal view less elongate, 2.3 times as long as broad, somewhat undulate striated with much anastomoses (Fig. 52). Gena beyond eye broadening ventrally (cf. Fig. 66). Apical foramen of carapace elliptic, 1.6 times as wide as high (Fig. 53). Fore femur + tibia rusty with brownish suffusion. ${ }^{\lambda}: 4 \mathrm{~mm}$. - Honduras

M. bermus sp. $n$.

25 (22) Temple in dorsal view not swollen (Figs 172, 254, 399, 408). Fore wing: pterostigma wide, 2.2-2.6 times as long as wide (Figs 174, 256, 404 see arrows).

26 (27) Mesoscutum and scutellum testaceous, rest of body black. Carpace in dorsal view elongate, 2.7 times as long as broad, apically coniculeshape (Fig. 409), strongly striated (Fig. 405). Fore wing: pterostigma 2.6 times as long as wide, 1-R1 0.75 times as long as pterostigma (Fig. 404 see arrows). Apical foramen of carapace oval, 1.6 times as wide as high (Fig. 410). Legs 1-2 yellow, leg 3 brownish. $\widehat{0}: 4.5 \mathrm{~mm}$. (A mem- 
ber of ruficollis-group, see couplets 54 (53) - 56 (55). - Brazil, Costa Rica M. ruficollis (Viereck, 1912)

27 (26) Mesosoma entirely black. Carapace in dorsal view less elongate, 1.92.4 times as long as broad, apically not conicule-shape, rounded (Figs $91,175,259)$.

28 (29) Frons laterally with a pair of arcuate carinuli (Fig. 79). Carapace in dorsal view pyriform, i.e. characteristically broadening posteriorly (Fig. 91); in lateral view apically obliquely incurved (Fig. 92). Apical foramen of carapace missing. Scutellum rugose (Fig. 82). Carapace basally with a pair of (pale) yellow maculae (nominate form, Fig. 91), or with a (pale) yellow transverse band (var. gilvus var. n.). $\delta^{\text {T }}: 3.8-4.2$ $\mathrm{mm}$. A member of ruficollis-group, see couplet 53 (54), distribution see also there.

M. buscki (Viereck, 1912)

29 (28) Frons laterally without a pair of carinuli (Figs 172, 254). Carapace in dorsal view not pyriform (Figs 175, 259).

30 (31) Legs and tegula lemon yellow, hind tibia apically brownish. Scutellum rugose (cf. Fig. 82). Fore wing: pterostigma 2.3 times as long as wide, issuing $r$ somewhat distally from its middle, 1-R1 long: 0.85 times as long as pterostigma (Fig. 174 see arrows). Apical foramen of carapace elliptic, 1.8 times as wide as high (Fig. 177). $\widehat{O}^{\lambda}: 3.8-4 \mathrm{~mm}$. - Costa Rica

M. effusus Papp, 2010

31 (30) Coxae 1-2 whitish (or pale) yellow, rest of legs 1-2 yelow, leg 3 brown to light brown, trochanters whitish yellow, tegula dark bown. Scutellum almost smooth, basally subrugulose (Fig. 257). Fore wing: pterostigma 2.2 times as long as wide, issuing $r$ proximally from its middle, 1-R1 short: half as long as pterostigma (Fig. 256 see arrows). Apical foramen of carapace more elliptic, 2.7 times as wide as high (Fig. 261). $3: 3.2 \mathrm{~mm}$. A member of the refluus-group, see couplets 14 (13) - 16 (15). - Jamaica

M. jamaicus sp. n.

32 (21) Penultimate flagellomere at most twice longer than broad (Figs 46, $263 b, 484)$.

33 (52) Scutellum smooth to uneven or hairpunctate, somewhat shiny to polished (Figs 57, 73, 118, 210, 267, 445, 449) (blackburni species-group).

34 (35) Head in dorsal view subcubic: 1.6-1.7 times as broad as long, eye and temple equal in length (Fig. 211). Gena broadening ventrally (Fig. 212), hairpunctate and polished (cf. Fig. 184). Apical foramen of carapce missing. Fore wing: pterostigma 2.6 times as long as wide, issuing $r$ 
distally from its middle, 1-R1 half as long as pterostigma (Fig. 213). Carapace in dorsal view 2.5 times longer than broad (Fig. 215), with parallel and dense striations (Fig. 214), its anterior two-thirds yellow. Legs, tegula and pronotum also yellow. $\delta^{\top}: 4.3 \mathrm{~mm}$. - Costa Rica

M. flavopax Papp, 2010

35 (34) Head in dorsal view transverse: 1.9-2.3 times as broad as long (Figs $55,70,119,307,343,441,485)$. Gena beyond eye variable in width and usually substriolate (Figs 56, 121, 265a-b, 308, 346, 486)) or (densely punctate (Figs 72, 442).

36 (39) Head in dorsal view conspicuously transverse: 2.1-2.3 times as broad as long (Figs 307, 485).

37 (38) Temple in dorsal view runded-receded and very short: eye 2.2 times longer than temple (Fig. 485). Fore wing: 1-R1 0.6 times as long as pterostigma, latter issuing $r$ from its middle (Fig. 495 see arrows). Cheek in frontal view converging as usually (cf. Fig. 272 see arrows). Apical foramen of carapace nearly round, 1.4 times as wide as high (Fig. 496). Wings hyaline. $\widehat{o}: 2.4 \mathrm{~mm}$. - Costa Rica

M. zobocus sp. n.

38 (37) Temple in dorsal view receded and less short: eye slightly longer than temple (15:13, Fig. 307). Fore wing: 1-R1 0.5 times as long as pterostigma, latter issuing $r$ distally from its middle (Fig. 312 see arrows). Cheek in frontal view somewhat less converging (Fig. 310 see arrows). Apical foramen of carapace wide elliptic, 2.5-2.7 times wider than high (Fig. 314). Wings subhyline. ${ }^{7}: 2.8-3 \mathrm{~mm}$. - USA: California, ${ }^{*}$ Costa Rica, ${ }^{*}$ Honduras

M. masoni (McComb, 1968)

39 (36) Head in dorsal view not conspicuously broad, at most twice as broad as long (Figs 55, 70, 119, 264, 276, 343, 441).

40 (45) Apical foramen of carapce slit-like: $4-5$ times as wide as high (Figs 60, $127,352)$. Carapace basally with a pale yellow band.

41 (42) Carapace in dorsal view belly, 1.6 times as long as broad (Fig. 123), longitudinally rugulose (cf. Fig. 113). Fore wing: pterostigma issuing $r$ just distally from its middle (Fig. 122). Eye in lateral view twice as high as wide (Fig. 121). ô: 3-3.2 mm. - USA, *Honduras, Mexico, ${ }^{*}$ Nicaragua

M. cautus (Cresson, 1872)

42 (41) Carapace in dorsal view less belly, 1.7-1.8 times as long as broad (Figs 62,350 ). Fore wing: pterostigma issuing $r$ distally from its middle (Figs $58,348-349$ see arrows). 
43 (44) Gena as wide as eye (Fig. 56 see arrows). Temple in dorsal view somewhat less receded (Fig. 55). Hind femur slightly less thick, 2.9 times as long as broad. Striations of carapace undulate and less dense (Fig. 62). Basal band of carapace usually pale yellow. $\overbrace{}^{\top}: 2.3-3.2 \mathrm{~mm}$. - USA: Hawaii, Mexico, Puerto Rico (introduced, also into further several countries) M. blackburni (Cameron, 1886)

44 (43) Gena one-third wider than eye (Fig. 346). Temple in dorsal view somewhat more receded (Fig. 345). Hind femur slightly more thick, 2.6 times as long as broad. Striations of carapace less undulate and dense (Fig. 350). Basal band of carapace usually yellow. 万ิ: 3.3-3.5 mm. - East Palaearctic and Nearctic Regions (introduced), Taiwan, China (introduced)

M. pectiniphorae (Cushman, 1931)

45 (40) Apical foramen of carapace not slit-like: elliptic to round, at most 2.7 times as wide as high (Figs 88, 275, 284). Carapace entirely black (i.e. without basal yellow band).

46 (47) Apical foramen of carapace nearly round, 1.4-1.5 times as wide as high (Fig. 275). Carapace in dorsal view 1.9-2 times as long as broad, densely striate to rugulose (Fig. 274). Cheek in frontal view somewhat less converging (Fig. 272 see arrows). Palpi pale yellow. Ô $^{\lambda}: 2.8-3.1 \mathrm{~mm}$. - Colombia, *Costa Rica, *Honduras, *Mexico M. johni (Marsh, 1979)

47 (46) Apical foramen of carapace elliptic, 2-2.7 times as wide as high (Figs $88,284)$.

48 (49) Fore wing: 1-R1 short, half as long as pterostigma (Fig. 280). Carapace in dorsal view rather belly, broadest medially, densely rugulose (Fig. 282). Hind femur 3.5 times longer than broad distally (Fig. 281). Gena substriolate, dull. Palpi brownish. ô: 2.6-3 mm. - Costa Rica

M. kellieae (Marsh, 1979)

49 (48) Fore wing: 1-R1 long, (0.6-)0.7-0.85 times as long as pterostigma (Fig. 75). Carapace in dorsal view less belly, broadest (slightly) posteriorly (Figs 74, 451).

50 (51) Apical foramen of carapace relatively large, 2-2.2 times as wide as high (Fig. 88). Gena confluently punctate, punctures elliptic-form (Fig. 72). Carapace in dorsal view apically less rounded, its striations undulate (Fig. 74). ô: 2.7-2.8 mm. - Brazil, *Costa Rica, *Honduras M. brasiliensis (Brues, 1912)

51 (50) Apical foramen of carapace relatively small, 2.2-2.5 times as wide as high (Fig. 452). Gena with somewhat thickening punctation, punc- 
tures round, interpunctures shiny (Fig. 442). Carapace in dorsal view apically more rounded, its striations parallel (Fig. 451). 万ิ: $2.6-2.9 \mathrm{~mm}$. - Argentina

M. topali Papp, 1999

52 (33) Scutellum sculptured: rugulose to roughly rugose, scabous (Figs 49, 82,412 ) (ruficollis species-group).

53 (54) Apical foramen of crapace missing. Frons laterally with a pair of arcuate carinuli (Fig. 79). Carapace in dorsal view pyriform, i.e. characteristically broadening posteriorly, its anterior third strongly striated, posteriorly rugo-rugulose (Figs 85-86). Carapace with a pair of (pale) yellow maculae. $\delta^{7}: 3.8-4.2 \mathrm{~mm}$. - *Costa Rica, *Honduras, *Panama, *Peru, Trinidad and Tobago

M. buscki (Viereck, 1912)

54 (53) Apical foramen of carapace present in variable sizes (Figs 53, 359, 410, 427).

55 (56) Mesoscutum and scutellum testaceous, rest of body black. Carapace in dorsal view elongate, 2.7 times as long as broad, apically coniculeshape (Fig. 409), strongly striated (cf. Fig. 405). Apical foramen of carapace oval, 1.6 times as wide as high (Fig. 410). Legs 1-2 yellow, leg 3 broenish. ${ }^{\prime}: 4.5 \mathrm{~mm}$. See also couplets 25 (22) - 26 (27). - Brazil, Costa Rica

M. ruficollis (Viereck, 1912)

56 (55) Mesosoma entirely black. Carapace in dorsal view less elongate except M. peruensis.

57 (58) Apical foramen of carapace very small, elliptic (Fig. 427). Penultimate flagellomere short, 1.5-1.6 times as long as broad. Carapace in dorsal view broad, weakly broadening posteriorly, striated (cf. Fig. 424). Gena hairpunctate, (subshiny. $03.3 \mathrm{~mm}$. After the female with long penultimate flagellomere the species is the member of the effususgroup. - Costa Rica, Honduras

M. subplanus Papp, 1999

58 (57) Apical foramen of carapace large, at least 1.3-1.5 times as wide as high (Figs 53, 359).

59 (60) Head in dorsal view less transverse, 1.7 times as broad as long, temple somewhat swollen, vertex + occiput densely rugose (Fig. 47). Fore wing: pterostigma wide, 2.3 times as long as wide, 1-R1 0.7 times as long as pterostigma (Fig. 51 see arrows). $\delta^{\top}: 4 \mathrm{~mm}$. A member of effususgroup, see couplets $22(25)-24$ (23). - Honduras M. bermus sp. $n$.

60 (59) Head in dorsal view transverse, twice as broad as long, temple not swollen (Figs 341, 353, 414). 
61 (62) Carapace in dorsal view belly, 1.6 times as long as broad, its striations less dense (Fig. 417). Temple in dorsal view moderately rounded (Fig. 414). Carapace in lateral view high, 2.6-2.7 times as long as high (Fig. 418 see arrows). Eye in dorsal view slightly longer than temple (16:15, Fig. 414). Carapace basally with yellow band. $\delta$ : 3.4-3.6 mm. - USA: Washington, ?Mexico

M. shenefelti (McComb, 1968)

62 (61) Carapace in dorsal view not belly, 1.7-2.4 times as long as broad, basally without yellow band.

63 (64) Carapace in dorsal view somewhat elongate, 2.4 times as long as broad, densely striated (Fig. 356). Legs blackish to brown. Fore wing: ptetrostigma less wide, 2.6 times as long as wide, issuing $r$ proximally from its middle (Fig. 355). Apical foramen of carapace 2.1 times as wide as high (Fig. 359). Palpi brownish. ô $^{\circ} 4.1 \mathrm{~mm}$. - Peru (=Cheonus sobrinus Szépligeti, 1904 nec Haldeman, 1849)

M. peruensis (Shenefelt, 1973)

64 (63) Carapace in dorsal view not elongate, 1.7-2 times as long as broad (Figs 342, 376). Legs yellow, palpi pale yellow.

65 (66) Apical foramen of carapace less elliptic: 1.3-1.6 times as wide as high (cf. Fig. 410). Carapace in dorsal view 1.7-1.8 times as long as broad, areolate rugose (Fig. 342), its anterior third striated. Antenna with 19 antennomeres. ${ }^{7}: 4 \mathrm{~mm}$. - USA: Florida, ${ }^{*}$ Costa Rica

M. paululus (McComb, 1968)

66 (65) Apical foramen of carapace more elliptic: 2.5 times as wide as high (cf. Fig. 314). Carapace in dorsal view twice as long as broad, rugulose, its anterior half striated Fig. 376). Antenna with 22 antennomeres. ${ }^{\text {O }}: 3.7$ mm. - Honduras

M. projectus sp. n.

\section{KEY TO THE SPECIES WITH A PAIR OF ARCUATE CARINULI ON FRONS (townsendi-forms; Figs 79, 335, 379, 384)}

The species keyed here do not represent a species-group, contrarily, they are ranged in several species-groups in the previous two identification keys to the females and males, respectively. The species herewith assigned are the townsendi-forms.

1 (4) Carapace in dorsal view apically either acute (Figs 7-9, or spine-form pointed (Figs 332-334) (parkeri species-group). 
2 (3) Carapace in dorsal view apically acute, anteriorly striated (Fig. 7). Head in dorsal view twice as broad as long, temple receded (Fig. 1). Legs testaceous. + : $3.3 \mathrm{~mm}$.

M. acutulus sp. $n$.

3 (2) Carapace in dorsal view apically spine-form pointed (Figs 332-334). Head in dorsal view 1.7-1.8 times as broad as long, temple rounded (Fig. 335). Legs testaceous, hind leg brown. Male carapace apically without foramen. + ${ }^{\widehat{T}}: 3.2-3.8 \mathrm{~mm}$.

M. parkeri Papp, 2010

4 (1) Carapace in dorsal view apically not acute and not spine-form pointed, either conicule-shape (Figs 139, 222, 390, 438), or rounded (Figs $85-86,382,457)$.

5 (12) Carapace in dorsal view apically conicule-shape (Figs 139, 222, 390, 438) (refluus species-group).

6 (7) Carapace in dorsal view apically with a short carinulus (Fig. 147). Fore wing: pterostigma twice (Fig. 146 see arrows) to 2.5 times (Fig. 151 see arrows) as long as wide, issuing $r$ from its middle. Tegula pale yellow or brown. Legs yellow with brown(ish) pattern. Apical foramen of carapace elliptic, 1.6 times as wide as high (Fig. 153). 워: 3-3.5 mm.

\section{M. curticarinulus sp. $\mathrm{n}$.}

7 (6) Carapace in dorsal view apically without a short carinulus.

8 (9) Carapace in lateral view inclivous, i.e. deeply incurved (Fig. 391 see outer arrow); in ventral view aperture of carapace clearly shorter than carapace itself (cf. Fig. 149 see arrows). Fore wing: pterostigma narrow, 2.8-3 times as long as wide (Fig. 389 see arrows). Apical foramen of carapace very small and round (hardly distinct). Carapace basally with a pair of straw yellow maculae. 우 ${ }^{1} 4-4.9 \mathrm{~mm}$.

M. refluus Papp, 2010

9 (8) Carapace in lateral view perpendicularly truncate, i.e. not deeply incurved (Figs 223, 439 see outer arrow); in ventral view aperture of carapace (almost) as long as carapace itself (cf. Fig. 377 see arrow).

10 (11) Carapace apically with a small round foramen (Fig. 440). Middle tibia with a few spinules (Fig. 435). Legs testaceous. + : $4-4.2 \mathrm{~mm}$, ${ }^{\lambda}$ unknown.

M. sulcifera sp. $n$.

11 (10) Carapace apically without foramen. Middle tibia with spinules (Fig. 225). Legs brown to black(ish) with little yellow pattern. $\circ: 5 \mathrm{~mm}, \hat{0}$ unknown.

M. fodicus sp. $n$.

12 (5) Carapace in dorsal view apically rounded or cupole-shape (Figs 85-86, $382,457)$. 
13 (16) Antenna long, penultimate flagellomere 2-3 times as long as broad (Figs 87, 378) (effusus species-group).

14 (15) Temple in dorsal view receded, eye 1.7-2 times longer than temple (Figs 78-79). Carapace in dorsal view somewhat less pyriform, less densely and weakly striated (Fig. 85). Legs dark coloured with much yellow pattern. 우: 3.6-4.6 mm. M. buscki (Viereck, 1912)

15 (14) Temple in dorsal view rounded, eye 1.3-1.4 times longer than temple (Fig. 379). Carapace in dorsal view pyriform, densely and strongly striated (Fig. 382). Legs dark coloured with little yellow pattern. : 5-5.5 mm, ô unknown.

M. pyriformis Papp, 2010

16 (13) Antenna short, penultimate flagellomere subcubic: 1.2 times as long as broad, flagellum beads-like: each flagellomere somewhat separated from each other (Fig. 456). Carapace in dorsal view twice as long as broad with parallel strong striations (Fig. 457). Scape, pedicel and first flagellomere testaceous, rest of flagellum darkening. $\circ$ : $3 \mathrm{~mm}$, ô not seen.

M. townsendi (Viereck, 1912)

\section{SPECIES-GROUPS OF THE NEOTROPICAL SPECIES OF MICROCHELONUS SZÉPLIGETI}

1.) Candidus species-group: carapace apically polished (Figs 100, 232, 365): candidus sp. n. + , curtulus sp. n. + , exceptus sp. n. + , fulgens sp. n. + , latistigma sp. n. + , polites sp. n. ㅇ, tuberulus sp. n. ㅇ․

2.) Parkeri species-group: carapace apically spine-form pointed (Figs 7, 9, 97, 332-334): acutulus sp. n. + , cacumenus Papp + , parkeri Papp $+{ }^{\lambda}$

3.) Refluus species-group: carapace apically conicule-shape (Figs 139, 222,

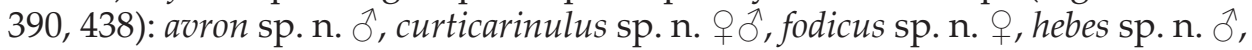
jamaicus sp. n. $\hat{0}$, refluus Papp $+\hat{0}$, sulcifera sp. n. + .

4.) Effusus species-group: flagellomeres long, penultimate flagellomere more than twice as long as broad (Figs 26, 77, 192, 368, 378, 419): avron sp. $\mathrm{n}$. $\uparrow$, bermus sp. n. $\hat{0}$, carinatus (Provancher) $+\hat{0}$, danzas sp. n. + , effusus sp. n. $+\hat{0}$, fascis Papp + , projectus sp. n. + , pyriformis Papp + , subplanus Papp $+{ }^{\lambda}$, vissas sp. n. + .

5.) Blackburni species-group: scutellum smooth to uneven, hairpunctate, shiny to polished (Figs 13, 23, 29, 57, 73, 118, 279, 326, 444): amelot sp. n. ㅇ, angustus Papp + , blackburni (Cameron) $q 0 \hat{0}$, bolsoni Papp + , brasiliensis (Brues)

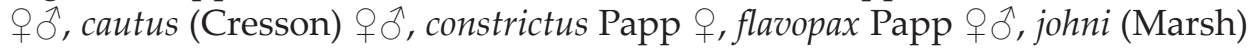
오, kellieae (Marsh) $+\hat{0}$, masoni (McComb) + , ormos sp. n. + , pectiniphorae (Cushman) ${ }^{0} \hat{0}$, topali Papp $+\hat{0}$, townsendi (Viereck) $\uparrow$, turgoclarus sp. n. + , zobocus sp. n. $+\overbrace{}^{\lambda}$. 
6.) Ruficollis species-group: scutellum rugose to scabrous, or strongly punctate (Figs 82, 202, 266-267, 311, 387, 412): buscki (Viereck) ${ }^{\dagger}{ }^{\lambda}$, cavei Papp , flavicoxa sp. n. ㅇ, levigena sp. n. ㅇ, mccombi sp. n. ㅇ, paululus (McComb) 웅, peruensis (Shenefelt) $\hat{\sigma}$, phthorimaeae (Gahan) + , projectus sp. $\mathrm{n} . \hat{\delta}$, rubescus Papp + , ruficollis (Viereck) 웅, shenefelti (McComb) 우 $\widehat{0}$.

7.) Townsendi-forms: frons with a pair of arcuate carinuli (Figs 79, 335,

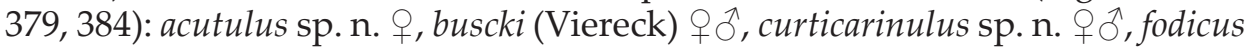
sp. n. + , parkeri Papp $+{ }_{0}$, pyriformis Papp + , refluus Papp $+{ }_{0}$, sulcifera sp. n. + , townsendi (Viereck) 우.

Acknowledgements - The following three curators, Dr W. J. Hanson (Department of Entomology, Utah State University, Logan), Dr Christer Hansson (Zoological Institute and Museum, The University, Lund) and Dr Robert R. Kula (Systematic Entomology, United States National Museum of Natural History, Washington) were kind enough to provide and support my taxonomic work with Neotropical Microchelonus material as well as with paratypic and reliably named Microchelonus species. My sincere gratitude should go to them.

\section{REFERENCES}

Achterberg, C. van (1988) Revision of the subfamily Blacinae Foerster (Hymenoptera, Braconidae). Zoologische Verhandelingen 249: 1-324. (Character states: p. 12-21.)

Achterberg, C. van (1993) Illustrated key to the subfamilies of the Braconidae (Hymenoptera: Ichneumonoidea). Zoologische Verhandelingen Leiden 283: 1-189.

Ashmead, W. H. (1895) Some parasitic Hymenoptera from lower California. Proceedings of the California Academy of Sciences (2) 4(1894): 122-129.

Belokobylskij, S. A., Zaldivar-Riverón, A. \& Quicke, D. L. J. (2004) Phylogeny of the genera of the parasitic wasps subfamily Doryctinae (Hymenoptera: Braconidae) based on morphological evidence. Zoological Journal of the Linnean Society 142: 369-404. http://dx.doi.org/10.1111/j.1096-3642.2004.00133.x

Belshaw, R., C. Lopez-Vaamonde, Degerli, N. \& Quicke, D. L. J. (2001) Paraphyletic taxa and taxonomic chaining: evaluationg the classification of braconine wasps (Hymenoptera: Braconidae) using 28S D2-3 rDNA sequences and morphological characters. Biological Journal of the Linnean Society 73: 411-424. http://dx.doi.org/10.1006/ bij1.2001.0539

Cameron, P. (1881) XXXV. Notes on the Hymenoptera, with descriptions of new species. Transactions of the Royal Entomological Society of London 4: 555-577. (Braconidae: pp. 559-561) http://dx.doi.org/10.1111/j.1365-2311.1881.tb00881.x

Cameron, P. (1886) in Blackburn, T. \& Cameron, P. 1886: On the Hymenoptera of the Hawaiian Islands. Memoirs and Proceedings of the Manchester Literary and Philosophical Society, 3rd series 10: 194-244.

Cresson, E. T. (1873) Hymenoptera Texana. Transactions of the American Entomological Society 4(1872): 153-292. http://dx.doi.org/10.5962/bhl.title.9428 
Cushman, R. A. (1931) Description of thirteen new American and Asiatic Ichneumon flies, with taxonomic notes. Proceedings of the United States National Museum 79: 1-16. http:// dx.doi.org/10.5479/si.00963801.79-2880.1

EAdy, R. D. (1968) Some illustrations of microsculpture in the Hymenoptera. Proceedings of the Royal Entomological Society of London (A) 43(4-6): 66-72. http://dx.doi. org/10.1111/j.1365-3032.1968.tb01029.x

Harris, R. A. (1979) A glossary of surface sculpturing. Occasional Papers in Entomology (State of California, Department of Food and Agriculture) 28: 1-31.

Gahan, A. B. (1917) Descriptions of some new parasitic Hymenoptera. Proceedings of the United States National Museum 53: 195-217. http://dx.doi.org/10.5479/si.00963801.532197.195

Gauld, I. D. \& Bolton, B. (eds) (1988) The Hymenoptera. British Museum (Natural History). Oxford University Press, p. I-XI + 1-332. (Structure terminologies: p. 58-76.)

Marsh, P. M. (1979) Descriptions of new Braconidae (Hymenoptera) parasitic on the potato tuberworm and on related Lepidoptera from Central and South America. Journal of Washington Academy of Sciences 69: 12-17.

МсСомв, С. W. (1965) A new Chelonus (Microchelonus) from Western United States (Hymenoptera: Braconidae). Entomological News 76: 179-181.

МсСомв, С. W. (1968) A revision of the Chelonus subgenus Microchelonus in North America North of Mexico (Hymenoptera: Braconidae). University of Maryland, Agricultural Experiment Station, Bulletin A-149(1967): 1-148.

Nascimento, A. R. \& Penteado-Dias, A. M. (2011) New species of Chelonus (Microchelonus) Szépligeti, 1908 (Hymenoptera: Braconidae: Cheloninae) from Brazil. Brazilian Journal of Biology 71(2): 511-515. http://dx.doi.org/10.1590/S1519-69842011000300022

PAPp, J. (1974) A study on the systematics of Braconidae (Hymenoptera). Folia entomologica hungarica 27(2): 109-133.

PApp, J. (1999) Five new Microchelonus species from the Neotropical Region (Hymenoptera, Braconidae: Cheloninae). Annales historico-naturales Musei nationalis hungarici 91: 177-197.

Papp, J. (2010) Ten new Microchelonus Szépligeti species from the Neotropical Region (Hymenoptera, Braconidae: Cheloninae). Annales historico-naturales Musei nationalis hungarici 102: 155-191.

Papp, J. (2014) Microchelonus deplanus sp. n. from Canada and checklists of the Nearctic and Palaearctic species of the genus Microchelonus Szépligeti, 1908 (Hymenoptera, Braconidae: Cheloninae). Natura Somogyiensis 25: 115-140.

Provancher, L. (1881) Faune Canadienne. Les Insectes Hyménoptères. Le Naturalist Canadienne 12: 193-207. http://dx.doi.org/10.5281/zenodo.25708

SHAw, S. R. (1991) An unusual manner of aggregation in the braconid Chelonus (Microchelonus) hadrogaster McComb (Hymenoptera). Journal of Insect Behaviour 4(4): 537-542. http://dx.doi.org/10.1007/BF01049337

Shenefelt, R. D. (1965) A contribution towards knowledge of the world literature regarding Braconidae. Beiträge zur Entomologie 15(3-4): 243-500.

Shenefelt, R. D. (1973) Braconidae 6 Cheloninae. In: Hymenopterorum Catalogus (nova editio), The Hague, 10: 813-936. (Microchelonus: pp. 873-907.)

Szépligeti, V. (1904) Südamerikanische Braconiden. Annales historico-naturales Musei nationalis hungarici 2: 173-197.

SzÉPligeti, V. (1908) Braconiden aus der Sammlung des Ungarischen National-Museums II. Theil. Annales historico-naturales Musei nationalis hungarici 6: 397-427. 
Toвias, V. I. (1967:) A review of the classification, phylogeny and evolution of the family Braconidae (Hymenoptera). Entomological Review 46: 387-399.

Tовias, V. I. (1995) New subgenus and species of the genus Microchelonus (Hymenoptera, Braconidae) with some comments on synonymy. Zoologicheskiy Zhurnal 74(7): 38-50. [In Russian with English summary]

ToвıAs, V. I. (2010) Palaearctic species of the genus Microchelonus Szépligeti (Hymenoptera: Braconidae, Cheloninae): key to species. Proceedings of the Russian Entomological Society 81(1): 1-354. [In Russian]

Toвias, V. I. (2011) A new species of the genus Microchelonus Szépligeti and a new species of the genus Chelonus Panzer (Hymenoptera: Braconidae) from Central Asia. Russian Entomological Journal 20(3): 327-330.

Viereck, H. L. (1912) Contributions to our knowledge of bees and Ichneumon-flies, including the descriptions of twenty-one new genera and fifty-seven new species of Ichneumon-flies. Proceedings of the United States National Museum 42: 613-648. http:// dx.doi.org/10.5479/si.00963801.42-1920.613

Viereck, H. L. (1913) Descriptions of twenty-three new genera and thirty-one new species of Ichneumon-flies. Proceedings of the United States National Museum 46: 359-386. http://dx.doi.org/10.5479/si.00963801.2031.359

Wharton, R. A., Shaw, S. R., Sharkey, M. J., Wahl, D. B., Wooley, J. B., Whitfield, J. B., Marsh, P. M. \& Johnson, W. (1992) Phylogeny of the subfamilies of the family Braconidae (Hymenoptera: Ichneumonoidea): a reassessment. Cladistics 8: 199-235. http:// dx.doi.org/10.1111/j.1096-0031.1992.tb00068.x

Yu, D. S. K., Achterberg, C. van \& Horstmann, K. (2012) Taxapad 2012. World Ichneumonoidea 2011. Taxonomy, Biology, Morphology and Distribution. http:www.taxapad. com. Ottawa, Ontario, Canada.

Received August 23, 2015, accepted January 11, 2016, published August 15, 2016 